United States Department of Commerce Technology Administration

National Institute of Standards and Technology

||i||||||||||||||||||

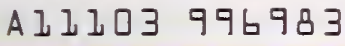

NIST

PUBLICATIONS

NIST Special Publication 849

Proceedings of the Joint DoD/NIST Workshop on International Precision Fabrication Research and Development October 27-29, 1992

J. D. Meyer, Editor

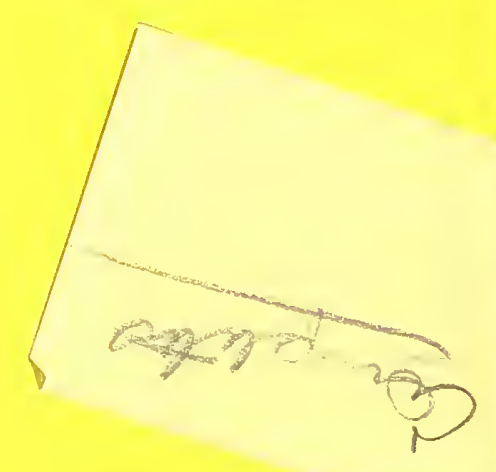

QC

100

.057

\#1849

1993 
$T$ he National Institute of Standards and Technology was established in 1988 by Congress to "assist industry in the development of technology ... needed to improve product quality, to modernize manufacturing processes, to ensure product reliability ... and to facilitate rapid commercialization ... of products based on new scientific discoveries."

NIST, originally founded as the National Bureau of Standards in 1901, works to strengthen U.S. industry's competitiveness; advance science and engineering; and improve public health, safety, and the environment. One of the agency's basic functions is to develop, maintain, and retain custody of the national standards of measurement, and provide the means and methods for comparing standards used in science, engineering, manufacturing, commerce, industry, and education with the standards adopted or recognized by the Federal Government.

As an agency of the U.S. Commerce Department's Technology Administration, NIST conducts basic and applied research in the physical sciences and engineering and performs related services. The Institute does generic and precompetitive work on new and advanced technologies. NIST's research facilities are located at Gaithersburg, MD 20899, and at Boulder, CO 80303. Major technical operating units and their principal activities are listed below. For more information contact the Public Inquiries Desk, 301-975-3058.

\section{Technology Services}

- Manufacturing Technology Centers Program

- Standards Services

- Technology Commercialization

- Measurement Services

- Technology Evaluation and Assessment

- Information Services

\section{Electronics and Electrical Engineering}

Laboratory

- Microelectronics

- Law Enforcement Standards

- Electricity

- Semiconductor Electronics

- Electromagnetic Fields ${ }^{1}$

- Electromagnetic Technology

\section{Chemical Science and Technology}

Laboratory

- Biotechnology

- Chemical Engineering

- Chemical Kinetics and Thermodynamics

- Inorganic Analytical Research

- Organic Analytical Research

- Process Measurements

- Surface and Microanalysis Science

- Thermophysics ${ }^{2}$

\section{Physics Laboratory}

- Electron and Optical Physics

- Atomic Physics

- Molecular Physics

- Radiometric Physics

- Quantum Metrology

- Ionizing Radiation

- Time and Frequency ${ }^{1}$

- Quantum Physics ${ }^{1}$
Manufacturing Engineering Laboratory

- Precision Engineering

- Automated Production Technology

- Robot Systems

- Factory Automation

- Fabrication Technology

\section{Materials Science and Engineering} Laboratory

- Intelligent Processing of Materials

- Ceramics

- Materials Reliability

- Polymers

- Metallurgy

- Reactor Radiation

\section{Building and Fire Research Laboratory}

- Structures

- Building Materials

- Building Environment

- Fire Science and Engineering

- Fire Measurement and Research

\section{Computer Systems Laboratory}

- Information Systems Engineering

- Systems and Software Technology

- Computer Security

- Systems and Network Architecture

- Advanced Systems

\section{Computing and Applied Mathematics}

Laboratory

- Applied and Computational Mathematics ${ }^{2}$

- Statistical Engineering ${ }^{2}$

- Scientific Computing Environments ${ }^{2}$

- Computer Services ${ }^{2}$

- Computer Systems and Communications ${ }^{2}$

- Information Systems

${ }^{1}$ At Boulder, CO 80303.

${ }^{2}$ Some elements at Boulder, CO 80303. 
Proceedings of the Joint DoD/NIST Workshop on International Precision Fabrication Research and Development October 27-29, 1992

J. D. Meyer, Editor

Manufacturing Engineering Laboratory

National Institute of Standards and Technology Gaithersburg, MD 20899

Sponsored by

U.S. Department of Defense and

National Institute of Standards and Technology

March 1993

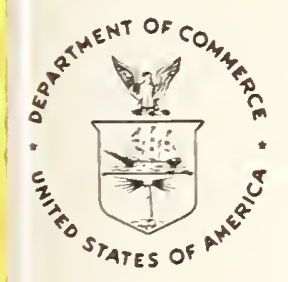

U.S. Department of Commerce

Ronald H. Brown, Secretary

National Institute of Standards and Technology

Raymond G. Kammer, Acting Director 
National Institute of Standards and Technology

Special Publication 849

Natl. Inst. Stand. Technol.

Spec. Publ. 849

244 pages (Mar. 1993)

CODEN: NSPUE2
U.S. Government Printing Office

Washington: 1993

For sale by the Superintendent of Documents U.S. Government Printing Office Washington, DC 20402 


\section{FOREWORD}

An international workshop was held in Rockville, Maryland, on October 27-29, 1992 to discuss major research and development programs in precision fabrication. Approximately 25 leading experts attended the workshop, which was co-sponsored by the U.S. Department of Defense's Manufacturing Technology Program.

Several papers, each covering a specific geographic region or topic, were presented at the meeting. Copies of these presentations are included in these proceedings.

In addition to individual R\&D programs and technology sources in North America, Western Europe, Eastern Europe, and Asia, the workshop participants also discussed R\&D needs, priorities, underlying motivations, and opportunities for international collaboration. The results of these discussions will be summarized in a separate report. Information about the summary report may be obtained from the editor of these proceedings.

J . D. Meyer

Gaithersburg, Maryland

October 1992 


\section{Precision Fabrication Research and Development Workshop October 27-29, 1992 \\ The Woodfin Suifes Hotel Rockville, Md.}

Ekkard Brinksmeier

University of Bremen

F.G. Ferrigungsverjahren

D-2800 Bremen 33,

GERMANY

Peter Brown

NIST

Metrology Bldg., Rm. A127

Gaithersburg, MD 20899

USA

Charies Carter

Association for Manufacururing

Technology

7901 Westpark Dr.

McLean, VA 22102

USA

Daniel Cundiff

OASD

8000 Defense Pentagon, Room 3B253

Washington, DC 20301-8000

USA

William Donnelly

U.S. Army

Bldg. 172, Atn: AMSMC-PBR

Picatinny Arsenal, NJ 07806-5000

USA

Russell Durtweiler

Lawrence Associates, Inc.

5100 Springfield Pike

Suite 509

Dayton, OH 45431

USA
Chris Evans

NIST

Metrology Bldg., Rm. A107

Gaithersburg, MD 20899

USA

Dan Gearing

Defense Logistics Agency

Attn: DLA-PRM, Cameron Station

Alexandria, VA 22304-6100

USA

Ted Hicks

U.S. Navy

Bldg. 75, Rm. 209, MC 205

Philadelphia, PA

USA

Richard Jackson

NIST

Metrology Bldg., Rm. B322

Gaithersburg, MD 20899

USA

Said Jahanmir

NIST

Materials Bldg., Rm. A329

Gaithersburg, MD 20899

USA

Bruce Kramer

National Science Foundation

1800 G Street, NW, ENG/DDM-Rm. 1128

Washington, DC 20550

USA

Lloyd Lehn

Office of the Secretary of Defense

OASD (P\&L), PR/MM, Rm.3B253

Washington, DC 20301-8000

USA 
John Meyer

NIST

Chemistry Bldg., Rm. B212

Gaithersburg, MD 20899

USA

Frederick Michel

Society of Manufacturing Engineers

8409 Felton Lane

Alexandria, VA 22308

USA

Robert Reynolds

NCMS

900 Victors Way, Room 310

Ann Arbor, MI 48108-1779

USA

Eugene Rivin

Wayne State University

5050 Anthony Wayne Dr.

Detroit, MI 48202

USA

John Simpson

NIST

Metrology Bldg., Rm. B322

Gaithersburg, MD 20899

USA

David Stieren

OASD

8000 Defense Pentagon, Rm. 3B253

Washington, DC 20301-8000

USA

Clayton Teague

NIST

Metrology Bldg., Rm. A117

Gaithersburg, MD 20899

USA

Sato Tomomasa

University of Tokyo

4-6-1, Komaba, Rm. 408, 45 Bldg.

Meguro-ku, Tokyo, 305,

JAPAN

Alex Wakulenko

Benet Laboratories

Watervliet Arsenal, SMCAR-CCB-SM, 40

Watervliet, NY 12189-4050

USA
Robert Warrington

Louisiana Technical University

P.O. Box 10348

Ruston. LA 71270

USA

William Zdeblick

Institute of Advanced

Manufacturing Sciences

1111 Edison Dr.

Cincinnati, OH 45216

USA 


\section{Table of Contents}

Page

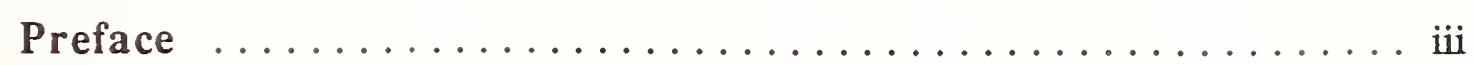

Workshop Participants List ...................

Introductory Remarks

John Meyer, National Institute of Standards and Technology

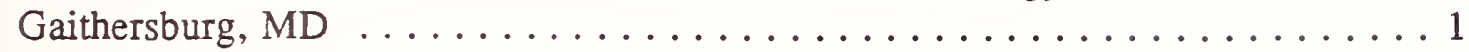

North American R\& D

Precision Manufacturing Practice and Research: A North American Perspective

William Zdeblick, Institute for Advanced Manufacturing Sciences

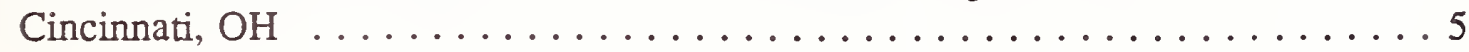

Western European R\&D

Western European R\&D Programs and Sources of Funding

Ekkard Brinksmeier, Bremen University

Bremen, Germany . . . . . . . . . . . . . . . . . 25

Eastern European R\&D

Precision Fabrication Technology in the Former Soviet Union and Other East European Countries

Eugene Rivin, Wayne State University

Detroit, MI ............................. 111

\section{Asian R\& D}

Precision Fabrication of Japan in 1993

Tomomasa Sato, University of Tokyo

Tokyo, Japan

Worldwide Microfabrication R\&D

Worldwide Microfabrication Research and Development

Robert Warrington, Louisiana Technological University

Ruston, LA 


\title{
Introductory Remarks
}

\author{
John Meyer \\ Manufacturing Engineering Laboratory \\ National Institute of Standards and Technology \\ Gaithersburg, MD 20899
}

Precision fabrication technologies are extremely important to many manufacturing industries, from automobiles and consumer electronics to machine tools and computer hardware. The development and use of these technologies have a direct impact on the products being produced and, ultimately, a manufacturer's ability to compete successfully in world markets.

Major advances in precision fabrication technologies are being pursued by numerous organizations around the world. In a field once dominated by American and European researchers, much of this $R \& D$ is now being conducted in other geographic areas. Undoubtedly, these research efforts will yield advanced technologies capable of producing parts with much higher precision, better quality and lower costs.

In the midst of this high level of on-going international research, there is a need for a mechanism for examining such efforts on a worldwide basis in an open forum, with an eye towards identifying collaborative research opportunities among regions. Workshops serve as one such mechanism.

To this end, a workshop was jointly sponsored by the U.S. Department of Defense (DoD) and the National Institute of Standards and Technology (NIST). Both DoD and NIST are actively involved in the development and implementation of advanced manufacturing technologies and each is interested in exploring international collaborative research projects in this field.

The purpose of the workshop was to provide an international forum for discussing major research and development programs in precision fabrication technology. Specifically, the objectives of the workshop were to:

1. Identify major R\&D programs and sources of advanced precision fabrication technology in Europe, Asia, North America and other parts of the world.

2. Determine the approximate level of resources being expended in each $R \& D$ area. 
3. Examine the goals and strategies of these R\&D programs, as well as the underlying reasons and motivations for undertaking such efforts.

4. Explore any unmet needs or high-impact research opportunities that may exist in the area of precision fabrication technology.

5. Discuss the potential for international collaborative R\&D projects and any key issues associated therewith.

For the purposes of this workshop, the term "precision fabrication" was very broadly defined and included the following topics:

-- Machining

-- Grinding

-- Other precision material removal processes

-- Stamping and forming

-- Micro- and Nano-fabrication technologies

-- Welding

-- Other precision joining processes

In each of these areas (with the exception of micro-fabrication), the primary emphasis was on fabrication technology for metals as opposed to other materials. However, within these areas, the primary focus was on technologies that can be used to produce "precision" and "ultraprecision" parts and assemblies.

Because of the focused and specific nature of the workshop's objectives, the meeting was conducted on a "by-invitation-only" basis. The total number of participants was limited to a maximum of 25 people. Each individual was expected to be an active participant in the discussions. Thus, only knowledgeable experts in the field were invited to participate in the meeting. The workshop was truly international in flavor, with leading observers from all regions of the world taking part in the meeting.

The meeting spanned a three-day period. The agenda was as follows:

Day 1:

Morning: Registration and individual presentations and questions Afternoon: Individual presentations and questions

Day 2:

Morning: Group discussion of R\&D framework and research programs Afternoon: Group discussion of R\&D needs and priorities 
Day 3:

Morning: Group discussion of collaboration opportunities Afternoon: Adjourn

Approximately 25 people attended the workshop. A list of the attendees is included in this proceedings.

As can be seen from the agenda, a considerable portion of the workshop was devoted to group discussions of various issues concerning manufacturing systems R\&D. A separate report summarizing these discussions is planned for preparation in 1993. More information about the report is available from the editor of these proceedings. 


\title{
Precision Manufacturing Practice and Research: A North American Perspective
}

\author{
William J. Zdeblick, Ph.D. \\ Technology Director \\ Institute of Advanced Manufacturing Sciences \\ Cincinnati, Ohio
}

Prepared for

NIST Precision Fabrication R\&D Workshop

October 27.29, 1992

Introduction

Precision: A Competitive Strategy

Machine Tool Industry: The Dynamics of Change

Machining Errors

Sources and Classification

Machine Tool Hardware

Environmental and Operational

Process and Process Engineering

Summary: Next Steps

Technology

Infrastructure

Acknowledgment

Bibliography

Appendix: Critical Machine Tool Technologies 
Precision Manufacturing Practice and Research: A North American Perspective

William J. Zdeblick, Ph.D.

\section{INTRODUCTON}

This paper summarizes key observations about the state of precision manufacturing practice and research in North America. The background of the author is in metalworking and machining and thus the majority of the discussion relates to these industries. However, many technologies that have emerged from other "clean" manufacturing, particularly from the microelectronics, microfabrication and pharmaceutical industries, have been adapted to precision machining.

Precision manufacturing focuses on improving part accuracy and process repeatability but the practical discussion often focuses on manufacturing errors. The historical precision research agenda has been structured by understanding the nature and types of manufacturing errors. Significant technology advances, as measured by the reduction of these focused upon error types, have resulted. Discussed later in this paper is a classifying of error types into machine, environment and process. A fourth group, measurement, is a whole science in itself and will not be addressed in this paper (although many of the scientific concepts of metrology have been applied in the reduction of manufacturing enrors).

Driven by this taxonomy of manufacturing errors, individual research efforts tend to be narrow in scope and focused only at the highest impact areas, namely, the largest error sources.

Advancements in individual hardware components (bearings, controllers, spindles, structures, etc.) are primarily driven by the individual machine hardware component builders. The rate of improvement and implementation of these precision technologies in general manufacturing is fairly predictable (see below) and is not sufficient to regain world leadership. An assessment of today's precision research agenda finds that gains are achieved in an evolutionary manner and that "the low hanging fruit has already been picked".

Unfortunately, today's precision research agenda is fragmented -- across the industrial, academic and federal government spectrums. As a result it is difficult to achieve a significant,

revolutionary impact on precision manufacturing. The time has come to reassess the nation's precision manufacturing research agenda if we are ever going to "reach for the high fruit." With the error taxonomy understood, a more systematic, integrated view of precision research is needed which strives toward a greater synergistic benefit. A shift from component driven research to an integrated systematic agenda that includes widespread technology deployment strategies is needed.

\section{PRECISION: A COMPETITVE STRATEGY}

A very important trend has been noted among machining system users -- accuracy requirements are dramatically increasing. The ability to consistently manufacture mechanical parts that are "straighter, rounder and flatter" yields significant product marketing advantages with respect to performance, reliability and life. For example, Cross Company is currently developing a machining system for the production of automotive engine components that will hold at least one dimension (a bore) to 67 microinches. Similarly, Texas Instruments anticipates that within 2 years, tolerance requirements for aerospace systems will be in the range of 50 microinches. Such levels of accuracy were unheard of in all but ultra-precision work a few years ago. 
Precision Manufacturing Practice and Research: A North American Perspective William J. Zdeblick. Ph.D.

To achieve such accuracy requirements consistently, both builders and users will have to alter many of the fundamental principles under which they have traditionally operated. This presents a strategic opportunity -- to develop the capability to reliably achieve very high levels of precision in high-productivity manufacturing environments. There are a number of reasons why this strategy is achievable:

- All industries are extremely concerned with product quality, and ultimately, high quality levels rely on the ability of process equipment to hold tight tolerances. The demand for increasingly precise manufacturing processes will grow.

- Increased machining system accuracy -- in the range of 1 microinch -- can only be achieved technologically. Whereas higher productivity can of ten be realized by such operational tactics as Just-In-Time or moving manufacturing off-shore, the battle for higher-precision production capability will be won or lost on the basis of sound R\&D integrated into shop practice.

- ROI is not a strong decision factor, since there are few viable alternatives to achieving higher precision other than investment in new equipment. This is not true, by contrast, in decisions involving investment in higher productivity (i.e., metal removal rates), since alternatives typically exist, (e.g., invest in the development of a machine that runs twice as fast as opposed to purchasing two standard machines).

- Much of the technological basis of high-precision machining has been developed with U.S. government funding and is available for use by U.S. companies. In fact, the ultraprecision technology that exists within the National Laboratories is the most advanced of its kind in the world.

- The achievement of very high precision capabilities in high-productivity operations will result from a coordinated series of developments, some small and some large in scope. This will require a concerted, continuing effort by many U.S. R\&D organizations coordinated by a single entity.

\section{MACHINE TOOL INDUSTRY: THE DYNAMICS OF Change}

Precision manufacturing capability is dynamic and it is constantly changing over time. The state-of-the-art of today leads to the State-of-the-Practice tomorrow. Knowing how this dynamic works is very important if programs that accelerate the rate of change of this process are to be developed. The general classifications of machining is defined as follows:

Normal machining:

Precision machining:

Ultra precision machining:
That which is performed routinely in the widespread production base.

That which is the state of the art in a high-quality production environment or laboratory.

Those processes/machines by which the highest possible dimensional accuracy is, or has been, achieved at a given point of time. 
Precision Manufacturing Practice and Research: A North American Perspective

William J. Zdeblick, Ph.D.

Historically, the time that lapses before techniques classified as "precision machining" move out of the laboratory environment and into the production environment, so as to be reclassified as "normal machining", is approximately 40 to 50 years. Furthermore, the time that lapses before "ultra precision machining" is reclassified as "precision" is another 15 to 25 years. In other words, there is a predictability for industry's ability to transfer technology from research to the production line. The transfer rate from "ultra" to "normal" is quite long indeed (55 to 75 years).

This historical time required for technology transfer can be projected onto the future, thereby producing considerable discouragement about chances for America's successful manufacturing or technological "comeback." On the other hand, by being fore-armed with such detailed knowledge about the phenomenon and expanding that knowledge in a structured way, it is possible that U.S. manufacturers could devise ways to significantly shorten the historical 50-75 year cycle.

To effectively introduce a fundamental change into the domestic machine tool industry, its inherent operational characteristics need to be understood. Through observation and discussion with a variety of users and machine builders, the following points tend to describe the industry's character:

- The machine tool industry is slow in accepting and developing new technology. For example, it was about 12 years from the first valid experiments on magnetic bearings until these bearings were implemented in a production machine tool in Japan (in 1988).

- New concepts, even if first thought of in the United States, seem to be implemented first in other countries. The first implementation of a truly unmanned machine tool, the first ceramic spindle, and a spindle operating at $100,000 \mathrm{rpm}$ with a set of antifriction bearings occurred in Japan. The first known experimental spindle made of carbon-fiber reinforced plastics and the first precision bearings for high-speed spindles came from West Germany.

- Most of the advances made in recent years in the technology of the major building-block elements have come from sustained, long-term improvement efforts, with small steps or advances taken progressively, rather than as the result of a major one-time R\&D push to leapfrog into a new realm of technology.

- In recent years, there has been a major increase in the amount and quality of R\&D work that relates to machining systems in the United States as well as in other countries. The number of universities doing work in this area has increased greatly, and the number of $R \& D$ projects in manufacturing has increased. As a result, many of the potentially interesting projects that have been identified are already being investigated to some degree in $R \& D$ organizations.

- Many U.S. machining system builders feel they have little incentive to innovate. Several novel machine tools that were developed by U.S. builders (e.g., high-speed spindle, faster broaching machine) were not accepted by U.S. users and, as a result, some of the U.S. builders have become unwilling to invest in new technology. 
Precision Manufacturing Practice and Research: A North American Perspective William J. Zdeblick, Ph.D.

\section{MACHINING ERRORS}

\section{Sources and Classification}

Several previous works have catalogued the sources of errors in machine tools. It is sufficient for this discussion to list the major sources of error and group them according to their type. They are:

\begin{tabular}{|c|c|c|}
\hline Machine & Environmental & Process \\
\hline $\begin{array}{l}\text { Geometric: } \\
\text { Displacement } \\
\text { Straightness } \\
\text { Squareness } \\
\text { Parallelism } \\
\text { Axes of Rotation }\end{array}$ & $\begin{array}{l}\text { Staff Training } \\
\text { Operator } \\
\text { Maintenance } \\
\text { Management } \\
\text { Tooling Support }\end{array}$ & $\begin{array}{l}\text { Tool wear } \\
\text { Size/Shape Change } \\
\text { Force Increase } \\
\text { Heat Increase } \\
\text { BUE }\end{array}$ \\
\hline $\begin{array}{c}\text { Controller errors: } \\
\text { Hardware Faults } \\
\text { Software Faults }\end{array}$ & $\begin{array}{l}\text { Thermal Changes } \\
\text { External } \\
\text { Part Stability }\end{array}$ & $\begin{array}{l}\text { Fixturing } \\
\text { Part Deflection } \\
\text { Dynamic Stability }\end{array}$ \\
\hline $\begin{array}{l}\text { Thermal Effects } \\
\text { Internal Sources }\end{array}$ & External Vibrations & $\begin{array}{c}\text { Surface Integrity \& Finish } \\
\text { Residual Stresses } \\
\text { Material Damage }\end{array}$ \\
\hline $\begin{array}{l}\text { Mechanical Effects: } \\
\text { Wear } \\
\text { Loading Effects }\end{array}$ & $\begin{array}{l}\text { Other } \\
\text { Air/Liquid } \\
\text { Part Handling }\end{array}$ & $\begin{array}{c}\text { Dynamic/Static Stability } \\
\text { Chatter } \\
\text { Deflection }\end{array}$ \\
\hline
\end{tabular}

Several error categories (particularly the process errors and thermal errors) have remained more elusive because they are so process and part specific. Up until recently they have been addressed only by human operators, using their brains and senses, and have only recently become candidates for treatment by artificial means.

\section{Machine Tool Hardware}

Errors due to machine tool hardware have received the most attention over the years. Machine tool builders themselves can, and have, taken the lead in the research and development initiatives since they exert total control over the design and manufacture of their products. Traditionally, two approaches to reduce hardware-based errors are used; namely, error reduction in design and construction and error compensation through on-line measurement and control. Steady and significant improvements have occurred in reducing the geometric-based and control-based errors and well-defined research needs can be identified by continuing the evolution of current research.

Builders have steadily improved the structural design and manufacturing method of machine tools to improve precision. Improved spindles, bearings, leadscrews, transducers, etc. have 
Precision Manufacturing Practice and Research: A North American Perspective William J. Zdeblick, Ph.D.

systematically evolved to higher precision. The evolution of improved components is expected to continue. However, the application of more global systematic design engineering practices is not common.

For example, the use of $\mathrm{CAE}$ analysis tools to improve the static and dynamic behavior of machine tools is readily available for use in the industry today. A recent survey completed by IAMS on "Improving Machine Tool Dynamic Stiffness" found that, by and large, sufficient CAE technology is available in commercial software products to analyze machine tool structures. However, implementation levels are low due to many non-technical (skill levels, cost, time, lab equipment, ...) reasons.

Thermal effects are different and particularly troublesome because it is difficult to separate them from other error sources (such as deffections). The consideration of new approaches to address these errors may be appropriate. There is no means for measuring them directly or detecting their presence during actual machining processes. They must be inferred from measurements of the thermal condition of the machine and its environment. The treatment of thermal effects is still far from mature enough to suggest preferred techniques appropriate for routine usage.

The principal means of thermal error elimination is temperature control and heat isolation within the structure. Significant progress has been made in the past twenty years on designs for environments for precision machine tools as well as control of temperatures within the machines themselves. The best example of this technology is the Large Optics Diamond Turning Machine (LODTM) at Lawrence Livermore National Laboratory. The surrounding air temperature is maintained at $20^{\circ} \mathrm{C} \pm 0.010^{\circ}$ and the cooling water flowing through the machine is maintained at $20^{\circ} \mathrm{C} \pm 0.001^{\circ}$. Machines with individual and integral controlled thermal environments were suggested at least as early as 1970 and are now commercially available.

The traditional compensation approach for thermal errors involves a method of determining correlation between temperature measurements at selected sites on and within machines and the resultant thermal effects errors. Further, they incorporate the temperature sensors in a system that inputs correction signals to a machine tool CNC which adjusts the machine drive systems. Historically, correlations are derived from the analysis of large amounts of data from tests performed on an existing machine by means of curve-fitting. Recently, at the Institute of Advanced Manufacturing Sciences, the use of Artificial Neural Network techniques are being explored as a method of building more generic and less engineering intensive thermal error compensation models.

A summary of some of the critical research and technology requirements for machine tools is presented in the Appendix. The science and research identified is intended to continue to push the technology envelope. However, to meet the challenge described above of widespread precision manufacturing improvement requires an effective and systematic technology deployment strategy, not necessarily a focused technology development agenda.

\section{Environmental and Operational}

The environmental and operational causes of machining and measurement errors are, for the most part, well understood. Much specialized work has been done to develop the technologies necessary to eliminate the effects of the environment that negatively impact precision 
Precision Manufacturing Practice and Research: A North American Perspective William J. Zdeblick, Ph.D.

manufacturing and precision measurement. In fact, a number of manufacturers have developed excellent techniques for controlling certain environmental factors in immediate proximity to precision equipment.

Examples of the degree to which methods currently exist for controlling the precision manufacturing environment are not difficult to find. Methods exist for:

1. Controlling ambient air temperature to a remarkable degree (better than $+0.01^{\circ} \mathrm{C}$ ).

2. Controlling aerobically bome particulate contamination (as is done routinely in Class 10 and less frequently in a Class 1 clean room in the semiconductor industry).

3. Controlling vibration within precision equipment and the vibration that is transferred to precision equipment from external sources (technology for blocking most external vibration greater than $5 \mathrm{~Hz}$ is available from vibration isolation suppliers).

The foregoing examples of the effective control of environmental impact on precision manufacturing were found within industries whose survival depends upon resolving highly specific problems in a focused way. The example of superb ambient air temperature management cited above can be found in manufacturing systems using electronically controlled, closed-loop feedback systems that connect the facilities' HVAC systems to precision manufacturing equipment temperature sensors.

A few semiconductor companies and equipment suppliers have demonstrated a remarkable capability for controlling airborne contamination. Such firms have met the stringent cleanliness demands of their industry by designing and implementing Class 1 clean room facilities.

Many examples of the control of precision equipment vibration can be found in U.S. industry. Designers have in fact developed highly sophisticated methods for controlling vibration within precision equipment and within the facilities that house precision equipment. Vibration control within precision equipment is currently focusing upon the use of advanced structural designs and advanced materials. The know-how needed to perform the difficult technical tasks of controlling the physical environment surrounding precision manufacturing (the facilities) currently exists and is available, providing that potential users are willing to apply adequate effort, thought, and money to proper implementation activities.

Much progress has also been made in the human resources arena of precision manufacturing management. Certain exemplary programs have been implemented and made effective in the task of developing personnel who can consistently perform state-of-the-art precision manufacturing work. By designing targeted training and education programs, organizations such as Lawrence Livermore National Laboratories have successfully trained employees in the operation of highly precise manufacturing equipment.

It is most important to note that even though many enabling technologies connected to precision manufacturing practices are highly specialized, each of those technologies contain principles and methodologies that may be utilized to considerable benefit in less demanding industries. A recent NCMS-sponsored assessment program has determined that state-of-the-art precision manufacturing technologies are in place within a number of companies and institutions across the U.S.; however, the documentation of those technologies is of ten not available, and has most certainly not been collected in a convenient, centralized repository. A notable exception is 
Precision Manufacturing Practice and Research: A North American Perspective William J. Zdeblick, Ph.D.

Lawrence Livermore National Laboratory where documentation is quite good and, for the most part, available to industry at large.

In addition to the fact that many precision manufacturing technologies are not documented, it is also true that the documentation that does exist is often in a condition that reduces its userulness to industry. Current literature generally lacks sufficient "how to" detail to allow an interested technologist to proceed with a similar precision manufacturing implementation. Those documents that do contain sufficient "how to" detail are frequently not readily accessible in a usable, public domain form.

In summation:

1. Most of the environmental and human factors technologies needed to make U.S. manufacturers nationally and internationally competitive in precision manufacturing do exist.

2. Very few new technologies have to be developed in order to allow U.S. manufacturers to be competitive in the current global precision manufacturing marketplace.

3. The needed expertise exists in various government laboratories, universities, and commercial enterprises.

4. Highly qualified people are available to help define and document the guidelines for precision engineering.

\section{Process and Process Engineering}

The activity of engineering the specific method to manufacture a precision part, including tooling, fixturing, NC programming, etc., is process engineering. The specific part material, shape and requirements must all be factored into consideration in addition to the machine tool and factory environment. The accumulation of all prior precision research and technology occurs in the process engineering activity; this is where the rubber meets the road!

Typically, as incremental technology is introduced to improve precision (e.g., reduce errors), process engineering absorbs the technology on an as-needed basis. For example, as touch probes were introduced by builders, the NC programmers leamed to program on-line inspection actions to dynamically calculate tool offsets. Today, the implementation phase of precision engineering research is considered to be the training and upgrading of process engineering. The rate of technology introduction and absorption is poor and typically incrementally focused upon individual error types. As with the overall precision research agenda, "the low hanging fruit has already been picked". Clearly, improvements in the rate of implementation can be made through:

1) The collection of precision engineering best practices into a general guidebook and companion training program,

2) The development of Precision Analysis Software Tools to assist in the application of the best precision practices for specific situations, and

3) Use of CAD/CAM tools such as Computer Aided Process Planning (CAPP) systems to leverage the widespread implementation. 
Precision Manufacturing Practice and Research: A North American Perspective William J. Zdeblick. Ph.D.

The opportunity to take a more systematic, integrated view of process engineering is available and a new paradigm for precision engineering research can be explored. Rather than focus independently on individual error types and attempt to eliminate or compensate each error, the use of Computer Aided Engineering (CAE) modeling and analysis techniques would allow the overall machining system to be viewed in an integrated manner. Research programs which specifically model and simulate (not just animate) the physical behavior of the process, equipment and environment and understand the interaction between each error type offers a tremendous opportunity to leapfrog current precision machining practices.

One paradigm which may be researched could be the general concept of open-loop compensation to reduce predictable and repeatable errors. Utilizing an improved CAE-based integrated process error model that is synchronized to a specific part, machine and environmental characteristics may drastically improve compensation strategies while maintaining (or even improving) production rates. A simple example to visualize this concept is the deflection of thin walls in airframe structures. To maintain low tolerances, extremely slow and conservative (low force) machining practices are typical. By having an improved process model able to analyze forces, deflection and, vibration an adjusted machining strategy, including a non-linear tool path allowing for part deflection and springback, could be developed. Sacrificing feed rates and thus productivity may not be necessary!

Another area of focus is in predicting and accounting for normal process changes, such as tool wear. Tool wear, like thermal effects, has been difficult to measure directly and has been attempted to be inferred through indirect measurements. Unfortunately, many researchers have overlooked the central problem; namely, the key objective is part size changes not necessarily only tool size changes. Extensive research efforts over the last 30 years have been too narrowly focused. Tool wear is now being practically measured and compensated for, in some cases online. Use is being made of tool setting stations with both touch and visual sensors. The common practice of the human operator to detect a worn tool by sound is being imitated by means of acoustic sensors.

However, the use of an integrated CAE-based model to understand the spectrum of errors would consider tool wear in an inter-related context with forces, deflection, vibration, thermal growth, etc. Without such an improved process model to formulate a predicted "open-loop" tool wear compensation strategy, the benefits of addressing tool wear errors alone are limited. Clearly, the effort to develop an on-line, integrated, intelligent sensor-based strategy for error compensation requires an integrated view.

Process errors have historically been the most elusive to systematically structure within a research framework since they are part and environment specific. Individual experience and expertise is the normal approach for improved precision. However, developing a systematic methodology to eliminate process errors has potentially the largest impact; namely, to implement precision engineering research into widespread practice and shorten the historical dynamic of machining precision evolution. Research in this area will not just focus on the physical science and must explore creative and revolutionary strategies. Only with this approach will "picking the high fruit" be achievable. 
Precision Manufacturing Practice and Research: A North American Perspective William J. Zdeblick, Ph.D.

\section{SUMMARY: NEXT STEPS}

\section{Technology}

Machine tool design has evolved from basically mechanical mechanisms to highly sophisticated systems involving many different technologies. The following list represents critical technologies that affect the capability and competitiveness of machine tools in manufacturing.
- Metrology
- Metallurgy
- Physics of materials
- Dynamics of structures
- Electronic controls
- Advanced precision bearings - Laser technology
- Software
- Sensors technology
- Advanced materials technology
- Artificial intelligence

Each of these technologies is critical to competitiveness because each affects the performance and capability of machine tools. They are universal in their application, although each one may not be used in every machine type. The performance and characteristics of a particular machine are determined by the:

- basic mechanical and physical design of the machine;

- materials used in its construction;

- selection and application of various bearings;

- controls that direct the motion and speed of movement as well as the repeatability of the machine;

- software that commands the controls;

- sensors and measuring devices that inform the software in the controls about the operation and positions of the various elements of the machine tool.

Developing these critical technologies requires significant multi-disciplinary research and development programs. Even within these general research needs lies a large range of prerequisite and application-specific research programs. For example:

- Precision improvement includes tool sensing to correct for deviation from programmed tolerances; hardware/software monitoring, mapping and correction procedures; and position and thermal sensing to compensate for structural errors.

- Sensing-research projects include the development of position transducers, so that sensors are accurate in increasingly higher-speed machining; sensor arrays to integrate the measurement taken during the various steps of the machining process; and the development of lower cost laser feedback systems.

- Computer software projects include expert systems and artificial intelligence; improved machine controls; and the development of a real-time, object-oriented computer language to develop numerically controlled machine software, as hardware development is constrained by the high cost of concurrent software development. 
Precision Manufacturing Practice and Research: A North American Perspective William J. Zdeblick. Ph.D.

The complexiry of these research undertakings is multiplied as advances in new materials and microelectronics continue. The scope and expense of such research efforts preclude all but the top few machine tool builders from undertaking the necessary effort. For the typical machine tool builder, with annual sales of about $\$ 7$ million, mounting even a small research and development effort is prohibitive.

\section{Infrastructure}

The job at hand is the structure by which cooperative, shared research and development can be organized. The demonstration of technology in a single, isolated case does not necessarily generate widespread use. Funding a single builder to demonstrate new technology may not even assure that the technology will be duplicated within the builders product line and customer base!. The wealth of science available is, for all but the most extreme cases, sufficient and applicable. The access to, justification for and deployment of this available science is the challenge facing the industry. Coordination of the nation's precision research agenda is the mission.

Clearly, builders respond to the market requirements. Pushing technology onto the builders via focused research programs has not resulted in the technology being pushed onto the end users! Only the increase of market demand for precision will result in precision technology being pulled into use. To accomplish steady, sustained implementation of precision manufacturing technology, the focus of any stimulation must be on the end user -- through education, information products, engineering assistance and economic justification assessments.

A historical model of this strategy is available in the cutting tool industry -- the Machinability Data Center (MDC). As new materials (primarily aerospace) were quickly being developed and put into production, a flurry of isolated research efforts were initiated to develop new cutting tools. Material science and coating technology was foreign to most machining end users and keeping track of new developments was impractical. As a result, making the investment to change was done reluctantly, if at all. However, with the MDC serving as an independent clearinghouse of information, a central training resource and provider of engineering between tool vendors and end users, new technology was effectively introduced. As a result the niche markets for aerospace tooling grew. The business incentives for individual firms to undertake advanced cutting tool research was stimulated. The lessons learned from the MDC could be applied to stimulate the use of precision manufacturing technologies.

A unified, coordinated approach to help USA companies regain a lead position in precision manufacturing is needed. This unified approach will be complex in implementation, but it is simple in principle:

1. Make technology READY to be effectively and efficiently transferred.

2. Make human resources CAPABLE of receiving and implementing advanced manufacturing technology through the development and implementation of effective Manufacturing Education Programs.

3. FACILITATE the technology transfer by establishing predictable, reliable transfer methodologies and organizations.

4. IDENTIFY technology voids through direct interaction with the end users. 
Precision Manufacturing Practice and Research: A North American Perspective William J. Zdeblick. Ph.D.

5. COORDINATE multi-organization research initiatives to pull research objectives that address these voids.

The nation requires a central Precision Manufacturing Access Point (P-MAP) to exchange and interact with technology. The Institute of Advanced Manufacturing Sciences is moving toward establishing itself as such a P-MAP.

\section{ACKNOWLEDGMENT}

The source of this paper's information is the author's 15 years of first-hand experience working in the machining industry. The majority of that time was spent at Metcut Research Associates and now at the Institute of Advanced Manufacturing Sciences which took over the Metcut operations. In addition, information was obtained through direct dialogue with several engineering directors at machine tool builders and from reviewing several recent NCMSsponsored studies addressing machine tool research needs. The author also wishes to thank $\mathrm{Mr}$. Nicholas Weil and Mr. Jack McCabe of NCMS for their input.

\section{BIBLOGRAPHY}

1. 66 Centuries of Measurement. 3rd Ed, The Sheffield Measurement Division, Dayton, Ohio, 1984.

2. Hayes, Donald J., et. al., Precision Manufacturing Guidelines: Human \& Environmental Eactors -- A State-of-the-Art Assessment. National Center for Manufacturing Sciences, 1990 (Contract number NCMS-66-MO-2).

3. Moore, Wayne, Eoundarions of Mechanical Accuracy, Moore Special Tool Co., Bridgeport, CT, 1970.

4. R. Hocken, Ed., Technology of Machine Tools. Yol. 5. Accuracy, Lawrence Livermore National Laboratory, UCRL-52960-5, October, 1980.

5. Blaedel, K., Ertor Reduction. MTTE Report, UCRL 529605, October, 1980, pp. 61-73.

6. Donmez, M.A., A General Methodology for Machine Tool Accuracy Enhancement by Exor Compensation, PRECISION ENGINEERING, Vol. 8, No. 4, October, 1986, pp 187-196.

7. Taniguchi, N., Current Starus in and Furure Trends of Ulta-precision Machining and Ultrafine Materials Processing, Annais of the CIRP, Vol. 21, No. 2, 1983.

8. SRI International, High Productivity Machining Systems: State-of-the-Art Assessment, National Center for Manufacturing Sciences, 1989 (Contract number NCMS-88-PE-4).

9. Council on Competitiveness, Comperitive Profile of the Machine Tool Industry, 1991 (Background Paper for CoC's Gaining New Ground Report). 
Precision Manufacturing Practice and Research: A North American Perspective William J. Zdeblick. Ph.D.

\section{APPENDIX: CRITCAL MACHINE TOOL TECHNOLOGIES}

\section{CRITICAL TECHNOLOGY: Electronic Controls}

DESCRIPTION: Electronic controls are used to command and control the motions and functions of machine tools. These controls may be relatively sophisticated Computer-based Numerical Controls (CNCs) which use numerical part programming information to command the machine, or Programmable Logic Controls (PLCs) which utilize electronic components to effect the sequential control logic previously provided by electromechanical relays.

WHY IS IT A CRITICAL TECHNOLOGY: In order to meet the demand for increased machine versatility and to efficiently produce parts having complex shapes and/or close tolerances, which are increasingly used in aerospace, defense and consumer products, it is necessary that the machines producing these parts be electronically controlled. Such controls eliminate the variability and inefficiencies associated with human control of machines. The increased emphasis on product quality also dictates use of electronic controls that allow the manufacture of parts with close part-to-part consistency.

THREATS TO U.S. RETAINING/GAINING PROMINENCE IN TECHNOLOGY: Although the concept of numerical controls was created in the United States and further developed at MIT in the early 1950s, the dominant supplier of such equipment today is Fanuc of Japan, which accounts for over 70 percent of the world market. As a result of and the fact that the Japanese government subsidizes considerable industrial research conducted in their country, the United States will have a hard time regaining the lead it once enjoyed. Recently the Japanese have exploited U.S. developed capability which allows user-friendly programming of complex parts right at the machine.

TECHNOLOGICAL INTERDEPENDENCIES -- RELATED TECHNICAL ISSUES:

Electronic controls are technologically dependent upon advances made in the semiconductor and computer industries. The emerging popularity of 32-bit Central Processing Units (CPUs) has decreased their cost to both computer manufacturers and to suppliers of electronic controls for production equipment. This development has in turn allowed the design and development of electronic controls having both increased functions and speed.

\section{CRITICAL TECHNOLOGY: Sensor Technology}

DESCRIPTION: Sensors are devices that provide an indication of force, displacement, power, temperature, or other process variables. They typically provide inputs to the electronic controls used to control a production process or piece of equipment.

WHY IS IT A CRITICAL TECHNOLOGY: The control over a manufacturing process is a function of the degree to which process variables can be measured and of the relationship between these process variables and the attributes of the finished part. Because of this, sensor technology is critical to the efficient production of close tolerance parts. Of critical importance is not only the technology of the sensors themselves, but also the technology of signal processing and communication related to the sensor output. 
Precision Manufacturing Practice and Research: A North American Perspective William J. Zdeblick. Ph.D.

THREATS TO U.S. RETAINING/GAINING PROMINENCE IN TECHNOLOGY: The U.S. machine tool industry is dependent upon others for much of the sensor technology it uses. Many of these are foreign firms. No U.S. firm is large enough or profitable enough to undertake research program of sufficient scope to compete with any of the foreign companies who of sufficient well-established footholds in these areas.

TECHNOLOGICAL INTERDEPENDENCIES -- RELATED TECHNICAL ISSUES: In many cases the critical element of a sensor is made of semiconductor material, thus there is a dependence of the sensor industry upon the semiconductor industry. This dependence extends to the devices used for sensed signal conditioning for signal conversions, and for sensed signal mixing and decoding.

\section{CRITICAL TECHNOLOGY: SOftware}

DESCRIPTION: Software is the collection of programmed instructions used to define the responding, controlling and communicating functions of computer-based engineering and manufacturing equipment and systems.

WHY IS IT A CRITICAL TECHNOLOGY: Software defines the responding, controlling and communicating functions of manufacturing equipment, it is critical in determining the capability and efficiency of the equipment being controlled. (An even more critical first-step is having a clear understanding of the process to be controlled.)

THREATS TO U.S. RETAINING/GAINING PROMINENCE IN TECHNOLOGY: The United States has been a recognized leader in software programming expertise. This exists primarily because electronic computers were first developed in the United States, and the installed base of computers, both main-frame and personal, is much larger here than in any other country. The rest of the world is rapidly catching up with the United States, as evidenced by the increasing number of Computer-Aided Design (CAD) systems available from overseas suppliers and by the increasing number of user-friendly features being added to Computer-based Numerical Controls (CNCs) produced abroad.

TECHNOLOGICAL INTERDEPENDENCIES -- RELATED TECHNICAL ISSUES: As noted above, being able to efficiently program computer-based systems can only be done once the process to be controlled is sufficiently understood. Thus, the development of "good" software requires a background in manufacturing engineering, process engineering, and mathematics as well as a good background in computer programming. In effect, continuing state-of-the-art expertise in software is dependent upon continually updated experience and/or education in all of the aforementioned fields.

\section{CRITICAL TECHNOLOGY: Artificial Intelligence}

DESCRIPTION: Artificial intelligence as applied to manufacturing is that branch of science devoted to computer control of a product or a process using algorithms, logic and/or cause-effect relationships which might otherwise exist in the mind of a human operator or process designer. 
Precision Manufacturing Practice and Research: A North American Perspective William J. Zdeblick. Ph.D.

WHY IS IT A CRITICAL TECHNOLOGY: Artificial intelligence has the potential to significantly improve the productivity of manufacturing operations by incorporating human experience and/or human thought processes in the control regimen. As such it has the potential to improve the competitiveness of those businesses which employ it.

THREATS TO U.S. RETAINING/GAINING PROMINENCE IN TECHNOLOGY: The United States has pioneered efforts to develop artificial-intelligence technology particularly as it relates to manufacturing and/or the organization of data bases. It is anticipated, as a result of international interest in the subject, that competitive advances in this field will come from around the world and will not be limited to those made by U.S. investigators.

TECHNOLOGICAL INTERDEPENDENCIES -- RELATED TECHNICAL ISSUES: The utilization of artificial intelligence techniques, as is the case with the development of manufacturing-related software, is dependent upon a knowledge of both the manufacturing processes to be controlled and the science of artificial intelligence. A strong background in both manufacturing and in computer science is required.

\section{CRITICAL TECHNOLOGY: Laser Technology}

DESCRIPTION: Laser technology is the use of narrowly-focused light beams for measurement, and processes requiring the discrete application of heat.

WHY IS IT A CRITICAL TECHNOLOGY: Possessing a continually updated inventory of state-of-the-art laser technology is critical to U.S. manufacturers because it can profitably be applied to such varied manufacturing tasks as measurement, cutting, joining, marking, etching, surface finishing, scribing, hole cutting, deburring, heat treating, chic breaking, etc. Indeed, many aerospace and commercial parts could not be economically produced without the use of laser technology.

THREATS TO U.S. RETAINING/GAINING PROMINENCE IN TECHNOLOGY: It is known that the Japanese have for some years had a program to develop a manufacturing system utilizing a high-powered laser and a split-beam delivery system. This and other Japanese and an research endeavors will challenge the leadership currently enjoyed by the United States in laser technology.

TECHNOLOGICAL INTERDEPENDENCIES -- RELATED TECHNICAL ISSUES: Laser technology is dependent upon precision turning and finishing technologies for mirrors, and on optics and fiber-optics technologies for other aspects of the beam-delivery systems.

\section{CRITICAL TECHNOLOGY: Physics of Materials}

DESCRIPTION: The physics of materials relates to the measurable properties and characteristics of materials. For manufacturing, these properties are primarily those that relate to how the material cuts, bends, shears and welds.

WHY IS IT A CRITICAL TECHNOLOGY: In order to produce a manufactured part, it is necessary to design an efficient process to create that part. In order to design the process, it is 
Precision Manufacturing Practice and Research: A North American Perspective

William J. Zdeblick, Ph.D.

critical that one understands the physical characteristics of the material of the part, and especially how the characteristics of the part and the selected tool(s) will interact.

THREATS TO U.S. RETAINING/GAINING PROMINENCE IN TECHNOLOGY: For a number of years the U.S. manufacturing engineers have maintained a wealth of data showing what feeds and speeds should be selected for the efficient production of parts produced by metal cutting techniques. These data were available for a variety of combinations of workpiece materials and tool materials. With the advent of new tool materials (such as coated carbides, ceramics and Cubic Boron Nitride (CBN) materials) the previously published data are no longer sufficient. Research and/or lab tests to establish appropriate feeds and speeds for workpieces made of newer alloys and for tools made of new materials must be developed.

TECHNOLOGICAL INTERDEPENDENCIES -- RELATED TECHNICAL ISSUES: The magnitude of the project to develop new feed and speed information is a function of the rapidity with which new alloys are developed by the primary metals and how fast too develop new materials and/or coatings for tooling. It at the need for the development of information on the physics of new materials (for both workpieces and tooling) will be forever ongoing as new materials continue to be developed.

\section{CRITICAL TECHNOLOGY; Advanced Materials Technology}

DESCRIPTION: Advanced materials include those not considered primary metals or their common alloys. They include metal matrix composites, graphite, fiber glass, ceramics and other man-made materials.

WHY IS IT A CRITICAL TECHNOLOGY: Many industries require the use of special materials capable of withstanding the rigors of unusual environments. These industries include the aerospace and supersonic transport industries, nuclear industry, undersea exploration industry, petrochemical industry, etc. These industries require parts manufactured from materials capable of withstanding severe temperature, pressure, nuclear bombardment, corrosive, and similar environments. In order to retain our lead in the industries requiring these types of parts, it is necessary that we retain our lead in advanced materials technology.

\section{THREATS TO U.S. RETAINING/GAINING PROMINENCE IN TECHNOLOGY:}

While the United States currently leads in advanced materials technology, this lead could be eroded by ignoring the research being pursued by firms in other countries including Japan, West Germany, France, Great Britain and Israel. The United States needs to be aware of and know the properties of these advanced materials in order to design and offer machines capable of producing parts made of such materials. The industry also needs to be aware and take advantage of the characteristics of these advanced materials when selecting the materials to be used in all newly designed machine tools.

\section{TECHNOLOGICAL INTERDEPENDENCIES -- RELATED TECHNICAL ISSUES:}

The U.S. machine tool industry depends upon other industries for the development of these advanced materials and must work closely with them in order to minimize the time delay between the availability of advanced materials and the availability of manufacturing equipment capable of processing and/or utilizing those materials. 
Precision Manufacturing Practice and Research: A North American Perspective William J. Zdeblick. Ph.D.

\section{CRITICAL TECHNOLOGY: Advanced Precision Bearings}

DESCRIPTION: Advanced precision bearings are used in machinery and technical products where there is a high demand for accuracy and reliability. Applications in jet engines, navigation devices and precision machine tools are typical.

WHY IS IT A CRITICAL TECHNOLOGY: Modern machine tools require bearings of high geometric accuracy and low mechanical wear over time. Jet engines also require advanced precision bearings because of the necessary tolerance for high temperatures.

Precision bearing races are especially ground, checked and aired together. Many state-of-the-art bearings come with ceramic balls for longer life and increased accuracy. Ceramic bearing technology is relatively new and only a few countries -- Japan, West Germany and the United States -- have that capability. Japan has a considerable lead over the United States.

THREATS TO U.S. RETAINING/GAINING PROMINENCE IN TECHNOLOGY: The main threat is that these bearings are available from Japan at competitive prices. The has been relatively low an U.S. suppliers have not been eager to adopt this technology.

TECHNOLOGICAL INTERDEPENDENCIES -- RELATED TECHNICAL ISSUES: Advanced precision bearing technology and especially ceramic bearing technology is dependent on the development of quality ceramic materials resistant to heat-induced cracking, and the availability of equipment to machine them. Here again, Japan has a the United States resulting from their previous work on ceramic rotors for automotive turbochargers and heat research and experimental work on developing components for the so-called "adiabatic engine."

\section{CRITICAL TECHNOLOGY: MetrologY}

DESCRIPTION: Metrology is the science of measurement and comparison of these measurements to an established system of references. Metrology is used extensively in manufacturing industries and especially in the machine tool and related industries.

WHY IS IT A CRITICAL TECHNOLOGY: Present day technical products require accuracy unheard of a few years ago. The established "rule of thumb" requires that measuring instruments be at least ten times more accurate tolerance on the measured value. This necessitates the use of such technologies as optics, fiber-optics, laser beams, microelectronics, computers, etc. Without well-founded metrology principles and the associated precision instruments, the United States would be incapable of manufacturing the precision parts required for contemporary products.

THREATS TO U.S. RETAINING/GAINING PROMINENCE IN TECHNOLOGY: U.S. research and innovation in this area has been lagging behind that of Japan, West Germany and Switzerland. While in the past, Germany was at about the level of the United States, it continued with its thrust toward better, more complex measuring instruments. Japan has made great strides over the last 10-20 years, and is today neck and neck with West Germany. While the United States still maintains equality in the theoretical field, regaining superiority in the commercial metrology industry will take substantial investment in manpower and capital. 
Precision Manufacturing Practice and Research: A North American Perspective William J. Zdeblick, Ph.D.

TECHNOLOGICAL INTERDEPENDENCIES -- RELATED TECHNICAL ISSUES: Future advances in metrology may be fueled by new developments in fiber-optics, optoelectronics speed microcomputers. There is renewed interest sparked by the drive for product quality throughout the manufacturing sector, including the machine tool industry.

\section{CRITICAL TECHNOLOGY: Dynamics of Structures}

DESCRIPTION: The dynamics of structures is a scientific discipline based on the fundamentals of the strength and elasticity of materials. This science focuses on the minute elements of a structure, analyzing its behavior when subjected to a given set of external forces.

WHY IS IT A CRITICAL TECHNOLOGY: Mechanical structures deform when subjected to external forces, such as those incurred by a machine tool. It is advantageous if the resulting deformation can be calculated and if steps can be taken to either minimize it or to use it as an advantage. Although the fundamentals of the dynamic behavior of structures have been known for some time, modern day computers have made possible comparisons between different structures subjected to a given set of forces. By using a technique known as "finite element analysis," one can predict the static and dynamic behavior of such structures and undertake countermeasures by either redesigning the structure or by rearranging the applied forces. This technology makes it possible to design superior structures, be they machine tools, aircraft, automobiles, bridges or any other complex product.

THREATS TO U.S. RETAINING/GAINING PROMINENCE IN TECHNOLOGY: The United States acquired prominence in this field at the time of the first mass introduction of powerful commercial computers. Lately, however, several industrialized nations have caught up with the United States. Japan, West Germany, Great Britain, Italy and even smaller countries like Belgium and the Netherlands are becoming world players in this discipline.

TECHNOLOGICAL INTERDEPENDENCIES -- RELATED TECHNICAL ISSUES: Computer technology plays a major role in this field. Proficiency in the use of computers and availability of the related software are of the utmost importance.

\section{CRITICAL TECHNOLOGY: MetallurgY}

DESCRIPTION: Metallurgy is the science of production and use of metals. It includes several disciplines, such as the extraction of metals from the ore, purification of the extracted metals, and their alloying, heat treatment and testing.

WHY IS IT A CRITICAL TECHNOLOGY: Modern high-technology metals are exposed to a variety of environments, such as high temperature in aerospace engines. Another key application for specialty metals is in hostile environments, such as highly corrosive environments, chemically aggressive environments, mechanically abrasive environments and the like. The rotor blades of the gas turbine portion of a jet engine are heavily stressed by centrifugal force and are subjected to thermal stress as well as to mechanical abrasion from ingested debris. In some applications, the requirement is based on the light weight of the metallic components and this is where light alloys come into play. In machine tools, the emphasis is on structural integrity, 
Precision Manufacturing Practice and Research: A North American Perspective William J. Zdeblick, Ph.D.

resistance to wear of moving parts and suppression of vibration induced by the cutting or on inertia forces due to the cycling of the machine.

THREATS TO U.S. RETAINING/GAINING PROMINENCE IN TECHNOLOGY: This is one of the areas where the United States once had overwhelming international superiority, some of which still exists. Much of this technology was first developed by the automotive industry and later by the aerospace industry, including NASA. Over the last several years, foreign auto manufacturers have at least caught up with the United States. The European "Airbus" consortium has made great strides in civilian aircraft technologies, including metallurgy. In addition, Japan is planning to develop a fighter plane based on the U.S. F-16. It is almost certain that they will learn some of the existing U.S. technologies. One of the factors working against future U.S. superiority in metallurgy is the fact that in the United States emphasis has shifted from metals to other man-made materials such as plastics, carbon fiber and different high-tech composites.

TECHNOLOGICAL INTERDEPENDENCIES -- RELATED TECHNICAL ISSUES: There is a high degree of competition between metallic materials and the newly developed high strength composites. In the automotive industry, plastics are replacing metal parts. All this directly affects the amount of funds budgeted for metallurgical research, chipping away at the historic U.S. preeminence in this field. 



\section{Precision Fabrication Research and Development}

\section{Workshop October 27 - 29, 1992 Rockville, Md, USA}

\section{Western European R \& D-Programs and Sources of Funding}

Prof. Dr.-Ing. E. Brinksmeier

University of Bremen, Germany 


\section{Table of contents}

1. Introduction

2. Necessity for research and development

3. Sources of riational Eunding in Germany

3.1. Funding of basic research by the German Research Foundation (Deutsche Forschungsgemeinschaft DFG)
3.1.1 General information
3.1.2 Tasks and funding
3.1.3 Eorms if support

3.2. Funding of findamental research by the Volkswagen Foundation (Vw-Stiftung)

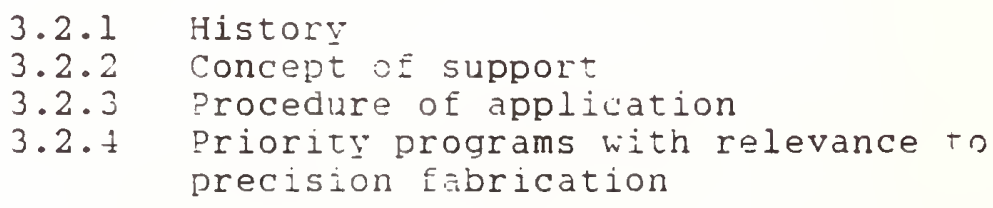

3.3. Eunding of appiied research ty the yinister di Researcin and Pechnology (BMFT)

3.4. Eunding of applied research by the German Eederation of Industrial Cooperative Research Associations iIf (Arbeitsgemeinschaft industrieller

Eorschungstereinigungen)
3. 1.1
History of the AIF
3.4 .2
Structure
3.4 .3
Funding procedure
3.4 .1
Einancing and budget
4. Sources of funding in western Europe
4.1. European Science Eoundation ESF


4.2. Funding of research and technical deveiopment (aTD) by the European Community (EC)

4.2.1 General information

4.2.2 Iechnical areas of Brite-EuRam II

4.2.3 Implementation of Brite-EuRam II programs

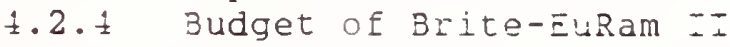

4.3. Eunding of $R \& D$ within the ECREKA program JESSI

4.3.I Situation of the European inicroelectronic industry

4.3 .2 JESSI

1.3.2.I History

\pm .3 .2 .2 Goals

4.3.3 Structure

4.3.3.1 subprogram technology

4.3.3.2 Subprogram equipment and materials

4.3.3.3 Subprogram Application

4.3.3.4 Subprogram 3 asic and Long-term Research

1.3.1 Budget

4.3.5 Conclusions

4.3.6 Aims for the future

5. Examples for the needs in precision

fabrication technology

5.1. Research in the drea of machine tools

5.1.1 Data base of the survey

5.1.2 Research activities outside the EC

5.1.3 Research activities indise the EC

5.2. Requirements on machine tools designed to machine hard materials

5.2.1 Preface

5.2.2 Aim of the studr

5.2.3 Course of action

5.2. 4 Production methods

5.2.5 Requirements for a lathe designed for hard turning

5.2.6 Prospects of hard turning in European Industry

6. References 
1.

Introduction

To give a survey on precision Eabrication oriented $R$ \& $D$ in Western Europe is an almost unsolvable task for several reasons.

First, the field of subjects and problems on which the scientific community and industry are working cannot be overseen from the knowledge point of view. There is no person who is able to be an expert in all spezialized items of this domain. To speak about research means to speak about the borderline of knowledge and shallow knowledge is obviousir not enough.

Secondly, the number of researchers in universities and external research institutions is such that it is impossible to know them all or only the laboratories in wich they are working. It is also impossible to read all their papers. Even the number of papers with original character (authors normally do not annouce the originality of their paper) would be too high.

A further problem is that temporal changes are a feature of any research activity. A survey has to be limited to a view over a certain time span. Any new $R$ i $D$ program or new topic wich becomes interesting for the research on precision fabrication will change the situation and make the surrey lose actuality.

And finally, there is the language barrier - which of course - is a general problem of Europe. There are valuable $?$ \& D activities published in languages which are not accessible to the person in charge of the survey.

That ineans that this survey will be incomplete. It cannot cover all items on precision fabrication $R$ \& $D$. Therefore the domain of this review has to be limited. This Iimitation will be in a way that primarily the $R$ \& D efforts taking place in Germany will be described. However, some important resources for funding in Western Europe will be discussed too. As we almost don't have any specific funding for precision fabrication, the sources for funding of production engineering research in general will be described. Of course, scientists or groups of researchers can apply for financial support within the more general programs if they have a good idea and good notivations for precision fabrication research.

Therefore, the content of this paper will be as follows:

- Necessity for research and development

- Sources of vational funding in Germany 
- Sources of funding in liestern Europe

- Examples for the needs in precision fabrication technology

2. Necessitv for research and development

Research and development are the Dasis for technological progress and industrial competitiveness. Therefore, $R$ \& $D$ is a permanent task for research institutes in universities and industry. because the life-time je $\bar{a}$ product or a certain type of production is limited (Eig. I).

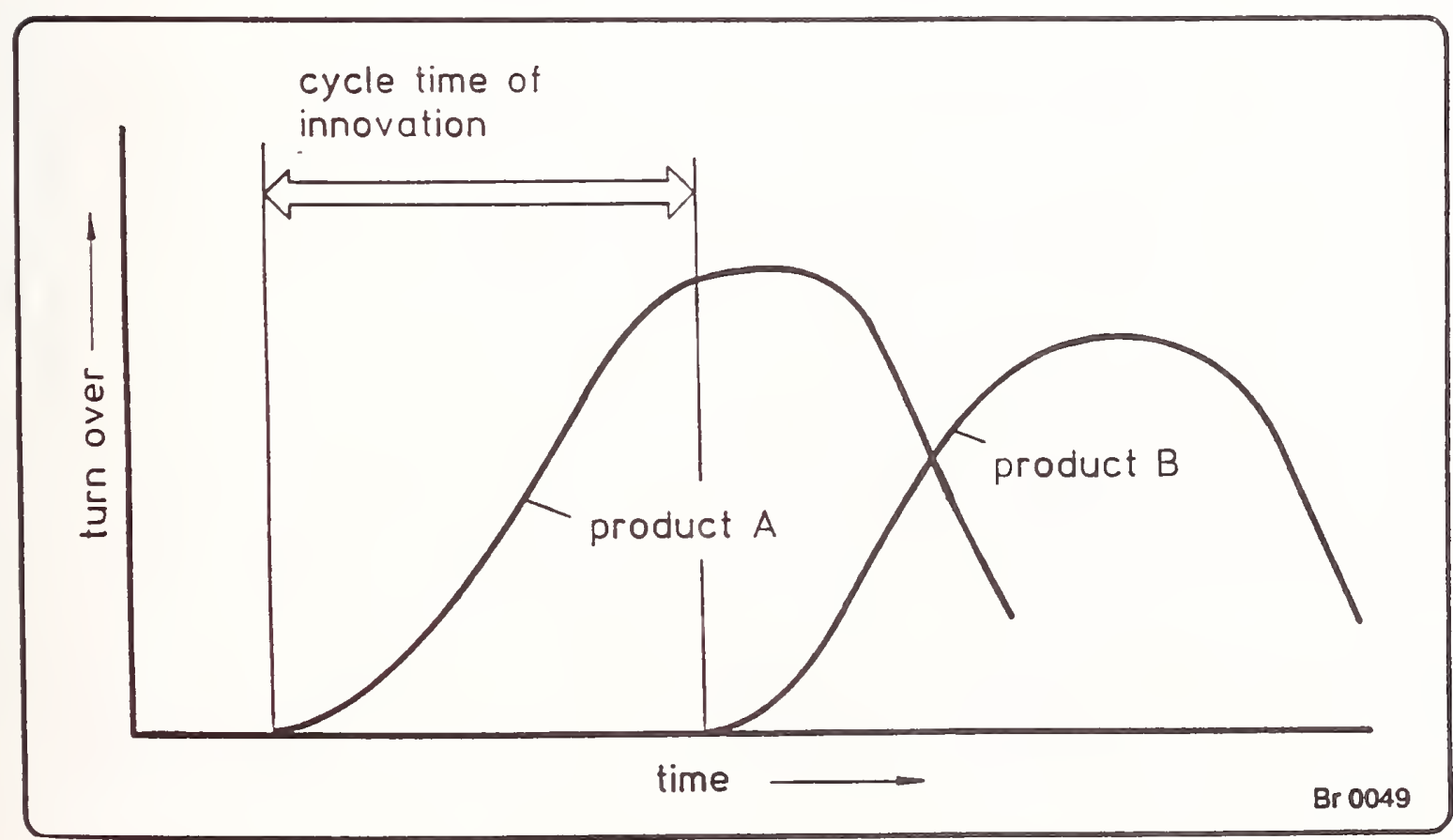

Eig. I: $\quad$ Cycle of products 
The reasons for the substitution of products may be

- a competitor with less costs,

- more and more competitors

- own development of a new product

However, the innovation process has to be enhanced because the life-time of products is lecreasing nore and more. This is underlined by an example for the life-time of machine tools:

$$
\begin{array}{lr}
\text { life-time 1930: } & 25 \text { years } \\
\text { life-rime today: } & 5 \text { years }
\end{array}
$$

The life-time is additionally acceierated br the microelectronic components. The cycle-time of lc-controls f.i. is only approximately 3 vears. Thus, it can be concluded that standing still means stepping backwards.

Fig. 2, which results from an analysis in the machine tool industry, shows the sources for innovation. The machine tool industry belongs to the small and medium sized companies in Germany with an average number of 200 employees.

- own development

- customer's stimulation

- research institutes

- literature / seminars / consultants

- competitors' stimulation

- acquisition of licence 
Such companies are of major importance for the trational pconomi because they produce $70 \%$ of the national income. ilthough there is considerable engagement into research and development within these companies, three difficuities have to be mentioned which result from three factors:

- The critical time Eactor

There is aiways been technological progress, but it was never combinded with such ateep gradients as in the iast years. An example can be concluded from the laser technology. The Eirst $\mathrm{CO}_{2}$-laser was avaijuble in 1971 and within only 10 years a new technology was established. Ioday, solid state iasers with glass fibres can be used in the production area.

The actual application of zasers in the production area is, however, rather small uncil today. The main reason is that innovation speed companies. This ieads to a critical time factor.

- The complexity factor

Today, it is necessary to think on systems. The computer is penetrating into almost all fields of industy and has to be used as a system's tool. Wis will lead to the introduction of cIM-components in many areas wich means a critical complexity factor for small ompanies.

- The critical depth factor

A changing is noticeable within the distribution of labour which results in a decreasing manufacturing depth. Speciallized suppliers are needed and involved. A change in the companie's production philosophy may lead to a critical depth factor.

For these reasons, small and medium sized German companies have learned to use the $R$ \& D-potential of research institutes and universities.

Eig. 3 shows how $R$ \& $D$ is financed in Germany. Yore than 50 o are covered by industry. 


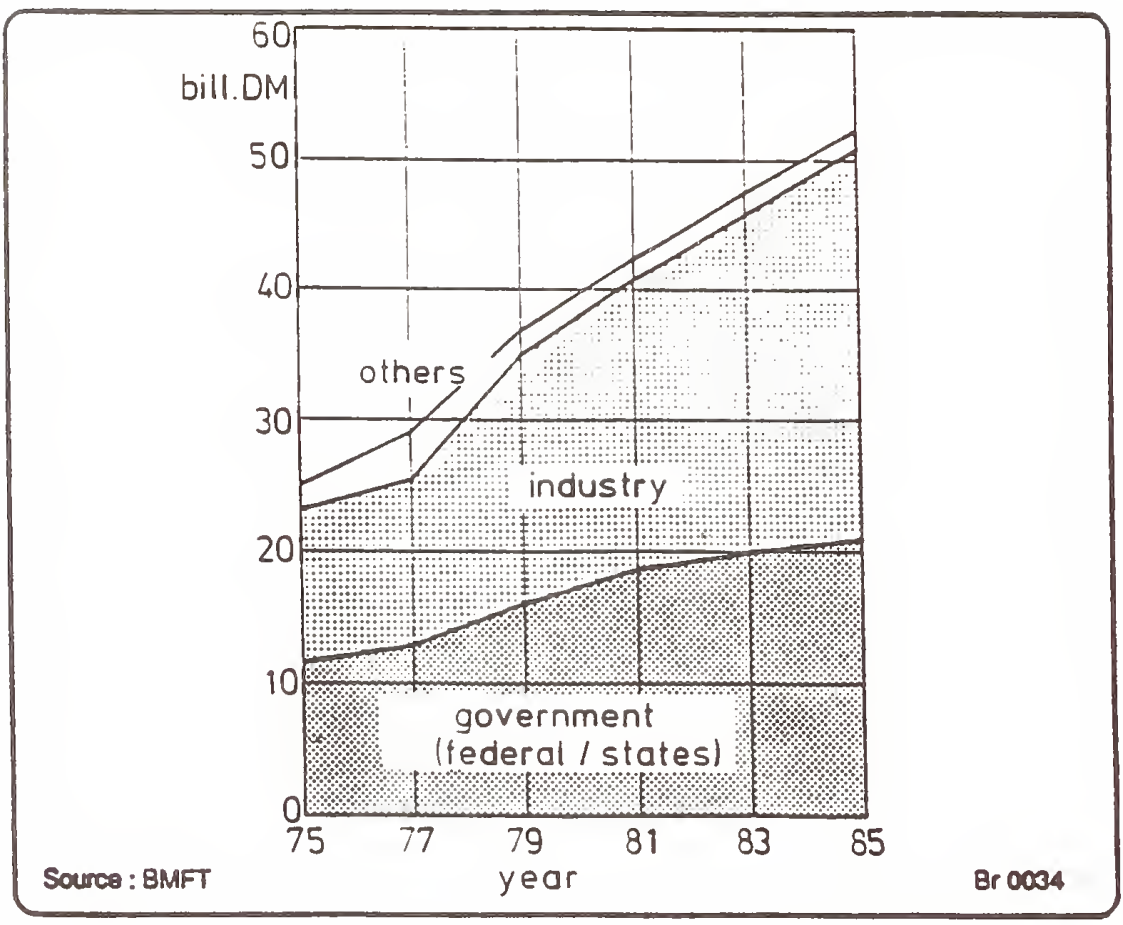

Fig. 3:

$R \& D$ expenditure

Yost of the research work is carried out in industry and at universities (Fig. 1). In production engineering, approximately 1000 scientific researchers are working at institutes and univiersities. The cotal number of employees in production engineering is about 2.500 .

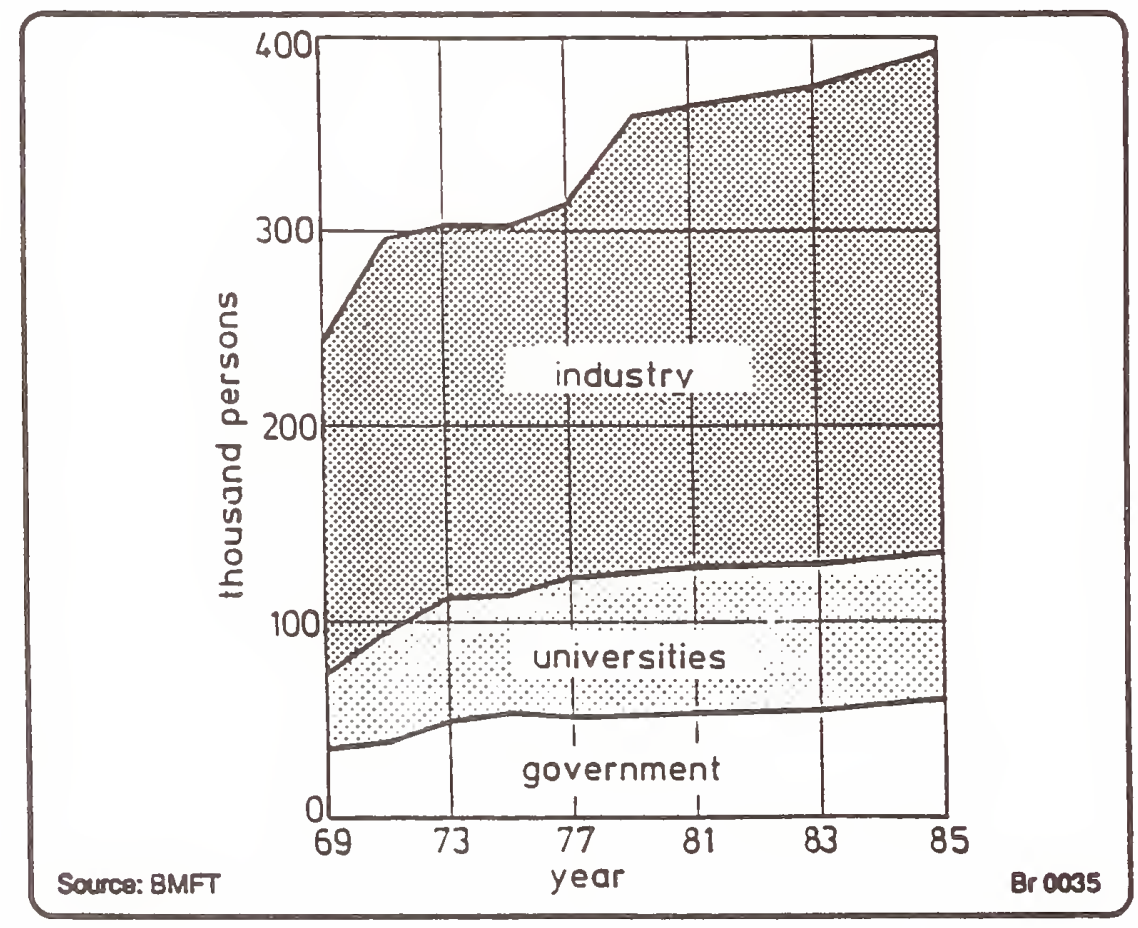

Fig. 1 :

$R \& D$ staff in sectors 


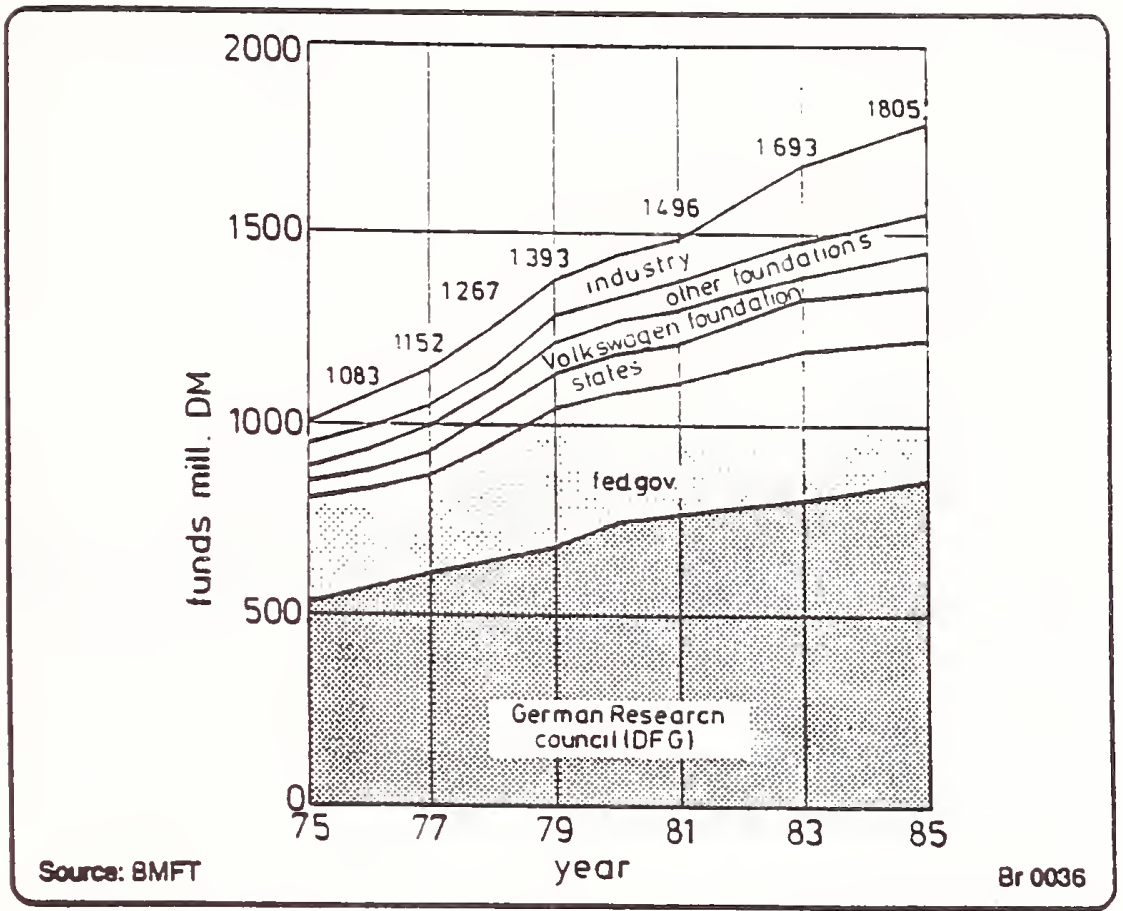

Eig. 5: Funding oz $R \propto \alpha$ at universities

Fig. 5 shows breakdown of the total funding of all German universities. It has to be recognized that in the field of production engineering the share of industrial funding is between 20 and $30 \%$ of the total budget. The sources of funding in Fig. 4 will by explained in the Eollowing chapter.

\section{Sources of National Funding in Germany}

To have Eunds is a necessary, jut by no means a sufficient condition for good research. However, especially in highly euipped fields like precision fabrication research, the necessary funding is a pre-requisite.

Laboratories in German universities receive their basic funding from the state because the universities are maintained by the 16 states of the Federal Republic. The basic funds for an average German laboratory of production engineering make between $10 \%$ to 25 of the whole expenditure including investment, naintenance of buildings, energr comsumption and administration. In addition, 75 \& to $90 \%$ have to be raised by projects.

Fig. 6 shows the sources where a german institution of an university can apply for support: 


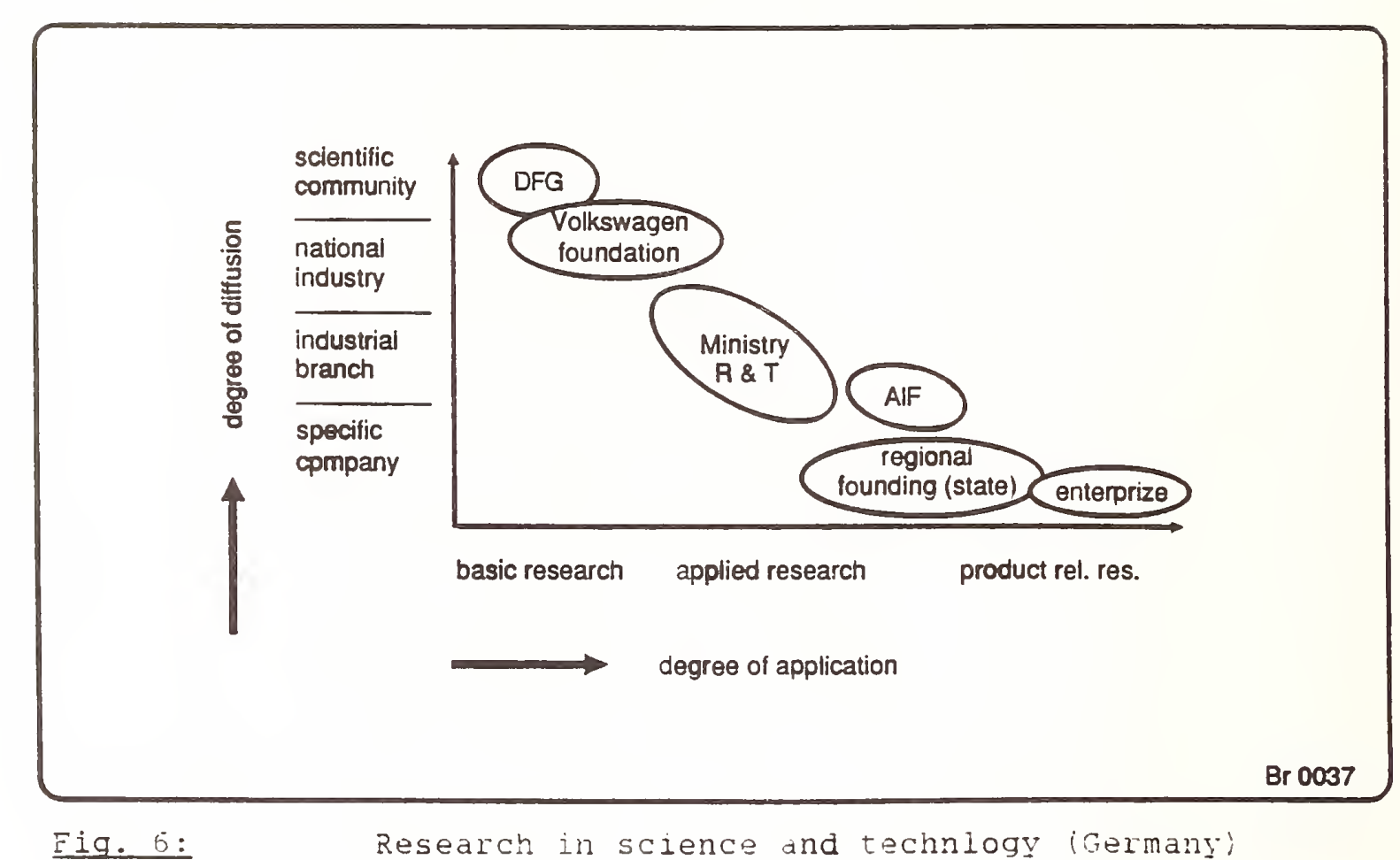

Fig. 6: Research in science and technlogy (Germany)

The cigure shows a wide ariety je different wiys research, as there are basic and applied research and on a specific product or production of a company focussed development. At the same time a look on different sources for funds gives an idea how projects are defined and how priorities are aet and who benefits form the output of $R \& D$.

3.1. Eunding of basic "̈esearch by the German esearch Foundation (Deutsche Eorsciungsgemeniscinat DEG)

\subsubsection{General information}

For basic research the German Eesearch Eoundaticn JFG is competent. This institution is comparable to the rational science Foundation XSF in USA. Basic research in this sense does not only mean e. g. physics, inathematics or chemistry. It also stancis for an applied discipline, like mechanical engineering and precision Eabrication in this case.

The DFG performs the task of funding basic research as an autonomous body within the German zcientific community, electing the academic members to its own organs il/.

The scientists and scholars choose their own subjects for research, and through plecting their own peer reviehers contribute their influence to decisions on resource allocation in universities and research institutes. The DEG's major eponsors, the Eederal Government and the Eederal gtates, grant those engaged in research the liberty of action they require. 
State and industry are currently investing some c:4 57 biliton in research and development. The share allocated to the Deutsche Forschungsgemeinschaft, just jver D.M l billion (Eig. 7), is relatively modest in comparison. Nevertheiess, as the largest external sponsor of university research, the DEG plays a major role in basic research.

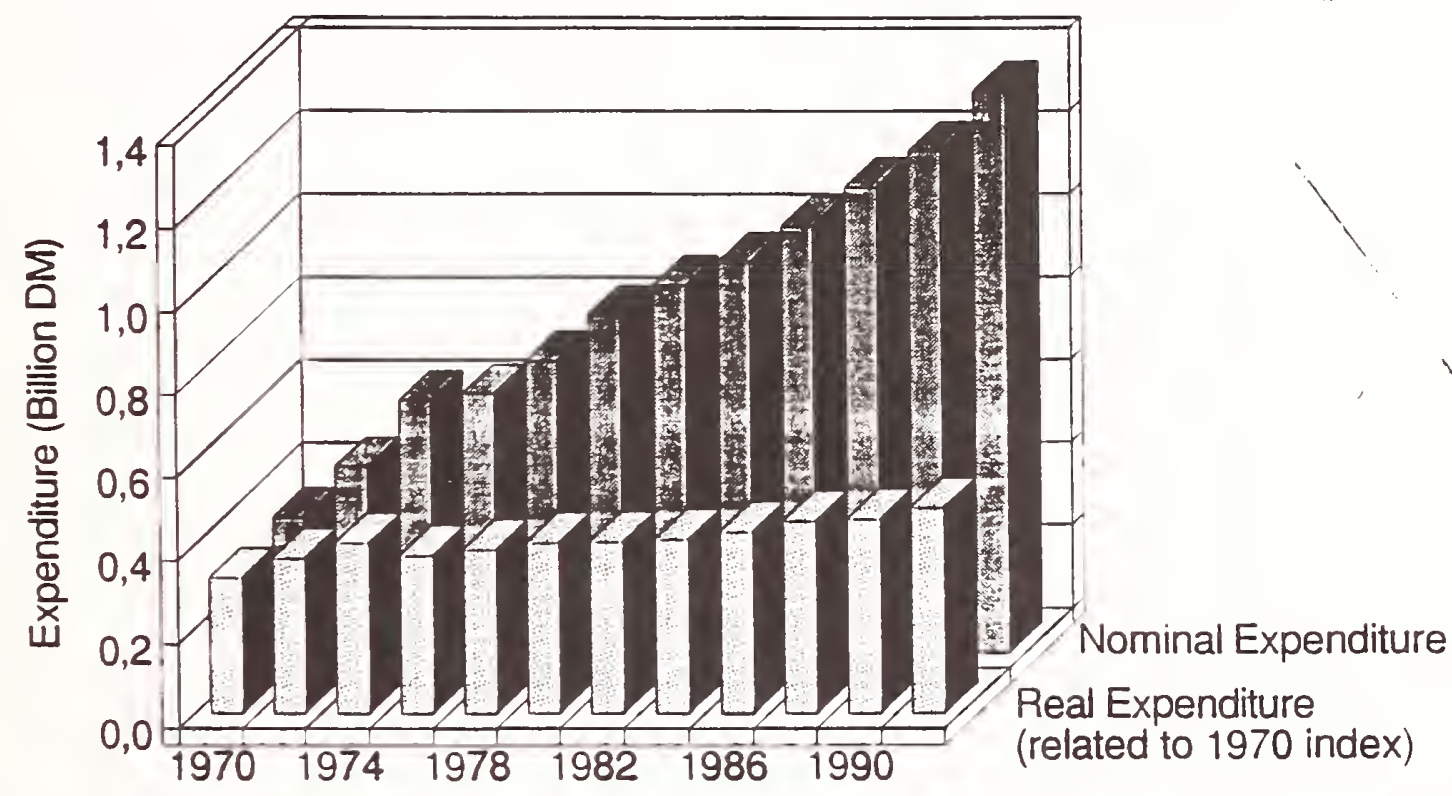

Sourco: DFG

Br 0038

\section{Fig. 7: $\quad$ Growth of DEG Expenditure}

The Deutsche Formungsgemeinschaft was founded in 1920 as the "Notgemeinschaft der Deutschen Wissenschaft". In 1949 is was re-established under the same title, but after merging with the "Forschungsrat", it was called the Deutsche Eorschungsgemeinschaft. In legal terms, the DEG is a registered society with its seat in Bonn. 


\section{3.i.2. Tasts and funding}

The tasks of the Deutsche Forschungsgemeinschaft are:

- To promote research by furnishing financial support for research projects in all fields of science and the arts. The DFG places special emphasis on fostering the acitirites of Foung scientists.

- To counsel parlisments and public authorities on scientific matters.

- To harmonize basic research effort in co-ordination with the direkt support given by the state.

- To foster academic relations with countries abroad.

Eor the accomplishment of these tasks, the Deutsche Eorschungsgemeinschalt is funded on a 50:50 basis by the Federal Government and the Federal states. Eor the Collaboratite Research Centers, the ratio of Eunding $2=75: 25$ jy the Eideral fovernment and the Eederal Btates respectirel.. The ZFG ilso receives an annuai grant from the Eunors issociation for the Eromotion of Sciences and Sumanities $n$ Germany (Stifterverband sür die Deutsche wissenschaft, and the Eederal Government and the governments of the Federal states may in mutual agreement place additional funds at the DEG's disposal Eor special purposes and projects.

In $199171.4 \%$ of the funds within the Individual Grants and Priority programs was approved for personnel, and $28,6 \%$ to expenditure on equipment, material, printing costs and travel. Changes in percentage distribution have been negligible in recent vears $/ 2 /$. 
3.1.3. Eorms of support

The DEG offers rarious forms of funding. They are outined in Fig. 3 .

\section{Individual Grants Prooram (Normalverfahren)}

The promotion of resocch propects recuested on the initative of the individual researchers.

Thes profects are inancod lor a pencod of one to wo vears.

Prlecity Programs (Schwerpunktverfahren).

Ths thencing and coordination of the work of severd researchers al fifterert places on a

corten lopk-as a nib-tor a penod $\alpha$ up to five yoars.

Besearch Units (Eorscheroruppen)

Sine groups of sciantets who are wonking on one subject (now research profects) at the

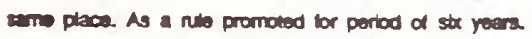

Central_Research Facillitles (Zentrals Elarichtungen)

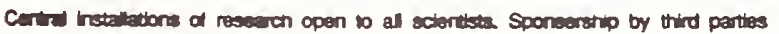

in pricto dosired.

Collaborative Research Centers (Sonderforschungsbereiche)

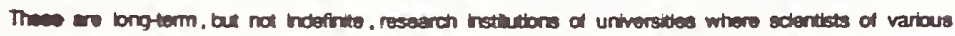

ductehes cooperate in the tramowork of a research progrem affecting inter-retating fiekts.

Graduate Collages_(Gradulertenkollegs)

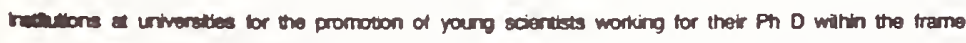

at en interdectipary crientaled suoy program

Promotion of Young Scientists in Special Programs_Nachwuchsförderung)

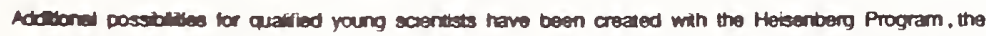

Powductorl Program, the Gerhard Hess Program, and the nowhy estabished Prolossorial Qualfication

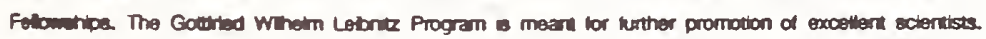

Fig. 8:

$$
\text { Eorms of DEG support }
$$

The major programs will be explained in the following:

\section{Individual grants program}

The individual grants program, which accounts for approximatley $45 \%$ of all funds aisbursed, forms the core of the DFG's research promotion. under this program any fully qualified research scientist may apply for Einancial assistance for his proposed project. He or she need not belong to a member instituion of the DEG. The initiative rests with the individual and, as a matter of principle, the DEG exerts no influence on the content of the project. However, applicants must be prepared to publish their results, to make them available for public consumption and to subject their project to the critical scrutiny of their peers in their capacity as elected reviewers. 
The report wich must : submitzed atter cne or two zars serves as the jasis zar deciding wether the project is to be extended or not. It also ofiers the elected reviewers a means of monitoring progress and hecking whether the funds are being used economicaliz and efficientiy.

Fig. $\exists$ summarizes the application and funding procedure of the German Research Foundation.

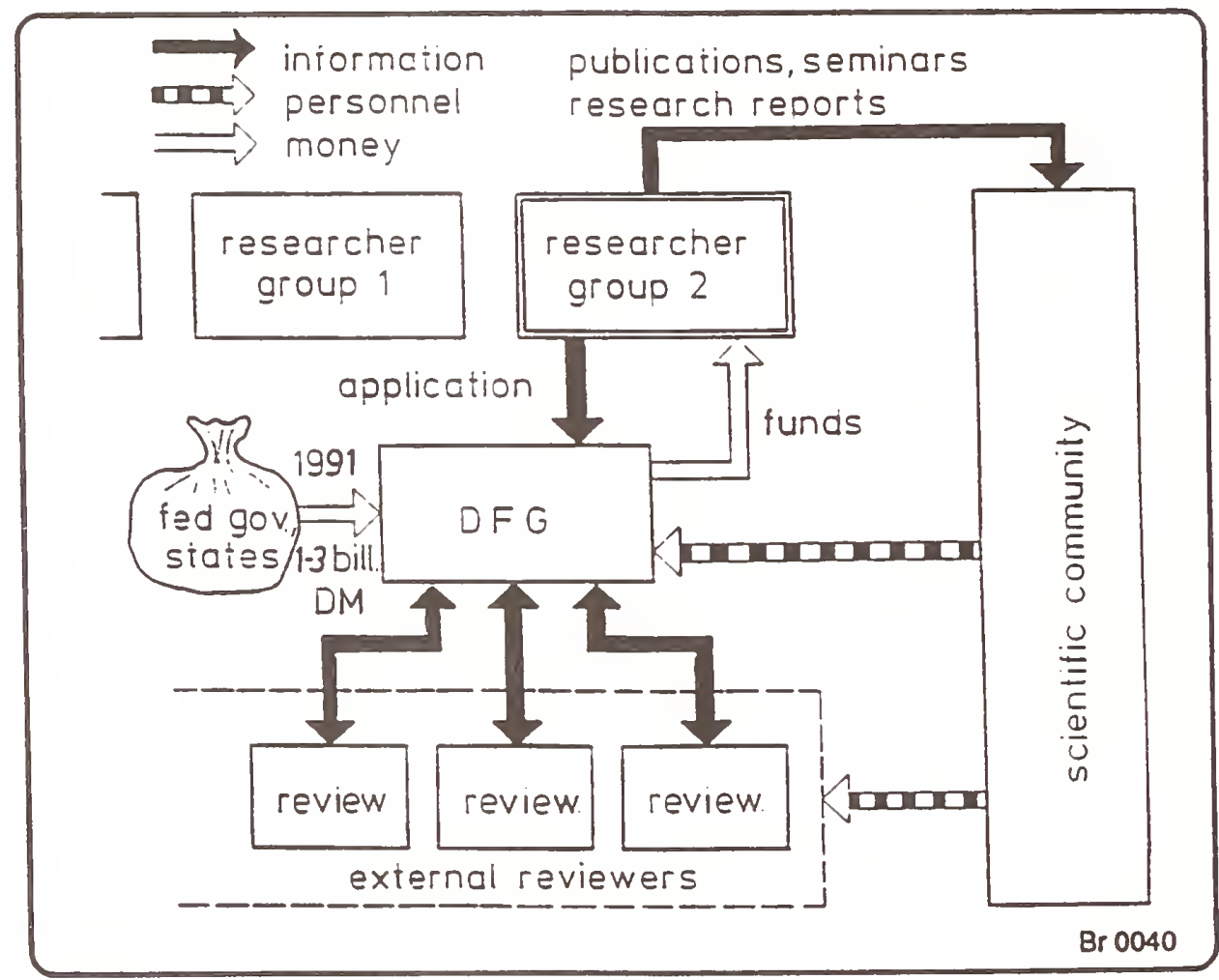

Eig. ?:

Application and funding procedure bঙ DEG

Within the individual grants program various modes af support are available, e. g. research grants, travel or printiug grants. Young scientists and scholars are given special support in the form of training Eellowships, research fellowships or fellowships to obtain i professorial gualification. The DFG "egards the individual grants program as the cornerstone for til research promotion, and the kndispensable pre-requisite for developing priorities. 


\section{Prioritr proarams}

inder the priority program, zesearchers working in $_{\text {ifferent }}$ institutes and laboratories co-operate within the framework of a given subject for a limited period of time. Approval for the initiation of a priority program is given by the senate on the basis of proposals submitted by scientists. Priority programs nay be instituted if the :o-ordinated assistance for the area in question promises to produce results of interest to science. Each participant in a priority program must contrijute to the given framework, within which ie -5 then Eree to choose his own project, research plan and methods. Assessment is performed riva voce by a yroup of =iected reviewers and special reviewers, usuaily headed by the chairman of a reviewers' committee.

In 1992 a total of 113 prlority programs with 1.510 projects and a total budget of 236,1 Mill. DM were granted. within the engineering sciences 3 priority programs were existing in 1991 with a total budget of $3 \dot{1}$ :lill. DM.

For the subject of precision fabrication the programs isted in Fig. 10 are of major significance.

- Knowledge-based diagnostic systems for flexible assembly (2.9 Mio. DM)

- Crystal growth and nucleation-mechanisms and kinetics (0.5 Mio. DM)

- Ceramics of high performance (3.4 Mio. DM)

- Ion and plasma assisted surface technology (4.6 Mio. DM)

- Sensor systems (1.2 Mio. DM)

- Flexible metal forming (2.5 Mio. DM)

- Residual stresses and deformation caused by the effect of heat (2.5 Mio. DM)

- Working-surface friction in the inelastic deformation of metals (0.6 Mio. DM)

- Beam-material interaction when working with laser beams (2.9 Mio. DM)

- Microstructure and mechanical properties of metallic high-temperature materials (new program)

- Innovative quality assurance in production (new program) 
It should be mentioned that a big priority program on fine-machining started in 1985 and was disclosed 2 years ago. Grinding and metal cutting processes as well as the subject of ultraprecision machining were investigated within this program.

Research units

A research unit is formed by a number of scientists collaborating over an extended period of time, and usualiy in one location. These engage in joint researcn into some special subject whose thematic, temporal and Ėnancial scope demands more assistance than is possible from the individuai zupport provided ander the individual grants program. The assistance afforded to research units is designed to promote close, medium-term cooperation normally for a period of six years - by ensuring the availability of the necessary staff and facilities. Research units often help to introduce new fields of activity which are still inadequately represented in Germany.

An example for a research unit on precision Eabrication is the collaboration of four leading scientists at the university of Aachen. The aim of the jroup is to effectively apply diamond turning techniques for the fabrication of non-symmetric laser optics. Fig. it shows the individual project parts.

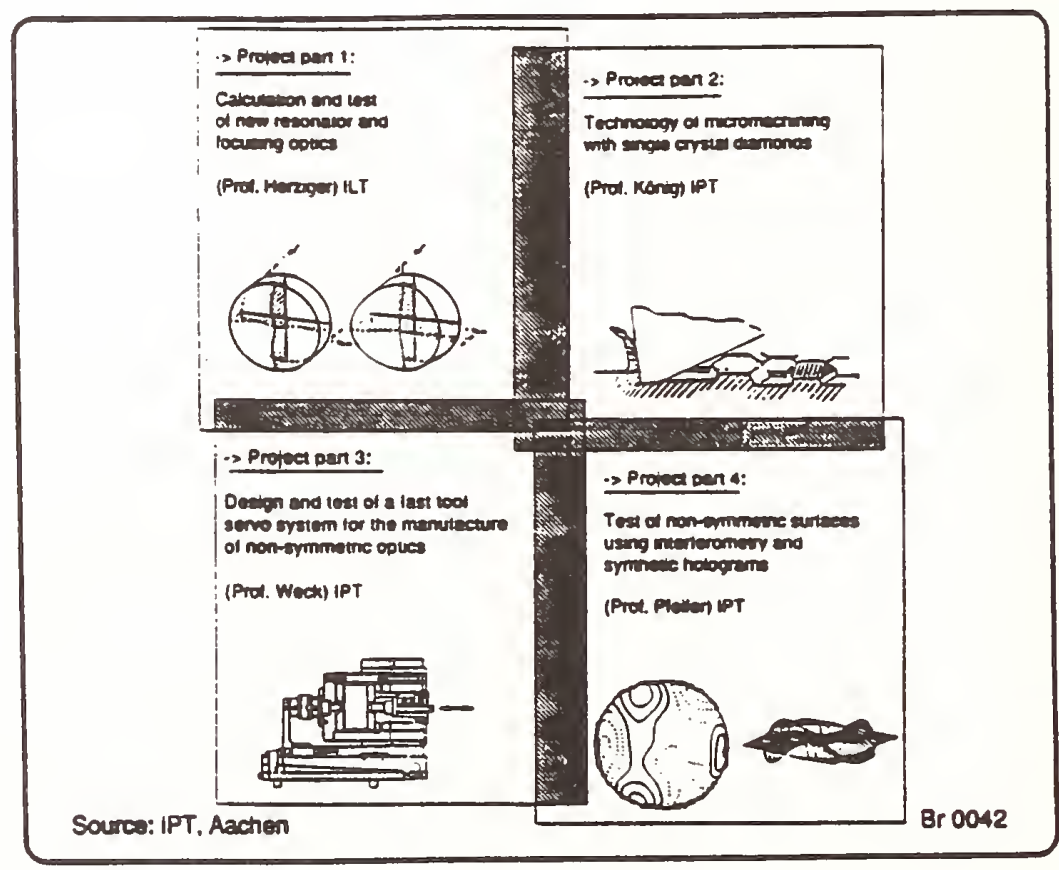

Fig. 11:

Targets of the research unit "Non-symmetric Laser Optics" 
The requirements on the new resonator and focussing optics come from the institute of laser technology. The fabrication of the optics is done by the scientists from the process technology and the machine tool lepartment. Einally the optics are quality controlled by the department of metrology.

An example of a diamond turned laser optic is shown in Fig. 12.

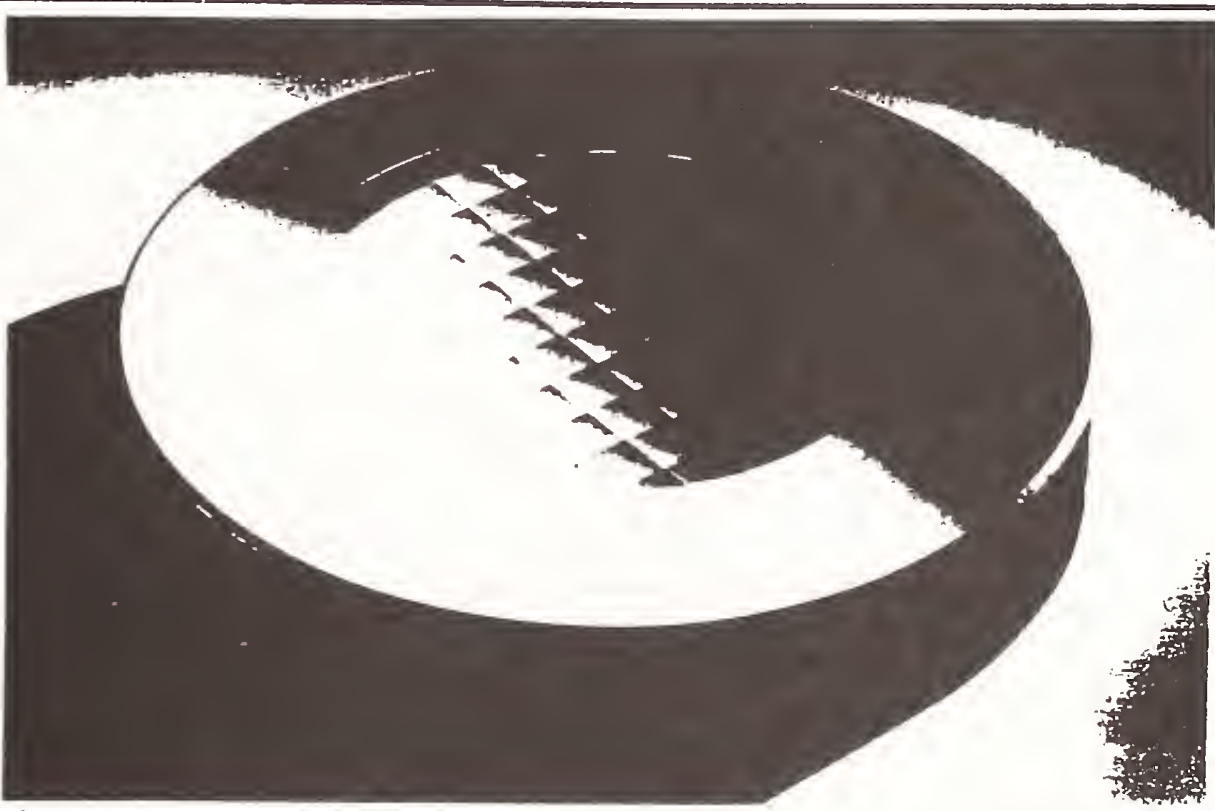

Br 0043

Fig. 12:

Diamond turned integrating laser optic

The special surface pattern was generated in the turning process by using a fast tool servo system, which was developed in one project part.

\section{Central research facilities}

Scientific and technical "service facilities" for research are eligible for support by the DEG in the form of "Central research facilities". Centralization of valuable personnel and hardware resources in one place ensures optimum exploitation of scientific and technical experience and rational operation of equipments or technical devices, which tend to be both large and expensive. 


\section{Collaborative research centers}

Collaborative research centers are research units in universities in which groups of sclentists join together, usually for periods of twelve to fifteen years, to co-operate within an interdisciplinary research program. In the question of assistance from the DFG, universities are both applicants and recipients (Fig. 13).

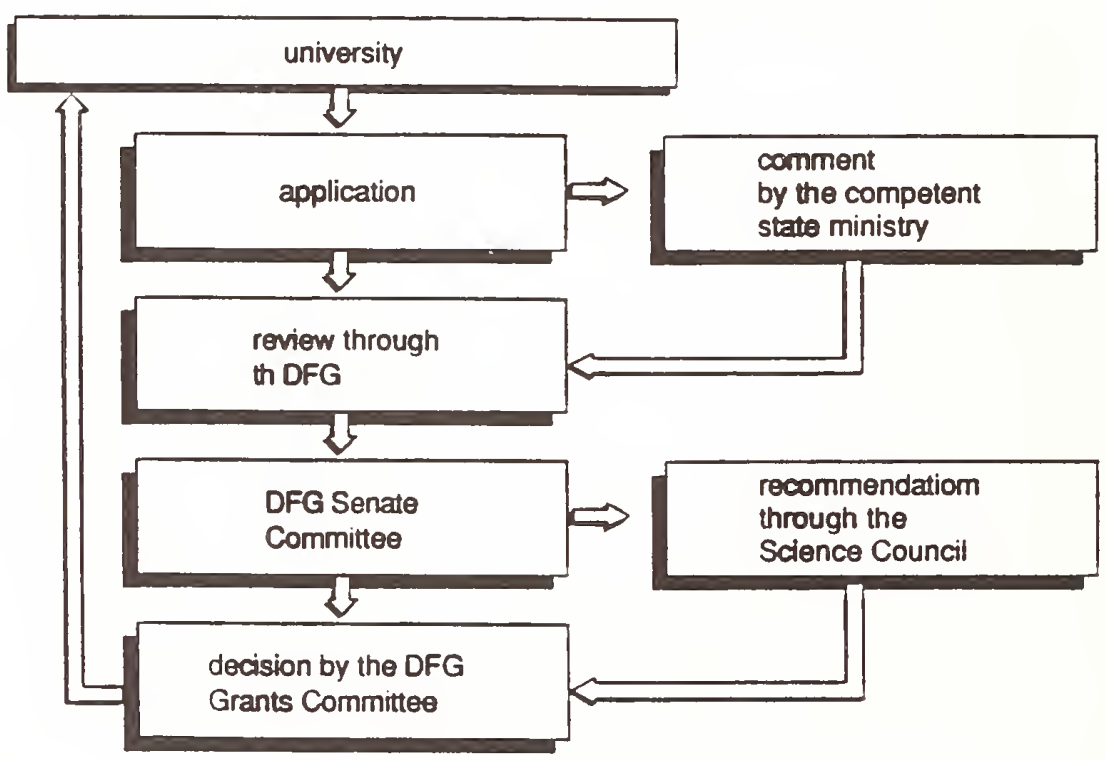

Source: DFG

Fig. 13: Procedure for the application of a collaborative research center

The universities, which both submit the proposals and administrate the DFG-funds in this program, supply the stafi and basic equipment required. Collaborative research centers enable demanding, expensive and long-term research projects to be accomplished through concentration and co-ordination of resources available to a.university.

$75 \%$ of the funds employed for collaborative research centers are supplied to the Deutsche Forschungsgemeinschaft by the Federal Government (Eederal Ministry of Education and Science), and $25 \%$ by the Federal states. 
Decisions relating to assistance for individual collaborative research centers are taken by a special grants committee. This committee consists of 22 academic members as well as representatives from the Federal Government and each of the states. The science council comments on initial applications for support prior to final approval.

Eig. It shows a list of collaborative research centers in engineering sciences with relevance to precision fabrication

- Properties of plastic materials (Aachen, 2.0 Mill DM)

- Very large scale integration, VLSI (Kaiserslautern/Saarbrücken, 3.8 Mill DM)

- Methods for saving energy and material (Aachen, 2.7 Mill DM)

- Fexible handling devices in mechanical engineering (Aachen, 2.7 Mill DM)

- Integrated mechanoelectrical systems (Darmstadt, 2.2 Mill DM)

- Tools and tool systems (Hannover, 3.0 Mill DM)

- Metal- and ceramic matrix composites (Dortmund, 3.6 Mill DM)

- Process integrated quality control (Hannover/Braunschweig, 2.1 Mill DM)

- Workpieces made of fibre-reinforced plastics (Aachen, 2.7 Mill DM)

Eig. 14:

\section{Graduate colleges}

Graduate colleges, since 1990 eligible for support by the DEG, are provided by the universities to assist graduates studying for doctor's degrees by enabling them to participate in research. They supplement the traditional system of individual tutoring by university teaching staff, providing the opportunity to conduct research in groups dedicated to specific terms of reference. A long-term aim is also to reduce the time spent at university. The Federal Government and the Federal states have decided to promote the graduate colleges for five vears in the first instance. This 
period will be necessar to check the effectiveness of the program.

\section{Special programs}

Since 1977, a series of special programs inas created additional possibilities, especially for supporting qualified young scientists. These programs will be supplemented in the next ten vears by additional funds. Special emphasis will be laid on the promotion of roung female scientists in all programs to increase the number of women professors in science.

3.2. Funding of fundamental research by the Volkswagen Foundation (rW-Stiftung)

The purpose of the Volkswagen Foundation is to support science and technology in research and teaching. The founders are the Federal Republic of Germany and the state of liedersachsen. The capital of the foundation is approximately 3 Billion D. $/ 3 /$.

\subsubsection{History}

After world war II the zights of possession on the rolkswagen $\mathrm{GmbH}$ (Limited) were uncertain. Therefore in ig6l the rolkswagen GmbH was changed into a joint-stock-company (Volkswagen $A G$ ).

The breakdown of stock shares was:

- $60 \%$ "Volksaktien" (private stock)

- 20 \% Federal Republic of Germany

- 20 \% state of Niedersachsen

The capital of the foundation results from dividends and realizations of the latter $40 \%$.

In 1988 the 20 of the Eederal Republic of Germany were denationalized and the proceeds ware added to the funds of the foundation.

Funds from 1962 to 1991: 960.5 million D.I

Fund in 1991:

from this:

66.2 million D.1

6.6 million D. for natural science

30.2 million DM for engineering science 


\section{2 .2 Concept of support}

The volkswagen Eoundation supports thematic and problem-oriented basic research. For this task priority programs are defined. The proposal comes from and is evaluated by the scientific community and the general board of the foundation. Hence this procedure is very similar to the establishing of priority programs of the DFG. Presently two of such programs are of interest for the engineering sciences and also for precision fabrication:

- Overlapping projects from differant fields of natural science and engineering science and

- Microcharacterization of materials and structural elements

A different type of granting is the support of infrastructure in research and teaching and also in scientific communication by

- symposia und summer schools

- research in foreign countries

- new professorships

\subsubsection{Procedure of application}

Proposals for projects within the present priority programs can be sent to the secretary at any time. External consultants wich are members of the scientific community are named by the secretary individually corresponding to the needs of the project. The experts' opinions are confidential. The final decision on the project is made by the truestees who meet several times a year for this purpose. For big projects a decision can take up to 6 month.

In $199154 \%$ of all the proposals were accepted.

\subsubsection{Priority programs with relevance to precision fabrication}

\section{Microcharacterization of materials and structural elements}

The scope of this program are the development of methods of microcharacterization and its use in materials research (material science, physics, mineralogy) and to establish cooperation with the purpose of using different kinds of instrumentation (trans- 
mission electron microscope, scaming electron microscope, tunneling microscope, ...l

Subjects of the program are

- Evaluation of faults in crystalline material and multiphase material

- Evaluation of early states of segregation

- Evaluation of dynamic processes in atomic scale (reaction kinetecs in mixtures)

- Further development of imaging methods with high lateral resolution

- Computer simulation and image processing

- Development of preparation techniques

Titles of individual projects with relevance to precision fabrication are

- Real-time-scanning-tunneling-microscope and temperature dependence of clean and adsorbated surfaces

- Fluctuations in the near-order sid zocalization of sipping in concentrated copper ilioys

- Analysis of adhesive substrate-polymer-connection in microscopic dimensions

- Real imaging microscopy and spectroscopy of surfaces with slow electrons

overlapping projects from differant fields of natural science and engineering science

The purpose of this program is to tackle new kinds of problems and to find creative solutions by an interdisciplinary collaboration in the engineering and natural sciences.

Examples for projects (1991) are:

- Development of an application-orientated measuring system for three-dimensional analysis of complex mechanical structures

- The dispersion of the velocity of crystallization caused by differant crystal perfections 


\subsection{Eunding of applied research br the Minister of Research and Technology (B:IFT)}

The German Iinister of Research and Technology supports applied research. He defines program corridors in which industrial companies together with $\lambda$ research group from an university may apply for funding of a collaborative project. Normally the output has to be published in general lines. The specific findings which are interesting for the industrial companies inore than for the scientific community need not to be published.

Generally, a $50 \%$ funding of the total expenditures of a project is usual.

As universities normall reed 100 r funding of their expenditures in project part, the funding of the collaborating companies will be lower than $50 \%$. In addition, there is also a funding procedure where indiridual companies or research laboratories can get support.

Fig. 15 shows the system and the procedure to apply for BMFT funding.

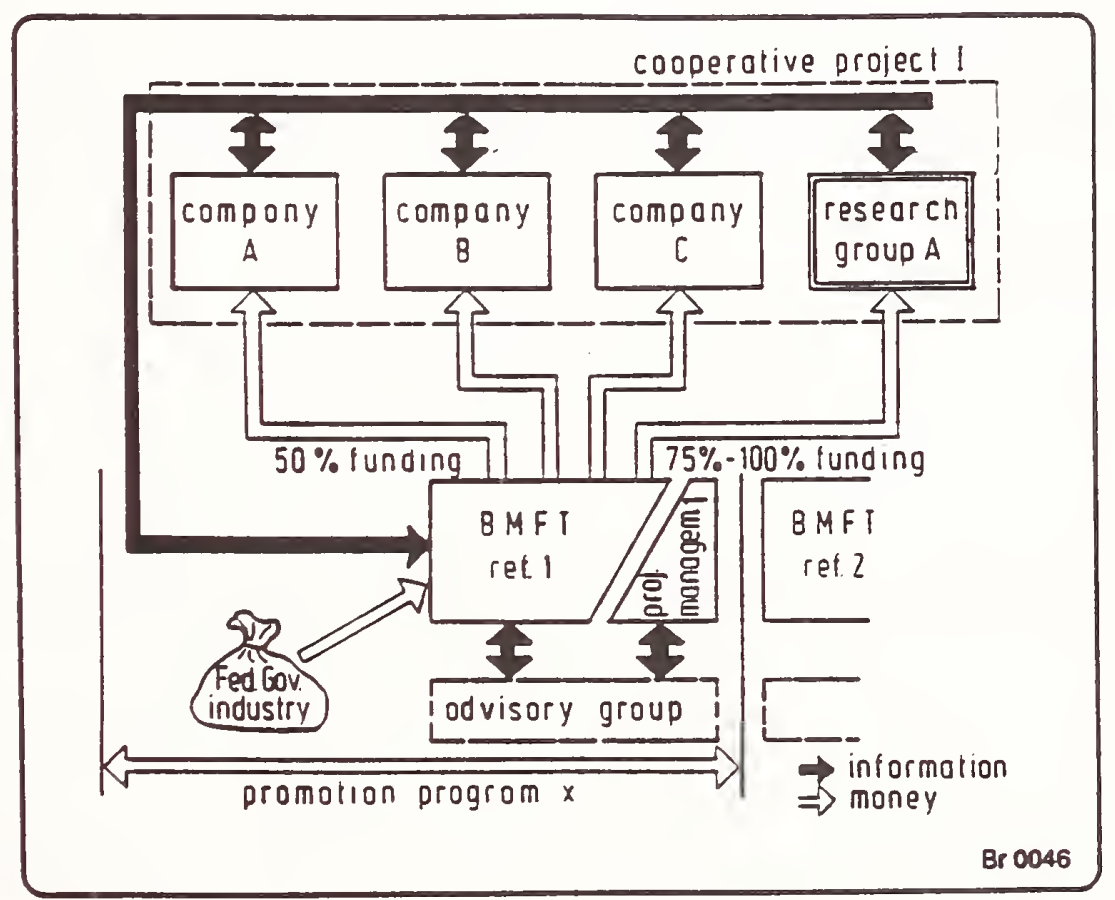

Eig. 15:

Collaborative research projects of BMFT 
The reviewing procedure for projects is similar to the procedure of other R\& D supporting institutions. Usually a funding of a project is only possible within a defined promotion program. Currently there are more than 30 of such programs / $1 /$. The nost important of them with relevance to precision fabrication and the funding within the programs are isted up in Eig. 16.

\begin{tabular}{|l|c|c|c|c|c|}
\cline { 2 - 6 } \multicolumn{1}{c|}{} & $\begin{array}{c}\text { number of } \\
\text { projects }\end{array}$ & $\begin{array}{c}\text { funding } \\
\text { volume } \\
\text { (Mio DM) }\end{array}$ & $\begin{array}{c}\text { industrial } \\
\text { companies } \\
\text { (Mio DM) }\end{array}$ & $\begin{array}{c}\text { universities } \\
\text { (Mio DM) }\end{array}$ & $\begin{array}{c}\text { other R\&D } \\
\text { laborator. } \\
\text { (Mio. DM) }\end{array}$ \\
\hline $\begin{array}{l}\text { Microsystems Technology inc. } \\
\text { Microelectronics and Mikropenpheric }\end{array}$ & 59 & 64.7 & 28.1 & 18.6 & 18.0 \\
\hline Production Engineering & 60 & 107.0 & 77.1 & 14.5 & 15.4 \\
\hline Advanced Materials & 262 & 125.7 & 74.4 & 24.8 & 26.5 \\
\hline Physical and Chemical Technologies & 244 & 153.3 & 62.4 & 50.9 & 40.0 \\
\hline $\begin{array}{l}\text { Quality Assurance } \\
\text { (New Program in 1992) }\end{array}$ & & & & & \\
\hline
\end{tabular}

Eig. 16: BMFT promotion programs with relevance to precision fabrication

The largest programs in Fig. 16 are ready to support the development of advanced materials and $R \& D$ work on physical and chemical technologies. 
A large new program wich has just been established is the Quality Assurance program. It has started in 1992. The financial support of the B.MFT for this program is given in three different ways:

1. Funding of collaborative research projects (applied research)

2. Funding of co-operating research groups from several universities (basic research)

3. Funding of a priority program of the German Research Foundation DEG (basic research)

The Quality Assurance program is not supposed to support technical measures on the manufacturing process level. Yuch more has it been established to promote the introduction of quality assurance systems in more general lines with the development of advanced strategies.

In order to give an idea on the type of projects and their budgets within the promotion programs listed in Fig. 16, examples of such projects with relevance $: 0$ precision fabrication are listed up below in the following $/ 4 /$. 
Examples for collaborative projects within the ByFT promotion program Microsistems zechnology incl. Hicroelectronics and Microperipheric are:

- Integrated optics on glass basis for sensors, sensor systems and signal processing

(5 partners, 19.4 . Mio. D.M total funding)

- Chemical sensor systems

(4 partners. 15 yio o. total funding)

- Micromechanical sensors

(5 partners, 3 Mio DM total funding)

- Micromechanical actuátors

(4 partners, 6.8 Mio D. total funding)

- Thin film-gas sensors

(2 partners, 2 Mio D.I total funding)

- Integrated optics on silicon

(4 partners, 3.5 'Iio D.I total funding)

- Application of micro sensors

(6 partners, 10.6 . Hio DI total funding)

- New sensors and actuators for laser beam machining

(6 individual industrial projects, 3 Mio DM total funding) 
Examples for allaboratire projects within the ByFT promotion program Production Endineering

- Quality assurance in flexible manufacturing systems with CMM (12 partners, 10.5 Iio Dy total funding)

- High precision metal cutting (28 partners, iO Mio D.I total funding)

- Precision metal forming (20 partners, 13.5 Uio D.I total funding)

- Sheet metal forming

(22 partners, 11 .Iio D:I total Eunding)

- Grinding of advanced ceramics

(13 partners, 7.2 :Iio D.1 total cunding) 
Exampies for collaborative projects within the 3MFT promotion program Advanced Yateriais

- Wear and material removal mechanisms when cutting with superhard non-metaliic tool materials

(3 partners, 2.6 Mio DM total funding)

- Development oE fibre- and particle-re-inforced light metal composites

(4 partners, 3.7 Mio Dy total funding)

- Development of fibre-re-inforced composites of high strength (4 partners, 10.2 Yio D.1 total funding)

- Joining Technologies for high strength Al-Li-alloys (5 partners, i.t Mio D.y total funding)

- Development of short fibre and whisher re-inforced ceramic composites

(7 partners, 13.6 :1io D.Y total funding)

- Joining at high workiece temperatures

(4 partners, 2.9 Yio Dy total funding)

- Molecular re-inforcing of polymers

(1 company, 2.3 Mio DM total funding)

- Ceramic fibres

(I company, 2.6 Mio DM of total funding)

- High temperature resistant materials

(44 partners, 12.8 Mio DM total funding)

- Ion implantation for tribological applications

(5 partners, 2 Mio DM total funding) 
- Optimized manufacturing for coating processes (6 partners, 2.2 Iio D.I total funding)

- Eibre re-inforced glass

( 3 partners, 2.8 Mio DM total funding)

- Physical vapour deposition at low temperatures (6 partners, 3 Mio DY total funding)

- Development of advanced cermet alioys (3 partners, 1.5 Mio D.I total funding)

- Coating of fibres with ceramic material (2 partners, 1.5 Mio D. total funding)

- Advanced ceramics (individual projects) (15 companies and universities, priority program of DFG (15 Mio DM), \$0 Mio DM total funding)

- Advanced polymers (individual projects) (18 companies and universities, i8 Mio DM total funding) 
Examples for collaborative orojects ivithin the ByFT promotion program Phvsical and Chemical Technologies

- PVD technologies at low temperature and new layer systems (incl. Jiamond films) / (12 partners, 13.3 Mio DM)

- Implentation technologies for tribological applications (6 partners, \pm .2 Mio DM)

- Diamond coating of components with complex shape ( 4 partners, $\$ .8$.10 D.M)

- X-ray microscope $(2$ partners, 1.8 Mio DM $)$

- New thin film technologies by molecular engineering (6 partners, 11.8 Mio D.I)

- Surface modification of plastics by ion implantation (2 partners, 1.8 MiO DM)

- Structuring of surfaces by Laser CVD (3 partners, 3.7 Mio DM)

- Cutting with high performance lasers (10 partners, 8.3 MiO DM)

- 3D-machining with high performance lasers (9 partners, 10.9 Mio DM)

- Surface treatment with $\mathrm{CO}_{2}$ lasers (19 partners, 10.6 MiO DM)

- Welding with solid state lasers (5 partners, 2.1 Mio DM)

- High power excimer lasers (phase I and II) (11 partners, 27.0 MiO DM)

- Laser workstation for surface treatment (3 partners, 5.5 MiO DM)

- Joining with $\mathrm{CO}_{2}$ lasers $(17$ partners, 7.1 Mio DM)

- Micro machining with excimer lasers (11 partners, 9.1 Vio DM)

- Material removal with solid state lasers (7 partners, \$.4 Mio DM)

- Superconducting materials (individual projects) (56 companies and universities, 80 MiO DM) 
It may be also of interest how the mentioned programs compare to other programs being funded by the 3MFT. A breakdown of expenditures for the sectors with the highest amounts of funding is shown in Fig. 17 .

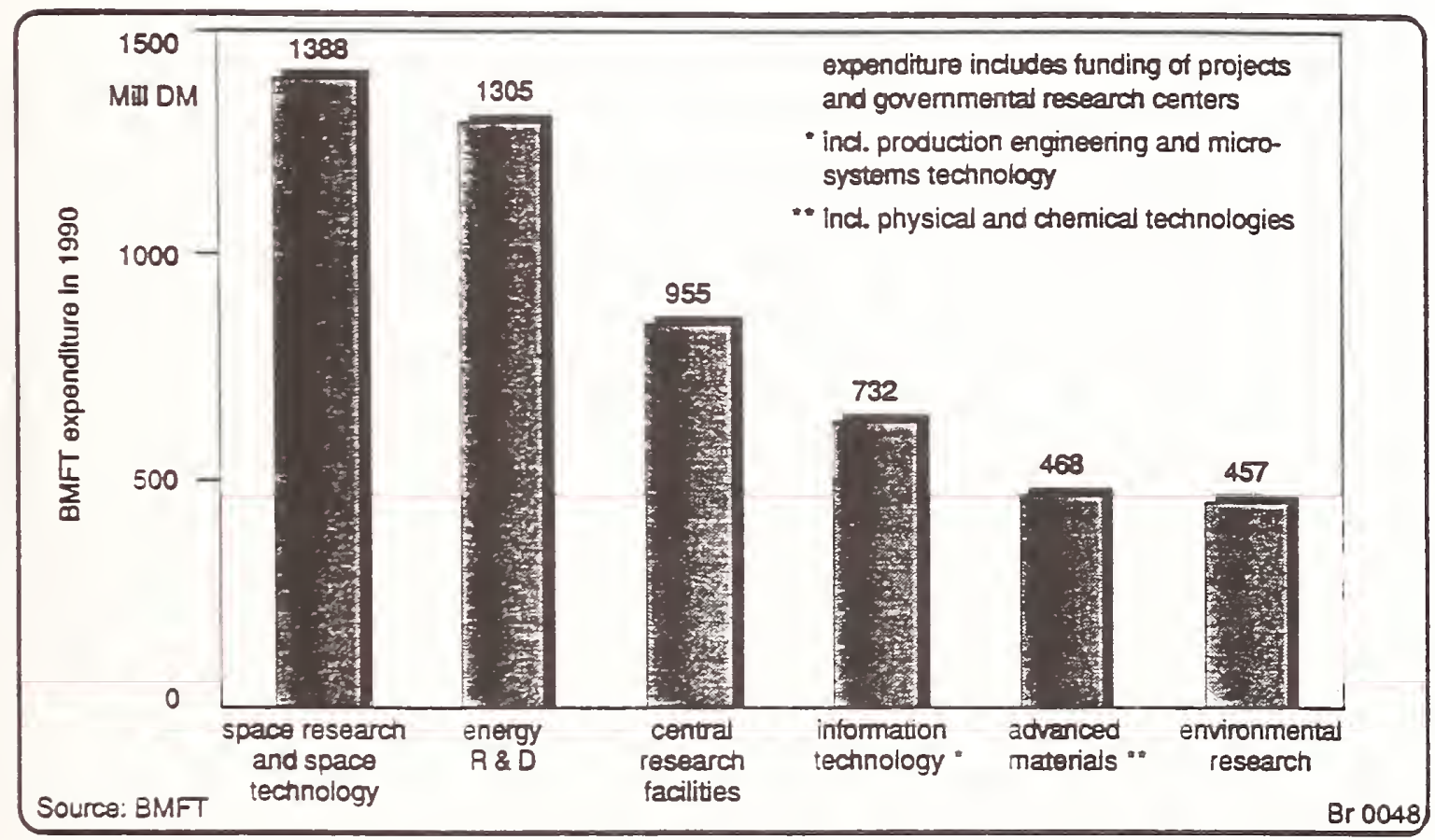

Fig. 17: BMFT expenditures on sectors of funding

It has to be considered that the given numbers do not only stand for the funding of individual projects but do also include the granting of governmental research centers within the listed sectors. Nevertheless it can be seen that the mentioned promotion programs have a relatively high priority within the frame of BMFT funding. Eurther sectors of support like the funding of $R \& D$ in sea technologies, bio-technologies, human health, social scienes, civil construction and aerospace technologies and others have lower budgets and are not mentioned in the figure. 
3.4. Eunding of applied research by the German Eederation of Industrial Cooperative Research Associations AIF (Arbeitsgemeinschaft industrieller Forschungsvereinigungen)

\subsubsection{History of the AIE $/ 5 i$}

At the beginning of the $1350^{\prime}$ ies German jovernment and industry recognized the neccessity of an elfective structural improvement for small and medium sized enterprises (SMEs) in the field of Research and Development $(R \& D)$. Due to the well known problems of SMEs to carry out or to finanze $R \& D$ on their bwn, a special instrument was needed to improve the technological standard of SMEs in an efficient way. Taking up the idea of precompetitive "Industrial Cooperative Research" in the vear 1954 the so called "Industrielle Gemeinschaftsforschung" was created.

"Industrial Cooperative Research" is not dedicated to a few or single enterprises but to all enterprises related to one or more branches or technical fields. The aim is to improve the technological standard and competitiveness of whole branches with projects being of common interest for all enterprises. Due to the big number of SMEs (nearly $95 \%$ of all European companies are SMEs) the promotion of "Industriai Cooperative ?esearch" is an important vlement of the governmental $R$ \& $D$ policy in Germany and it should play a substantial role in the $R \dot{\alpha} D$ poilcy of the European Communities, Łoo.

Nevertheless, "Industrial Cooperative Research" is only one kind of $R \& D$ in Germany. Since its creation in 1954 the AIF, the "German Federation of Industrial Cooperative Research Associations" is acting as an agency between the partners in this special field of $R \& D$. Figure 18 shows the AIF between other parts of the R\&D organization in Germany. 


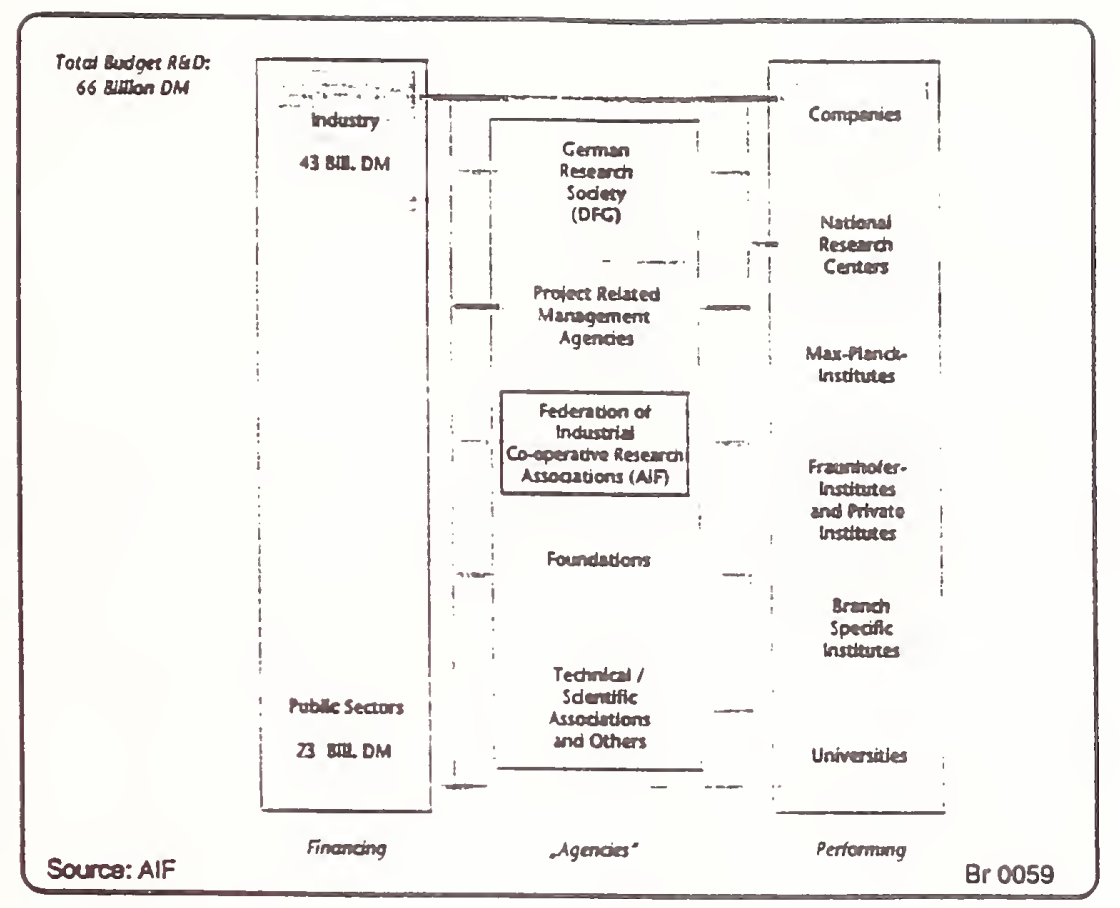

Eig. 18:

The AIF in the field of $R$ \& $D$ organizations in Germany

\subsubsection{Structure}

In a lot of branches and technological fields, German SMEs have linked together in industrial research associations. They are working as a frame for their companies, dllowing them to act together in the field of industrial cooperative research. Starting with 17 industrial research associations in 1954, today 102 research associations are united under the imbrelid of the AIF - the independent German Eederation of Fildustrial cooperative Research Associations. These research associations iave more than 50.000 companies as their members and more than $90 \%$ of these members are SMEs. All these companies are members on a voluntary basis.

Some of the 102 research associations are supporting R\&D work also in the area of precision fabrication. Examples are:

- Association of motive power technique (Antriebstechnik)

- Mechanical engineering association (Maschinenbau)

- Machine tool builders' association (Werkzeugmaschinenfabriken)

- Heat treatment and materials' technology (Wärmebehandlung und Werkstoff-Technik)

- Tool- and workpiece materials (Werkzeuge und Werkstoffe)

- Ultraprecision technology (Cltrapräzisionstechnik) 
Task of the Research Associations is to find out the research needs of their industr. and to create cooperative research projects in order to improve the competitiveness of all their members. This process is industry driven, that means the ideas and proposals for research projects are coming "Bottom up" from the industry. Some research associations have own institutes, others are working together with external establishments like universities or contract zesearch organizations. Cooperative research in Germany is based on the industrial research associations and not on the institutes, anyhow the institutes are acting as performers, and relations between research associations and institutes might be rary strong in some rases. Eig. 19 shows levels of "Industrial Cooperative Research" in Germany. It is the process of generating and conducting cooperative research projects which makes the difference to the pure contract research organizations.

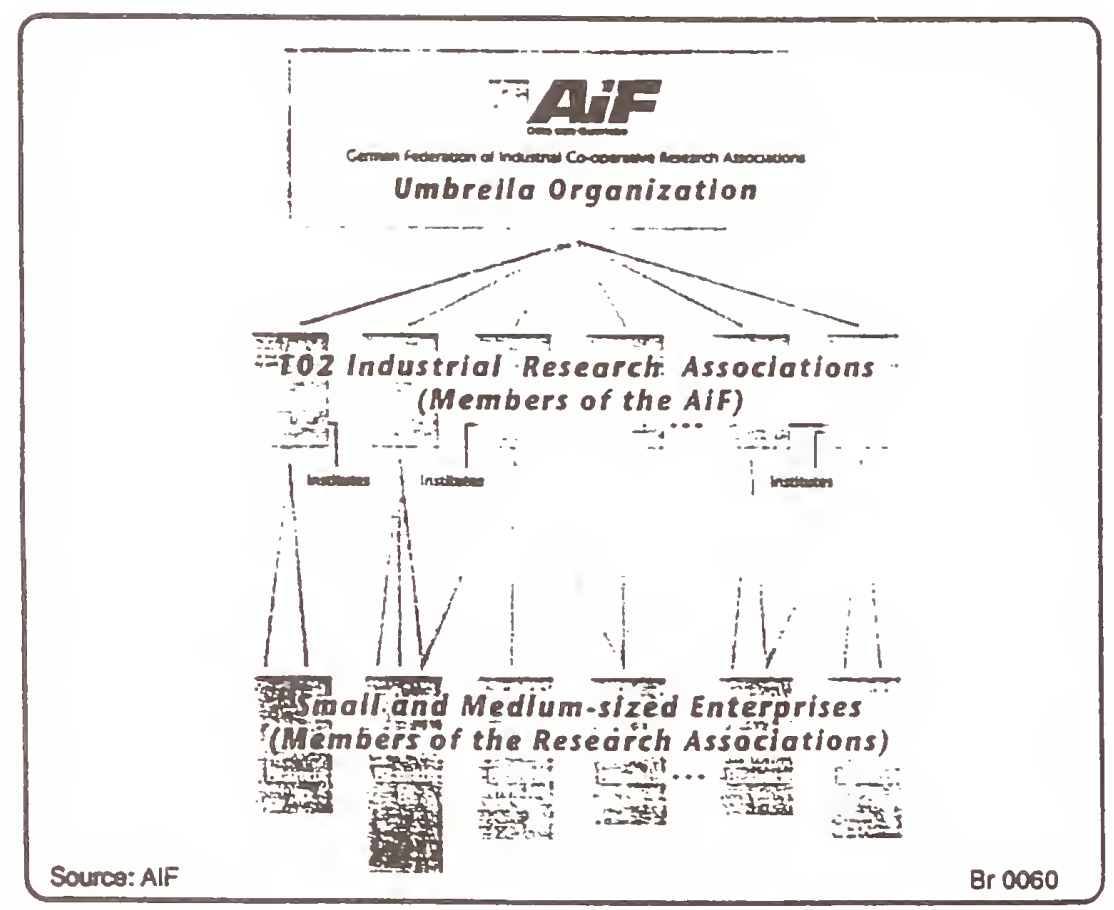

Fig. 19: Levels of industrial cooperative research

It is also essential to this system of $R \& D$ that SilEs which are usually competitors are working together in research projects before they enter into competition. Due to this, cooperative research projects must have a precompetitive character. That means at least, not every technical problem can be solved by this 
kind of $R$ a $D$. But there are a lot of technological and scientific problems which can anly be solved by cooperative research because $-t$ is too expensive for individual companies to work on them alone.

\subsubsection{Eunding procedure}

Eig. 20 shows the funding procedure of the AIF.

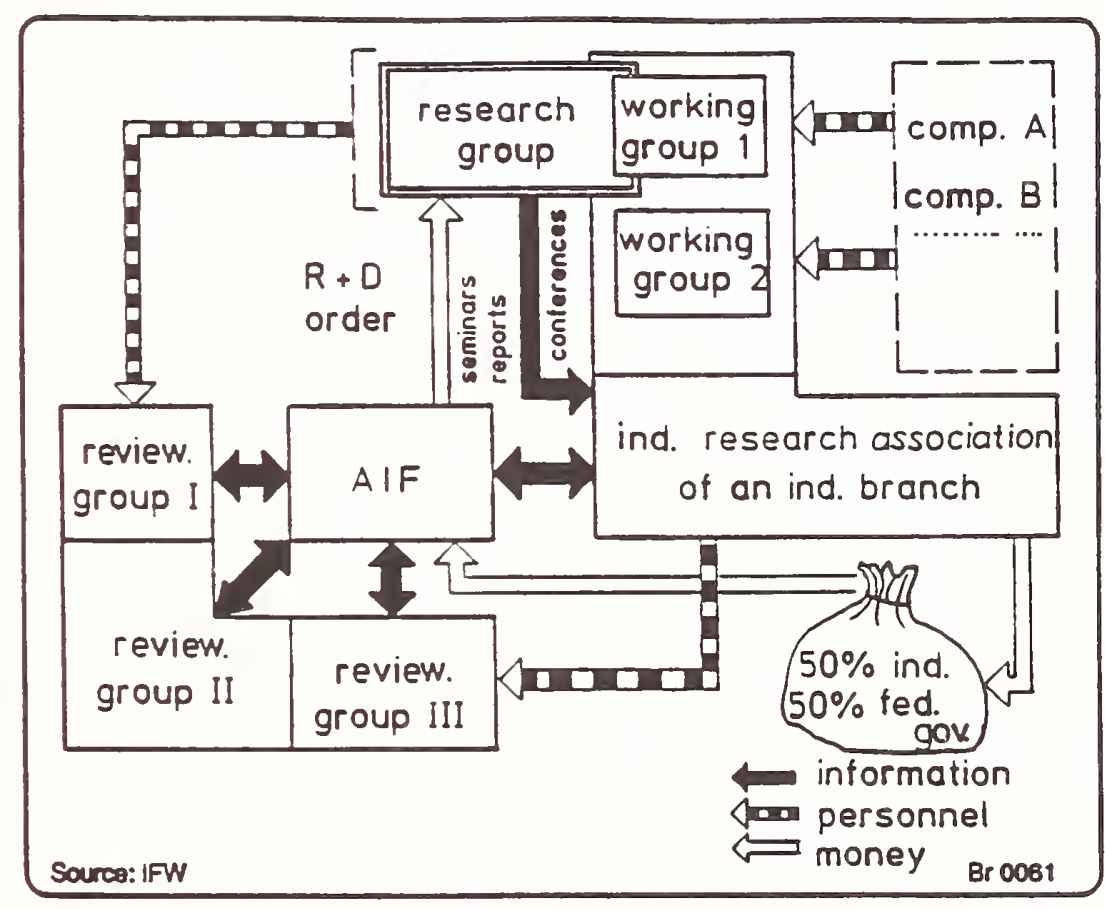

Fig. 20: $\quad R \& D$ support by AIF

Different tasks of the Research Associations are:

- discussing ideas, problems and needs coming "Bottom up" from the industry

- evaluating proposals for research projects

- selection of qualified research facilities

- planning and formulation of research projects

- deciding about the financing of the projects 
- providing financing mechanisms

- monitoring and controliing of the research work

- evaluating the research results

- transfering and disseminating the research results

- training and advicing for the utilization of the research results

For all these tasks expert groups and committees are acting in each research association :onstituted by experts from industry, science, authorities and other :ivolved organizations.

If the research associations want to receive public money for cooperative research projects they have to apply for it at the AIF. Eight expert groups of the AIF, constituted by nearly 140 independent experts Erom industry and science will evaluate the applications of the associations. If these expert groups decide to support an application at least an authorizing committee has to evaluate it again and to recommend it for public funding.

\subsubsection{Financing and budget}

The possibility to participate in the public support depends on a fundamental precondition which is one of the basic principles of the "Industrial Cooperative Research" system. Those associations which want to receive pubiic support for their "esearch projects have to prove that they have invested at ieast the same amount out of own funds for cooperative research. Iil general the AIF evaluates this industrial contributions annualir. The availability of public funding for single research association will be fixed every year depending on the governmental budget for cooperative research and on the own contributions of industry spent for this purpose. In general it should be stated that the amount of industrial contributions to cooperative research gives the maximum amount of public fundings for the same purpose.

It is important to this system that the distinction between public funds on one side and funds from industry on the other side is not related to the single research project. That means that cooperative research projects are totally financed either by money from industry or by public money. The research association must decide whether a project is suitable for the more time consuming procedure of public support or whether it should be implemented directly by industries own funds and forces. Fig. 21 shows the relation between public fundings and industrial means for specific branches. 


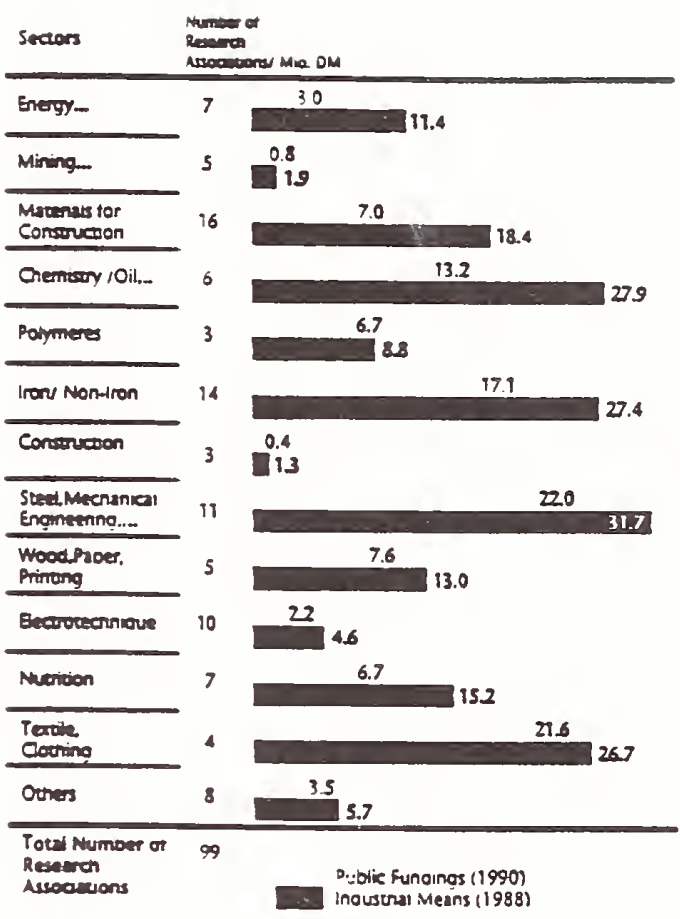

Fig. 21:

Public funding for industrial branches

Industries main contributions for cooperative research are the following:

- cash contributions to the work of research associations mainly used for researcin projects

- specific contributions directly to research institutes on an individual cooperative research project basis

- "in kind" contributions on an individual project basis

- administrative costs covered by industries

Yore than two third of industries contributions for ooperative research is cash contribution and nearly $20 \%$ is "in hind" contribution for specific research projects.

The average costs for a cooperative research project funded by the AIF is around 400.000,-- DM. Having in mind the public budget of 200 million marks for cooperative research and the number of 50.000 companies which are members of the research associations and which have direct benefit from this budget, at least the funding for each company is around 4.000,-- DM. No other procedure gives the opportunity to contribute more successfully and efficient to the technological progress of small and medium sized enterprises by using so less money.

Due to the precompetitive character of cooperative research it is not easy to demonstrate the benefit of this kind of $R$ \& $D$. It is the task of the single companies to transfer the research results into $a$ success on the market. But the willingness of industry to increase the industrial budget for "Industrial cooperative Research" is the best evidence for the efficiency of this kind of $R \& D$. 


\subsection{European ocience Euncuation EsE}

For Dasic research, scientists can jplir for funding from the European Science Foundation ESF. The ESF is an association of Ẽs 56 member research rouncizs and academies in 20 countries. The ESF brings European scientisis together to work on topics of common concern, to b-orizate tie se cz expensive facilities,

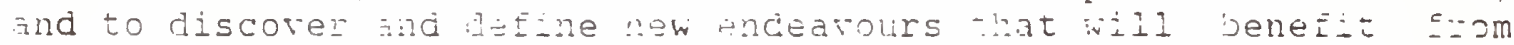
a cooperative ipproaci i i i.

The scientific work jponsored by ED inciudes basic rosearch in

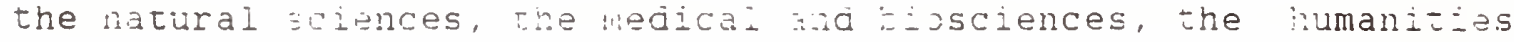
and the social sciences.

The ESF links "cholarship and research supported by its members and adds value by cooperatio: äross rational frontiers. Through its Eunction as a co-jrisator, and aiso jy holding workshops and conferences and $z \underline{y}$ enabling zesearchers to visit and study in laboratories throughout Europe, the EsE rorks Eor the advancement of European science.

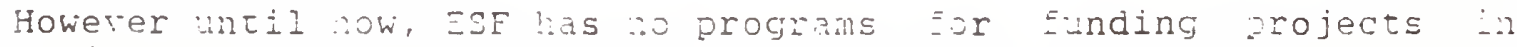
engineering research.

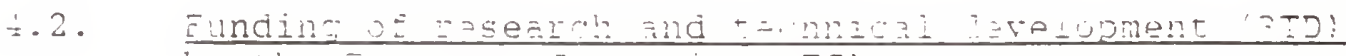

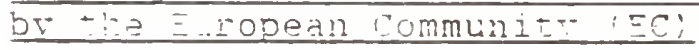

1.2.2 Generi inormation

In EC research programs the results are explicitrr requested to be precompetitive. The results are desired to lead irectiy to products which help the European industry to improre ixeir competitiveness.

Since 1383, the European Community (EC) has coordinated - is research and cechnical levelopment (RTD) actirities inrougin multiannual saamework programs. These Eramework programs ire implemented through specific RID programs dealing hith selected areas of research - such as the environment or health. so sar there have been tho framework programs.

On 23 April 2990 , the Council adopted the third framework program. This nas a duration of 5 years, a budget of 5.7 bilition ECU and contains 15 specific RTD programs in the Eozowing areas / $/$ : 
- information technoiogies

- communications technologies

- development of telematics systems in areas of general interest

- industrial and materials technologies (Brite-EuRam II)

- measurement and testing

- environment

- marine science and technology

- biotechnology

- agricultural and agro-industrial research

- biomedical and health research

- life sciences and technologies for developing countries

- non-nuclear energies

- nuclear fission safety

- controlled thermonuciear fusion

- human capital and mobility

For engineering sciences the RTD program Industrial and Materials Technologies Brite-EuRam II is of prior relevance. This program will be carried out through shared-cost research projects. This means that the EC participation in the cost of the research is in principle 50 \% of the total project costs. Funding can only be applied for collaborative projects ivith co-operating companies and universities from differant member states.

The program's main objectives are:

- to increase the competitiveness of European producer and user industries

- to strengthen European economic and social cohesion

- to promote the scientific, technologcial, and economic integrations of European industry

A number of strategic aims complement the general objectives of the program:

- to increase the application of advanced technologies by smaII and medium sized enterprises (SMEs)

(An SME is a company which has less than 500 employees, has a net annual turnover of less than 38 million ECU and is not more than one third owned $b_{Y}$ a parent company or any other organization larger than a SME, although larger shareholdings held by investors such as banks or venture capital firms are permitted) 
- to increase the involvement of manufacturing SMEs in European RTD through developing links with other enterprises aid promote a better management of their resources

- to reinforce and diversif engineers for modern Europan industry

- to give full consideration to the social, human and environmental impact je advanced technologies

- to ensure an appropriate dissemination and exploitation of results, especially for development of standards and user specifications.

The EC has defined some general criteria which a research project must fulfill. These criteria are listed in Fig. 22.

- Conformity with the scope and objectives of the program

- Scientific and technical excellence and novelty

- Precompetitive character

- Scientific, technical and economic benefits

- European dimension

- Transnational collaboration

- Ability to provide for a high quality project management

- Technical competence of the partnership

- Environmental aspects 
Fig. 23 shows the decision procedure for EC projects.

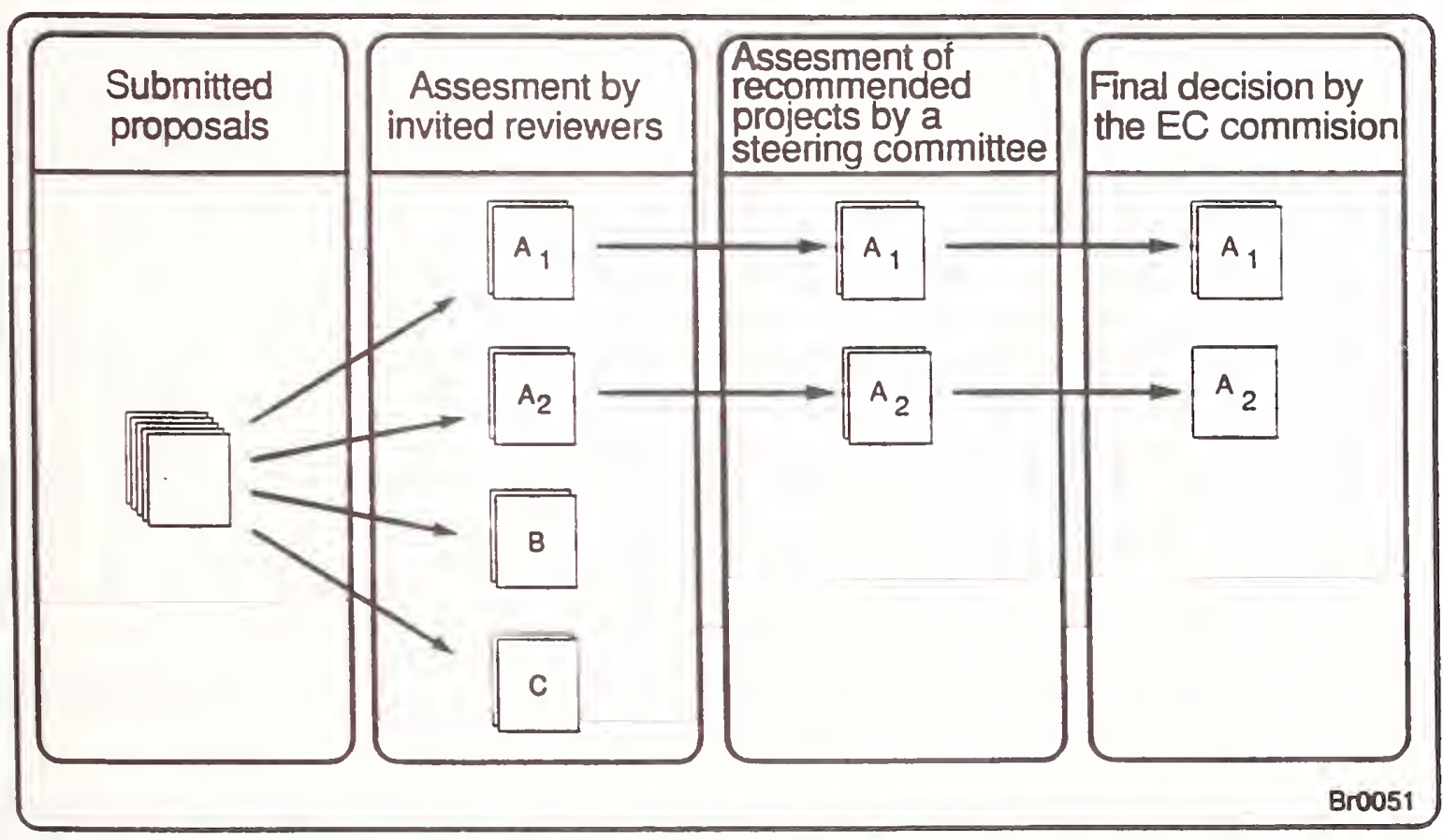

Eig. 23: Decision procedure

\subsubsection{Technical areas of Brite-EuRam II}

The scope of the technical areas reflects the multisectorial approach of the program and emphasizes the need to bring together, in RTD, partners drawn from suppliers, producers and end-users as well as from basic research intitutes and industrial enterprises (including SilEs) /8/.

For engineering sciences and precision fabrication $R \& D$ two areas are of major interest:

$$
\begin{aligned}
& \text { Area 1: Materials/Raw Materials } \\
& \text { Area 2: Design and Manufacturing }
\end{aligned}
$$


The objectires of the drea Materials/Raw Yaterials are to improve the performance of both advanced and tuaditional naterials at a cost which permits competitive industrial exploitation over a broad range of applications. This extends to improving the technologies to ensure the supply of raw material resources and for recycling, so promoting an integrated approach to the whole life-crcle of materials. It also includes the cost-effective use of new materials in a broad range of products and applications and their diffusion to new application fields. Sub-areas are shown in Fig. 21.

- Raw Materials: covering existing processes and new techniques relating to exploration technology, mining technology and mineral processing;

- Recycllng: covering technologies involved in the recycling and recovery of industrial waste including non ferrous metals and reuse of advanced materials;

- Structural Materials: including metals, ceramics, polymers, their corresponding alloys, composites and hybrid combinations, and advanced glasses;

- Functlonal Materiais for Magnetic, Superconducting, Optical, Electrical and Blomaterial Application: focusing on synthesis, processing, design and manufacturing within the constraints of optimized performance;

- Mass Commodity Materials: covering in particular packaging materials and new construction industry materials.

Fig. 24:

Brite-EuRam II

Sub-areas within Materials/Raw Yaterials

The objectives of the area Design and Manufacturing are to improve the capability of industry to design and manufacture products which take account of functionality, cost-effectiveness, quality, reliability and maintainability, and environmental and social acceptability.

Sub-areas are shown in Fig. 25. 
- Design of Products and Processes: tools and techniques for innovative design, design methodologies for complex high-technology components, maintainability and reliability;

- Manufacturing: tools, techniques and systems for high quality manufacturing, manufacturing techniques for industrial use of advanced materials and integrated approaches to chemical and process engineering;

- Engineering and Management Strategies for the whole product life cycle: design integrating strategies, engineering, human factors in engineering, quality and manufacturing management.

Fig. 25:

Brite-EuRam IZ

Sub-areas within Design and Manufacturing

For the interesting area of Design and Yanufacturing a more detailed break down of the technical content is given in the following:

Innovative design tools and techniques

Objectives

To develop design tools such as decision support jystems :0 promote more efficient jesign methods, more economic manufacture, assembly and ismanting, and reliable and ergonomic products.

Design Methodologies for complex components

Objectives

To develop approaches for the incorporation of multifunctional components in product design. To advance the capability of isigh precision and micro-engineering systems together with design for micro-miniaturisation.

Maintainability and reliability

Objectives

To develop the support tools, including sensor gystems, for improved product performance, reliability and maintainbility. To advance the capability and applicability of mathematical modelling to support design, including the integration of modelling techniques with defect and failure mode analysis needed for reliabilitr and predictive maintenance. 
Tools, techniques and systems for High Quality Manufacturing

Objectives

To develop skill supporting technologies to make human skills and judgement more effective in the manufacturing process. To develop innovative tools and techniques for high quality and cost effective manufacturing systems to give better process control, higher precision and faster operation and the integrations of new processing technologies with established manufacturing processes.

Manufacturing techniques for industrial use of advanced materials

Objectives

To develop cost-effective and afficient manufacturing techniques for advanced materials to help realise their full potential

Integrated approach to chemical and process engineering

Objectives

To tailor manufacturing technology to the requirements of chemical engineering and to integrate design with process control. To advance the understanding needed to design and control chemical processes with increasing complexity to include avoidance and prevention of pollution.

Design integrating strategies

Objectives

To develop new and more holistic approaches to support the integrations of engineering tasks for the whole product iife cycle, such as simultaneous engineering concepts wich bring together design, engineering and manufacturing.

\section{Engineering}

objectives

To bring an integrated approach making full use of new materials, new design and manufacturing technologies and process and product control to traditional manufacturing industries, with particular attention to new requirements for environmental control and improved working conditions.

Human factors in engineering and manufacturing management

Objectives

To accelerate the take up of new technology by developing new management techniques which allow identification and reconciliation of potential areas of conflict between new technologies and human resources. To improve methods for the 
evaluation of the performance $=$ products and processes and their linkage to the oieraiz business.

\subsubsection{Implementation of Brite-EuRam II programs}

The Brite-EuRam II program is implemented in the following three ways:

$$
\begin{aligned}
& \text { 1. Shared-cost yesearch } \\
& \text { 2. Concerted Actions } \\
& \text { 3. Accompanying Yeasures }
\end{aligned}
$$

The main actions of the program are carried out through sharedcost Contracts between the EC and pan-European consortia, made up of partners from industry, research institutes, universities or similar higher education establishments. This type of implementation will cover $36 \%$ of the total budget. Fig. 26 shows the three types of shard-cost research.

- Industrlal Research involving industrial enterprises form different member States collaborating in precompetitive research. The research must have the potential for a significant medium-term industrial and economic impact $(2-3$ years after the end of the project).

- Focused Fundamental Research for applied research which is up-stream of industrial research but is nevertheless of industrial relevance. The research requires the endorsement of industrial enterprises from different member States.

- Cooperative Research (CRAFT) to enable groups of enterprises without research facilities - especially SMEs - to contract with outside research institutes, universities or enterprises to carry out research and development on their behalf (Comparable to the AIF in Germany).

Source: EC

Br 0054

Eig. 26: Types of Shared-cost Research in Brite-EuRam II

A summary with the major data of these three types of research can be taken from the Fig. 27 to 29 . 
INDUSTRIAL RESEARCH PROJECTS

(i)\% of tolal budget for researcn)

- Conformity with research tasks

- Precompentive and collaborative

- Subsequent exploitation expected

Duration $\quad 2-4$ years

Total cost - $1.5 \mathrm{MECU}$

Funding - EC funding: normally not to exceed 50\%

Industrat funding: minımum $2 / 3$ of EC funding

Partners . at least 2 independent industrial enteronses

Cafls

from different Member States

fixed closing dates

3 Apnl 1992

26 February 1993 (provisional)

Source: EC

$\mathrm{Br} 0055$

Eig. 27: Industizal Research projects

FOCUSED FUNDAMENTAL RESEARCH PROJECTS

(10\% of lotal budget lor researth)

- Basic research udstream of Industral Researcr

- Conformity with research tasks

- Precompetitive and collaborative

- Industrial endorsement

Duration . 2 - 4 years

Total cost - $0.5-1.0 \mathrm{MECU}$

EC Funding - up to $50 \%$ of full costs

up to $100 \%$ of additional (marginal) costs

Partners at at least 2 organisations from different

Endorsers $\quad$ Member States
$\quad$ at least 2 indedendens industral enteronses

from difterent Member States

Calls - fixed closing dates: see above

Source: EC

Br 0056

Fig. 23: Focused Fundamental Research projects 


\section{COOPERATIVE RESEARCH (CRAFT)}

( $9 \%$ of total budget for research)

- Conformity with technical areas

- Research defined by industry (bottom-up approach)

- Precompetitive and cooperative

- Research pertormed by third parties for a group of proposers

- Exploitation oriented

- 2 step application procedure

Cost $\quad 0.4-1$ MECU

Duration 1.2 years

EC Funding - up $1050 \%$ of full costs

Partners - Step 1 : at least two SMEs from different Member States

Slep 2 : at least four SMEs from at least two Member States

Calis - open Cail (approxımately 2 evaiuations/year)

Fig. 29: Cooperatire Research (CRAFT)

A speciality and new experiment is the introduction of the CRAFT program. The objective is to transfer the good experiences with the AIF in Germany to an European level.

The scheme will provide Énancial support to a group of industrial companies, nainlY SMEs, facing a common industrial or technological research need. CRAFT will enable these SMEs to come together and assign outsice organisations (research centers, universities, or other companies) to carry out RTD under contract on their behalf.

\section{$\dot{1} 2 . \pm$ Budget of Brite-EuRam II}

The program has a total budget of $663.3 \%$ ECU for the period of 1991 - 1994. Eig. 30 shows the breakdown of budget by technical areas and $b$ Eunding the different types of research. 
Breakdown of the budget by technical area:

Area 1: Raw Materials and Recycling Materials

$\begin{array}{cr}80 \text { MECU } & 12 \% \\ 228.8 \text { MECU } & 35 \% \\ 301.5 \text { MECU } & 45 \%\end{array}$

Area 2: Design and Manufacturing

53 MECU $8 \%$

Area 3: Aeronautics Research

53 MECU

$8 \%$

The total indicative funding devoted to research is:

$\begin{array}{lrr}\text { Industrial Research } & 483.8 \mathrm{MECU} & 77 \% \\ \text { Focused Fundamental Research } & 62.8 \mathrm{MECU} & 10 \% \\ \text { Cooperative Research } & 56.5 \mathrm{MECU} & 9 \% \\ \text { Concerted Actions } & 6.3 \mathrm{MECU} & 1 \% \\ \text { Feasibility Awards } & 6.3 \mathrm{MECU} & 1 \% \\ \text { Specific Training } & 12.6 \mathrm{MECU} & 2 \%\end{array}$

Source: EC European Currency:

$1 \mathrm{ECU}=2 .-\mathrm{DM}=1.3 \mathrm{US} \$$

$\operatorname{Br} 0058$

Fig. 30: Breakdown of budget of Brite-EuRam II

Most of the funding is devoted to industrial research in the area of design and manufacturing.

4.3. Eunding of $B$ i ? within the EUREKA orogram IESSI

EUREKA stands for a frame for an increased technological cooperation on innovative research in Europe. EURKEA is neither a promotion program nor is it definded by the governments of European countries. Yuch more comes the initiative for projects from the European industries and research centers. They have to establish the entire research group with its members and they will determine the way of co-operation. There is also ro central EUREkA budget. That means, that all participants have to provide for a financing by using their own resources for $R$ \& $D$ support in their home country. So EUREkA is a bottom up approach for an European cooperation. One of the big and successful programs is the Joint European Submicron Semiconductor Industry program JESSI. This will be explained in the following chapter. 


\subsubsection{Situation of the European microelectronic indust:...}

The recent development of the technology-driven industries in the European community shows, that microeiectronics is the key to competitiveness in the areas of data processing and communication systems, electrical engineering, precision mechanics and optics, automotive, and nachinery industry. The diffusion ot microelectronics in these fields is a result of its dynamic development in terms of cost, und size zeduction and increasing level of comlexity and $=$ affects strongly the performance and costs of the products and systems in which it Within the next decade the electronic industr will become one of the largest manufacturing industries in Europe.

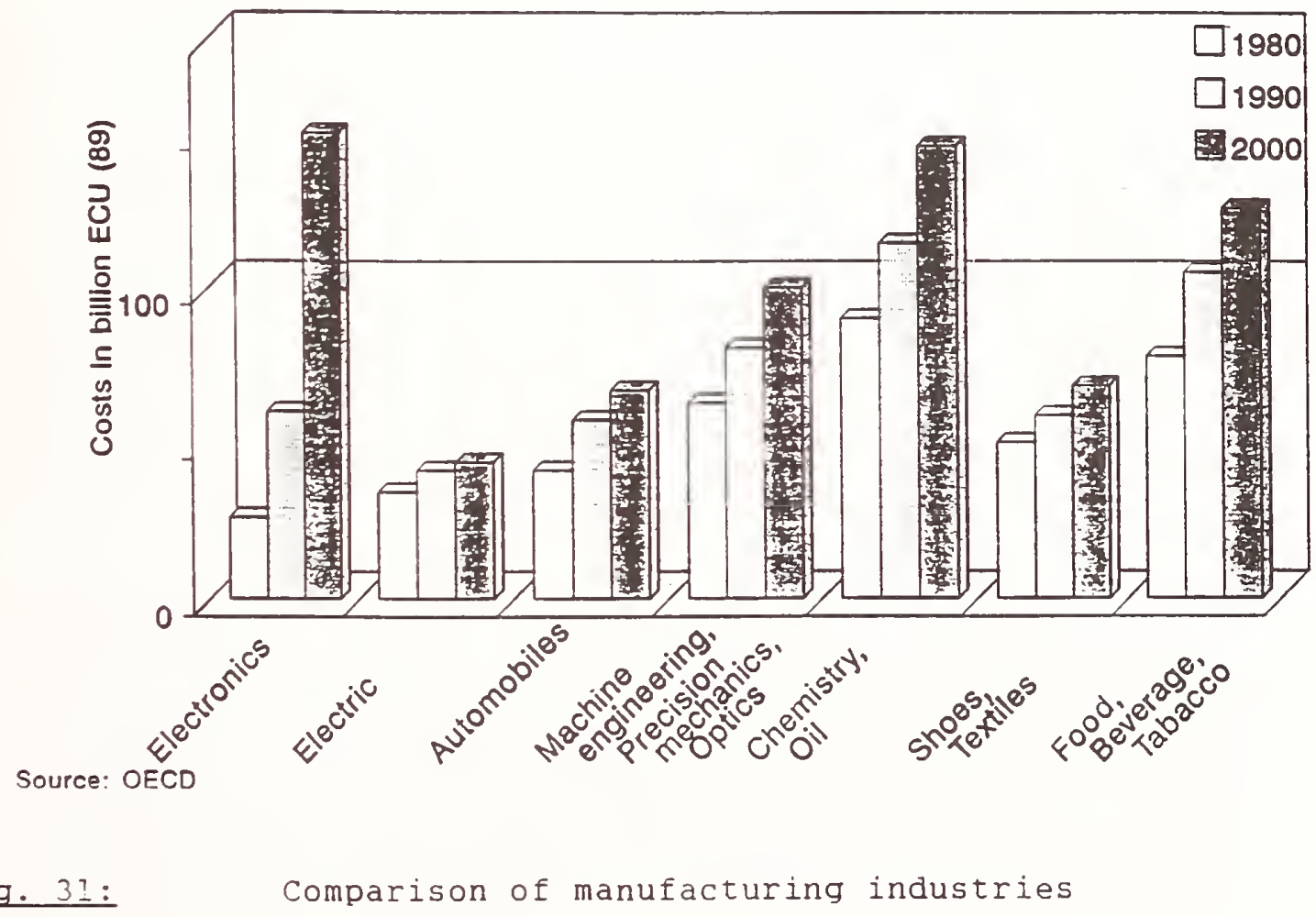

Although the European integrated circuit industry by itself is very small. In size, compared to the Japanese companies NEC, Toshiba or Hitachi, the European system houses are comperatively small (Fig. 32 ). 


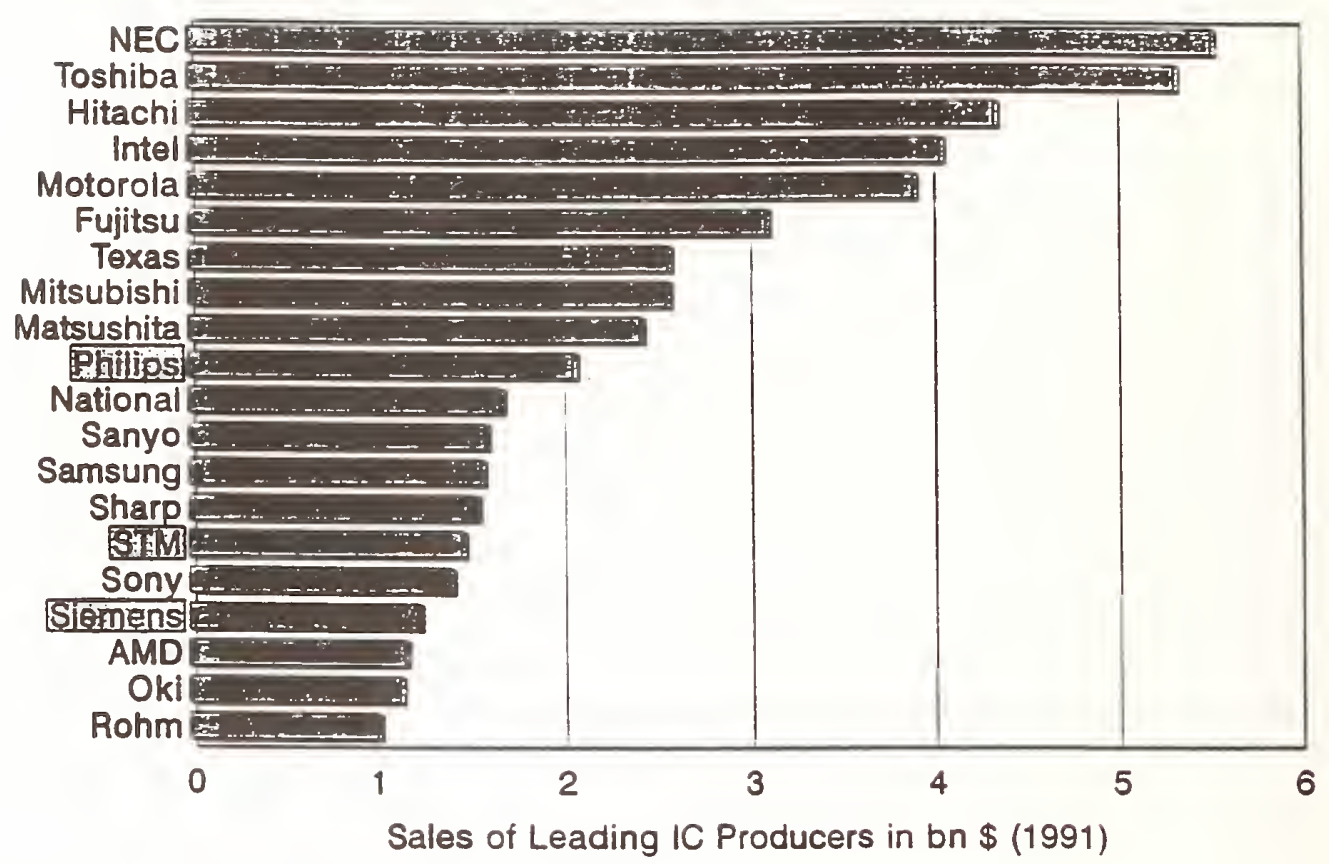

Source: Dataquest, 1992

Fig. 32: Sales of leading iC producing companiés

In Japan, microelectronics has been recognized since the late . $70 \mathrm{~s}$ as a key industry for virtually all sectors of the economy and cor the country's international competitiveness. Through its long-term, carefully coordinated assignment Jf research and development resources (particularly by the often-quoted VITI, the Ministry for International Irade and Industry), Japan has been able to capture a dominant market position in many sectors.

Compared with the other highly industrialized regions of Japan and North America, western Europe still represents a "developing country" in the semiconductor business. The per capita consumption of semiconductor products in liorth imerica is double, in Japan six-fold that of Western Europe. In addition, Western Europe is the only region in the triad producing fewer semiconductors per head than it consumes (Eig. 33). At $\$ 230$ compared to $\$ 17.6$, Japan's per capita production volume is 13 times greater than Europe's! This indicates that Europe has large potentials for growth. And the political transformation of Eastern Europe promises additional market potential over the long term /10/. 


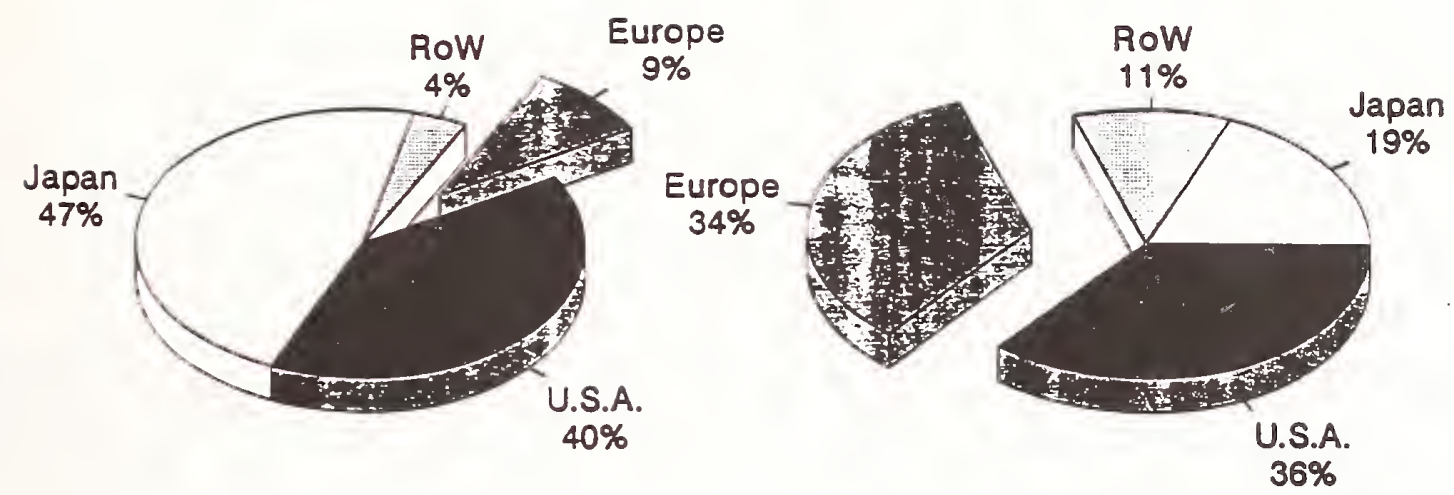

Source: Dataquest, Elsevier, SIS (1991)

Fig. 33: $\quad$ Comparision of IC production and application

\section{$4.3 .2 \quad$ JESSI}

\subsubsection{History}

The pxtremely ligh $R$ \& $D$ effort required for VISI dircuits faces a compatible smail turn over in ICs in European companies. Io compensate for this disadvantage irst t strong cooperation between the IC companies and secondly a financial support for the high $R$ \& $D$ expenditures are needed.

This problem has been recognized by the politicians already years ago. Consequently they launched in 1984 the well-known "Yega Project" /11/.

However in the "Mega Project" there was not enough attention paid for the built up of a strong equipment infrastructure that time. Because of the lack of key components in manufacturing the ICs the strong efforts of the Mega Project did not have the desired success for the microelectronics industry. To relief this unsatisfying situation a much stronger cooperation between IC and equipment companies was needed.

In the beginning of 88 a planning group was established to elaborate the technical base for the JESSI Program (Fig. 34). According to the important areas within the JESSI Program the "Planning Team" was divided in four "Section Teams": 
- Technologr

- Equipment + Yaterials

- Application

- Basic and Long Term Research

The entire Planning Group was coordinated by the Core Feam which entailed under the leadership of the Eraunhofer Geselischaft an appropriate mix of inainly industrial people from the different sections. The section Team 2 responsible for the planning in Equipment and :iaterial was structured in a wav that beside the core of the Equipment and Yaterials companies, the influence of the IC manufacturers as weil as of the basic and long term research was tnsured luring the entire planning phase. The results of this planning (description of selected product areas, rough time schedule, llanpower alocation etc.) are put down in the so called "Green Books" ill/.

\begin{tabular}{|c|c|}
\hline Jan 1988 & Start of JESSI Planning Group \\
\hline Feb 1989 & Realease of JESSI Green Book (results of planning phase) \\
\hline Jun 1989 & JESSI declared EUREKA project EU 127 \\
\hline Jul 1989 & JESSI organisation starts business \\
\hline Nov 1989 & First JESSI labels assigned \\
\hline Apr 1990 & Agreement on Industrial Property Rights \\
\hline May 1990 & First projects started \\
\hline Jun 1991 & JESSI's main phase $(1992-1996)$ approved by EUREKA \\
\hline Jan 1992 & JESSI's main phase started \\
\hline
\end{tabular}

Eig. 34: JESSI history

In June 89 JESSI was declared to EUREKA Project 10 . EU 127 by the Commission of the European Communities. Thus in July 89 the JESSI organization started to work in the JESSI office in Munich. 
In all the JESSI Board, the aighest authority in the uESSI organization, investigated over 300 individual projects proposals from more than 50 different Jrganisations, and more than 70 entries were allowed to proceed.

In the early phase of the jogram (April 1990) an important agreement has been achieved on industrial property rights enabling the full exploration of the JESSI results to the mutual benefits of all participants.

Thus far, major indiridual zojects have included tie memory project, optical i̇thograpnw, i frame project for designing chips using Computer Aided Design (CAD), Specific CAD Tools, and a research program to pave the way Eor Euture chips with structures of around 0.25 micron.

JESSI has concluded the start-up phase of its European microelectronics program end of 1991.

Based on the experiences gained during the start-up phase with so many good project proposals, a consolidation of the program has been achieved with respect to the progress reached in projects to date, a thorough evaluation of the situation and orientation towards the main phase /10/.

\section{3 .2 .2 Goals}

The main goal of JESSI (Joint European Sibmicron Sizicon) is to secure the availability of woricl-competitive microelectronics for the European Industry. It is an EUREKA research and development program for the technology of system integration based on silicon (Fig. 35). The program has four main issues /9/:

Technology:

* Development of the basics and proving of a flexible competitive manufacturing technology for advanced system applications, to be available by the mid-90s.

The most advanced technical goal, within the framework of the JESSI Program, is a CMOS-process with minimal structures in the $0.3 \mu \mathrm{m}$ range. This fine structure range is achieved through intermediate steps at $0.7 \mu \mathrm{m}$ and $0.5 \mathrm{~lm}$. Each intermediate development involves the overcoming of technical barriers through innovative process steps. Reduction of manufacturing costs will be one of the most important targets. Memories (DRAM/VRAM/SRAM/ ERROM) are to be used as the technology drivers. 
Application:

: Building up of flexible competitive system-design procedures and tools which are ipplicable throughout Europe, for the development of highly complex integrated circuits and their integrations into systems, is well as their verification in advanced joint pilot projects in major areas of application.

The European industr. has i world-wide ieading position in solution-oriented system know-how in a broad range of application fields. The direct hnownow transfer into microelectronic systems realized on silicon is of increasing importance in comparison with the use of standardized integrated circuits. The competitiveness - today and in the Euture - in standard circuits (e.g. memories) will be determined largely by the smallest structure size, the highest intergration density and production technique. The competitive strength for the development of application-oriented system solutions within this time frame, however, is to the largest extent determined by the availability of flexible process capabilities and design tools.

Within the framework of JESSI, application-oriented systemdevelopment tools will be tested in pilot projects (Europrojects), for example, in information processing, industrial electronics, automobile electronics and in the consumer sphere.

Equipment and Yaterials:

* Deveiopment of manufacturing equipment ind materials for microelectronics in selected areas of the European supply industry.

World competitiveness for the European semiconductor industry requires immediate access to the most advanced manufacturing equipment. This can only be achieved by the support of a strong European supply in the areas of manufacturing equipment and semiconductor materials. The earliest availability of equipment and materials according to the technological developments in the semiconductor industry must be secured. 


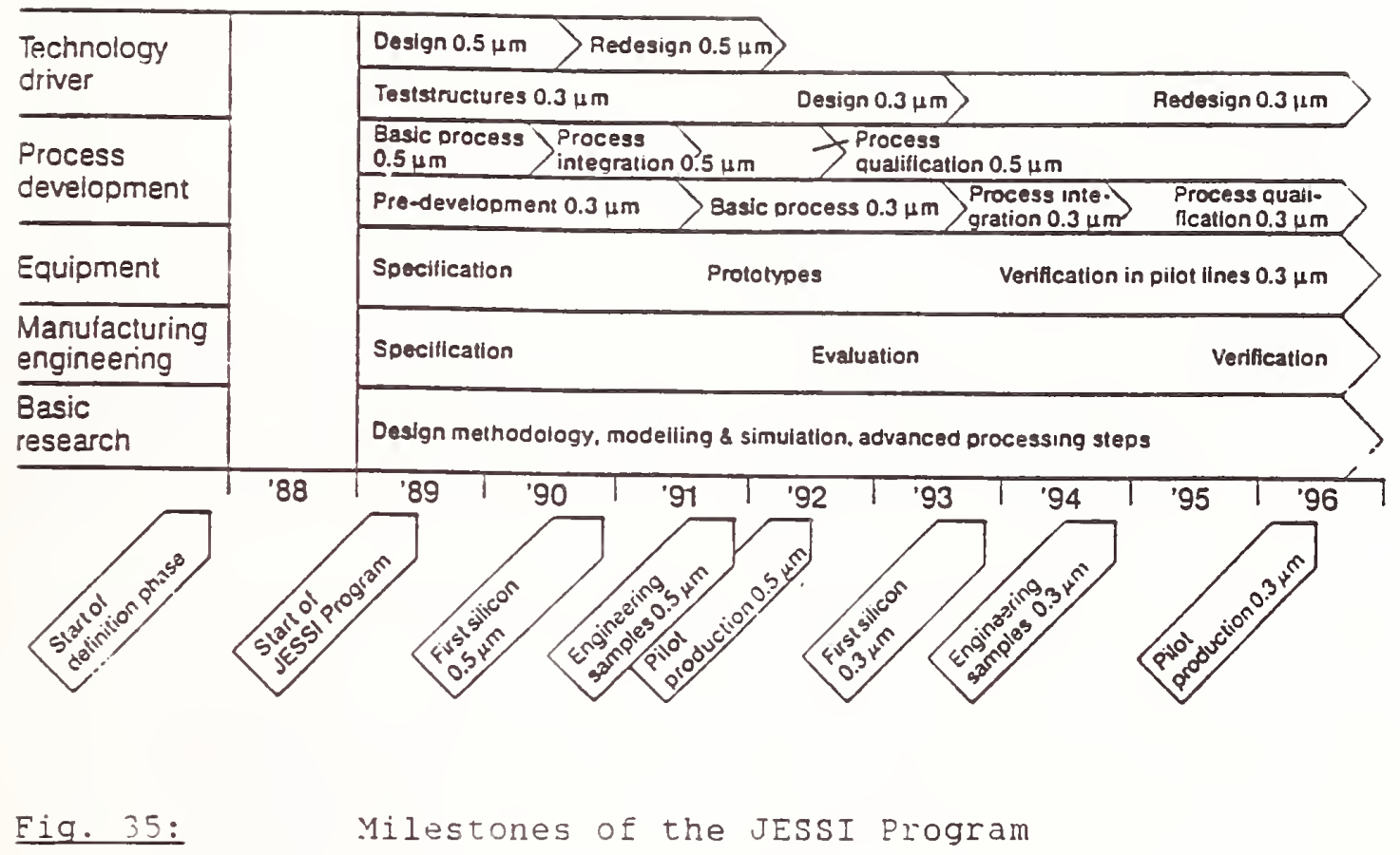

Close co-operation between European IC nanufacturers and the European equipment/Material suppliers is essential, as the case of Japan shows. Effective forms of co-operation will be developed within the framework of the JESSI Program.

Basic and longterm research:

- Complementary appliej research Eor the long-term future

In order to secure europe's future economic interests and to capitalize on its current strengths in microelectronics, JESSI's starting point must be a wellorganized interaction between industry and research institutes. Nediumterm goals of the "basic and longterm research" are to support the industrial development of ICs and their application, with feature sizes down to $0.3 \mathrm{\mu m}$, and to work out alternative solutions.

The contribution to JESSI may rary by country, depending on industrial and academic infrastructure and on national political and Einancial strategies. A balance has to be found in Europe between a uniform approach for JESSI for all countries and parties, and a participation according to national and sectorial interests. 


\section{t.3.3. Structure}

The JESSI program with more +3ai i 10 international participants needs an efficient organization. Because of that there tre $t$ subprogram management boards 'SHBl. They represent the illajor participating industries, take care for industrial monitoring and coordination of subprogram jrogress, coherence, isnsistency and adaption. The management soards nominate their representatives for the JESSI voard (JB) :3/! : IG. 35).

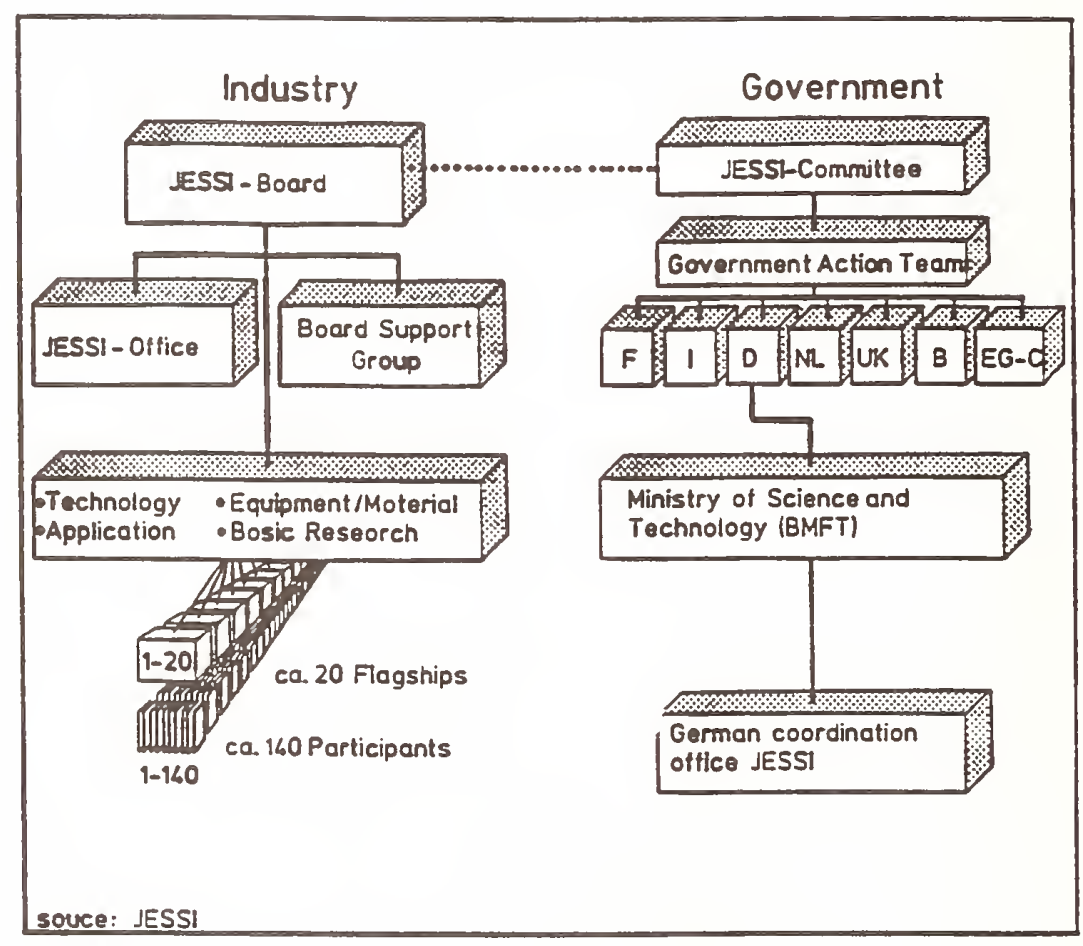

Fig. 36:

JESSI Organization

The JB consists of three IC manufacturers (Philips, Biemens, ST) three Application companies (Bosch, Alcatel, Olivetti), one Equipment + Yaterials company (Electrotech) and one Basic and Long Term Research Institution ( $5 T$ T /Dimes). In additicn to these voting members the chairman of the various SMB's are invited to take part in the meeting as non-voting members. The chairman which is full time in charge of the JESSI organization has no vote in the gremium. 
The $J B$ is responsible for:

- General strategy

- funding negotiations

- Einal decisions on proposals

- criteria for project selection

- initiation of progress assessment

- rules for project management etc.

There are at least tro meetings a rear. The jB has the final decision on the proposals Eor granting the "JESSI LabeI". However, the rejection of a project proposal accepted already by the SMB needs $2 / 3$ of votes of the $\mathrm{JB} / 11 /$.

The board support group supports ihe jESSI board in the tasks mentioned above. The duties of the JESSI office located in Munich are the organization of meetings, public relations and clerical work /12/.

On the government's side the cEs committee works closely together with the J3. They evaluated the proposals and decide on their acceptance. The jovernment iction team supports the committee in decision making. Every participating country has a coordination office for their national work /i3/.

Based on experiences in the start-up phase, target sectors (clusters) and flagship projects were selected for the main phase of JESSI as significant innovations for implementing the program (Eig. 37).

The goal is to achieve a strengthened and inproved focus on central themes of the program /io/.

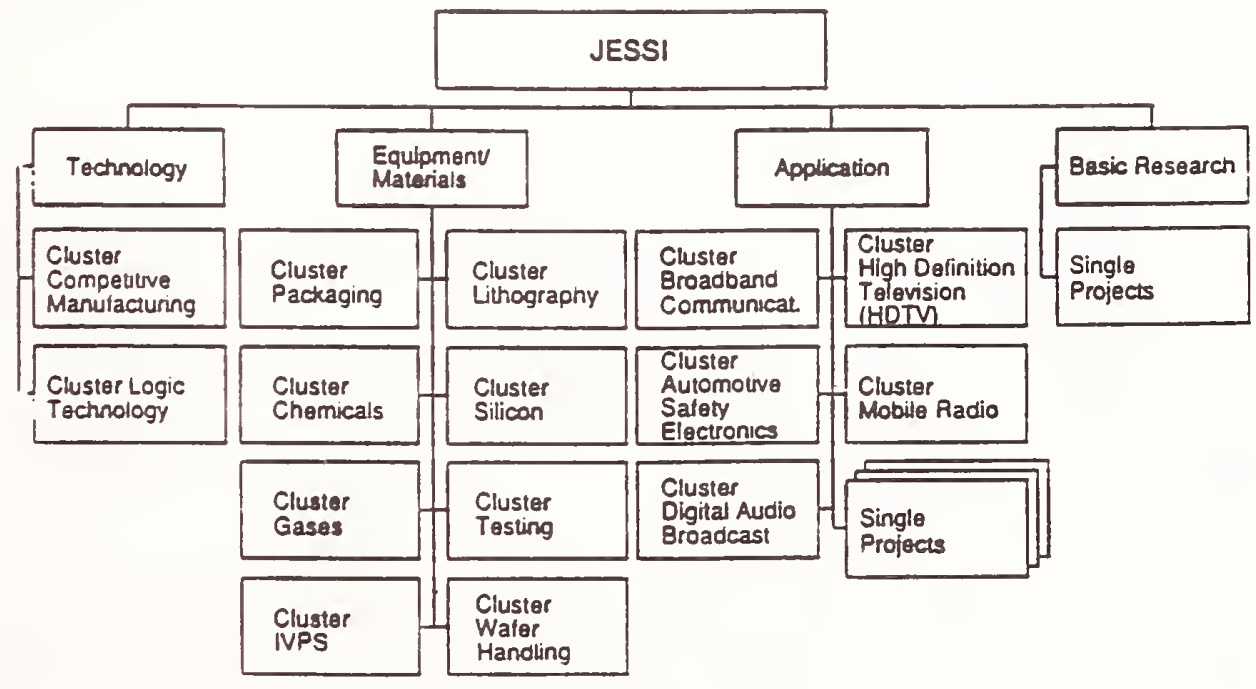


Clusters consist of İinked projects whicin share same joais and common technology.

Flagships are greater srojects of high smportance, aiming at commerical products and etiphasizing rertical cooperation.

Linked projects are necessary to reach the fiagship goals ilo/.

\subsubsection{Subprogram Iosmo:ogy}

Yastering memory technologies and the sorresponding hanufacturing technologies are the necessar (but not sifficient) ingredients for the competitive manuiacturing of logic circuits. The strategic value of ijglc aircuits in general - of ASICs in particular - for the uropean and users is high and ripected to grow /9/. JESSI is ossential to increase the necessity towards a closer cooperation of IC nanufacturers especialiy in logic circuit technology. The íigures 38 and 39 describe the different categories of logic ICs and their share in the markat / $11 /$.

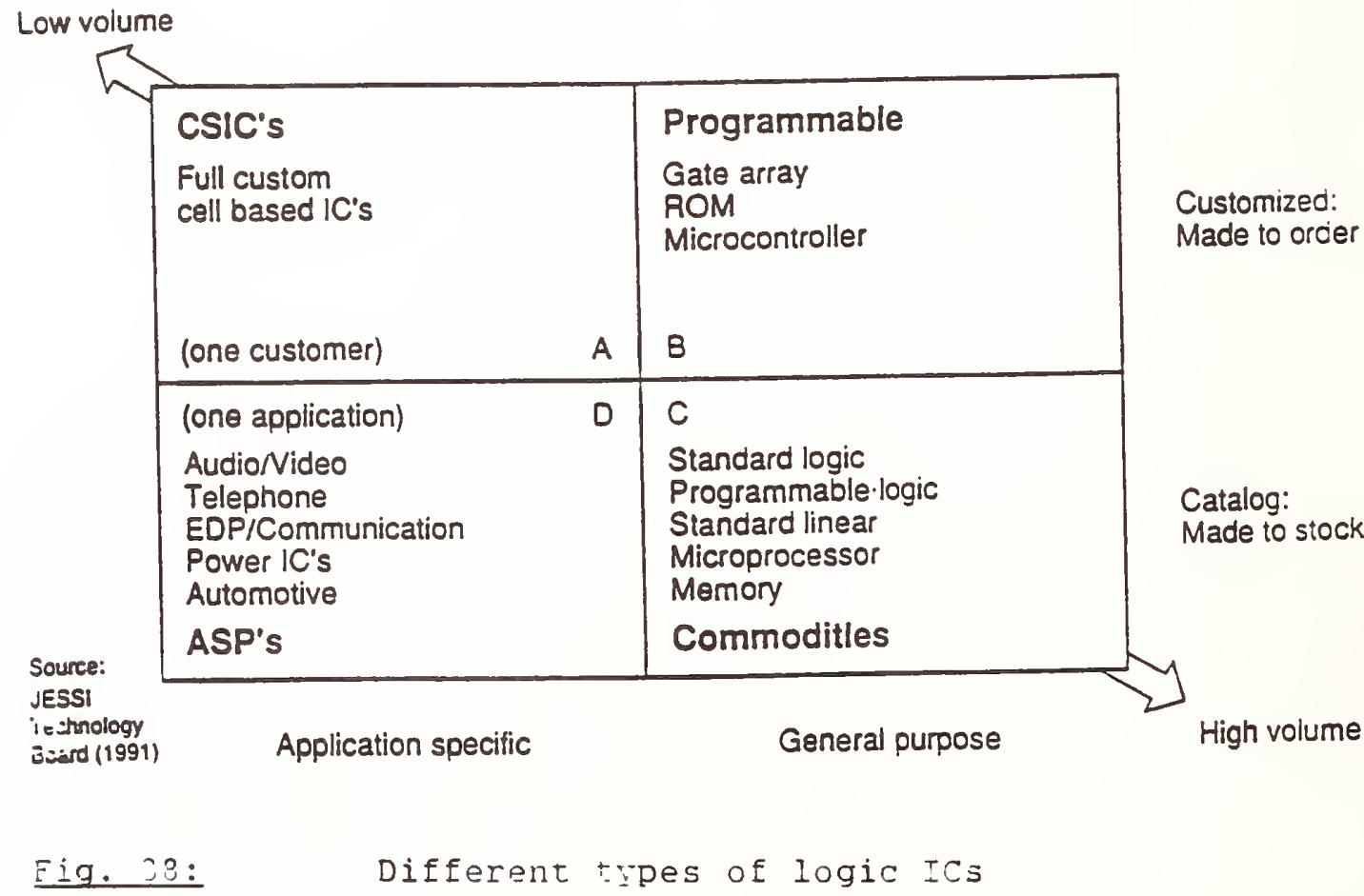


There are three major activities in the technoiogy subprogram/9i:

1) Developinent of submicron (down to 0.3 jm memorr generations (DRAM/VRAM, BRAY, EPROM) zncluding the work needed to provide the necessary processing environment.

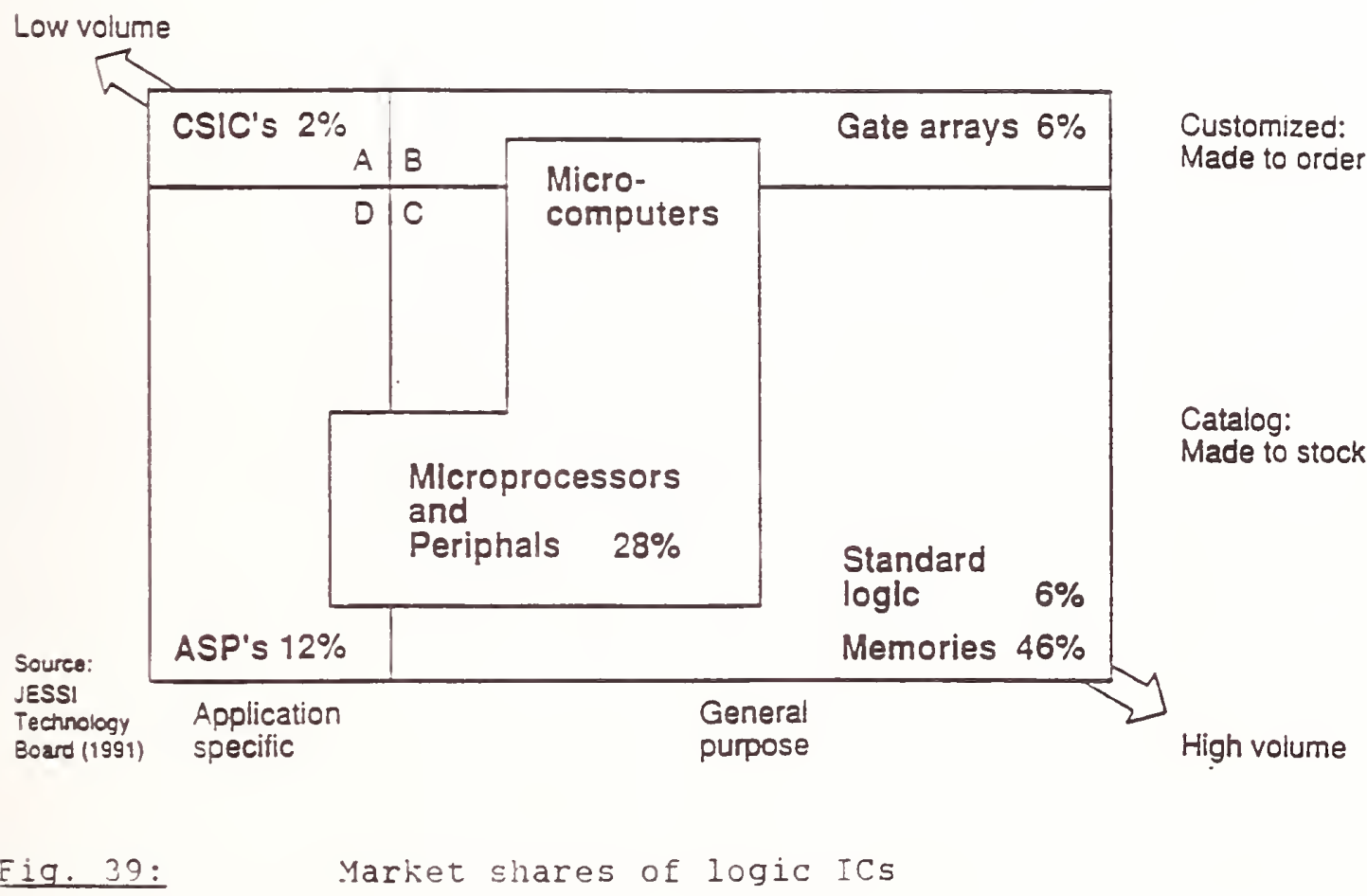

2) Development of logic technologies starting from todays $1 \mathrm{\mu m}$ technology-base to utilization of submicron technologies that will be provided by the memory projects. This development includes ciruits derived as directly as possible from memory processes (e.g. microprocessors, gate-arrays) and more advanced ciruits that contain process-modules not directiy related to à corresponding memory generation (e.g. BICMOs or Logic with E2 PROMS).

3) Development of manfacturing engineering methods that assure timely and cost-efficient production of present and sub-micron circuits on $150 \mathrm{~mm}$ and $200 \mathrm{~mm}$ hiafers. 
4.3.3.2 Subprogram Equipment ind :aterials

The following sectors have been assigned highest priority in the equipment and materials subprogram (Eig. \$0) /:0, i5/:

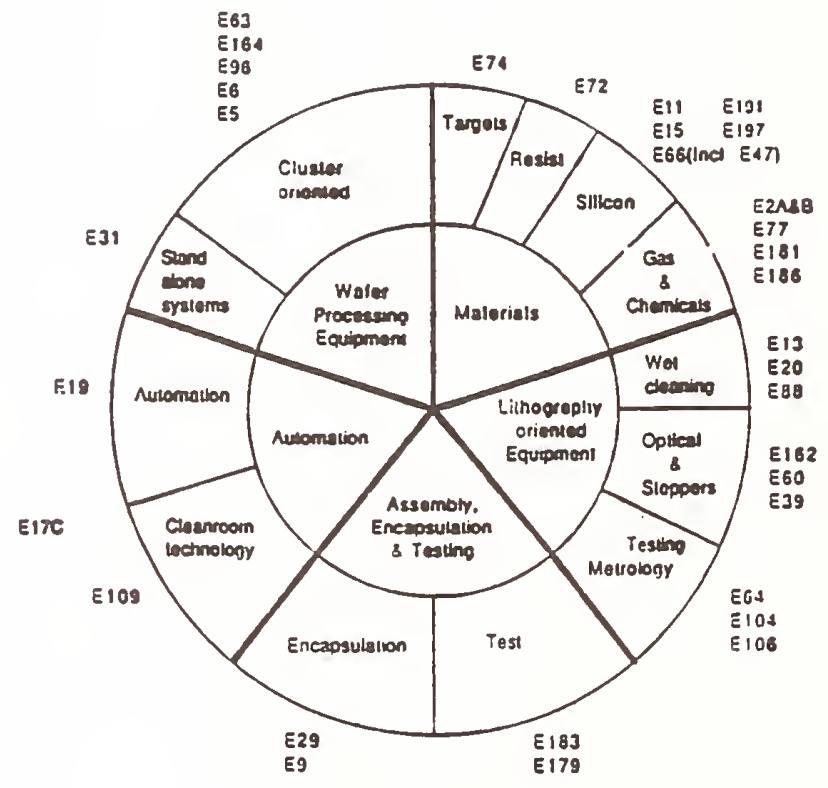

Eig. 0 : Distribution of labeled projects in the $E+M$ subprogram

- Lithography in the deep- CV range:

This basic process for all IC production involves the development of a suitable wafer stepper, optics (lens) and photoresist for each generation of chips 10.5 microns structural width for 16-Mbit chips, 0.35 microns for 64 -Mbit memory ahips). Vertical cooperation, i.e. between production equipment and material development and users (i.e. IC manufacturers) is especially important at this stage. Significant advances have already been made in accuracy of positioning and wafer throughput, placing us ahead of worldwide - particularly the Japanese - competition. 
- Integrated vacuum processing system and automated hâfer handing:

Under extremely pure : leanroom conditions, the integration of various components, standardization of interfaces and development of cluster tools is becoming zncreasingly important.

- Chemicals and gases:

Cltra-pure chemicals, : ¿aning íuicis and gases largely letermine the defect density and iltimately the vield of the entire VLSI production process. Supplying local wafer fabrication with these products opens up additional perspectires and options.

- Silicon wafers:

The basic material must be :ontinually adapted to the requirements of each chip generation with respect to planarity, contamination and other ritical factors. The aim is to improve processes and equipment zor growing wafer crystals with a diameter of $200 \mathrm{~mm}$ and greater.

In the last two points, Europe enjoys a position that is fully competitive on the world market.

\subsubsection{Subprogram Application}

Eollowing the concentration with regard to funding cestrictions and having the aspect of vertical integration in mind the following four market sectors are covered by the Application Subprogram when entering the main phase of JESSI:

- Electronics for Automotive Industry

- Consumer Electronics

- Telecom

which are represented by one or two flagship clusters and the sector of:

- Graphics Information Systems

represented by the single roject "Digital Controls for High Resolution Display" (Fig. Ii) " $\$ 6 /$. 


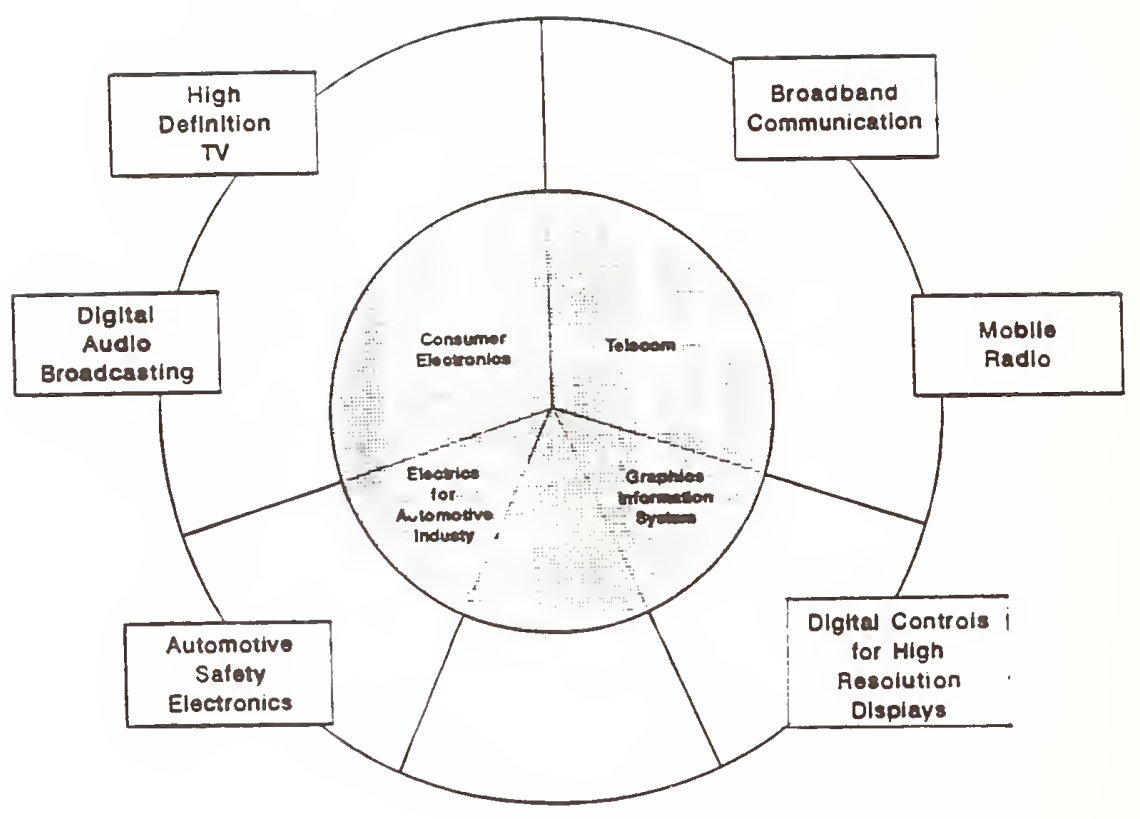

Eig. 11: JESSI's application areas

After the restructuring for the main phase of JESSI the Application subprogram encompasses Eive Elagship clusters covering different market sectors and five single projects not included in flagship clusters.

Cluster: Automotive Safetr Electronics

Elagship Project: Ultra Large scale Integrations of a Controi Cnit for Safety Critical systems

Linked CAD Project: Synthesis, optimization and inalysis

Systems such as ABS, iSR, airbag and electronic fuel injection already heavily rely on electronic control. An increasing number of functions and speical conditions with respect to safety (e.g. fault tolerance), environment conditions (e.g. air pollution), high roltage and electromagnetic compatibility create specific requirements for the operation of microelectronic ircuits. Therefore electronics are the critical technology of tomorrow's automotive industry.

Cluster: Digital Audio Broadcasting (DAB)

Flagship Project: Implentation of Prototype Building Blocks for a DAB Standard

Linked CAD project: Development of an EMC workbench for Yicroelectronic Application

The European market for consumer electronics is the iargest in the world with the highest growth potential. Worldwide the 
consumer plectionicis uarket is dominated by iapan but there is still a good ranking of some isge European companies. To hold this position strong efforts have to be made illinly by implementing new European transmission atandards ireceivers, recorders, etc.) in advanced c:os processes.

Cluster: HDTV

Elagship Project: Europroject SDTV

Europroject: Signal Processing Eor AD/HD PCR

Einked CAD Project: Fest jeneration and Design for Testability

support

High definition television is to be unsidered as the most important new market segment in consumer electronics for the late goies. All over the worla strong fforts are nade to deveiop chipsets with sufficient processing capabilities, enhanced bandwidth and digital control. Europe has chosen a clear approach towards tomorrow by taking into account the situation today. Improved transmission standards (MAC), worldwide agreed new screen format $(16: 9)$ and finall HD-MAC is the clear European roadmap towards a new trpe of rision in the home.

Cluster: Mobile Radio

Elagship Project: Advanced rLSI components for the GSM Pan European Digital Cellular Radio System

Europroject: Mobile Automatic cellular Radio

Einked CAD Project: Analog Expert Design Brstern

Within the telecommunication markets of the future digital radio telephony is one of the biggest market segments. With the release of the GSM description ind of 2390 by the European Postal Organizations and the industry the..Pan European Cellular Digital Radio system is going to become reality. The requirements of the IC development efforts are challenging as portable sets need to be maximally integrated in order ro reduce volume, weight, power consumpition and cost.

Cluster: Broadband Communication

Flagship Projects: Advanced VLSI Components for B-ISDN ATM vetworks, Advanced VISI Chipset for ISDN Videophones

The integration of all services, which are currently provided on a multitude of networks, on a single ATM (Asynchronous iransfer Mode) broadband communication network will boost both application and equipment provided in the goies. In addition high speed data transfer will offer new services ilke videotelephony, two way TV, HDTV, video Iibrary provided via cable to the commerical and private clistomer. 
Integrated JESSI CAD System

The main actirities on CAD tools within jESSI are assembled in the different CAD projects inked to the corresponding Eiagship projects. But this link does hot nean that the respective CaD project only follows the demands of that flagship. The goal of all JESSI CAD projects is rather to offer tools which ineet the requirements of ali applications in the respective desgin field and to make leading edge tools arialable to the benefit of all European microelectronic designers.

To offer all these $\mathrm{AD}$ - zois $\vdots$ in a common but open environment they will be integrated into the JESSI Common Eramework to be developed in the JESSI-COMYO-ER:IE project. (Eig. 12 ). With that integrated system the user jets the powerful JESSI CAD tools under a common design infrastructure which is open to include any other tools needed by the designer for special purposes /16/.

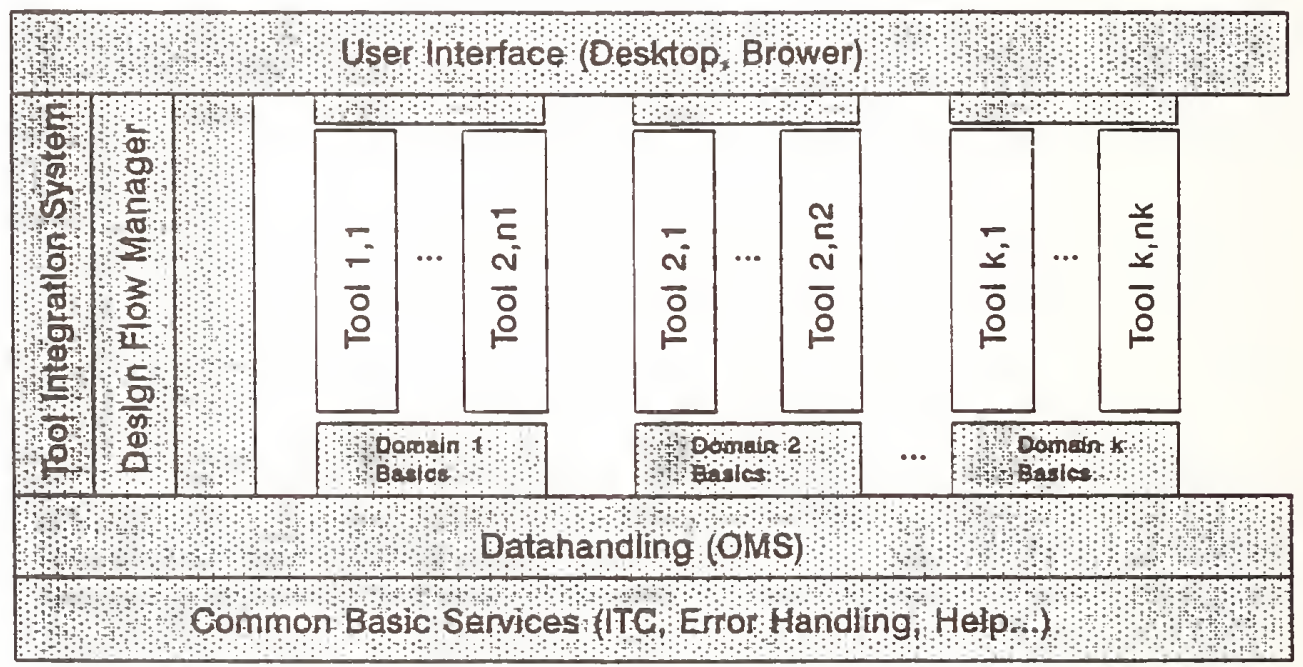

\section{System Environment}

Source: Radelaar

Fiq. i2: Architecture of the JESSI-COMMON-FRAME 
4.3.3. 4 Subprogram Basic and Long-term Research

The Basic and Long-term Research (BIR) subprogram goals could be defined as /9/:

1) Support the European micro-electronics industry with research results to ensure that

- The IC manufacturers can reach their joais of $0.3 \mu \mathrm{m}$ structure width, $500 \mathrm{~mm}^{2}$ chip area and $10^{7}$ - $10^{8}$ transistor complexity in the pilot production $\vdots n 1996$ and beyond.

- a growing field of materials and equipment suppliers will reach a strong competitive posiiton.

2) Broadening of the basis of the tnicroelectronics industry by developing aiternatives to improve on and enhance estabiished technologies and to overcome unforeseen future technical and economic bottle-necks.

3) Assure long-term continuity for the microelectronics industry by developing new nethods and technologies to be exploited economically after 1396 .

The BLR-projects are all closely :onnected with other jESSIprojects. The 3LR-projects are partitioned and defined such in order to optimize internal coherance within JESSI.

\subsubsection{3udget}

The whole JESSI project will comprise almost 22.000 man years of scientific and technical work from 1989 until 1996. This will involve a financial outlay of about 3.3 Y ECC. About 50 of of these Eunds will be supplied by industry and the institutions involved, $\dot{i} 0 \%$ by national governments and $10 \%$ by the European Communitÿ/13/.

The budget sor 1992 has been approved in the common JESSI BoardJESSI Commitee neeting in october 1991. It comprises total project costs of 130 miliion ECU for 1392. Distribution on individual countries and the European Commission for 1992 and in the start-up phase, is shown in Fig. $43 / 17 /$. 
JESSI budget 1992

430 MECU national governments and CEC total 215 MECU for 1992

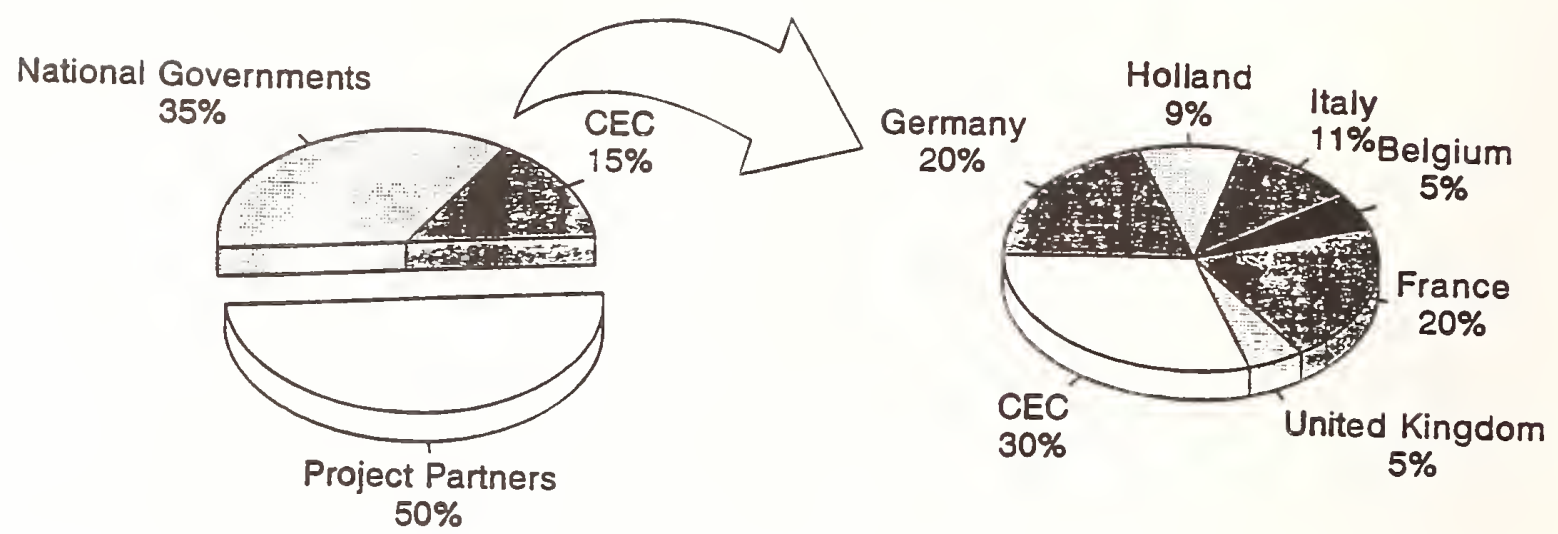

Source: JIL Issue No.10/92

Fig. 13: Financing of the JESSI project

Fig. 14 shows the distribution of the number of projects and the total man years in 1992 to the participating countries.

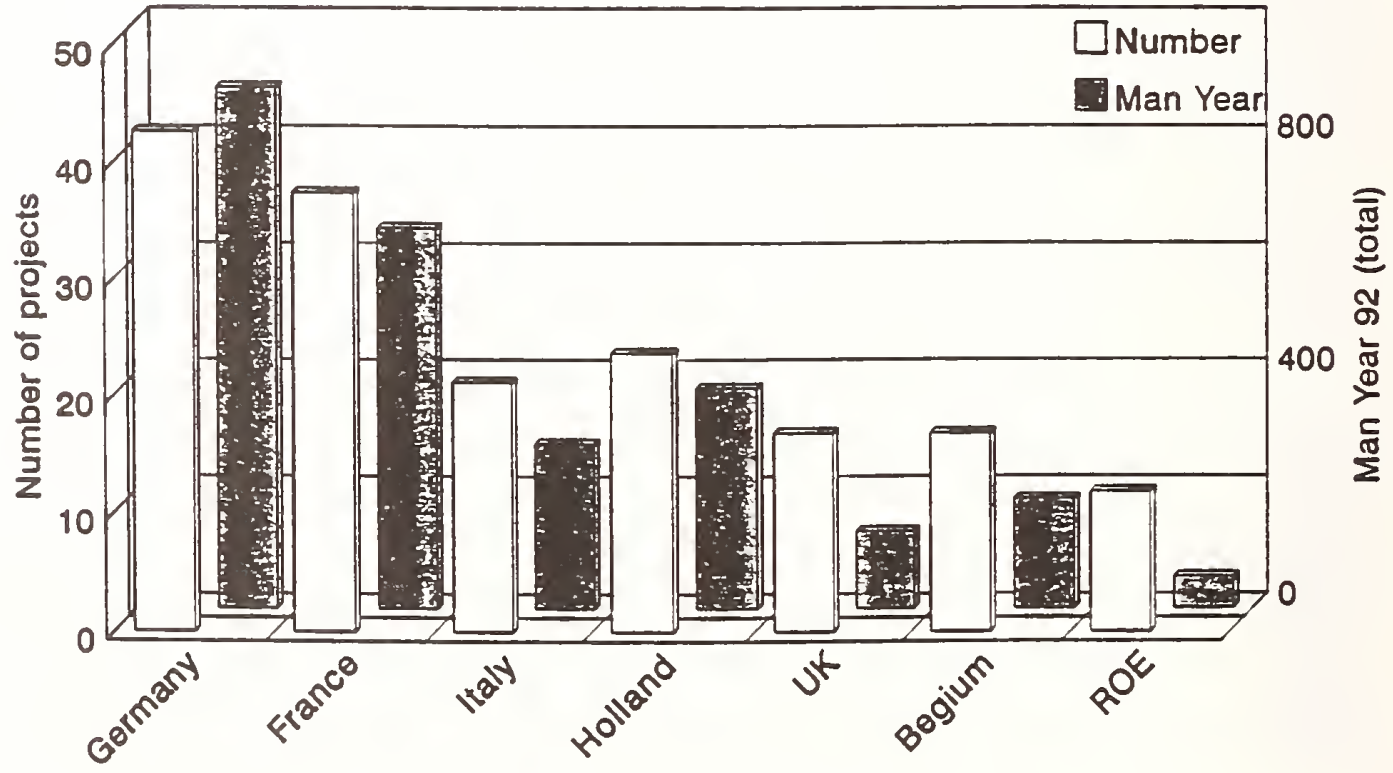

Source: JIL Issue No.10/92

Fig. 44: Distribution of projects and man years in 1992 
4.3.5. concivisions

The JESSI project has started in the middle of 1990. At that time the project was stily at its infancy with a lot of great ideas and proposals but few established working relations ind concrete results.

A lot has changed, moved and improved in the meantime /18/:

First, the program las been ciearly recognized and established inside the impanies and institutes as the curopean iffort towards the highly competitive markets in our business.

Second, the "sutside world" ind the public authorities are now fully understanding and supporting the program.

Therefore, the major milestone was the approval of the program for the main phase at the Eureka ministerial conference last year. The jidgement was based on a thorough rvaluation of the program, specificalir taking into account the utmost necessity of our program for the ihole European information technology industr and the application of advanced microelectronics.

Third, based on these considerations, cor the first time in such type of a Eureka project a common inderstanding between all participants and partners of the program - industry, institutes and public authorities - could be achieved. Esentially the newlY adopted structure $\dot{i s}$ a concrete zesult of these zar vaching negotiations.

Eourth, and Iast but not least considerable resulta could already be achieved in the start-up phase.

\subsubsection{Aims for the future}

Microelectronics have a high significance for the human race and the technical progress. Because the innovation speed the price for microelectronics decrease up to 100 times per decade. On the other hand the costs for developing and producing inicroelectronics increase. Eig. 15 shows the cost structure for a high volume $f a b$ line. One can see that there is almost a 8 times higher price for a fab by comparing the years 1970 and 1990-. It is difficult for the most political economies to finance such fabs with a maximum lifetime of $q$ years. These countries without modern microelectronics will become levelopment countries from the technical point of view in a very short time. Because of that I propose to make worldwide cooperations and exchange of knowledge. The actual trends are of great promise: Siemens, IBM and Toshiba signed the contract (13.07.92) of common developing the 256 :Ibit DRAM. 


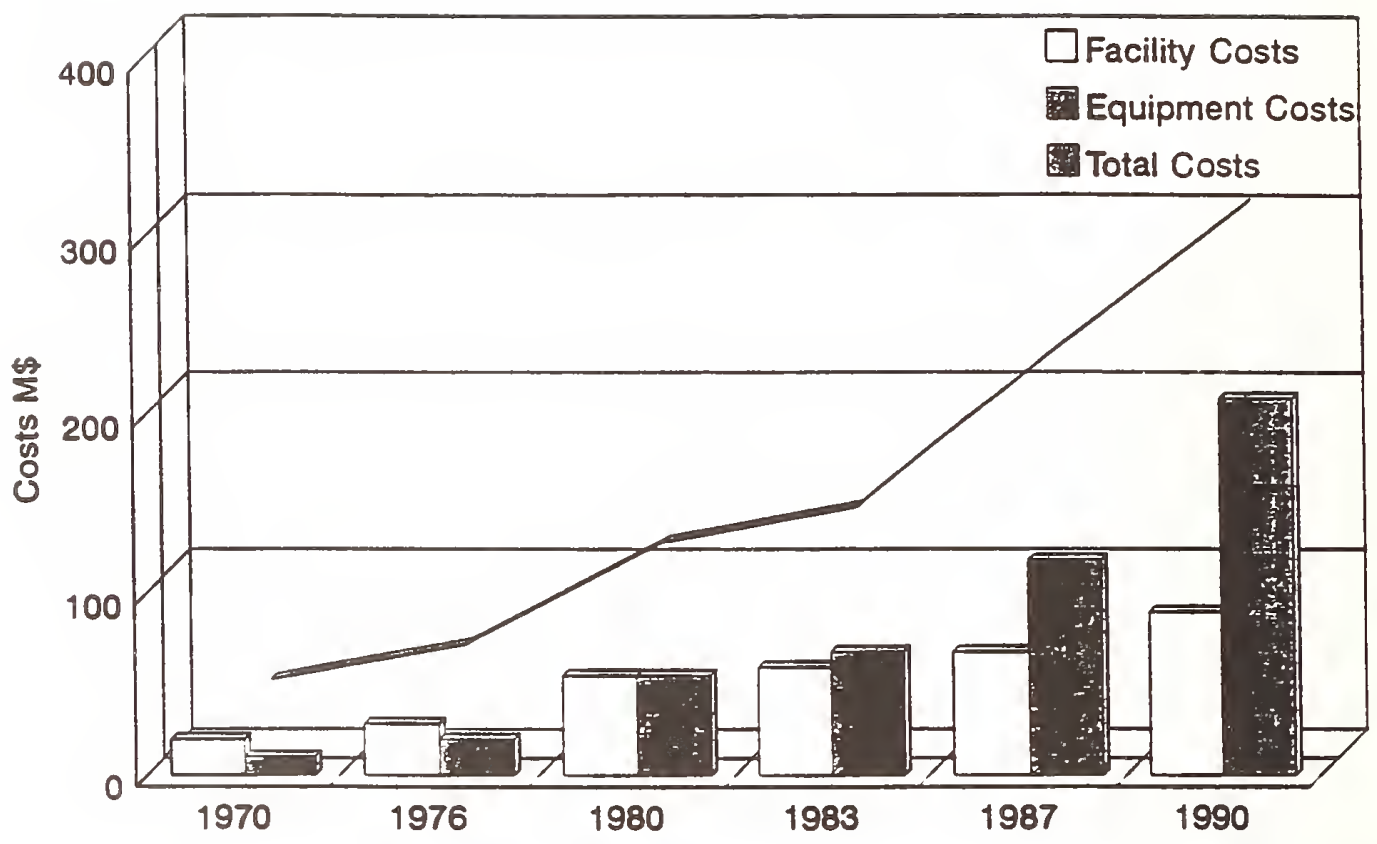

Source: Dataquest

Fig. 15: Costs of a fabrication line

5. Examples for the needs in precision fabrication

In this chapter, an example shall be given for he reeds in precision Eabrication f parts produced ir netal cutting. For this task, the design of machine tools and the application of an advanced machining technology are key issues. Therefore the European activities of research in the area of machine tools are introduced. This chapter is taken. from a report by Tönshoff, Band and Giöckner /19/ (IFW, University of Hannover) which was written for an EC-commission. It is based on a survey by questionnaire. This chapter is followed by s survey on machine tools designed to machine hard materials by metal cutting. This survey was done for a machine tool builder and was composed also by IFW, Hannover $/ 20 /$.

5.1. Research in the area of machine tools

5.1.1 Data base of the survey

The data used for this survey were collected in two steps: For a first overview data were collected from national surveys which were made by several CIRP nembers. In a second step, this was completed bỵ means of a questionnaire. 
The CIRP national survers were avialable for Belgium, the Vetherlands, Erance and Japan. Their Liormation contents nostly comprized the main research topics and the numbers of researchers employed in the sndividual institutes. So, national profiles, e.g. the french and british focus on machine systems, could already be derived.

The answers gave representative images of the national research and development actirities for all addressed countries except for Erance where only tivo out sifteen questionnaires returned. There, an estimation iad to be made an the basis of other sources, especially the national CIRP jurvey. Eor Ireland, Luxemburg, portugal and spain the data base was insufficient to derive any figures about "esearch and development activities.

The domain of machine tool rasearch is divided in 3 categories $($ Iig. $\div 6)$ :

- machine tool systems

- machine tool uriented processes and

- machine tool components

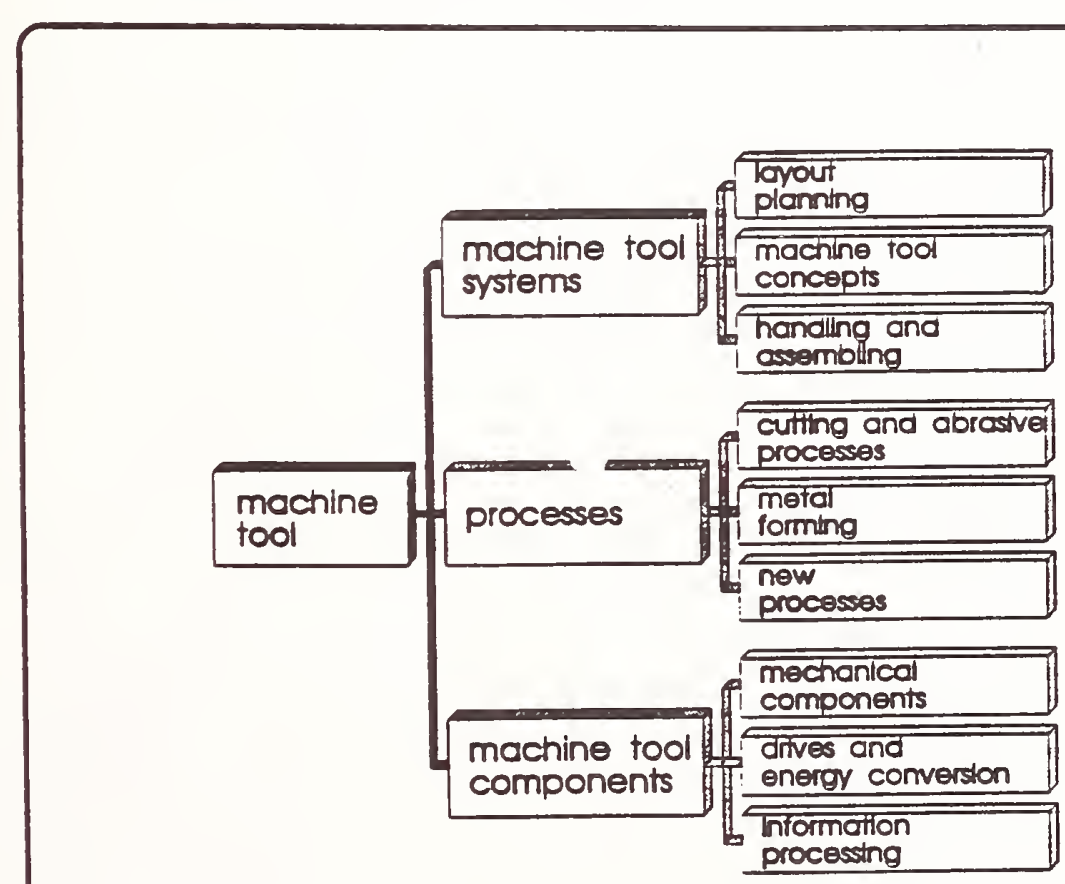

source: IFW

Br 0063

Eig. $\pm 5:$

Fields of machine tool $R \& D$ 
$R$ \& D activities in the category machine tool sustems comprize methods to define the production task and the related demands from given manufacturing liata such as single workpieces, workpiece families and general boundary conditions. It comprizes the identification of the production problem a machine tool or a production system has to fulfill, and of the requirements towards forms and magnitudes to be inanufactured, towards qualiti., productivity and the adaptation of machine tool systems to the workers and the environment.

The 4 criteria

- working space and Generable Forms

- Quality of Workpiece

- Productivity

- Adaptation to Workers and Environment

are equal and have all without exception to be taken into consideration. This is not a new iclea. These basic criteria were formulated more rhan 50 years ago by otto kienzle. And it has to be said that human and environmental aspects were already then stated as a mandatory criterlum for lesigning or investing in machine bois car jefore goliticians ind he sociery thought about it. It is of course an jther fuestion how ind to what extent these iemands were followed by the industrial practice.

Machine tool oriented processing is an important field of research and development. And processes of course are of governing effect on the ray. out, the operation and the performance of a machine tool. Therefore, research in this field has to be mentioned, when speaking about machine tools.

A look to scientific journals on production engineering over the last decades shows that in the past works on processes iere by far dominant. There were little publications on systems. With the beginning of the 70 ies activities about flexible inanufacturing systems, about machining cells, workpiece and tool handling and lay out planning of systems came up step $D y$ step. In processes today, conventional cutting and abrasive methods are less worked on whereas new processes iike laser beam machining, electrodischarge sinking and wirecutting and cutting of hard metals is dealt with increasingly, although from the point of riew in the industrial turnover - in machine tool building and in production by machine tools - the :onventional processes are by far dominant, are still bread and butter for a majority of companies. 
Finaliy, ve name $R$ \& $D$ activities on machine tool romponents that include mechanicai components : the the mechanlcal structure of a machine, yuide ways, splndle zystems, the drives and energy conversion sistems ind the mportant sield of information processing in the machine and in its neighbourhood.

\section{1 .2 Research actionias outs ise the EC}

Before examining the structure of the Ec zesearch activities in detail, we sill sist bok it jeher members of the triade. Excluding the states of the former soviet lnion, for which there is to reliable lata trialable, there iemain two countries performing major research effort on machine tools: the UsA and Japan. As Eig. $\div 7$ nows, whe EC :an be regarded as the very center of machine rool zesearch $\vdots n$ the world with more researchers than the tio other domains together.

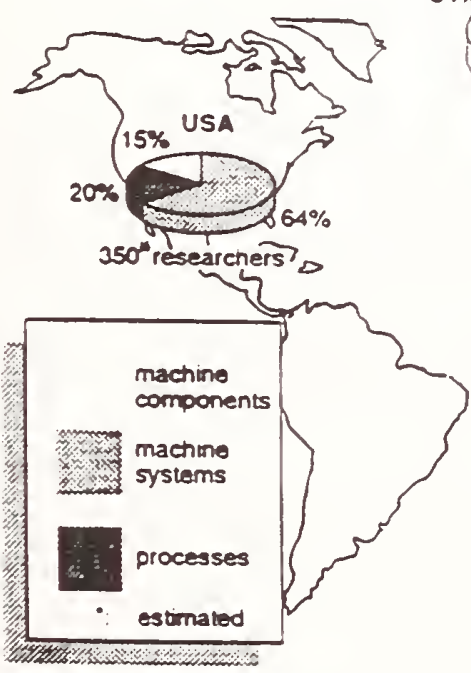

European Communtty

$34 \%$

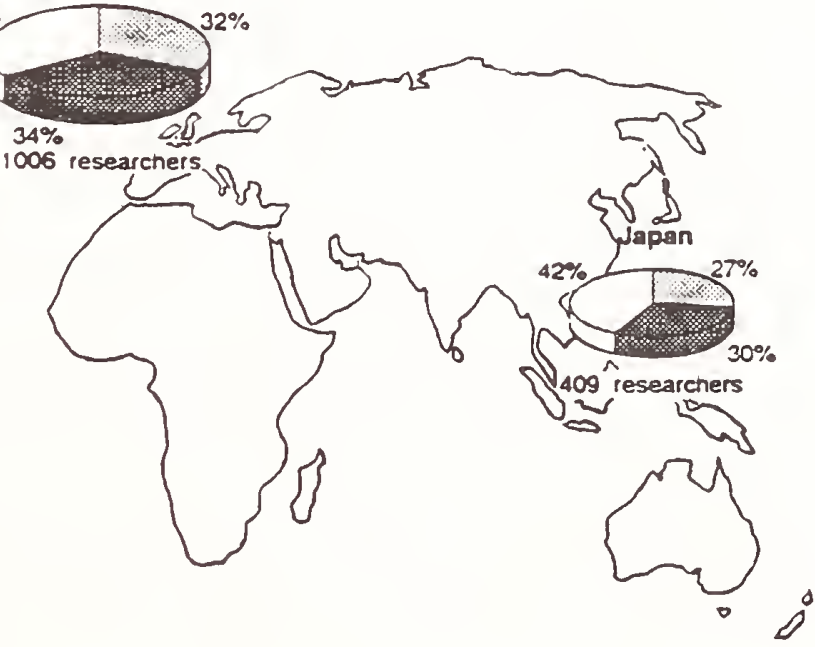




\begin{abstract}
Inside the western Europe, here are especialli tro countries outside the EC performing hajor research on inachine tools: Switzerland and sweden. In jweden, 52 researchers work in all three topics (machine tool systems, components and processes) with slight focus on components. In Switzeriand about $\div 0$ researchers work on processes and the other topics. Beside Germany, Switzerland is the only country where funding by a foundation of the national machine tool industry plays a major role.
\end{abstract}

5.1.3 Research activities irside the EC

After having stressed the dominant role of the EC in world wide machine tool research, the internal structure will be examined in terms of funding and research topics.

Funding

\begin{abstract}
In nost countrias, -he ational jovernments ire the thost important source of funding (Eig. $\dot{1}$ ). Only in the lnited ningdom their ontribution is overweighed by industrial funding. on the other hand, EC funding was not specified by any britisin research institution. lveraged over all EC countries, EC funding reaches a level of $9 \%$ of overall funding, which means 73 researchers on machine tools (in academic and other research institutions) in total. Also here, there are extreme differences between the nations. The total absence of EC funding in the addressed institutions in the united kingdom contrasts to the extremely high percentage in Belgium.
\end{abstract}




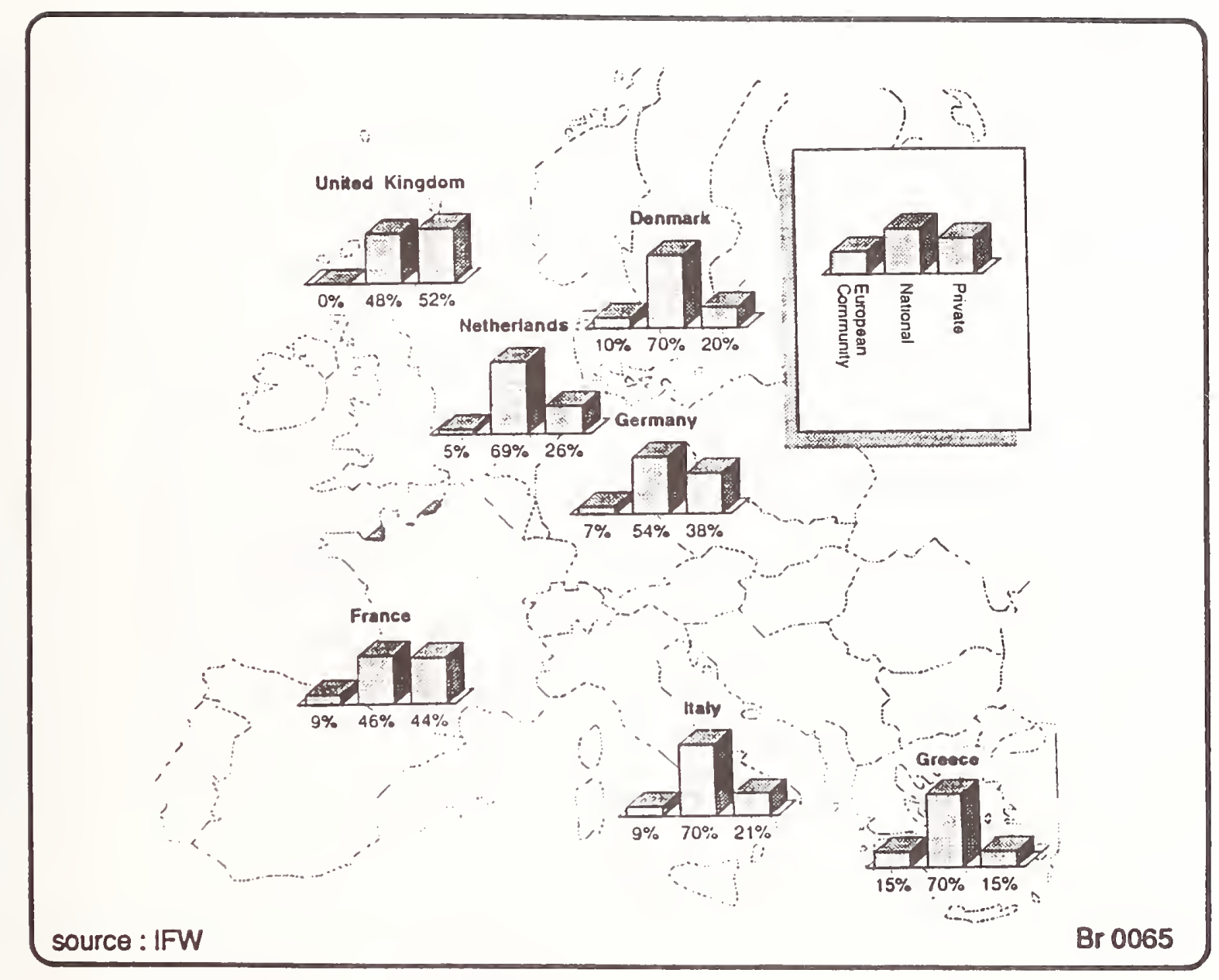

Eig. 18 : Funding of European $R \& D$ on machine tools

In Germany, for basic research, the German Research Foundation (DFG) is competent. This institution is comparable to the NSF in USA. The German Research Eoundation contributes approximately $15 \%$ to $20 \%$ to the budget of an average institute for machine tools.

In EC research programs the results are explicitly requested to be precompetitive. The results are desired to lead directly to products which help the European industry to improve their competitiveness. Foundations closely related to the national industry, e.g. the AIF, close the gap between these programs on one hand and direct industrial $R$ \& $D$ on the other hand. 
The evaluation of the fuestionnaires and several nationai CIRP surveys revealed a strong heterogenity of the topics tackled with in the different countriss (Eig. 19).

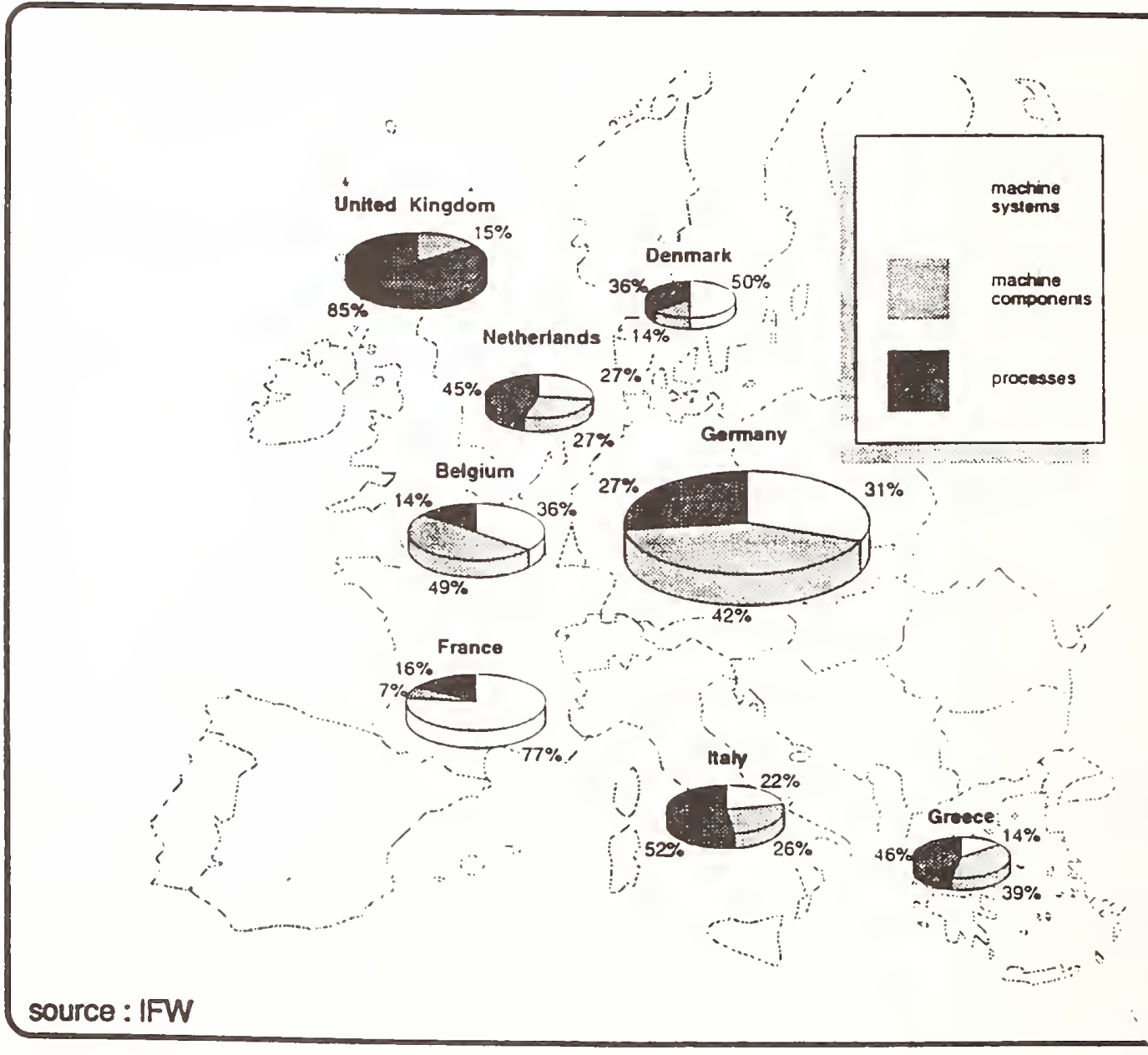

Eig. +9 : European research activities on machine tools

Especially, there are two countries with major research effort concentrating strongly on one research field. In the tnited ringdom, the focus of research lies on processes with $85 \%$ of all research effort performed there. Research topics nostly named here tackle with the jinding process. -n contrast, french research institutions mainiv work on the machine tooi system as: 
whole. Topics ilke EMS softivare, JNC, automation and CAD-CA:M demonstrate the ziench focus of achieving higher productivity by means of making automation more fiexible.

ds Fig. 17 shows, these ational differences are quite complementary. Summed ip, they lead to a distribution comparable to that of the main competitor Japan.

A further differentiation of the research topics ied to the result shown in Eig. 50. Fhere, iny topic is divided into three subtopics.

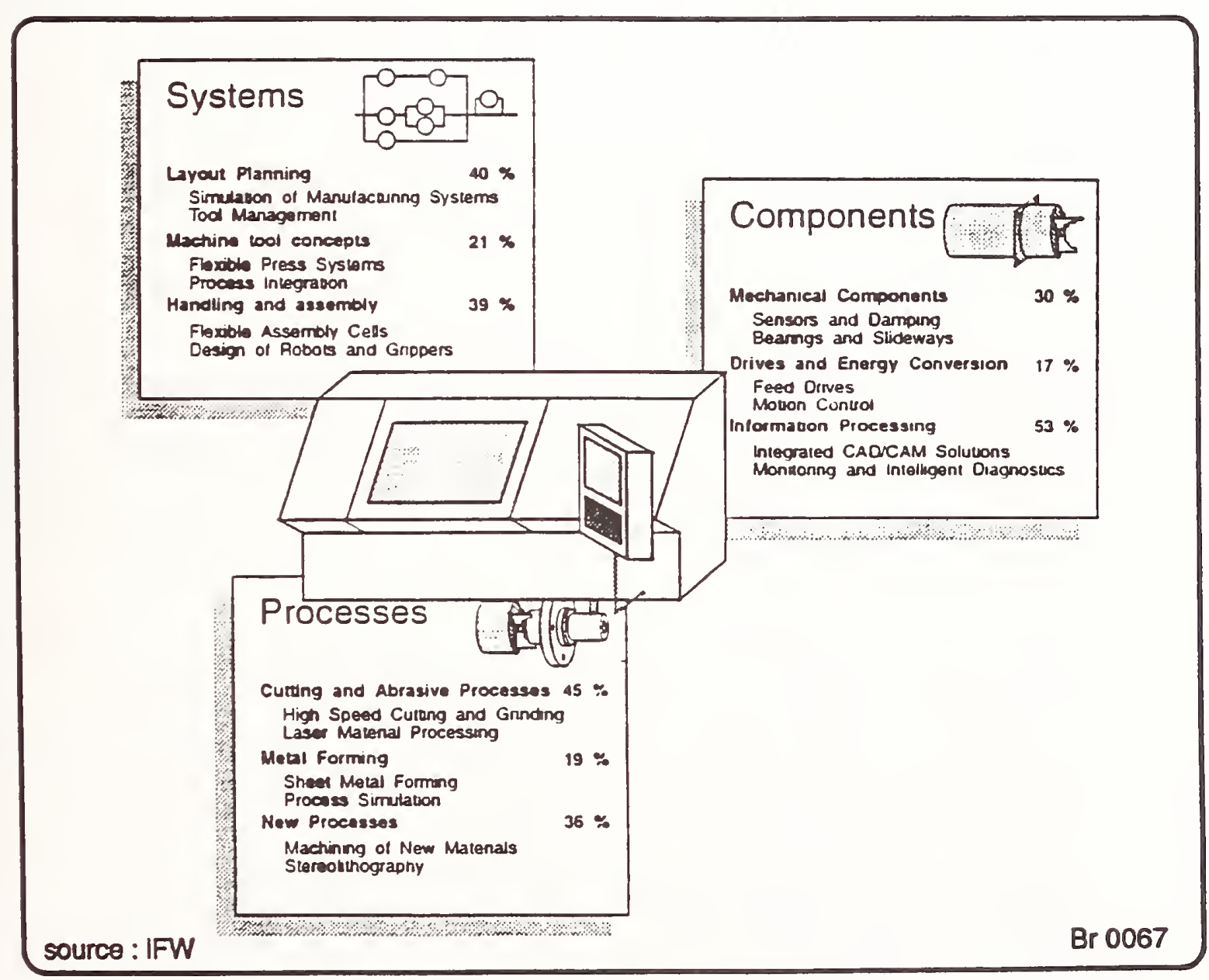

Eig. 50: Research topics on machine tools

d detailed description of individual projects in these treas can be taken from the cited report /19/. 
5.1.t Conclusions

Research and levelopment $\vdots n$ liestern Europe is widespread over many academic and other pliblic research institutions. The number of researchers exceeds those of the USA and Japan considerably. This variety stimulates reatirity and innovation and is an excellent source for IJung scientific engineers. On the other hand this situation inight split the power too. To minimize disadrantages and to intensif $z$ the great advantages of Europe's research structure in the field ot machine tools, a specific program $i n$ this field :ould help to strengthen the competitiveness of this key technology in manufacturing.

5.2. Requirements on machine rools designed to machine hard materials

\subsubsection{Preface}

Due to the development of polycrystalline Cubic Boron litride tools (CBN) and inprovements in the processing of ceramic tool materials $\left(\mathrm{Al}_{2} \mathrm{O}_{3} / \mathrm{I} i \mathrm{C}\right)$, turning instead of grinding of hardened steels has become possible. This new technology has the potential to replace grinding processes and hereby achieve significant reductions $i n$ production iime and :ost. a order to judge the capabilities of these nachining processes - is necessary to consider some technological as liell as economical aspects of hard turning and drilling.

Machining of hardened rotational components by conventional grinding is substituted more and more by hard turning. Improved cutting tool materials were the most important reasons for this development. Especially the group of reinforced oxide ceramics and cubic boron nitride are suitable for nachining of ferrous alloys in their hardened state. CBN tools are preferred for interrupted cutting because of their superior fracture toughness.

The main applications for hard turning obviously are finishing processes with high quality requirements concerning form and size accuracr of the workpiece, surface finish and surface integrity. These attributes are defined not only by the machinging paramaters like feed rate or cutting speed but also by the tool material, the cutting edge jeometry, the composition and admission of coolants, the workpiece material and the static and dynamic properties of the machine tool (Fig. 51). 


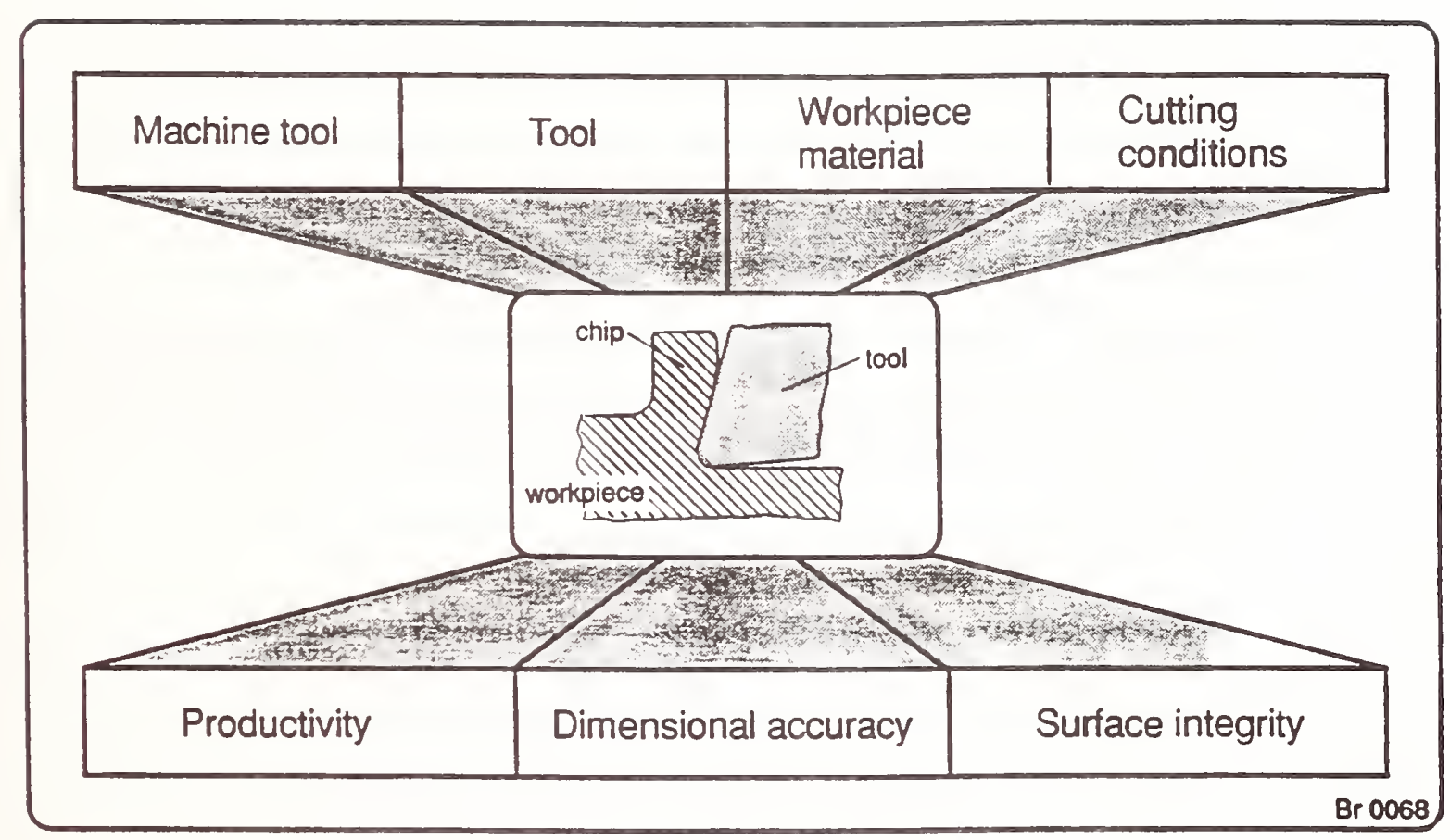

Eig. 5I:

Influence of input parameters on workpiece quality in hard turning

Usually, higher Eorces are applied in the grinding wheel contact area on a single-point tool. To avoid dimensional inaccuracy, grinding requires rery rigid machine tools. Yet, the dynamic characteristics of the grinding process are different from those of autting. Expecially vibrations can be suppressed by squeezefilm damping in the umparatirelr iarge contact rea. Bo, in general, hard turning requires a dyamicaliz more rigid machine tool than grinding in order to perform the same operation.

\section{2 .2 Aim of the studr}

The new technology of hard turning significantiy reduces production time, tooling cost and capital investment. However, only a very limited number of applications have been introduced in industry up to today. The rate avialability of lathes specially designed for hard machining is regarded as one reason.

Existing lathes are not adapted to the demands arising from hard turning. Stiffness, accuracy of the control and gauge systems of conventional machines are usually not within the range wich may be necessary for precise hard turning operations. Aim of the study therefore was to define the demands on a lathe for hard turning. 


\section{2 .3 Course of action}

To judge the situation on the European user market, the IFW selected and interviewed companies involved with the machining of hardened steels and alloys. The selected branches and the number of companies were as follows:

\footnotetext{
- automobile industry (5)

- bearing sø̃stem producers ?:

- aerospace/aircraft industr

- gear engineering industry $(\vdots)$

- others (5)
}

It turned out that the majority of the enterprises that took part in the study are nedium sized, which is typical for German and European metal-working companies. The nedium sized enterprises represent the biggest proportion of the market volume for hard machining machine tools and should certainly be addressed with the same intensity as the big enterprises in sale activities.

Eorm the interviews onducted with Eading inploves Ẽm production departments, information was extracted to characterize the possible demand for hard turning. This was done by examining the scope of components presently produced. A result was that only a fraction of these parts is already produced by hard turning, many are still finished by grinding. Yet, according to the statements of the company zepresentatives, these are the parts that they consider interesting for hard turning in future.

It is important to mention here that the results of the study have to be treated confidental and are thus disclosed. Therefore in the following, only some remarks on the production methods of the involved companies can be given. 
5.2.: Eroduction methods

Grinding, mostly with onventional corundum wineels still by far dominates hard turning (Eig. 52 ).

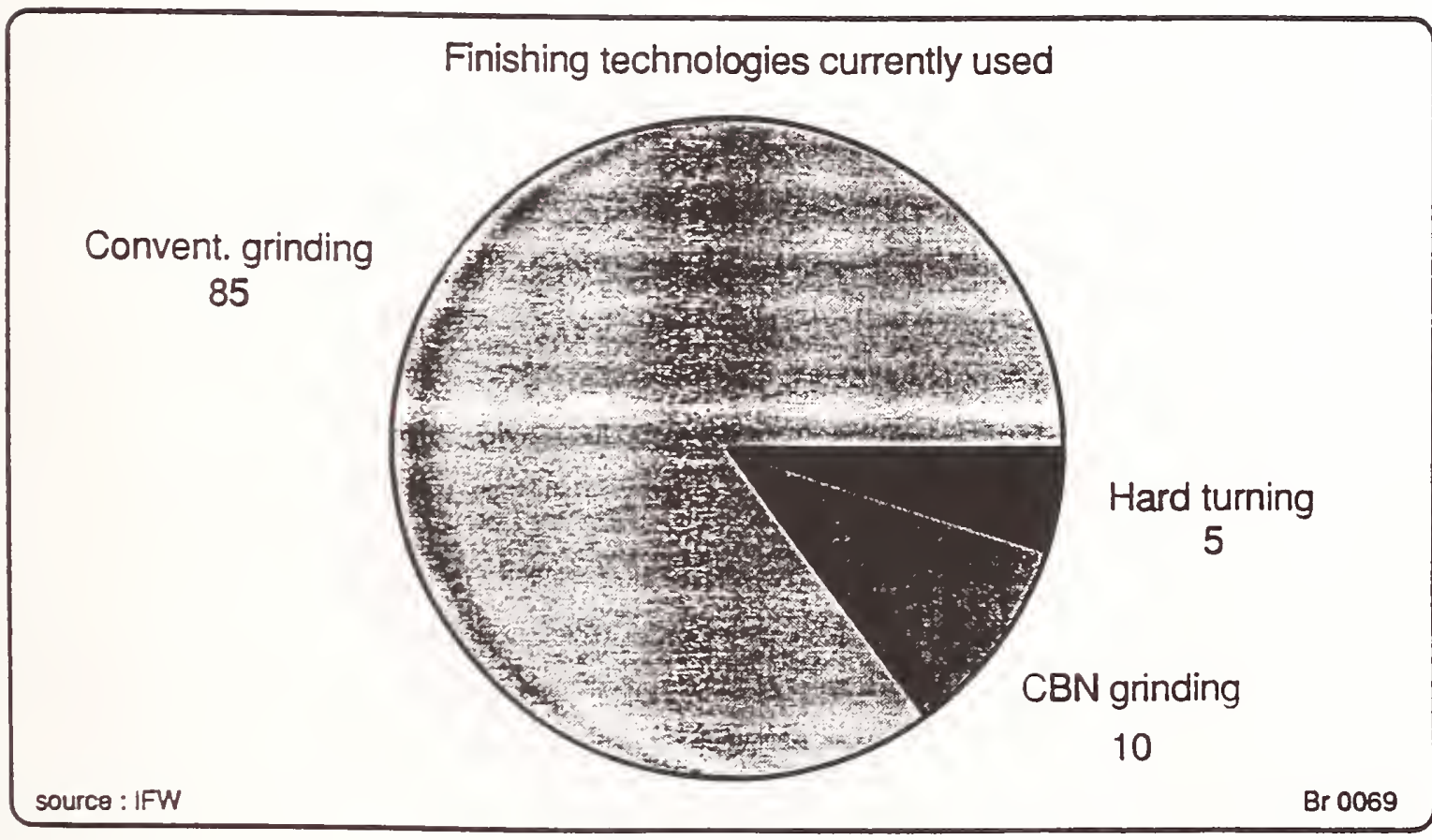

Eig. 52:

Yethods presentiy used for finishing

of hard steel components

At present, hard turning accounts for no more than $5 \mathrm{p.c}$. of large scale production. CBN grinding with 10 p.c. has twice the number of applications as hard turning. The technologies of hard turning, grinding with CBN and possibly also with the recently emerging improved grades of sintered alumina are activley competing for overlapping sectors of the finishing market.

Due to the limited experience of most useres with hard turning, considerable dispartiy exits concerning suitable tool inaterials. The aisting lincertainty about the right choise of tools is reflected by a number of publications on machining investigations. Their authors do not present a simple solution. Contradictory in part, differant qualities of CBN as well as alumina-based ceramics are presented as the optimum for the turning of hardened steels. The investigation :onducted ir the 
IFW reveald equalif divergent pinions with industrial isers vino have attempted hard turning. large group ises aramics tools only, partly for historical reasons and in part in order to avoic high cost when damaging a tool. (Eig. 53).

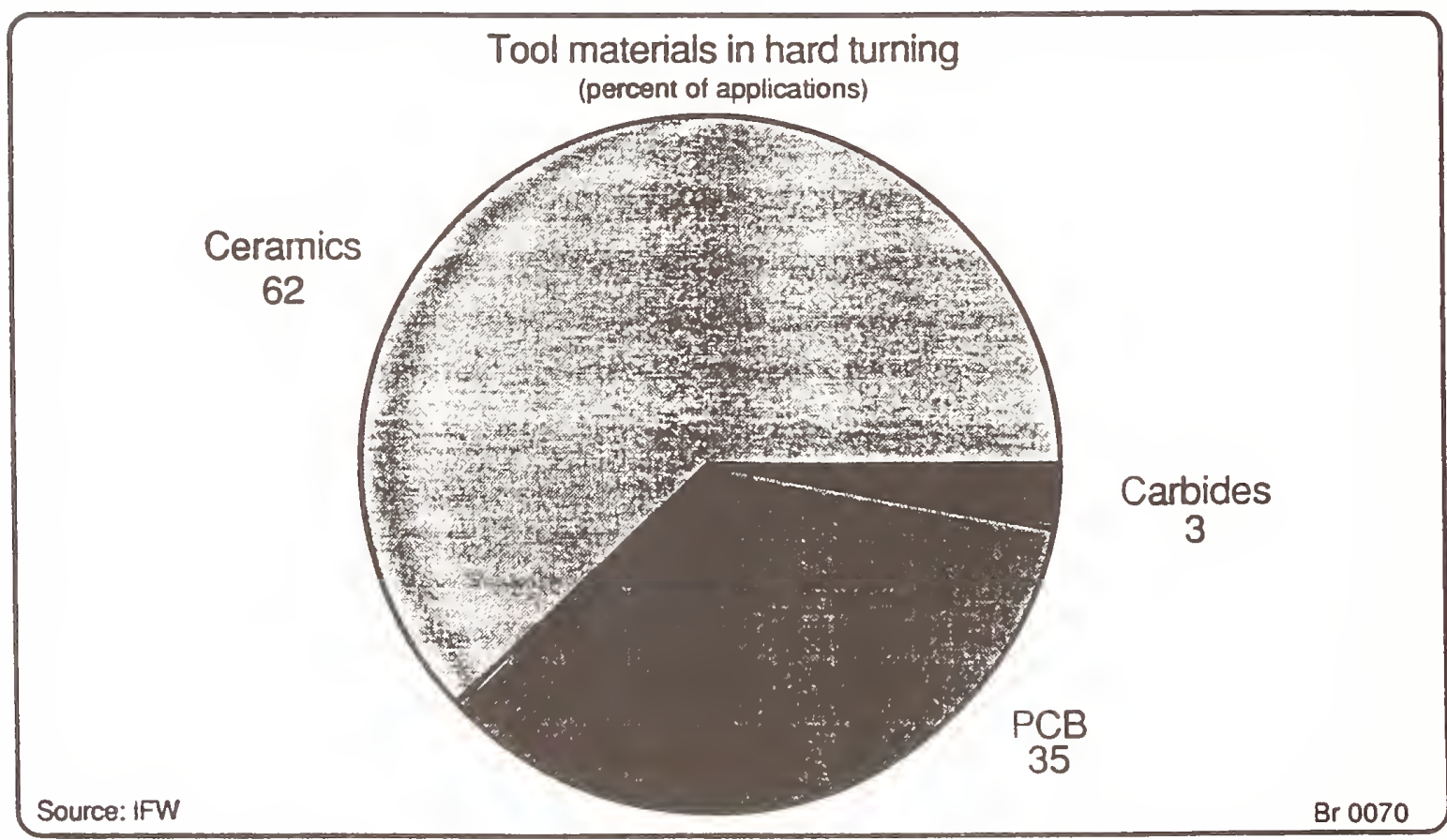

Fig. 53: Tool materials in use for hard turning

Some are convinced of the performance of CBN grades with reduced thermal conductivity, especially in inishing operations with small depths of cut. Others, concerned with surface integrity, propose ordinary CBN. Carbide tools find a very i imited use with materials like annealed steel of no more $\vdots 0-50$ HRC. Adequate tooling for the various machining operations will have to be studied in depth to present a convincing overall concept for hard turning. 


\subsubsection{Requirements for a lathe designed for nard tunring}

The lesign of a lathe aust take into consideration the prerequisites imposed $b y$ the users who are interested in hard turning. While a considerable degree of uncertainty exits because of lacking technological experience, minimum conditions can be defined as a function of workpieces. Furthermore, isers were asked to define requirements from their point of view. Questions were very letailed and amed it :llachinable viorkiece sizes, speeds, resolutions in programming, accuracy, stiffness of the various axes/spindies, and additional letails like automation. Generally, users were not able or wiling to give a clear picture of the necessary apabilities of a lathe for hard turning. It was a general opinion that developing a suitable design belonged to the cuties of machine tool manufacturer. The letailed results of the study in this area are also disclosed.

\subsubsection{Prospects of hard turning in European industr:}

In today's production, precision finishing of hardened steel components is an upcoming task. The demand arises from the permanent endeavour to increase the specific power of $r . g$. drive components. Rising Etress lemands vardened workpiece materials which inust :e produced it :ompetitiro ost. 3ecause jf its flexibittr, finishing hardened serrous workieces by turning offers great savings in time and cost over conventionai frinding. At present, the industrial practice of hard machining is still in its experimental or at most iii an introductory stage iith most European companies. It has not been for long that iurning of hardened ferrous workpieces has been feasible at ail. The new process of hard turning now has to compete with wellknown and trusted abrasive processes of long standing. These are able to satisfy high quality requirements at a high level of productivity. Hard turning has ret to gain acceptance as being equivalent or even superior for the special applications of a company. Regarding their experiences with and attitudes towards hard turning, the 20 companies interviewed divide into three groups of differant strength (Fig. 51). 


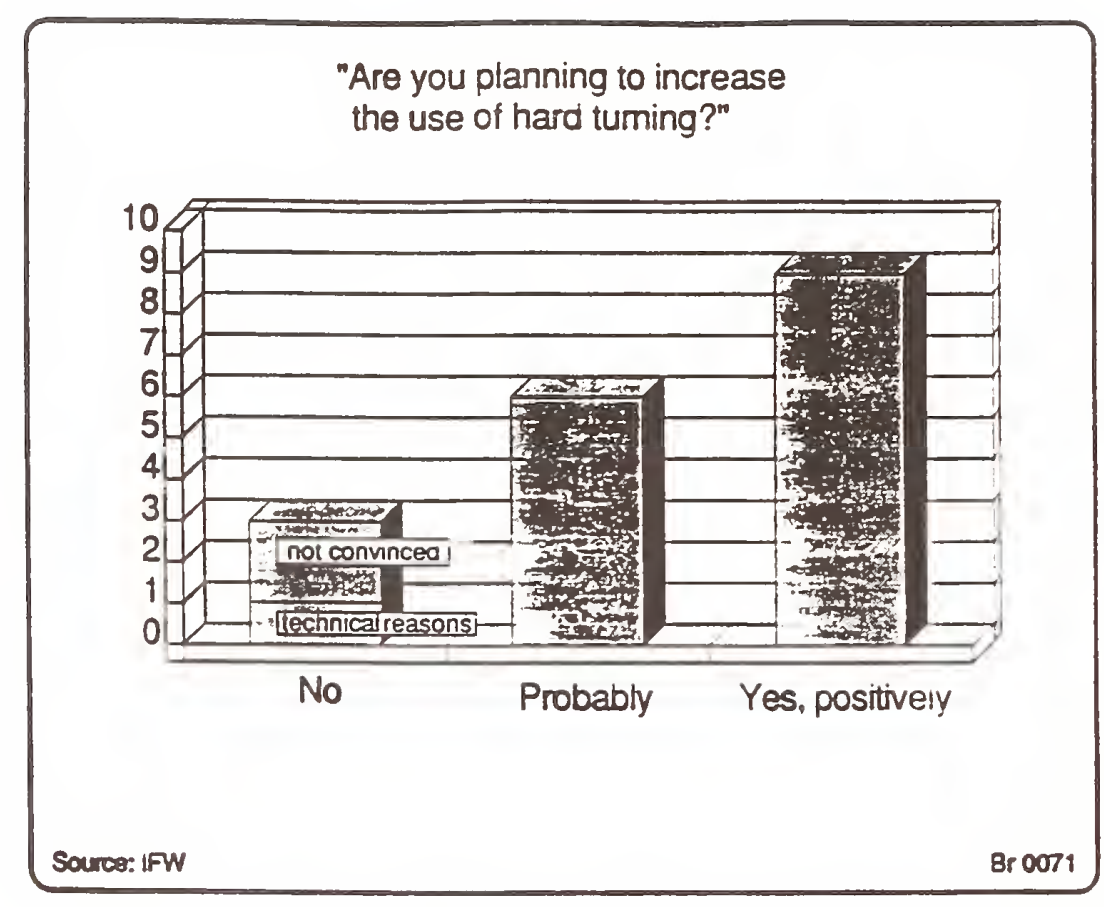

Eig. 54: Attitude of companies towards hard turning

Half of the companies are currently busy testing specific applications and puttirg thent into practice. Some of them ise conventional achine jols in : Zose boperation with the manufacturers, à few are about to buy an iltra-precision -athe. Research activities with EC support are conducted by some companies. Neither of these companies need to be convinced of the benefits of hard turning. Instead. most of them will seriously consider buying an adapted type of lathe from a renowned manufacturer.

At different levels of information and progress, another third of the firms are basically interested in hard turning for some of their parts. These :ompanies haven't ret been able to define a viable machining operation. They are strongly interested in competent support from outside.

The small rest ff the enterprises do not think hard turning can be beneficial for them. In one case (bearing industry) the "wite layer" problem is considered to rule out hard turning altogether although test are presently conducted at similar companies to check the real significance of this issue. The remaining companies seem to have lack information about hard turning. Companies like these are an untapped market potential as they can possibly be won over by hard facts showing cost and time savings at a constant ?evel of qualitz. 
With any change in production methods such as from grinding to hard curning, Joubts lave to be dispelled with the responsible production manager. in additional nachine earn the money for itself and ilso for the present equipment. Substitution is easiest when depreciation of the existing machine tools allows a replacement anyway. In any case customers have to be convinced that investing in a lathe rather than a grinder will pay off in terms of quality and productivitr.

All the topics involved, Lechnological issues like tool life, surface finish and surface integritz as well as aconomic reasons still wait Eor thorough anestigation. The availability of a suitable lathe with high zrecision capabilities and superior static and dynamic stiffness is prerequisite to progress in hard turning. 


\section{References}

\begin{tabular}{|c|c|c|}
\hline$/ 1 /$ & - & $\begin{array}{l}\text { The Deutsche Eorschungsgemeinschaft } \\
\text { Organizations and Functions } \\
\text { DFG Report, Bonn } 1990\end{array}$ \\
\hline$/ 2 /$ & - & $\begin{array}{l}\text { Statistics } 1991 \\
\text { DEG Report, Bonn } 1992\end{array}$ \\
\hline 131 & - & $\begin{array}{l}\text { Volkswagen-Stiftung } \\
\text { Annual Report } 1991\end{array}$ \\
\hline$/ 4 /$ & - & $\begin{array}{l}\text { BMFT-Förderungskatalog } \\
\text { BMFT Report, Bonn, } 1992\end{array}$ \\
\hline$/ 5 /$ & - & $\begin{array}{l}\text { The German System of Industrial } \\
\text { Cooperative Research } \\
\text { AIF Internal Report 1992, unpublished }\end{array}$ \\
\hline $16 /$ & - & AIF-Handbuch, “̈̈ln 1991 \\
\hline$/ 7 /$ & - & $\begin{array}{l}\text { European science Foundation } \\
\text { Annual Report, Strasbourg, I990 }\end{array}$ \\
\hline 181 & - & $\begin{array}{l}\text { Industrial and Materials Technologies } \\
\text { Information Package Brite-EuRam II. } \\
\text { Edition l991 }\end{array}$ \\
\hline 191 & - & $\begin{array}{l}\text { JESSI Program } \\
\text { An Initiative of European Institutions and } \\
\text { Companies } \\
\text { Results of the Planning Phase Itzehoe } 1989\end{array}$ \\
\hline$/ 10 /$ & Radelaar. 3. & $\begin{array}{l}\text { JESSI for the Main Phase-European Micro- } \\
\text { electronics on its way } \\
\text { Presentation of the JESSI program } \\
\text { Hannover } 16.03 .1992 \text {, pp. } 9-33\end{array}$ \\
\hline
\end{tabular}


III Betz, 法.

/12/ Knapp, ̌.H.

/13/ Grünewald, $\because$.

/14/ Dumas, G.

/15/ Doche, C.

' $6 /$ Sauer, ¿.

$1171 \quad-$

/18/ Grünewald, 1.

/19/ Tönshoff, H.K.

S. Brand

4. Glöckner

/20/ Tönshofe, H.K. H.G. Wobker P. Roth
JESSI- Europa sucht Anschluß in der Mikroelektronik

spektrum der Wissenschaft (1992)1,pp.16-23

Das Mikroelektronikprogramm für Europa "JESSI" (Geräte)

Halbleiterfertigung - veue Irends bei Produktionsstrukturen und Fertigungsgeräten Yünchen 07.,08.11.1389, pp. 221-211

Das JESSI-Programm:

Ein hechsel auf die europäische Zukunft

Siemens-Zeitschrift (1991)3, pp. 34-38

The JESSI Subprogram Technology Presentation of the JESSI program Hannover 16.03.1992, pp. $51-77$

The JESSI Subprogram Equipment \& Materials Presentation of the JESSI program

Hannover 16.03.1992, pp. 77 - 89

The JESSI Jubprogram Application Presentation of the JESSI program Hannover $16.03 .1992, \mathrm{pp} .33$ - 51

Funding lews JESSI-Information-Letter, Issue No. 10 January 1992

Presentation of the JESSI program Hannover 16.03.1992, pp. 5-9

Research on Machine Tools in Academic and Research Insitutions

Report, IFW Hannover, 1992

Investigations into the possibilites and limits of a lathe specially designed to machine hard materials

Report, IFW Hannover, 1992 


\title{
Precision Fabrication Technology in the Former Soviet Union and Other East European Countries
}

\author{
Eugene I. Rivin, \\ Department of Mechanical Engineering \\ Wayne State University, Detroit, MI 48202
}

\section{Introduction}

Surveying precision fabrication in the former Soviet Union is an especially difficult task because it is "former" and because it was largely a classified area. The industries responsible for precision fabrication (military industries and affiliated industrial establishments) do not exist anymore, at least in the form they did two years ago, and new development has practically stopped. However, the survey, even going back more than one or two years, may be of the significant value, since the infrastructure still exists and, more importantly, the people who were developing precision fabrication technology are still there (or languishing in the West) and are available and eager to transfer the technology.

Two basic premises, formulated earlier in [1] are:

- The inferior products of Soviet industry should not be equated (or confused) with its superior achievements in research and development. The R\&D effort was represented by hundreds of research institutes, all very large by Western standards, all employing many talented and well-educated researchers, and many equipped with state-of-the-art facilities.

- The outrageous Soviet system of intra-industrial cooperation resulted in shortages of practically everything, and forced R \& D practitioners to come up with simple solutions not requiring complicated supplies and/or imported components; in other words, necessity was the mother of invention.

To these premises, one more can be added: precision fabrication, especially in the last five to ten years, received the special attention (and, thus, resources) of the military due to the strategic importance of precision optical components, computer memory systems, etc. This relates both to manufacturing research institutions in the military-related industrial ministries (at least, twelve huge institutions), and to the civilian research institutions and laboratories of the institutions of higher education which were involved in precision fabrication activities. This presentation is based on information on both activities, with the latter better documented for obvious reasons. The infrastructure associated with development and implementation of precision fabrication technology is not addressed since it has been dramatically changing during the last couple of years. Only basic areas of and development in precision fabrication are being discusse. Information on the old infrastructure (which was essentially stable until recently) can be found in [1].

Modern precision engineering has deep roots in the Soviet fabrication industry. It was understood from the beginning that machine tools are precision 
fabrication machines and that many issues related to machine tools, machining processes, tooling, and measuring instrumentation must place emphasis on accuracy, and on the design and production factors influencing accuracy. Recent developments in the precision fabrication area in the former Soviet Union cannot be well understood without some excursion into this historical background.

The leading institutions for promoting these efforts were the Experimental Research Institute for Machine Tools (ENIMS) and the Moscow Machine Tool Institute (Stankin, an educational institution), both organized in the early 30's. ENIMS from the very beginning embraced an approach to machine tool accuracy originated by G. Schlesinger, and made the development of standards of machine tool accuracy and means and techniques for its measurement one of its leading activities (V. Dikushin, N. Atcherkan). This activity still continues, and there is now available a most comprehensive set of state standards embracing all basic types of machine tools. The important feature of many of these standards is classification of machine tools by accuracy levels, from general-purpose levels to "enhanced accuracy," "precision," and "ultra precision" levels. In many cases, the accuracy parameters of the higher levels of precision were specified before the machines were built, and then efforts were made under pressure from the military industry customers, to build these machines.

This effort toward continuous development of high precision machine tools and tooling was supported by extensive work at Stankin on the development of a theory of "dimensional chains" which allows us to formulate and assign tolerances on constitutive parts, based on the required output accuracy of the machine or its unit (B. Balakshin). This theory was developed during the 1930's and 40's, and immediately became part of the curriculum for all students in manufacturing technology, machine tool design, measurement, and instrumentation, both at Stankin and at numerous similar institutions around the country.

Recently, this activity has served as the basis for developing a general analytical technique for the assessment of machine tool accuracy at the design stage, and for automatic error correction in CNC machine tools (D. Reshetov and V. Portman [2]). It should be noted that one of the leading Japanese researchers in the area of machine tools and manufacturing, Prof I. Inasaki, considers [2] as "one of the most interesting and informative books relating to machine tool technologies" [17].

All over the country, students in machine tools and manufacturing engineering take intensive two-semester courses on metrology, tolerances, and mechanical measurements, supplemented by a one-semester hands-on laboratory course on metrology and the operation of basic precision measuring instruments. Note that the total length of the machine tool/manufacturing engineering curriculum in the former Soviet Union is five years (with 40-43 weeks a year and 30-40 contact hours a week); see [3].

Some indication of the mode of operation of ENIMS is the fact that in 1982 its library held more than 125,000 volumes directly or tangentially related to the machine tool industry. I would guess that this exceeds the total number of 
volumes on these topics in all U.S. machine tool companies combined by at least 100 times. The library in Stankin is significantly larger.

Another very important factor which should be considered in assessment of the state of the art of the Soviet fabrication technology, is an excellent information service. World-wide developments are continuously monitored and provided to researchers and designers via comprehensive abstract journals which are published in all important areas of science and engineering. Abstract journal on "Manufacturing Engineering and Technology' contains substantive abstracts on 2,000-2,500 publications and patents in each monthly issue. It surveys literature from many languages (English, Russian, Japanese, Polish, French, German,...) on metal cutting, machine tools, assembly, special processes, forming and forging, casting (see Appendix 1). This information, besides alerting researchers and designers to the latest developments, allows to clearly visualize principal directions of development in various areas of manufacturing engineering.

It was understood at a very early stage that accuracy of machine tools does not depend just on geometrical errors in the machining and assembly of their constitutive parts, but is also heavily influenced (especially for precision machines) by deformations of the structural parts and their joints under both cutting and weight forces, and by thermal deformations in the machine tool structure.

Research on contact deformations in joints was pioneered by $V$. Sokolovsky in the 1930's and 40's. The issue was studied in a very comprehensive way by D. Reshetov and Z. Levina, and now their book [4] is a desk tool for designers of precision machine tools and other precision mechanical devices. A similar comprehensive study was performed on structural deformations of machine tool parts (D. Reshetov, V. Kaminskaya, Z. Levina [5], [6]). Their developed and validated close-form techniques are still useful, notwithstanding available finite element analysis packages.

Research work on the stiffness-related issues was accompanied by widescale measurements of stiffness characteristics of machine tools, both generalpurpose and precision. As early as in the 1950's, these efforts led to development of industry standards on machine tool stiffness, mostly for factory acceptance checks, supplementing standards on geometrical accuracy. Now there are dozens of standards on machine tool stiffness which might be of use to the Western machine tool makers. Starting in the late 60's and early 70's standards for vibration levels of machine tools at idle running conditions were also developed. These are widely used for acceptance checks.

The importance of thermal deformations in machine tools was recognized at the very early stages of development of precision fabrication techniques. Pioneering work by D. Reshetov and Y. Sokolov in the early 50's ([6], [7]) led to a good understanding of thermal processes, and allowed design predictions and modifications. Now, ENIMS has developed a software package for analyzing thermal deformations of machine tools.

It can be noted that a multi-authored monograph [6] with heavy emphasis on precision machine tools sold 43,000 copies. This monograph 
essentially summarized the ENIMS results. Besides other topics, it has large chapters on spindle bearings, guideways, vibration control, mechanisms for small precision displacements, and thermal deformations.

\section{Precision Fabrication in the Former USSR (Machine Tool Industry)}

The major difficulty in building machine tools in the former Soviet Union, and especially precision machines, was a lack of specialized components such as bearings, guideways, ball screws, drives, controls, etc. This led to many frustrations and failures, but also to many breakthroughs: necessity really was the mother of invention.

With the developing need for high speed/high power/high precision machine tools, special attention was given to machine tool spindles. At the first stage (in the 1950's and 60's) original designs of self-aligning multi-pad hydrodynamic bearings for precision grinding and turning machines were designed and widely implemented [6].

These bearings allow machining of round parts with out-of-roundness within $0.2-0.3 \mu \mathrm{m}$. They were incorporated into more than 40,000 machine tools, especially cylindrical grinders, but also boring mills and precision lathes. A heavy-duty lathe was developed which machined fifty-ton parts $1,000 \mathrm{~mm}$ in diameter with a roundness of $0.2 \mu \mathrm{m}$. Precision boring mills equipped with the self-aligning hydrodynamic spindle bearings machined holes with the overall tolerances within $1.5 \mu \mathrm{m}$ [9].

Hydrostatic guideways for a rotary table were implemented on a heavy vertical cylindrical grinder (Kolomna Plant). Out-of-roundness for $1,500 \mathrm{~mm}$ diameter parts was within $2 \mu \mathrm{m}$. Use of hydrostatic guideways and bearings on a horizontal cylindrical grinder (Kharkov Plant) improved surface finish $\left(R_{a}=\right.$ $0.125 \mu \mathrm{m}$ ).

The Vilnius Branch of ENIMS (now in Lithuania) specialized in the development of smaller high-precision grinders and gear-cutting machines. In about 1965, this affiliate developed and started production of a cylindrical grinder for diameters of 100-150 mm with out-of-roundness within 0.1-0.15 $\mu \mathrm{m}$.

A large effort was started in the 60's and is still continuing on the development of precision spindles on ball and roller bearings (A. Figatner, [6]) and on the development of domestic production of spindle bearings with high degrees of precision. Several facilities for manufacturing ultra-precision ball and roller bearings were established at the large ball bearing plants in the 1970's and 80 's. This work was characterized by thorough, comprehensive testing and analysis of the best bearings from all major manufacturers worldwide, combined with analytical and experimental studies of the influences of various bearing parameters on spindle performance.

Extensive work on stiffness, thermal deformations, and bearings has recently resulted in a comprehensive software package for analysis of spindles at the design stage.

Extremely high priority was given in the 1960's and 70's to the development of various types of precision gyroscopes. Several research institute/manufacturing plant amalgamations were equipped with state-of-the- 
art precision machining facilities, and special departments were created at the leading ball bearing plants and research institutes for fabricating ultra-precision miniature bearings.

As early as the late 50's or early 60's S. Sheinberg at ENIMS developed and validated a comprehensive theory of gas lubrication which was immediately employed in designs of high-speed grinding spindles for miniature precision bearings, and for jig-grinders for grinding holes in housings for precision gyroscopes and other instruments [24]. Detailed analytical study of numerous undesirable dynamic phenomena by Sheinberg made ENIMS a leader in the implementation of $60-100,000 \mathrm{rpm}$ grinding spindles in the Soviet ball bearing industry, mostly for military application precision bearings. These spindles, which until recently were produced by the Moscow Plant for High-Speed Precision Electric Drives, comprise three models: $0.8 \mathrm{~kW}, 15-40,000 \mathrm{rpm} ; 0.25 \mathrm{~kW}$, 40-100,000 rpm; and $0.08 \mathrm{~kW}, 120-250,000 \mathrm{rpm}$ [9]. Later a similar spindle $(0.25$ $\mathrm{kW}, 20-72,000 \mathrm{rpm}$ ) was developed for precision CNC drilling machines for printed circuit boards (manufactured by the same plant), and a heavy duty spindle (7.5-25 kW, 24-48,000 rpm) was also developed and implemented.

Aerostatic bearings were used for circular guideways and a tool carriage guideways of a lathe for machining large precision mirrors.

Other critical units in precision machine tools are motion supporting (bearings, guideways) and motion transforming (lead screws, rack-and-pinion mechanisms, etc.) devices. Some outstanding studies on the behavior of these components have been performed and published (e.g., in [6]). These results are extremely helpful to designers but, unfortunately, are not widely known in the U.S. Obtaining high-precision components was extremely difficult in the Soviet Union, since they were produced by different branches of industry, i.e., by different ministries. This situation provoked the generation of ideas and concepts for the design of motion-supporting and motion-transmitting components which could be produced in-house. As a result, the Soviet machine tool industry (especially its R\&D component) was for many years a leader in the development of hydrodynamic, hydrostatic and aerostatic bearings, lead screws, etc.

An extensive effort related to hydrodynamic and then hydrostatic lubrication of bearings and guideways was launched in ENIMS in the late 1950's and early 1960's (G. Levit).

ENIMS developed, together with the machine tool building plants, hydrostatic systems for spindle bearings, rotating tables, lead screws, worm-rack transmissions, etc., mostly for large machine tools. A simple and effective technology was developed for producing high precision hydrostatic linear transmissions (screws, worm-racks) without a need for high precision machining, by using epoxy resin for "printing" counterpart surfaces. Some commercially produced machines in the 1970's included a vertical boring mill with a radial runout of $5 \mu \mathrm{m}$ at $4,000 \mathrm{~mm}$ machining diameter, and a $10 \mu \mathrm{m}$ face runout at the same diameter. This machine was manufactured by the Kolomna Heavy Machine Tool Plant for boring submarine propellers. A vertical grinding mill for grinding ball bearing races had a radial runout of $2 \mu \mathrm{m}$ at $2,000 \mathrm{~mm}$ diameter, and $5 \mu \mathrm{m}$ at $2,500 \mathrm{~mm}$. Practically all machines of these types are now built with hydrostatic 
guideways. The Kolomna Plant, the largest plant in the former Soviet Union producing heavy machine tools, uses hydrostatic worm transmissions widely. Other heavy machine tools plants, e.g., in Minsk (gantry milling machines), Kramatorsk (large lathes), and Ulyanovsk (gantry milling machines), also use hydrostatic systems extensively, especially for lead screws. A special technology for "printing" long nuts and precision joining of segments of long components of lead screw mechanisms was developed and implemented. Some of the leading participants in this project are now residents of the U.S.

Successful attempts were made at using grease instead of oil in the hydrostatic units of heavy machine tools. In my opinion, in the 1960's and 70's, the Soviet machine tool industry was the world leader in the application of hydrostatic lubrication in heavy precision machine tools.

Hydrostatic spindle bearing technology developed in ENIMS was also utilized in many smaller machines manufactured by its experimental plant, as well as by its Vilnius branch and by the specialized precision machine tool plant Kommunaras in Lithuania. These machines include diamond boring machines using standard boring spindle units with hydrostatic bearings (a line of five models with out-of-roundness within $0.3 \mu \mathrm{m}$ ). Single spindle NC milling machines and a special three-spindle milling machine with spindles in hydrostatic bearings produce surfaces with $R_{a}=0.16 \mu \mathrm{m}$.

The critical strategic importance of precision machine tools was well understood in the early 60 's. It was clear that building of quiet submarines, of advanced jet and rocket engines, of precision navigation equipment for ballistic missiles, of radar equipment, etc., was not possible without precision fabrication equipment. As a result, a major decision had been made at the highest governmental level to construct large precision manufacturing facilities at about 15 leading machine tool building plants. These units included buildings of 310,000 sq. $\mathrm{m}$ (30-110,000 sq. ft) floor area with temperature maintained within $\pm 0.5^{\circ} \mathrm{C}$, with smaller areas in some facilities in which the temperature was maintained within $\pm 0.1^{\circ} \mathrm{C}$; state of the art measuring laboratories equipped with the best imported and domestic instrumentation; dozens of large vibration isolated foundations for precision manufacturing machinery and for assembly stations, etc. These units were given the highest funding priority and were constructed within 5-6 years.

An especially advanced "thermo-constant" building was constructed in ENIMS in 1967. Its ground floor had 2,880 sq. m. (32,000 sq. ft) maintained at $\pm 0.5^{\circ} \mathrm{C}$, and it was used for the assembly of precision machine tools produced by the Stankokonstruktsia Plant, an experimental facility at ENIMS which also commercially produced machine tools. The $900 \mathrm{sq}$. m. (10,000 sq. ft.) basement was maintained at $\pm 0.1^{\circ} \mathrm{C}$; it also contained several cabins in which the temperature was maintained at $\pm 0.05^{\circ} \mathrm{C}$ and humidity at $50 \pm 5 \%$ [9]. This facility was used by ENIMS, sometimes in cooperation with metrology institutes of the State Standards Committee, for the development and calibration of photoelectric and laser comparators, dividing machines, and reference scales. It was also used for other programs. For example, the Astronomy Institute of the USSR Academy of Sciences used the cabins to conduct experiments which allowed the 
determination of the gravity constant to within the five-decimal-point accuracy; geophysicists used it for tests related to continental drift. Precision components for three-crystal spectrometers and precision magnetometers for an isochronous cyclotron were also built here.

This facility was intended for the development of ultra-high accuracy measuring systems for the machine tool industry. Even before the precision temperature-controlled building was constructed, a highly accurate dividing machine for linear scales was developed. It used an automatic photoelectric microscope and a correction system. The machine had a line accuracy of $0.3 \mu \mathrm{m}$ and an accumulated pitch error not exceeding $1 \mu \mathrm{m}$ per $1,000 \mathrm{~mm}$. Calibration of a scale could be performed within $0.2 \mu \mathrm{m}$. After the temperature-controlled facilities were constructed, a precision laser interferometer accurate up to $0.02 \mu \mathrm{m}$ was designed and built. It is interesting to note that during the Soviet era only three precision linear scales were imported (from the SIP Company in Switzerland). Numerous regional and state metrology centers are equipped with high-accuracy reference scales of domestic origin. Thousands of precision linear scales were used in jig-borers and other precision production machines and measuring instruments [9].

A part of the program on construction of precision manufacturing facilities was to develop guidelines on vibration isolation of precision fabrication equipment. Special advanced vibration isolating foundations and their critical components were developed and widely used in the precision manufacturing facilities. In 1962-64, there were also developed advanced vibration isolating mounts, along with guidelines for their application for various groups of machine tools, especially precision tools, and for other production equipment [6], [8]. The high technical effectiveness and ease of use of these mounts led to their rapid acceptance in industry. During the 1970's and 80's 700,000 units per year were produced. Some 150-170,000 units of machinery were installed per year. The most eager users of this installation technique were military industrial plants, which claimed a noticeable improvement in machining accuracy. Later, original self-levelling pneumatic mounts have been developed for ultra-high precision machinery installation.

During the development of the vibration isolating mounts for precision machine tools, it was clear that the Western approach, in which a supplier selects different mount sizes for different mounting points and provides technical consulting services, was absolutely out of the question. This realization, together with thorough research into the principles of vibration isolation, led to the development of a self-adaptive passive vibration isolator which did not require determining the loads on each point, and which combined optimal stiffness and damping characteristics. As a result, one size of isolator can be used for a variety of types and sizes of precision and general-purpose machine tools, with performance which is clearly superior to the leading Western models [8].

Simultaneously with the construction of precision fabrication facilities at the machine tool plants, precision fabrication facilities were also erected at the leading military-related manufacturing plants producing critical units for advanced military equipment. I participated in consulting on and designing of 
vibration isolation systems for the Kirov Mechanical Plant in Leningrad in 1962. Several ultra-precision gear hobbing and gear finishing machines for producing submarine gear reducers were purchased in Germany. I remember the delivery of a Schiess gear hobbing machine capable of producing $5 \mathrm{~m}$ diameter gears with a pitch accuracy within one arc second.

Large quantities of state-of-the-art imported equipment and parts were purchased, mostly through third countries, and frequently through fourth countries, to avoid export restrictions. Some American vibration isolators for my research, which was sponsored at a high level of government, were purchased via France and then Austria. However, very heavy emphasis was given to the development of domestic equipment.

For many years, a very significant effort was underway in ENIMS to develop high-precision and high-productivity machine tools for cylindrical and bevel (especially spiral bevel and hypoid) gears. High precision gears are needed in the automotive industry, and especially in the aircraft and missile industries. The Gear Manufacturing Department of ENIMS employed numbers of highly educated and talented researchers and designers who developed novel kinematic solutions for many gear-manufacturing machine tools. Especially worth mentioning are universal gear grinder mod. 5872 for grinding spiral bevel gears up to $800 \mathrm{~mm}$ in diameter using a generating method, and mod. MA5A87B for high precision grinding of spiral bevel gears up to $125 \mathrm{~mm}$ diameter from a solid blank. High-precision automated gear hobbing machines, mods. 5408A and $5310 \mathrm{~A}$, were developed and implemented in commercial production by the Vilnius (Lithuania) branch of ENIMS. This branch also developed a cost-effective technology for manufacturing ultra-high precision curvic couplings using vibratory processes [10], [11].

As early as the 1960's, ENIMS developed and started commercial production of the so-called "master machine" for hobbing ultra-high accuracy worm gears for workpiece drives of high precision gear hobbing machines (mod. 543 , pitch accuracy 1.6 arc sec; axial runout of the hob spindle $3 \mu \mathrm{m}$; axial and radial runout of indexing worm $2 \mu \mathrm{m}$; maximum diameter $1,080 \mathrm{~mm}$ ). The machine was very simple in design, to improve accuracy; it was at the technical level of the best contemporary Western machines of this type.

This technology was continuously upgraded. Later, a similar "master machine" was designed and fabricated for indexing worm gears with both cyclic and accumulated pitch errors within 1 arc. sec. Similar technology was used to produce "master machines" for globoidal indexing worm gears used in diamond boring machines. These high-accuracy indexing worm gears allowed building diamond boring machines with positioning accuracies for the axes of the machined holes within 0.6-1.0 $\mu \mathrm{m}$. "Master Gear Grinder" mod. MA5878C was designed and built in the 1970's for high precision grinding of spiral bevel and hypoid gears with diameters up to $1,000 \mathrm{~mm}$. These machines were complemented by a precision measuring machine, Model 5726, for worm and hypoid indexing gears with a maximum diameter of $1,100 \mathrm{~mm}$.

A complete line of general purpose precision balancing machines for rotating parts of various weights (from $10 \mathrm{~g}$ to $100 \mathrm{t}$ ) has been developed in 
ENIMS in the 1960's - 70's. It was supplemented by many special balancing systems, such as one for balancing assembled IC engines. Two examples are commercially produced machines for balancing of rotors up to $1 \mathrm{~kg}$ with balancing accuracy $0.3 \mu \mathrm{m}$, and for automatic balancing of electric motors with balancing accuracy $1.0 \mu \mathrm{m}$.

The ENIMS branch in Erevan (Armenia) developed a novel concept for balancing high-speed gyroscopes at their working speed using exploding wires as generators of the balancing masses. The results satisfied specifications for precision gyroscopes. Working speed balancing was required, since the thinwalled shells of the gyroscope rotors changed their deformations depending on rotational speed. Two leaders of the balancing group emigrated to the U.S. in 1975.

In mid-80's the Soviet Union produced over $40 \%$ of the total world output of EDM and ECM equipment [9]. ENIMS has developed numerous pioneering concepts which resulted in dramatic advances of both productivity and accuracy of the so-called "energy ray" machining techniques. High precision/high productivity grinding was facilitated by development of electrochemical /abrasive (especially, diamond) grinding technology. Whirl copying and combination EDM/ECM technologies allowed to produce high accuracy molds and dies with high productivity. Ultrasonic and laser technologies were developed for precision dimensional processing of hard and brittle materials, such as glasses, ceramics, gem-quality stones, and semiconductor materials, such as silicon.

A very strong group of researchers in the area of precision fabrication was organized in Stankin [1]. It concentrated mostly on development and application of high performance hydrostatic and aerostatic lubrication systems, especially (but not only) for small and medium size machines of the highest precision. This group was headed by M. Shimahovich (now living in the U.S.), who calls the area in which he was working, and which is much broader than just machine tools, "contactless mechanics."

The first high precision lathe (16" maximum turning diameter) with a hydrostatic spindle was designed in 1962 for the Krasny Proletary plant in Moscow. Its fabrication was delayed since the plant was overwhelmed by the mass production of general purpose lathes of the same size, at a rate of 1,000 per month. Later, the plant was forced to increase this to 20,000 per year.

As a part of this program, the plant was pressured to make a highaccuracy modification of these lathes. However, in the true spirit of the machine tool industry world-wide, they preferred to avoid the untested but promising concept of hydrostatic bearings for the spindle, and spent time making all the critical parts of the production lathe (bearings, spindles, etc.) to higher accuracy, frequently at immense expense. The result was one lathe producing parts with out-of-roundness below $3 \mu \mathrm{m}$.

Two lathes with hydrostatic spindle bearings were finally fabricated in 1967. The machines were thoroughly tested at the plant, with outstanding results. A brass sleeve with $100 / 50 \mathrm{~mm}$ diameters was machined with deviations from roundness and flatness as well as runout within $0.2 \mu \mathrm{m}$, and surface finish $R_{a}=$ $0.16 \mu \mathrm{m}$. The lathes have also shown excellent results in diamond turning; diamond burnishing of hardened alloyed steel parts (RC 62) developed a surface finish $R_{7}=0.08-0.16 \mu \mathrm{m}$, and roundness, flatness, and relative runout of the 
It is interesting to note that this high accuracy coexisted with absolute dynamic stability. No chatter developed at any regimes, including regimes critical for this type of machine tool, such as $12 \mathrm{~mm}$ depth of cut and 0.01 $\mathrm{mm} / \mathrm{rev}$ feed at $70 \mathrm{~m} / \mathrm{min}$ cutting speed. Depth of cut was limited only by the strength of the cutting edge or the power of the motor. The high dynamic quality of the lathes allowed cutting thin, uniform steel bands from solid blanks. A chip $0.02 \mathrm{~mm}$ thick and $15 \mathrm{~mm}$ wide was nearly perfect. Another interesting note is that one of these machines did not live up to expectations when it was installed at the cutting tools lab of the Togliatti Automobile Plant (producing Lada cars). The lathe was used for testing cutting tools for production lines. However, these results were misleading, since all the tools performed three to four times better on this lathe than on any other machine tool in the plant. Notwithstanding this exceptionally good performance, the lathe was not put in production. There were several reasons for this. The lathe was not offered to a customer, but had to be approved by the State Commission appointed by the Ministry. One influential member of this commission was a lathe operator who was also a member of the Supreme Soviet. He asked, "Who needs a lathe with such accuracy?" Another reason was that the Krasny Proletary Plant management was afraid that if they promoted this machine, they would be forced by the State planners to produce huge quantities of them and to sell them at the same price as their regular, less complicated machines.

In 1967, the Department of Boring Machines of ENIMS, together with Stankin, made several diamond boring heads with hydrostatically supported spindles and special driving misalignment-compensating couplings which machined $40 \mathrm{~mm}$ diameter holes in brass with roundness within $0.04 \mu \mathrm{m}$. One of these heads was used at a military electronics R\&D center for diamond milling of the faces of large (about $180 \mathrm{~mm}$ diameter) polygons made of monocrystallic $\mathrm{NaCl}$ for ultrasonic signal delay lines for application in long range radars and color TV systems. These boring heads not only provided a high degree of surface finish, but also greatly reduced damage to the surface layer of the crystal. As a result, energy losses of reflected ultrasonic waves were reduced by an order of magnitude, thus allowing extending the delay time and enhancing the accuracy and range of radar systems, and the picture quality of color TV systems. The percentage of rejects was reduced from 80 percent to 40 percent, the latter number being due to defects in the crystals which were present before diamond milling.

A strong interest in ultra-precision machining by the nine ministries comprising the Soviet military-industrial complex became noticeable in the late 1960 's and early 1970's. Initially, it was directed toward memory discs; later, it was predominantly laser optics-related. In the early 1970's there were no commercially available precision lathes for magnetic memory discs, and Soviet computers designed with hard disc memory units were manufactured without hard disc memory, but with space for its future insertion. Meanwhile, the computers used tape memory units.

In the late 1960's the Stankin group designed and in 1972 Krasny Proletary started production of a diamond-turning lathe with a horizontal spindle. The 
first machine had hydrostatic spindle bearings and guideways, and machined hard magnetic memeory discs with a surface finish $R_{z}=50 \mathrm{~nm}$. The machine was completely redesigned in 1979 , becoming a vertical lathe with aerostatic spindle bearings, contactless pneumo-hydraulic guideways and feed drives, and inertial spindle drive. The spindle is accelerated by the driving motor during the workpiece changing process, but during machining the motor is disconnected and does not transmit any vibrations to the spindle. The driving unit for the cutting tool is designed as a piston separated from the cylinder by a hydrostatic sliding bearing. The lathe was designed for machining memory discs as well as flat and spherical components of laser optics; microasperities on the machined surface are characterized by $\mathrm{R}_{\mathrm{z}}=10 \mathrm{~nm}$, and macrogeometry (waviness) is within $20 \mathrm{~nm}$ for machining magnetic memory discs. Production lathes are available in five models (see Table 1 [12]). A modification of this lathe for turning flat and spherical components up to $500 \mathrm{~mm}$ diameter for laser optical systems produced surface finishes of $R_{z}=4-5 \mathrm{~nm}$. More than eighty machines were manufactured. This lathe was exhibited last September at IMTS-92 in Chicago, and attracted some interest because of its exceptional performance and low price $(\$ 60,000)$. Interest would be much greater if the machine had a more decent appearance. When this machine was exhibited in 1975 at the All-Union Industrial Fair, there was an error in the accompanying specifications list; this stated that the spindle was supported in electrostatic bearings. The machine excited a lot of interest from foreign visitors, especially the Japanese. M. Shimanovich remembers the Japanese group, fifteen strong, completely surrounding the lathe, looking for "electrostatic bearings." The error was corrected. A similar Japanese lathe (with hydrostatic bearings) was shown in Moscow in 1980.

Some modifications of this lathe were produced, e.g., for machining the internal optical surfaces of an X-ray laser. Designs were developed for larger, ultra-precision lathes for machining optical components. These include machines for huge (several meters in diameter) mirrors, not only flat and spherical, but also cylindrical with an elliptical cross section. Krasny Proletary designed an ultra-precision lathe with contactless mechanisms, such as lead screws. However, only the prototypes were fabricated; production could not begin due to the non-availability of suitable NC controllers.

In 1968, Kolomna Plant also started designing an ultra-precision turning machine for mirrors several meters in diameter.

An obvious question arises: Why were the machine tool plants undertaking such expensive projects, knowing that they could not even start production? The answer is very simple: These were special assignments formulated in decrees by the highest military-industrial/party authorities, who committed all necessary resources for these projects, which were needed for the huge Soviet "Star Wars" program.

One of the most important centers for developing military-related optics was the Lebedev Institute of Physics of the USSR Academy of Sciences. The head of this activity was one of the inventors of the laser, Nobel Prize laureate Academician A. Prokhorov. He had unlimited power, but he did not believe in machine-tool technology, and was firmly against diamond-turning lathes. In the 
Institute, he collected the best skilled precision instrument makers, and they manually polished metal optic components for lasers. However, comparison of the machined (turned) and manually polished optical components has shown that the former have 1.5 decimal orders of magnitude better endurance under intense laser radiation. As a result, Prokhorov visited Krasny Proletary and personally ordered the machines.

During the 1970's and 80's, Krasny Proletary Plant manufactured about 1,000 high accuracy general-purpose lathes with spindles in hydrostatic bearings and with digital display. The customers were nine military-industrial ministries, where the lathes were used for machining hard-to-machine and/or nongrindable materials, at both rough and finish regimes. The spindle journal diameter is $100 \mathrm{~mm}$, and cutting forces up to $7,000 \mathrm{~N}$ for the radial component and up to $18,000 \mathrm{~N}$ for the axial component are allowable.

In the early 1980's, there was a decision at the highest level to start domestic production of consumer video cassette recorders, using the facilities of the military radioelectronics industry. However, there was an acute shortage of high precision machine tools for producting the mechanical parts of VCRs, especially heads. The proposed solution was to retrofit the popular Swiss turning machines produced by the Schaublin Company by changing the existing spindle bearings for hydrostatic and gasostatic bearings. Unfortunately, the only plant with a large inventory of Schaublins was located in the town of Pripyat, just next to Chernobyl, and after the Chernobyl catastrophe the modernization program was scrapped.

In 1988-1989 Krasny Proletary Plant and Ryazan Machine Tool Plant manufactured high-speed, high-accuracy CNC lathes with hydrostaticallysupported spindles. The Krasny Proletary lathe has maximum machining diameter of $400 \mathrm{~mm}$, a spindle journal diameter of $110 \mathrm{~mm}$, and a maximum spindle speed of 4,000 rpm. The Ryazan lathe has a maximum diameter of 600 $\mathrm{mm}$, a spindle journal diameter of $160 \mathrm{~mm}$, and a maximum spindle speed of $3,800 \mathrm{rpm}$. Both machine tools keep the roundness of machined hardened steel parts (RC62) within less than $1 \mu \mathrm{m}$ [13]. The energy losses at high rpm in these machines are claimed to be no higher than for similar machines whose spindles are supported on antifriction bearings, due to the specifics of the hydrostatic bearing designs.

In 1988, Ryazan Plant manufactured a special high-precision lathe incorporating contactless mechanics for cutting thin precision teflon strips with a wide cutter from a solid teflon bar $600 \mathrm{~mm}$ diameter and $300 \mathrm{~mm}$ long. The strip, for use in miniature capacitors, is $300 \mathrm{~mm}$ wide and $5 \pm 0.1 \mu \mathrm{m}$ thick. Other approaches were tried, but failed to produce a tape within these parameters.

The Stankin group under M. Shimanovich was also involved in the development of high-accuracy grinding machines. In 1969, an effort began in the Moscow Transfer Lines Plant (MTLP) to design grinders with hydrostatics in both the spindle bearings and guideways. Production of centerless grinders with wide grinding wheels $(600 \mathrm{~mm}$ in diameter, $500 \mathrm{~mm}$ wide) and with both grinding and supporting wheels in hydrostatic bearings started in 1970. The use of hydrostatic bearings led to dramatic increases in allowable regimes and power 
utilization, in wheels life, and in reduction of rejects. Hundreds of piston pins and bearing races were ground per hour with out-of-roundness within $0.1 \mu \mathrm{m}$ and taper within $0.5 \mu \mathrm{m}$. Only one grinder, instead of two or three, was required for the finishing stations in the transfer lines. The machines showed an amazingly low sensitivity to the environment. About one hundred such grinders have been manufactured. Dne modification, which resulted in a noticeable improvement in maintenance procedures, had a spindle for the wide grinding wheel made as a sleeve rotating on hydrostatic bearings around a stationary axle.

Special cylindrical and internal grinders with hydrostatic spindle bearings and guideways were developed for bearing races. These grinders combined high accuracy with high cutting speed $(125 \mathrm{~m} / \mathrm{s}$ for OD grinding, $80 \mathrm{~m} / \mathrm{s}$ for ID grinding) and high power (drive motors up to $100 \mathrm{~kW}$ ). About three hundred such grinders were manufactured and installed at a new ball bearing plant (GPZ16) in Kazakhstan, where they were operated by hard-core convicts who frequently sabotaged the machines. However, the grinders proved to be extremely reliable and maintained high accuracy and productivity.

Grinding machines with hydrostatic spindle bearings were also used at the completely automated production line for \#209 ball bearings at the leading Soviet ball bearing factory, GPZ-1 in Moscow. The internal grinder for grinding the outer race has a high-speed/high-power motor-spindle $(30 \mathrm{~kW}, 30,000 \mathrm{rpm}$ ) with hydrostatic bearings. Tests have shown that bearings whose races were machined by the grinders with hydrostatic spindles have dramatically longer useful lives. These grinders were designed by the Moscow Design Bureau for Transfer Lines and Special Machines, and built by MTLP. The Stankin group (M. Shimanovich) developed the spindle bearing designs.

In addition to the $30 \mathrm{~kW}, 30,000 \mathrm{rpm}$ motor spindle, there were developed other high speed motor-spindles with gydrostatic bearings with the maximum sliding speed $70 \mathrm{~m} / \mathrm{s}\left(\mathrm{dn}=1.4 \times 10^{6}\right)$. The prototype units had been built also for $15 \mathrm{~kW} / 60,000 \mathrm{rpm} ; 3 \mathrm{~kW} / 90,000 \mathrm{rpm}$; and $1.5 \mathrm{~kW} / 120,000 \mathrm{rpm}$. Special design features (especially thrust bearing design) assured relatively low losses, $15-20 \%$ of total power at the nominal speed (with the exception of the $1.5 / 120$ spindle which had $0.5 \mathrm{~kW}$ losses). These units were intended for internal grinding, but instead have been successfully tested for high speed/high power/high accuracy milling on turning machines. Enhancement of accuracy was due to reduction of cutting forces (in comparison with turning) up to three decimal orders of magnitude and, consequently, reduction of deformations. This concept was also successfully tested for precision contour turning (on the example of an automotive piston). Tool movements for generation of the profile are much easier to accomplish since the workpiece is rotating with a much lower $\mathrm{rpm}$ than for turning ( $150 \mathrm{rpm}$ vs $1,500 \mathrm{rpm}$ for the piston machining). Another test was performed for finish machining of the tapered holes in hardened spindles at the Krasny Proletary plant; both productivity and accuracy were significantly better than for grinding when the spindle was supported in the hydrostatic work rest.

In the 1970's the Kama Truck Plant started full production of heavy trucks, especially for the army. The plant uses numerous American-made machines. A 
problem developed with machining cylinder liners for the diesel engines which were produced on the American production line. Ground external and face surfaces of the liners were out of specifications most of the time. The Stankin group, together with MTLP, developed a high-precision grinder for OD and face grinding of the liners. The liner being machined was supported by gasostatic bearings and driven by an original drive which did not create undesirable loads on the liner. The grinding spindle and table were supported by hydrostatic bearings/guideways. These bearings and the workpiece drive resulted in the accuracy of the OD being an order of magnitude better than ID. Initially, these machines were installed at the Kama plant, where they completely eliminated rejects and also dramatically increased productivity to 1,400 liners a day, since the power used for the grinding process could be increased from 4 to $26 \mathrm{~kW}$.

Seventy such machines were manufactured for Soviet diesel engine plants, including all tank plants. One such grinder is now being evaluated at a Litton Corporation plant.

About 2,000 cylindrical and internal grinders with hydrostatic bearings designed by $\mathrm{M}$. Shimanovich were manufactured. They were mainly utilized for machining the components of internal combustion engines and antifriction bearings. A large number of big surface grinders of such makes as Matrix and Waldrich Coburg were retrofitted by incorporating hydrostatic bearings for the wheel spindle, while the widely-used Churchill universal grinders were retrofitted by incorporating hydrostatic bearings in the workpiece spindle. Both the accuracy and productivity of these machines were significantly improved.

The Stankin group consulted Moscow Grinding Machines Plant (MGMP) in developing vertical hydrostatic guideways for the rams of gear-grinding machines. More than 2,000 such machines have been produced. Out of this number, about 1,000 gear grinders used modified guideways: a flat $+V$ combination with so-called "mutually-reciprocal choking," which were developed in the early 1980's. Such guideways were exhibited as a novelty by one American company at IMTS-92.

MGMP also made five heavy gear grinders with hydrostatics for gears up to $1.2 \mathrm{~m}$ diameter, specifically for helicopter transmissions.

Non-contact hydrostatic fixtures (bearings) were developed for supporting shafts and workpieces with interrupted surfaces during precision machining. Examples include hydrostatic steady-rests for grinding the principal surfaces of spindles for mass-produced lathes at Krasny Proletary plant, and combined hydrostatic/gasostatic supports for tailstock sleeves with a key slot. The latter is used for grinding the Morse taper hole in the sleeve.

Typical results were observed after hydrodynamic spindle bearings were replaced by hydrostatic bearings in a grinder for diamond rollers for trueing the worm-shaped abrasive wheels of Reishauer-like gear grinders. After retrofitting, the accuracy of the rollers and the productivity of the trueing process have improved. The life of the corundum wheels used for grinding and periods between dressings have increased. Also increased are such parameters as the life of the rollers, the trueing rate of the worm wheels, the accuracy of the ground 
gears, and the life of the worm wheels. All these improvements were very significant, in many cases by two or three times.

The Stankin group developed some other advanced concepts of contactless mechanics which were tested in prototypes in application to machine tools. These concepts include boring spindles with automatic tool retraction from the machined surface turing the back stroke, both with rotating and nonrotating spindle; lathes and grinders with oscillating spindles, e.g. for chip breaking; machine tools with asially movable spindle to provide for the feed motion (thus eliminating feed drives and guideways). Use of hydrostatic spindle bearings as guideways for microdisplacements allows to compensate geometric errors as well as thermal and force-induced deformations; they demonstrated resolution of about $10 \mathrm{~nm}$.

\section{Other Efforts Related to Precision Fabrication}

Not only the machine tool community was involved in developing Soviet precision fabricating technology.

As reported in [14], the East German concern of Carl Zeiss of Jena, together with unspecified Russian collaborators, developed in the mid-1970's, years ahead of U.S. companies, an advanced electron beam lithographic system, ZRM12, which could print circuit linewidths as narrow as $0.5 \mu \mathrm{m}$. Within the next few years, steady progress in this equipment was monitored. Models ZBA-10 and $Z B A-20$ were able to print lines as fine as $0.1 \mu \mathrm{m}$ and edgewidths on the order of $0.05 \mu \mathrm{m}$ while handling up to eight 3-inch wafers per hour. Thus equipment capable of fabricating the most advanced microcircuits at the time, such as $256 \mathrm{k}$ RAM, was domestically produced, and used a Soviet-built processor to provide the high data rate necessary for the required throughput. This very sophisticated equipment was shipped to a number of Comecon countries, including the Soviet Union, and some units were sold to Japan, one of the world leaders in this technology. There is no reason to believe that the technology did not progress further. Many other breakthroughs in precision fabrication in the micro-electronics area have been described in the open journal Soviet Microelectronics, and it can only be guessed what else was available in the numerous classified institutes. Another Nobel Prize laureate for lasers, N. Basov, is reported in [14] as leading the Soviet effort in developing very high density optical processors and data storage systems, which obviously require extremely high precision.

A large research center, "Vibrotekhnika," in Kaunas (now Lithuania), headed by K. Ragulskis, concentrated on developing precision mechanical systems and their units [15]. A large area of activity is precision vibromotors based in novel conceptual approaches. Vibro-motors with positioning accuracy within $1.0 \mathrm{~nm}$ (and prototypes with positioning accuracy within fractions of one angstrom), and with positioning speeds from $1 \mu \mathrm{m} / \mathrm{min}$ to $200 \mathrm{~mm} / \mathrm{s}$, were claimed to have been developed. Some other specific developments: a wave transformer for continuous or discrete reversible rotation with $\omega_{\max }=8 \mathrm{rad} / \mathrm{s}$, $\mathrm{T}_{\text {nom }}=0.015 \mathrm{Nm}$, positioning accuracy 1.0 arc. sec., dimensions $40 \times 35 \mathrm{~mm}$, weight $0.1 \mathrm{~kg}$; a vibratory screw mechanism with minimal axial step $2 \mathrm{~nm}$, force 
$80 \mathrm{~N}$, dimensions $150 \times 120 \times 85 \mathrm{~mm}$; a precision vertical vibrodrive with a range of $0.5 \mathrm{~mm}$, minimal step $10 \mathrm{~nm}$, maximum transported mass $5 \mathrm{~kg}$, dimensions 60 $\times 52 \times 24 \mathrm{~mm}$; a linear vibromotor with minimal step $20 \mathrm{~nm}$, force $20 \mathrm{~N}$, max velocity $40 \mathrm{~mm} / \mathrm{s}$; a thin-film deformable surface (60 $\mathrm{mm}$ diameter) employing local displacement at 60 points by electrostatic forces, with a range of deformation of $\pm 3 \mu \mathrm{m}$, positioning accuracy $10 \mathrm{~nm}$, and response time $1.0 \mu \mathrm{s}$; a precision linear measuring device of a novel ultrasonic type, with a measurement limit of $250 \mathrm{~mm}$ and $10 \mathrm{~nm}$ resolution, intra-step nonlinearity 0.2 percent, and measurement rate $100 \mathrm{~mm} / \mathrm{s}$; and a two-coordinate inclinometer with a resolution of 0.01 arc sec.

Although funding was provided by the military, one gets the impression that the Center (affiliated with Kaunas Polytechnic Institute) was not very eager to move beyond developing working prototypes.

Both reversible and unidirectional precision piezoelectric vibromotors were also developed by the cooperative establishment "Kvant," in Kiev, Ukraine.

Diamond tools, with both discrete cutting edges and abrasive cutting tools, are critically important for precision fabrication. This was clearly understood at the very early stages of industrial development in the former Soviet Union. Concerted efforts were launched to develop domestic sources for industrial-grade diamonds. These efforts resulted in the discovery of very rich resources of natural diamonds, and in the development of a large industry for the production of synthetic diamonds and other superhard materials. Several research institutes are dedicated to R\&D in new superhard materials, and their applications to tooling. These include the Institute of Superhard Materials in Kiev, the Institute of Technical Physics in Minsk, and the Institutes for Diamond Tooling and for Abrasives and Grinding in Moscow. Very advanced results in diamond grinding and the design of diamond grinding wheels are described, for example, in [21].

A significant effort was made to develop advanced technologies for fabrication of optical parts, since even before the advent of lasers and "Star Wars" the optical industry represented a large and important component of the military infrastructure. Besides the high precision diamond cutting machine tools described above, original and very effective technologies were developed for fine grinding and polishing of optical parts. One of these technologies is magneto-abrasive machining [21], which allows removal of $0.02-0.5 \mathrm{~mm}$ from a metal part in 10-120 sec, while achieving a surface finish of $R_{a}=10-80 \mathrm{~nm}$ and the required geometric shape. This technology was further advanced in the Institute of Heat and Mass Transfer in Minsk by the application of a magnetorheological fluid, recently developed there, with improved characteristics for programmed (CNC) machining of optical (including aspherical lenses) or other critical parts to nanometer tolerances and angstrom surface finish (Table 2, [22]). This technology is being developed in the U.S. under license by Byelocorp Scientific Inc. (New York). Other technologies, such as anodo-mechanical grinding, etc., are described in [23]. 
Another technology (developed in a mitary industry-related institute) is briefly described in [26] for machining optical surfaces on silicon and silicon carbide by polishing to surface finish within $5 \mathrm{~nm}$.

There was also developed a technology for making precision optical parabolic mirrors which doesnot require precision machinery and thus is the ultimate in cutting the red tape. This technology [27], patented in the former Soviet Union, is using rotating reservoires with fluid whose surface become parabolic due to interaction of forces of gravity and centrifugal forces. Special arrangements provide insensitivity to vibrations and variations of rotational speed and it is claimed that liquid mirrors have accuracy at least on par with the best glass mirrors.

Significant efforts were applied to developing near-net-shape manufacturing techniques, especially precision casting and forming technologies. While precision casting processes were developed mostly in military industry manufacturing technology institutes, precision forming techniques for gears, complex shape shafts, balls, etc., were successfully developed in VNIIMETMASH (Moscow). Precision forming of splines on shafts was performed in ENIMS. A promising "squeeze casting" technology was originally developed in the Soviet Union and was under development for both military and civilian industry applications.

A concentrated effort was also extended towards development of automated assembly technologies, especially for small precision mechanical devices. As early as 1950's - 1960's, transfer eines for machining and assembly of various size watches (including wrist watches) were developed and successfully implemented (NIIChasProm, Moscow). This work resulted in solving many generic problems related to automated production of precision mechanical systems. One has to remember, that watch-producing plants (as well as photographic equipment plants) were, essentially, military plants which were kept "warm" by assigning to them manufacturing of consumer products in times where demand for the military products was not very high.

\section{Metrology and Precision Measuring Instruments}

A very significant activity was undertaken in metrology and precision measuring instruments for manufacturing. The common image of the Soviet manufacturing industry as backward in measuring technology is definitely not correct. To begin with, the most common dial indicators used in the Soviet plants (the cheapest, mass-produced, and very affordable) have $0.01 \mathrm{~mm}$ divisions, compared to $0.025 \mathrm{~mm}(0.001 \mathrm{in})$ in the U.S. Thus, all measurements involving dial indicators are noticeably more accurate. The Soviet dial indicators use a combination link-gear mechanism whose theory was developed in the Soviet Union, instead of gear mechanisms in the U.S.-made indicators. Dial indicators with such mechanisms are much cheaper to produce; they have special compensation components built in, which provide for easy adjustments at the assembly stage. 
Gage blocks of all grades of accuracy are domestically produced. There is a very well established infrastructure of regional metrology centers which is a part of the State Committee of Standards and Quality. All measuring instruments must be periodically certified at these centers. Technical guidance for the regional centers is provided by several Research Institutes on metrology, the largest located in St. Petersburg and Moscow.

Very popular in the Soviet metal fabricating industries are high precision mechanical measuring instruments such as microcators and opticators with 0.02 $1.0 \mu \mathrm{m}$ divisions. Ya. Tseitlin, former head of the linear measurement laboratory in the St. Petersburg Mendeleev Institute of Metrology (VNIIMS) and now a U.S. resident, estimates that inventory of these instruments is about one million. In the last few years, annual production was about 10,000. The microcator uses a twisted metal strip as a sensitive element; it is a reasonably rugged device. The addition of a simple transducer makes it an electronic transducer with a resolution of $0.03 \mu \mathrm{m}$ which can be used in automatic systems (Ya. Tseitlin). Production of such instruments never began, despite very successful prototype testing. Microcators and opticators are not manufactured in the U.S.; the only other manufacturer in the world is Johansson in Sweden. In U.S. shops, measuring instruments with resolutions less than 0.00005 in $(1.25 \mu \mathrm{m})$ are a rarity.

One explanation for the wider use of precision mechanical measuring instruments in the former Soviet Union is the generally poorer quality of the available precision production equipment. Accordingly, tight tolerances are produced manually by extremely skilled toolmakers, with an ensuing need for precision measurements.

High-accuracy measuring instruments are manufactured in large quantities at such huge and well equipped plants as Kalibr (Moscow), Izmeron (St. Petersburg), the Chelyabinsk Plant for Tools and Measuring Instruments, etc. However, the incorporation of electronics and digital systems has progressed very slowly, due to a need for cooperation with other ministries.

Advanced sensors and measuring systems for active control of machining processes, for tool condition monitoring, are developed in several "open" places, not mentioning classified institutes. One of the leaders is Kiev Polytechnic Institute (V. Ostafiev) where some advanced optical (and fiber-optic) systems with resolution of fractions of one $\mu \mathrm{m}$ were developed (e.g., [16]).

Due to lack of commercially produced sensors, many novel and effective sensor concepts have been developed and, usually, disclosed in open publications and certificates of invention. One example is a torsional sensor described in [18] and later perfected at Ford Research laboratories to measure torsional velocity variations less than $0.01 \%$ [19].

With the advent of "nanotechnology", role of ultra-precision measurements became even more important. Since only imported precision electronic and opto-electronic instruments were available, the emphasis was on manually operated precision optical metrology instruments, such as interferometers, which are available with the highest degrees of precision, together with highly skilled technicians. 


\section{Other East European Countries}

Except for the former East Germany, there was not a substantial activity in other East European countries related to ultra-precision fabrication, although Chechoslovakia was producing machine tools of high accuracy. This can be explained by absence of the pressure from the "Military-Industrial Complex" in these countries. East Germany was an exception since its traditional optical and measuring instrument industries were closely cooperating with the Soviet computer electronics and militarized optical industries. On the other hand, Poland was cooperating with heavy military equipment industries (tanks, artillery) and Czechoslovakia-with heavy and light (machine guns, assault weapons) military equipment industries. A high-precision turning laboratory was only recently established in Hungary [20].

Poland, Czechoslovakia, and Bulgaria were producing small quantities of precision mechanical measuring instruments. Poland also has established a synthetic diamond industry producing about $1 \mathrm{mln}$ carats a year [25].

\section{Conclusions}

1. The former Soviet Union had numerous developments in the area of precision fabrication technology which, mostly, had only a limited implementation, first of all in the defense industry. A wider implementation was hampered by the bureaucratic system of industry management.

2. These developments even now may be of a significant interest for the U.S. industry. Besides the examples of such developments which were accomplished in the open institutes and industrial plants, there are definitely much more developments which were accomplished in numerous formerly classified institutes, design bureaus, and plants of the military industries.

3. Many leading engineerings and researchers who played key roles in the precision fabrication area are now residing in the U.S. or in Israel and their expertise is frequently under-utilized.

4. Facilities, infrastructure, and expertise, related to precision fabrication technology in the former Soviet Union might be utilized to the benefit of the U.S. machine tool and other companies if a proper cooperation were organized.

5. The continuing publication "Abstract Journal on Manufacturing Engineering and Technology" contains immence world-wide information on latest developments in Manufacturing Engineering, including precision fabrication issues, which is far more comprehensive than any other available data bases.

\section{Acknowledgment}

This paper would not be possible without cooperation of many former Soviet engineers now residing in the U.S. Especially helpful was Dr. M. Shimanovich who prepared a memoir reflecting his work in the area of "contactless mechanics" resulted in 5,000+ precision machines with hydrostatic and gasostatic bearings and guideways successfully working all over the former 
Soviet Union. Other people whose input has been used are Mr. A. Tabenkin, Dr. Ya. Tseitlin, Dr. I. Churin, and Dr. W. Begell.

\section{References}

1. Rivin, E.I., "Soviet R\&D: The Benefits for U.S. Industry," Mechanical Engineering, April 1983, Vol. 105, No. 4, pp. 62-71.

2. Reshetov, D.N., Portman, V., "Accuracy of Machine Tools," ASME Press, 1988.

3. Rivin, E.I., "Engineering Education-European Style," The Journal of Applied Manufacturing Systems, Spring 1990, pp. 15-19.

4. Levina, Z. M., Reshetov, D.N., "Contact Stiffness of Machines," Moscow, Mashinostroenie Publish House, 1972 [in Russian].

5. Reshetov, D.N., Kaminshaya, V.V., Levina, Z.M., "Beds and Frame Parts of Machine Tools," Moscow, Mashgiz Publishing House, 1960 [in Russian].

6. Reshetov, D.N., ed., "Components and Mechanisms of Machine Tools," vol. 1-664 pp, vol. 2-520 pp, Moscow, Mashinostroenie, 1972 [in Russian].

7. Sokolov, Yu. N., "Temperature-Induced Deformations of Machine Tools," in Automatizatsiya privoda i upravleniua mashin, Moscow, Nauka Publishing House, 1967 [in Russian].

8. Rivin, E.I., "Principles and Criteria of Vibration Isolation of Production Machinery," Transactions ASME, J. of Mechanical Design, 1979, Vol. 101, No. 4, pp. 682-692.

9. "ENIMS is 50 Years Old," Moscow, 1983, $156 \mathrm{pp}$.

10. Rivin, E.I., "Trends in Tooling for CNC Machine Tools: ToolSpindle Interfaces," Manufacturing Review, 1991, Vol. 4, No. 4, pp. 264274.

11. Galinskas, A.V., Mikuckas, Yu.-R, "Experimental Study of Vibratory Method and Means for Obtaining High Accuracy of Gear Elements of Dividing Devices," Vibrotekhnika, 1988, 60(3), pp. 83-89 (in Russian).

12. "Krasny Proletary," The Catalogue of Production, $44 \mathrm{pp}$, 1990.

13. Shimanovich, M. "Hydrostatic Spindle Unit of a Large HighPrecision CNC Lathe," Stanki i instrument, 1990, No. 1, pp. 16-19 [in Russian].

14. Wohl, R., "Soviet Research and Development", Defense Science \& Electronics, September 1983, pp. 11-19.

15. Vibrotechnika-20, Kaunas, 1988, 40 pp.

16. Ostafiev, V.A., et al, "Monitoring of Limiting Conditions of Cutting Tools with Opto-Electronic Analysis", in Proceedings of "Stanki'91", Kiev, 1991, p. 50-51.

17. Inasaki, I., Private communication.

18. Rivin, E.I., "Measuring of Torsional Vibrations with Asynchronous Tachogenerators," in Antivibratsionnye Elementy Dlya 
Technologitcheskogo Oborudovaniya [Anti-Vibration Elements for Machinery], Proceedings of the VNIINMASH, Vol. XYIII, Moscow, 1974, pp. 144-152.

19. Milenkovic, V., Shmuter, S., "Axle in Process Diagnostic Tester: Development of Angular Sensors", Ford Motor Co., 1987.

20. Szabo, O., "Ultra-Precision Lathe", Gepgyartastechnologia, 1991, vol.31, No. 10, pp417-418.

21a. Yascheritsin, P.I., et al, "Diamond-Abrasive Processing and Strengthening of Parts in Magnetic Field", Nauka i tekhnika, Minsk, 1988, 272 pp [in Russian]

21b Skvorchevskii, N.Ya., et al, "Effectiveness of MagnetoAbrasive Machining", Navuka i tekhnika, Minsk, 1991, 215 pp [in Russian]

22. "Electro- and Magnetorheological Technologies", A.V.Lykov Institute of Heat and Mass Transfer, Minsk, 1992, 42 pp [in Russian]

23. Tsesnek, L.S., et al, "Metallic Mirrors", Mashinostroenie, Moscow, 1983, 231 pp [in Russian]

24. Sheinberg, S.A., ed., "Sliding Bearings with Gaseous Lubrication", Mashinostroenie, Moscow, 1979, 290 pp [in Russian]

25. Bakon, A., Bakon, M., "Poland - the Foreseeble Future", Industrial Diamond Review, 1991, vol.51, No.547, pp.299-300

26. "Russian Specialists at the Congress on Surface Processing", Air et cosmos, 1991, vol.29, No.1357, pp.32-33 [in French]

27. Vasiliev, V.P., "Second Birth of Hydrooptic", Khimiya i zhizn, 1980, No.7, pp. 34-36 


\title{
Table 1. Technical Specifications of Ultra-High Accuracy Lathes
}

\author{
Manufactured by Krasny Proletary Plant [12]
}

\begin{tabular}{|c|c|c|c|c|c|}
\hline Parameter & $\begin{array}{l}\text { MK- } \\
6501 \\
\end{array}$ & $\begin{array}{l}\text { MK- } \\
6502\end{array}$ & $\begin{array}{l}\text { Model } \\
\text { MK- } \\
6504 \\
\end{array}$ & $\begin{array}{l}\text { MK- } \\
6516 \\
\end{array}$ & $\begin{array}{l}\text { MK- } \\
6562\end{array}$ \\
\hline Max machined diameter, $\mathrm{mm}$ & 500 & 500 & $\begin{array}{c}130 \\
\text { optional } \\
45 ; 90 \\
200\end{array}$ & 500 & $90-380$ \\
\hline $\begin{array}{l}\text { Max thickness of workpiece, } \\
\mathrm{mm}\end{array}$ & 50 & 120 & 45 & 150 & - \\
\hline Max length of workpiece, mm & - & - & - & - & $270-670$ \\
\hline Spindle speed, rpm & $\begin{array}{l}300- \\
2,805\end{array}$ & $\begin{array}{l}300- \\
2,805\end{array}$ & $\begin{array}{l}600- \\
6,000\end{array}$ & $\begin{array}{l}300- \\
2,800\end{array}$ & $\begin{array}{l}300- \\
2,500\end{array}$ \\
\hline $\begin{array}{l}\text { Working feed, } \mathrm{mm} / \mathrm{min} \\
\text { Fast feed rate of transverse } \\
\text { support, in } / \mathrm{min}\end{array}$ & & 20 & $\overline{2}$ & 200 & \\
\hline $\begin{array}{l}\text { Installed power of main } \\
\text { motor, } \mathrm{kW} \\
\text { Dimensions, } \mathrm{mm}\end{array}$ & & & 4.8 & & \\
\hline Length & 2,120 & 2,120 & 850 & 2,500 & 2,730 \\
\hline Width & 1,470 & 1,170 & 850 & 1,860 & 1,520 \\
\hline Height & 1,950 & 1,950 & 1,310 & 2,440 & 1,360 \\
\hline Weight, $t$ & 4.68 & 7.75 & 1.5 & 7.9 & 4.5 \\
\hline
\end{tabular}

Table 2. Performance Results of Magnetorheological Polishing Unit [22]

\begin{tabular}{|c|c|c|c|}
\hline Naterial & $\begin{array}{l}\text { Initial } \\
\text { Surface } \\
\text { Finish } \\
\mathrm{R}_{\mathrm{a}}, \mu \mathrm{m}\end{array}$ & $\begin{array}{l}\text { Final } \\
\text { Surface } \\
\text { Finish } \\
\mathrm{R}_{\mathrm{a}}, \mu \mathrm{m}\end{array}$ & Productivity \\
\hline Zink Selenide & $2 \cdot 10^{-2}$ & $12.8 \cdot 10^{-4}$ & $0.08-0.1$ \\
\hline Gallium Arsenide & $65 \cdot 10^{-2}$ & $10 \cdot 10^{-4}$ & 0.34 \\
\hline Sapphire & $1.5 \cdot 10^{-2}$ & $25 \cdot 10^{-4}$ & 0.02 \\
\hline Quartz & $30 \cdot 10^{-2}$ & $40 \cdot 10^{-4}$ & 0.15 \\
\hline Carbosital & $25 \cdot 10^{-2}$ & $150 \cdot 10^{-4}$ & 0.15 \\
\hline $\mathrm{Si}_{3} \mathrm{~N}_{4}$ Ceramics & $25 \cdot 10^{-2}$ & $35 \cdot 10^{-4}$ & 0.1 \\
\hline TF-10 Glass & $9 \cdot 10^{-2}$ & $12 \cdot 10^{-4}$ & 0.5 \\
\hline
\end{tabular}




\section{Appendix 1 \\ CONTENTS OF 'REFERATIVNYI ZHURNAL' (ABSTRACT JOURNAL) ON \\ MANUFACTURING ENGINEERING AND TECHNOLOGY}

Topic

General issues of machine tool industry

Metal cutting

Metal processing by cutting tools

Metal processing by abrasive tools

Metal-cutting machine tools

General topics related to machine tools

Design and research issues for machine tools

Control of machine tools

Multipurpose machine tools and machining centers

Flexible manufacturing systems and cells

Transfer lines

Multispindle heads and special machine tools

Turning machines

Drilling and boring machines

Broaching, shaping, and planing machines

Milling machines

Sawing and filing machines

Gear cutting machines

Grinding machines

EDM and ECM machines

Combination and miscellaneous machine tools

Components and units of machine tools

Auxilliary equipment and fixtures for machine tools

Metal-cutting tooling

52

General issues of machine-building technology

General topics of manufacturing

Metal-cutting technology

Production process planning

Design of production processes and fixtures

Special and universal fixtures

Machining quality

Effectiveness of production processes
No. of abstr.per mth

92

35

11

18

40

35

55

7

11

56

3

25

17

10

60

50

5

36

105

17

50

35

12

8 
Fabrication of non-metallic parts

General topics

Fabrication of plastic parts

Fabrication of parts from hard-to-machine materials

Fabrication of parts from miscellaneous materials

Technology and equipment for energy-ray processing

General issues

Laser, plasma, EB machining

ECM

Physico-chemical machining

Ultrasonic machining

Technology and equipment for thermal and strenthening processing

General issues

Heat treatment

Thermomechanical processing

Chemico-thermal treatment

Other thermal-strengthening techniques

Surface stengthening by plastic deformation (burnishing and shot blasting)

Powder metallurgy

Miscellaneous production processes (balancing, abrasive jet cutting, etc)

Production technology for machine components and units

Components for vehicles, tractors, construction machinery

Components for metal processing equipment

Components for heavy and energy-generating equipment

Components for instruments, electronic, and electrotechnical devices

General purpose mechanical components

Production technology for fixtures, tools, etc.

Miscellaneous components

Technology and equipment for assembly

General issues

Mechanical joining

Welding

Soldering

Adhesive joining

Process planing for assembly

Assembly systems for machines, instruments, and their units

Assembly automation

Hand-held machines

Technology and equipment for surface treatment and coating

General issues

Surface cleaning

Surface preparation

Metallic coatings

Painting and other non-metallic coating processes 
Temporary surface protection and part conservation

Patterning, engraving, etc.

$\begin{array}{ll}\text { Combination and miscellaneous coatings } & 7\end{array}$

Installation, maintenance, and repair of machine building equipment

20

General issues of metal forming production

55

Complex (combined) forming processes

10

Forging

10

Die stamping (forging)

$\begin{array}{ll}\text { Theory and research of die stamping processes } & 18\end{array}$

Technology of die stamping

43

Equipment for die stamping

25

Tooling and fixtures for die stamping

10

Rolling of threads, splines, and gear teeth

Sheet metal stamping

Theory and research

Technology of sheet metal stamping $\quad 22$

Equipment for sheet metal stamping $\quad 17$

$\begin{array}{ll}\text { Automation } & 25\end{array}$

$\begin{array}{lr}\text { Tooling and fixtures } & 34\end{array}$

$\begin{array}{ll}\text { Pulse forming techniques } & 7\end{array}$

Rotary forming 9

Bending and righting of sheets and profiles; spring coiling
Bending of sheets and profiles

Righting of sheets and profiles 9

Spring coiling 9

$\begin{array}{ll}\text { Cutting of blanks } & 14\end{array}$

Extrusion

Theory and research $\quad 5$

Extrusion technology 12

Equipment $\quad 4$

$\begin{array}{ll}\text { Heating } & 7\end{array}$

Comprehensive automation of metal-forming production $\quad 10$

General issues of casting production $\quad 33$

Theory of casting processes

$\begin{array}{ll}\text { Crystallization of metals and alloys } & 6\end{array}$ 
Casting alloys

Cast iron

Steels

Non-ferrous alloys

Special alloys

Castings

Casting design

Quality of castings and their cleaning

Melting and pouring of metal

Theory and research

Melting of cast iron

Melting of steel

Melting of non-ferrous alloys

Pouring and handling of metal

12

Quality control instruments

Molding materials

Basic materials

Molding and core blends

Regeneration of molding materials

Molding paints

Casting into sand molds

Gating systems

Patterns

Mold and core making

Molding and core making machinery

Mold filling

Casting cleaning

Special processes

Special casting processes

Lost wax process

Injection casting

Low pressure casting

Permanent mold casting

20

Centrifugal casting

Continuous casting

Miscellaneous processes

Note: Numbers of abstracts are given for 11-1990 issue; they vary significantly between issues. 


\title{
Precision Fabrication R\&D Workshop
}

\section{Precision Fariegín

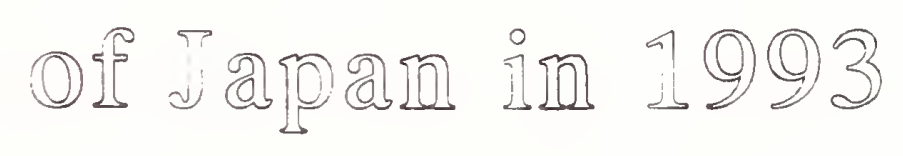

\section{Tomomasa SATO}

\author{
RCAST,University of Tokyo \\ ( Research Center for Advanced Science and Technologu)
}

This documant is a collection of the reports by each author shown in corresponding article. 


\section{Precision Fabrication of Japan in 1993}

\section{Projects}

Advanced Material-Processing and Machining Technology Micro Machine Technology

SAKAKI Quantum Wave Froje: :

Quantum Functional Devices Project

Ultimate Manipulation of Atoms and Molecules

26 Indivisual Research Activities

$<$ National Laboratory and Universities>

Mechanical Engineering Lab., AIST, MITI(3)

Sophia University(1)

Tohoku University(1)

University of Tokyo

Faculty of Engineering(3)

IIS(2)

$\operatorname{RCAST}(3)$

$<$ Companies $>$

Central Research Lab. Mitsubishi Electric Co.(1)

Fuji Electric Co. R\&D Ltd.(1)

Kawasaki Heavy Industries(1)

Matsushita Research Institute Tokyo, Inc.(1)

Mechanical Engineering Research La.,Hitachi(2)

MEITEC Co. R\&D(1)

Olympus Opt, Co.LTD.(2)

Toshiba Co.(3)

Manufacturing Engineering Reserch Center

Energy and Mechanical Eng.ineering Labs. R\&D Center Yokogawa Electric Co.(1) 


\section{Projects}

Advanced Material-Processing and Machining Technology Micro Machine Technology

SAKAKI Quantum Wave Prores

Quantum Functional Devices Project

Ultimate Manipulation of Atoms and Molecules 
Advanced Material-

Processing and Machining

Technology (AIST MITI)

FY1986-1993 \$125 Million/ 8 Years

Establishment of Excimer Laser, Ion Beam Technology and Ultra-Precision Machining Technologies, which realize precise and highly-functionated parts, necessary for a variety of advanced industries. 
Project Nawe: Advanced Material-Processing and Machining Technology --- Large-Scale $R$ \& D Programa

Adress: (Planning) Agency of Industrial Science and Technology(AIST),

MITI

1-3-1 Kasumigaseki, Chiyoda-ku, Tokyo, 100

Tel. +3-3501-9222. Fax. +3-3501-9229

(Execution) Advanced Material-Processing and Machining

Technology Research Association(AMMTRA)

Suaitomo Seimei Shin-0saka Bullding South fing $10 \mathrm{~F}$.

5-5-15 Nishi-Nakajima, Yodogawa-ku, Osaka, 532

Te1. +08-390-7021. Fax. +06-390-7061

Perlod \& Budget: Period ; FY 1986 - 1993

Budget ; 15 bllllion Yen / 8 Years

Organization:

Planning

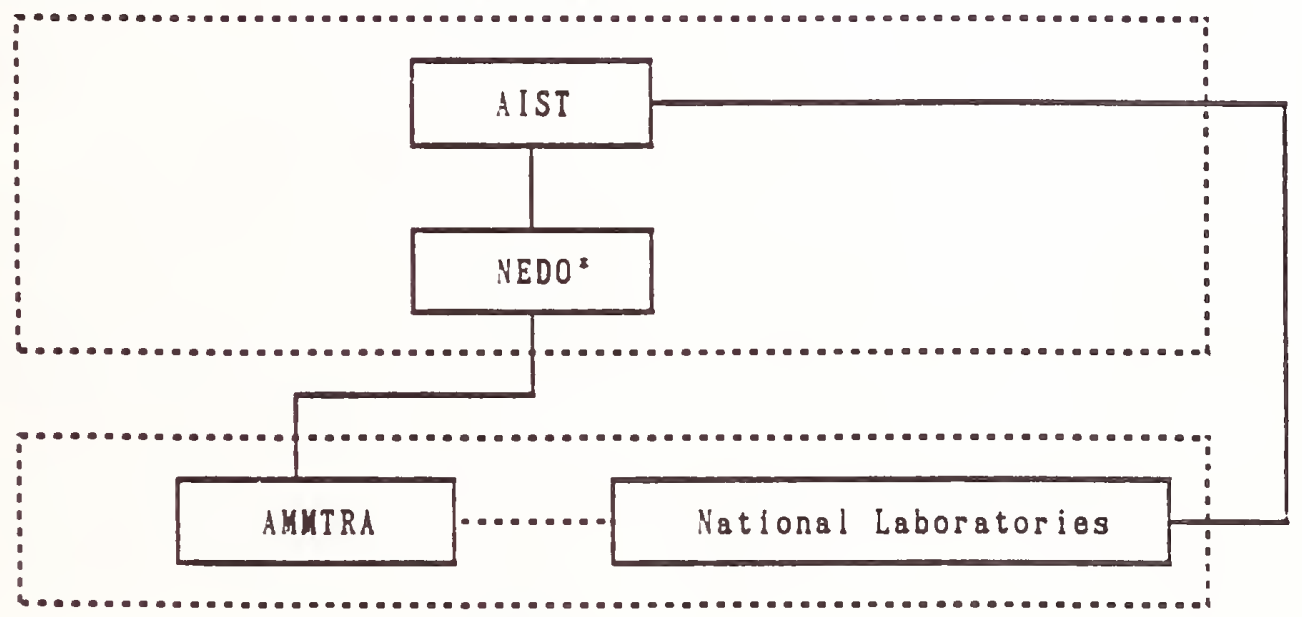

Execution

New Energy and Industria! Technology Developaent Organization

Research Overvien:

Establishment of Exciuer Laser and Ion Bean Technologies and Ultra-

Precision Machining Technologies, which realize precise and highly-

functionated parts, necessary for a variety of advanced industries.

Maln R \& D Subjects:

A) $R \& D$ on Machine and Instrument Technologies

1) Exciner Laser

2) Ion Bean

3) Ultra-Precision Machining, including Grinding and Superfinish

B) Adyanced Processing \& Machining Technologies

C) Supporting Technologles, including ultra-precision measurement

D) Total System Technology 
Background:

it can be said that 20 th Century is the era of Quantum Sclense and Technology; the typical development wight be seen in Electronics. Many industrial revolutions have been brought about. But, in order to achieve the real utflization of such sclentlllc and technological knorledge, it is Ineyltable to get ner fundamental processing means or tools to aeet IIth neods of 2lst Century. To realize such technologies, the program has been started in 1988, undertaken by AIST, MITI.

Research Issues in Details:

Rather detalfed research issues are shorn belor:

A) Adranced Machine and Equlpant Technologles;

1) Excimer Laser Equipment--High pomer,high reputation,high quality and short gavelength excluer laser equ.

2) Ion Bean Equlprent------tocuced, clustered, and Fide-range energy Ion beal and large-current, high energy ion bean eqs.

3) Ultra-Precision Machine--Cutting, Grinding and Pollshing Machines for Complex 3D Parts, with high-accuracy and high-efflclency

B) Advanced Material Processing and Machlning Technologles:

1) Super-preclse Form Generatlon--Hachlnnlg Cndltions etc.

2) ThIn-f1lu Coating----Excimer Laser/Ion Bean Processing Cond. etc.

3) Modlfication of Materlal Properties---Exclted Beam Process etc.

C) Supporting Technologles:

1) Uitra-precislon Measurment--Hechanlcal, Electrlcal, Optlcal, Chemlcal Propertles etc. of Products and Materlais

2) Evaluation Technologles----Eyaluation of deveploped Machines and Processing Technologies

(Mainly executed by National Research Laboratories)

D) Total System Technology:

1) Investigations-----------International \& Domestic Hove torards AMMT $R \& D$

2) Corroborative Eyidence----Design of Proving Tests in the Program

3) Systea Concept--------opfer of Total Systen Concept for the practical Advanced Materlal-Processing and Machining Technologies

The $R$ \& D schema is shown in Fig. 1, and Potential Applications for noxt generation in Fig. 2 .

International Cooporation:

1) Annually-held International Symposium by AMMUTRA

(Overseas Technology Exchange Programa)

2) General Accademic Presentaitions

3) Information Exchange betreen each sector 


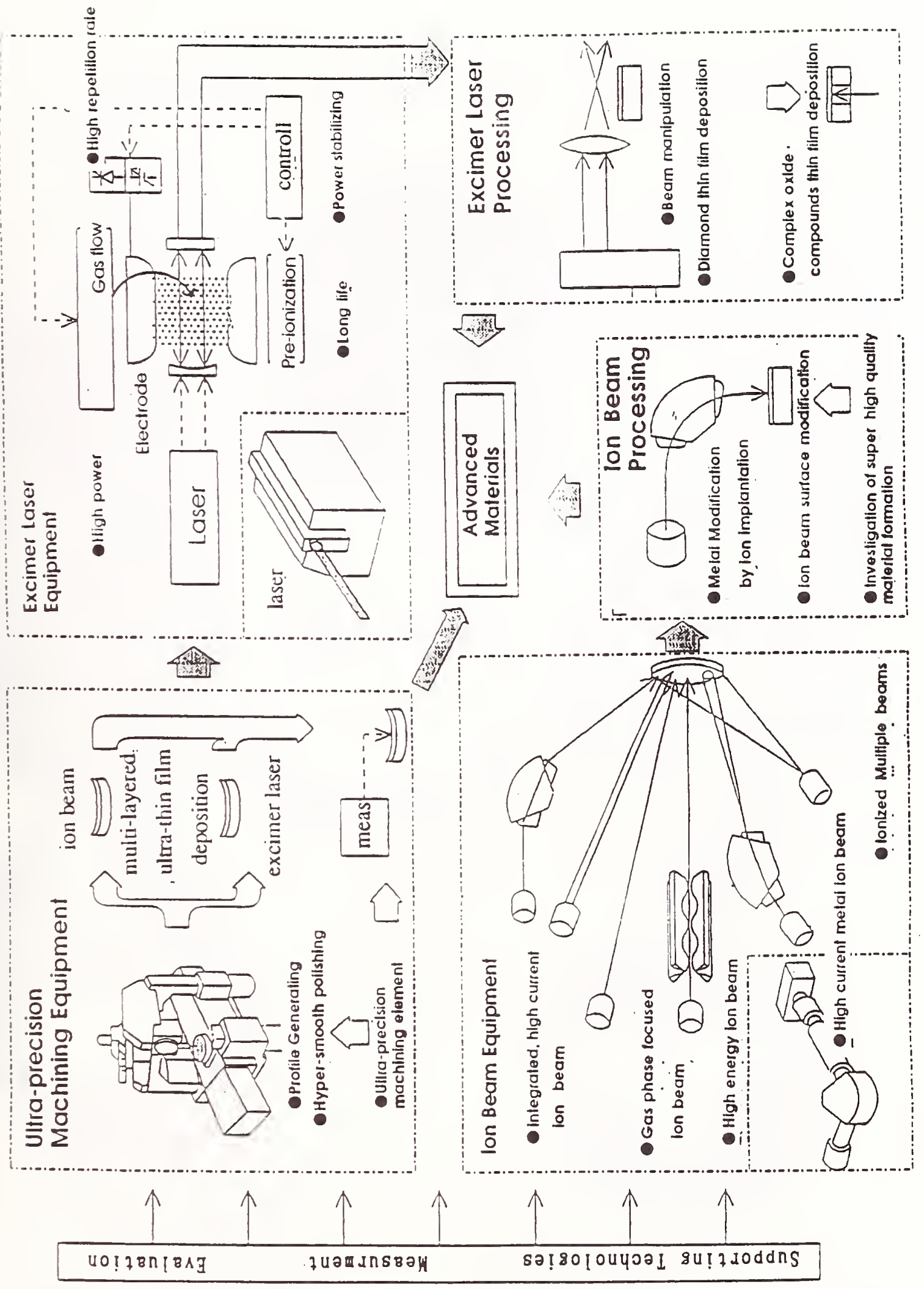




\section{APPLICATIONS FOR THE 21 st CENTURY}

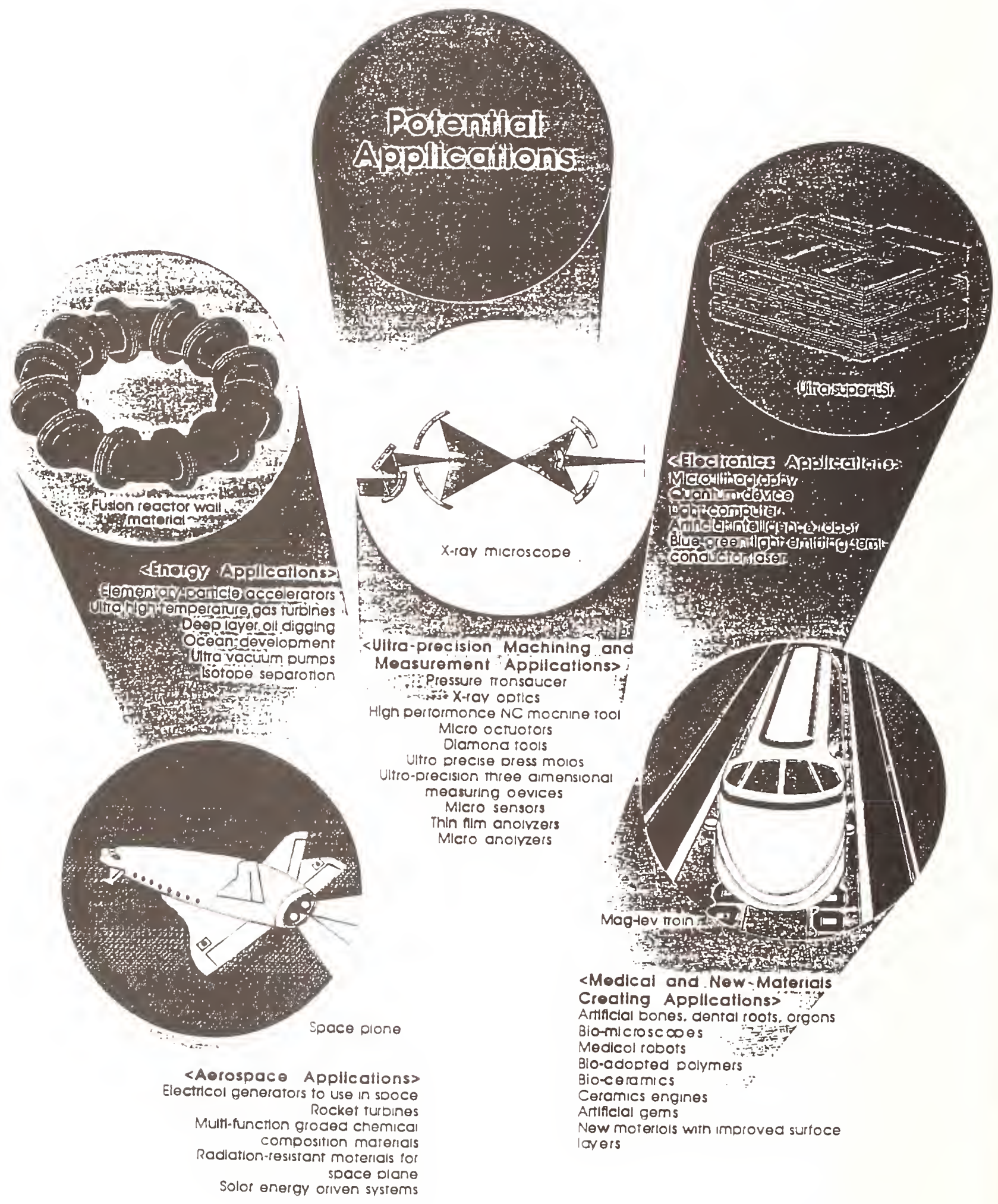


Research Schedule(Arrot Dlagram)

R\&D Diagram

\begin{tabular}{|c|c|c|c|c|c|c|c|c|}
\hline 0486 & (1) & 的 89 & $\because 90$ & & & & 93 & $\therefore$ \\
\hline \multirow{9}{*}{\multicolumn{2}{|c|}{ 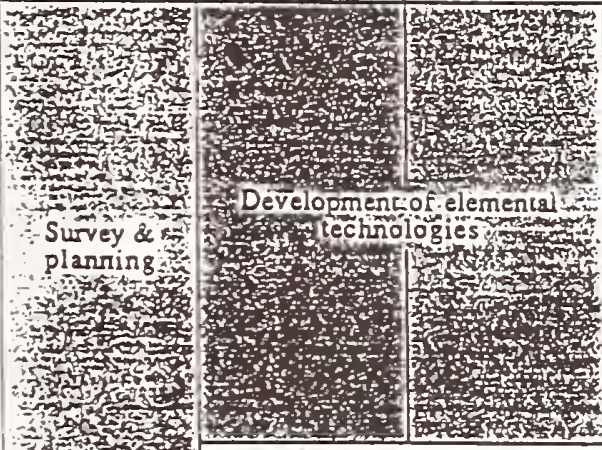 }} & & & \multirow{9}{*}{ 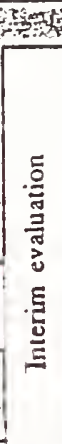 } & & \multicolumn{3}{|c|}{ 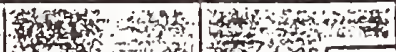 } \\
\hline & & 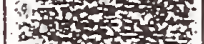 & 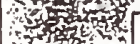 & & 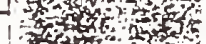 & S 34 & & \multirow{8}{*}{ 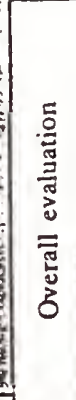 } \\
\hline & & \% & int & & ( & & & \\
\hline & & Experimental & production & & & & & \\
\hline & & 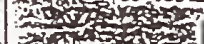 & & & $-45+-1$ & & & \\
\hline & & 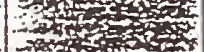 & (1) & & & & & \\
\hline & & $12 x+2$ & & & & & & \\
\hline & & \multicolumn{2}{|c|}{ Optimization iest } & & $\begin{array}{l}\text { Pro } \\
\text { Prod } \\
\text { \& }\end{array}$ & Not & & \\
\hline & & \multicolumn{2}{|c|}{ 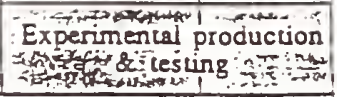 } & & Des & & & \\
\hline$=4 \pi+x-10$ & & & & & & & & \\
\hline
\end{tabular}

Research Resuls in FY 1991-1992

1) "Intermediate Report of Advanced Materlal-Processing and Machining Toohnology R \& D Prosraga". 1991-3. AMMTRA, (In Japanese)

2) "Proceeding of the 3rd Simposiua on the Advanced Materlal-Processing and Machining Technology Research Project", 1991-12, AMMTRA

3) "Reports of "92 AMHTRA Overseas Technology Exchange", 1992-6 


\section{Micro Machine Technology (AIST MITI)}

FY1991-2000 \$210 Million/ 10 Years

The target of the project is establishment of micro machine technology for micro machine systems which can move in confined spaces, such as inside a pipe in power plant or inside a living organism for autonomous carrying out inspection and repair or treatment. 
Project Name: Large-Scale Project "Hicro Machine Technology R\&D"

Adress: (Planning) Agency of industrial Science and Technoiogy(AIST). MITI

hasumigaseki 1-3-1, Chiyoda-ku, Tokyo 100, jAPAN

Tel. $+3-3501-9222$. $5 a x .+3-3501-9229$

(Execution) Micromachine Center

Sanko BIdg. 3E. Mita 3-12-16, Minato-ku. Tokyo 103, ZAPAN

Te1. +3-5443-2971, : ax. +3-5443-23?5

Period and Budget: Period 10 years

First phase: Fy1991-1995

Second phase: Fy1996-2000

Budget 25 billion yen/10 years

Fy1991: 30 million yen

Fyl992 800 million yen

Orsanization:

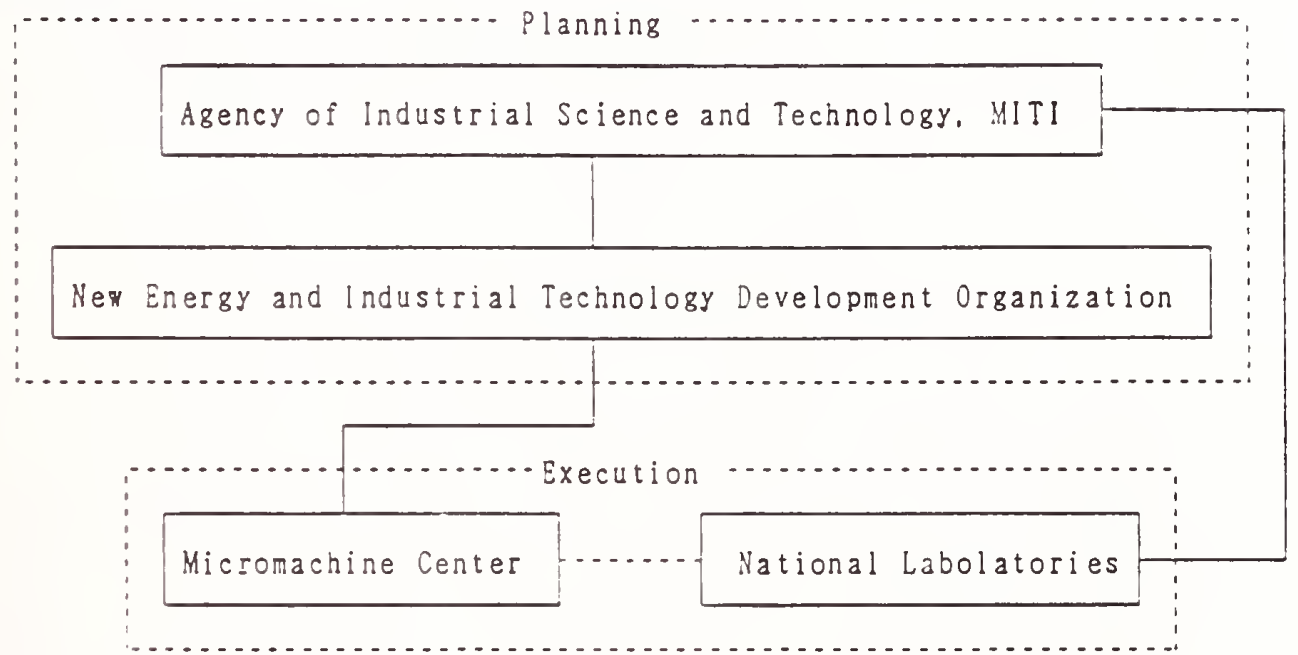

Research Overview:

The aig of the project is to establish micro machine technology for reallzing micro machine systems which can move in confined spaces, such as inside a pipe in porer plant or inside a living organism, for automonous carrying out inspection and repair or treatment.

Pesearch Main Subjects:

A] R\&D on Advanced Maintenance System for Power Plant

1) Micro-Capsule R\&D

2) Mother Ship R\&D

3) Inspection Module R\&D

4) Repair Module R\&D

5) Research into Complete Systen

3] R\&D on Intraluminal Diagnostic and Therapeutic System

1) Sensor device $R \& D$

2) laser device $R \& D$ 


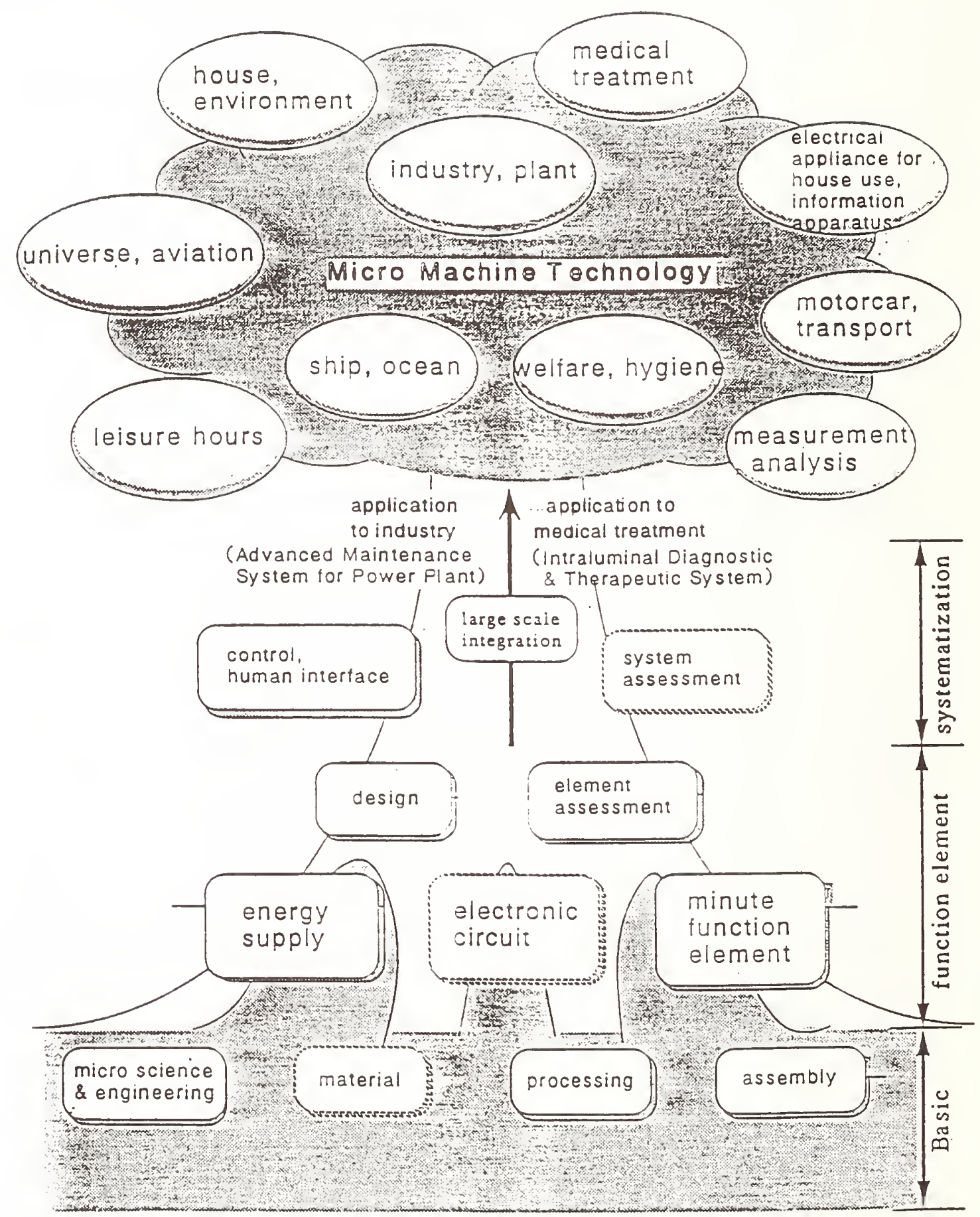

Fig. 1 Micro machine technology and its applications 


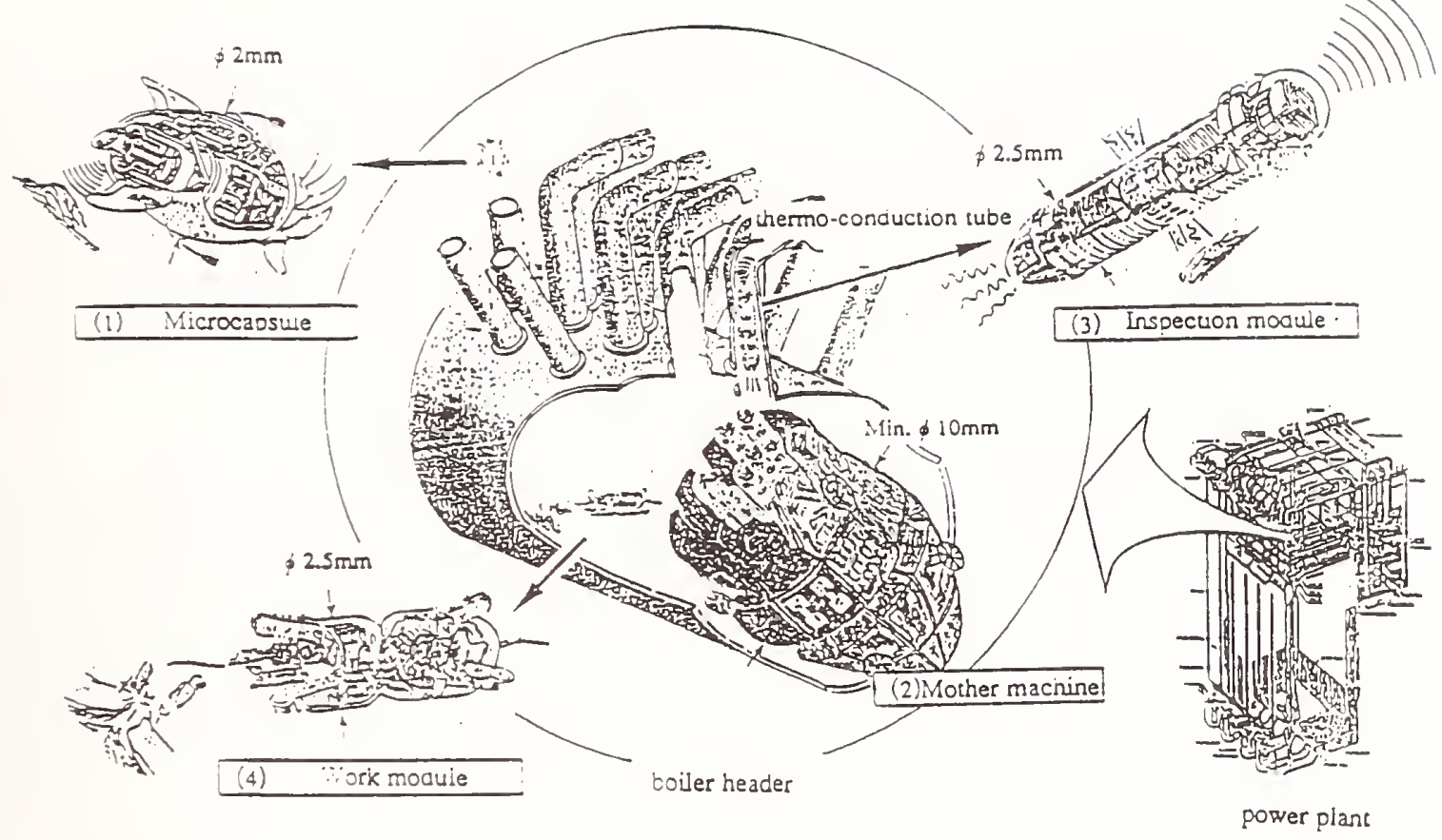

Fig. 2 Image of micro machine system (Advanced maintenance system for power plant). This system consists of the following micro-macrines.

(1) Micro-Capsule, (2) Mother Ship. (3) Inspection Module. (4) Repair Module

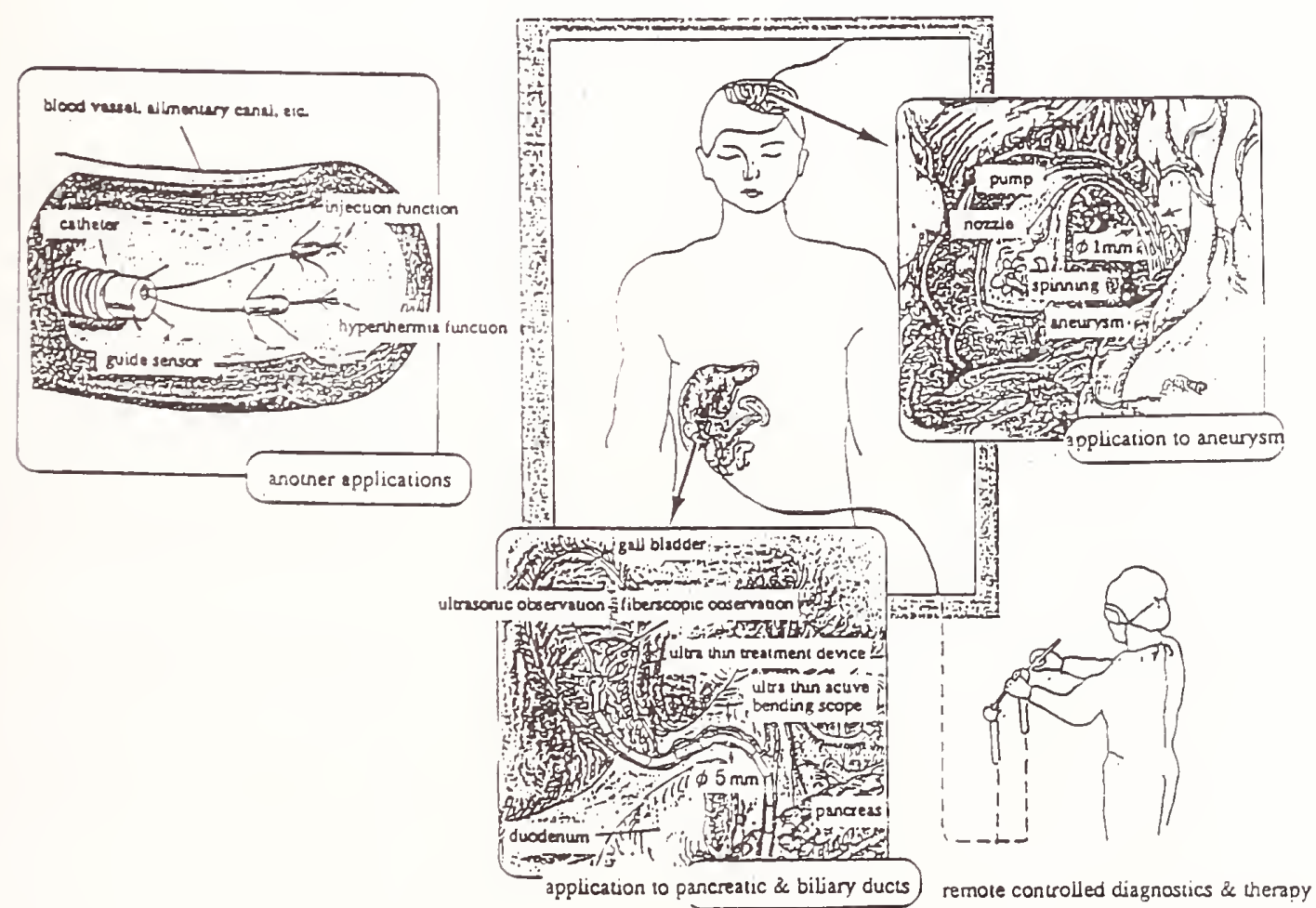

Fig. 3 Image of micro machine system (Intraluminal diagnostic \& therapeutic system). This system consists of the folloring micro-machines.

(1)Flexible active catheter, (2) Multi-functional diagnostic device, (3) Multi-functional treatment device 
Backgrouna:

Hicro machine systers composec of a number of sinall-sized functional elements are expected to produce far-reacning changes in various fields of technology. As micro machine technology is still in its infancy, the establishment of the technology 1 il involve heavy funding, high risk and a long period of time. In view of these circumstance, the Ministry of International Trade and Industry(MIII) emoarked on "Wicro Hachine Technology R\&D" as one of the Large-scaie Projects in Fylg9l.

Research Issues in details:

This project envisions an advanced maintenance system for power plant (Fig. 2) and an intraluminal diagnostic and therapeutic system system(Fig. 3). and developes verious kinds of functional modules(shown in Table 1) that compose these systems. The R\&D in the first phase of the project(Fy1991-1995) is aimed at establishing the basic technologies shown in Table 2. The R\&D plan during the second phase(Fy1996-2000) has not been determined in detail yet. but will focus on the advancement and systematization of the micro macnine technology through R\&D of devices. uodules and systems.

Table 1 Functional modules and its components

\begin{tabular}{|c|c|}
\hline Hodule & Main Couponents \\
\hline Micro-Capsule & $\begin{array}{l}\text { Dynamo. Steering mechanism. Flaw detection device. } \\
\text { Position detecting device. Signal oscillation device }\end{array}$ \\
\hline Hother Ship & $\begin{array}{l}\text { driving mechanism, Optical device, Clamping mechanism. } \\
\text { Battery, Group control. Behavior control }\end{array}$ \\
\hline Inspection Module & $\begin{array}{l}\text { inching worm ariving aechaniso. Yisuai sensing device, } \\
\text { Spectrum annalying device. Functional connection. Light } \\
\text { energy supply device. Coordination control }\end{array}$ \\
\hline Repair Module & $\begin{array}{l}\text { Tube type manipulator. Optical driving mechanisw, lligh } \\
\text { pomer source. Photo-cell \& boosting device. Environment } \\
\text { sensing device }\end{array}$ \\
\hline Others & $\begin{array}{l}\text { Tactile sensor. Multi-sensor device, Laser irradiation } \\
\text { device }\end{array}$ \\
\hline
\end{tabular}


Table 2 Basic technoiogies on micro macnine

\begin{tabular}{|l|l|}
\hline & \multicolumn{1}{|c|}{ Basic Technologies } \\
\hline $\begin{array}{l}\text { Functional } \\
\text { Micro-Elements }\end{array}$ & $\begin{array}{l}\text { (1)Actuators, Motion transier Mechanisms. Sensors } \\
\text { (2)Micro-Hachining \& Fabrication. Bonding }\end{array}$ \\
\hline Energy Supply & $\begin{array}{l}\text { (1)External Energy Suppiy } \\
\text { (2) Internal Energy Suppiy }\end{array}$ \\
\hline System Control & Information Processing, Communication. Cooperative Control. \\
\hline Evaluation & Measurement and Evaluation for Micro Elements and Dovices \\
\hline
\end{tabular}

\section{International Cooperation:}

:SSRI international(U.S.), IS Robotics inc. (U.S.) and Helbourne Institute of Technology(Australia) have been participating in the project since Fyl992.

2) Micromachine Center Executing the project has some cooperation plans which are the support of international conferences. exchange of reseachers between Japan and abroad, and others related to aicro machine technology R\&D.

Research Schedule(Arrow Diagram):

Schedule of Large-Scale Project "Micro Machine Technology R\&D" is shown in Fig. 4.

\begin{tabular}{|c|c|c|c|}
\hline & 1991 & $\begin{array}{l}\text { First Phase } \\
\text { 1992::393|1994/1995 }\end{array}$ & $\begin{array}{l}\text { Second Phase } \\
1996-2000\end{array}$ \\
\hline $\begin{array}{l}\text { Advanced Maintenance } \\
\text { System for power plant } \\
\text { (Micro-capsule. Mother } \\
\text { ship. Inspection module. } \\
\text { Repair module \& System) } \\
\text {.................................. } \\
\text { Intraluminal Diagnostic } \\
\text { \& Therapeutic System } \\
\text { (Sensor Devices, Laser } \\
\text { Device \& System) }\end{array}$ & $\begin{array}{l}\text { Survey } \\
\text { on } \\
\text { Technology }\end{array}$ & $\begin{array}{l}\quad R \& D \text { or } \\
\text { Basic Techrologies } \\
\text { \& Micro-Devices }\end{array}$ & $\begin{array}{l}\text { ( R\&D on } \\
\text { Devices. } \\
\text { Modules. } \\
\text { \& Systems) }\end{array}$ \\
\hline
\end{tabular}

Fig. \& Schedule of Hicro llachine Technology R\&D 
Research resuits in Fy 1991-1992:

1) Detailed survey on the present state of micro machine technology

2) Concept design of porer plant mantenance system and medical system

3)Feasibility study on the system concepts

4 ) Reseacn on basic technologies (functional eiements, fabrication methods, and others)

\section{References:}

"Survey on Hicro Nachine Iechnology" (in Japanese). Micromachine Center. 1992-3 Project Name: Large-Scale Project "Yicro Macrine Technology R\&D" 


\section{SAKAKI Quantum Wave Project (ERATO JRDC)}

FY1988-1993 \$17M/ $/ 5^{5}$ years

The project is studying quantum wave effects in advanced quantum microstructures of 50-200 $\AA$ such as quantum wires and boxes, highly heterogeneous layered structure containing organic materials, metals and/or insulators as well as conventional semiconductors. 

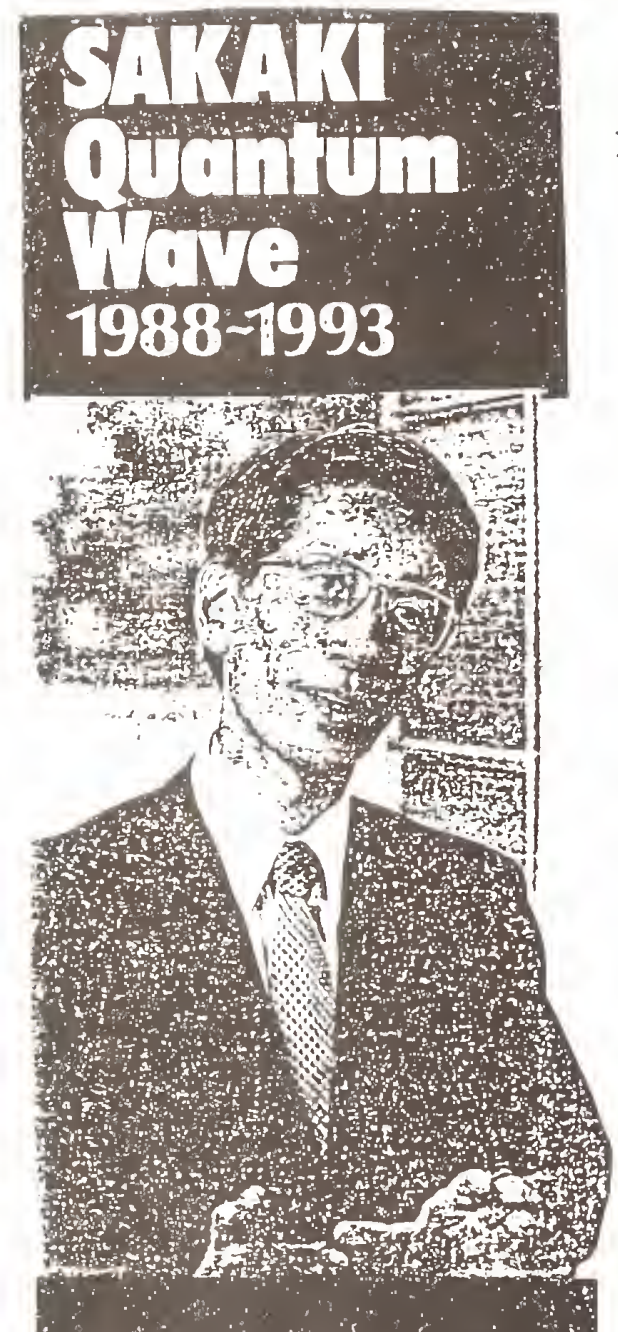

project Director:

Dr. Hiroyuki Sakkiki

broblession

Research oenter for Advariced

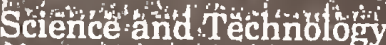

Unitiversity or tokjo!

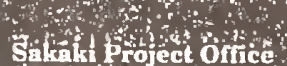

Kevalki tousc 300

324 Konmaba-chom

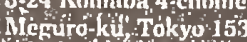

Plionc: 03-3485-9484.

Prax: 03-3.60-9026

\section{Background}

The evolution of the theory of quantum mechanics has made possible a deep understanding of the characteristics and behavior of electrons, atoms, molecules and crystal structures. Included in quantum mechanics is wave-particle dualism; this phenomenon' does not limit-applications hut, rather, fosters wide-ranging possibilities

Though electrons in a semiconductor are many times analyzed using quantum mechanics, their behavior in devices with dimensions greater than 1000 angstroms $(\AA)$ can be thought of as particles with threedimensional freedom, since the wavelengths involved are relatively smail. Most existing semiconductor devices have sizes greater than $1000 \dot{A}(=0.1 \mu \mathrm{m})$. The transistor can, thus, be described in terms of current control, just as water flow in a pipe.

By using nano-fabrication techniques, however, there is the possivilIty to make semiconductor structures with atomic-scale features. Electrons confined at this level lose their particle nature and behave like waves in the confinement direction: quantized with restricted energy levels, depending on their wavelengths, just as sound in an organ pipe is restricted by the pipe length.

Hiroyuki Sakaki has been a pioneer from the early 70's in pursuing low-dimensional solid-state devices that are based on the wave nature of electrons. The types of targets that he set more than ten years ago have become common targets for many materiais scientists.

\section{Research Strategy}

The Sakaks quantum wave project is studying quantum wave effects in advanced quantum microstructures of $50: 200 \AA$, which have hitherto been difficuit to produce. These inciude sucn novel 'structures. as quantum wires and boxes, highiy heterogeneous layered structures containing organic materials, metals and/or insulators as well as conventional semiconductors.

Applications are being sought which transcend the usual views of electronics and devices: a novel electronic filter in which electrons of particular wavelength are strongly reflected by periodic arrays of quantum wire and/or boxes. Electrons confined in a quantum wire structure should exhibit an extremely limited change in the propagation direction through scattering and obtain high mobilities. By using quantum-box arrays as a semiconductor laser material, with completely quantized electronic levels, this system should behave as an "artificial atom" with a large lasing efficiency. Such devices may open an entire new field in which the quantum wave nature of electrons could be fully controlled and exploited. 


\section{Research Progress}

Theoretical works have been made to predict, control, and explain novel transport and optical properties of electrons in quantum structures: they include a novel scheme to suppress phonon scattering in semiconductors, a noise analysis of quantum interferometers, a light modulator and a light source using quantum wires.

To allow the full exploitation of quantum effects, novel methods have been explored to fabricate quantum wire structures with feature sizes of about $100 \AA$.

One method is an etch-and-overgrowth approach to form the wire on the edge surface of quantum wells. Here, all processings are carried out in an ultrahigh vacuum (UHV) environment to maintain a clean: sample surface. A special multi-chamber system has thus been designed? in which molecular beam epitaxy (MBE) is carried out in one chamber: and electron beam induced etching in another. After growing an: AlGaAsiGaAs layered structure, it is selectively chlorine-gas etched to form V-grooves. This pattern is drawn by electron beam irradiation AIAs/GaAs multilayer facet structure grown which by molecular beam epilaxy on a reverse which enhances or suppre layer is then regrown over the " $\mathrm{V}$ " edge. An etching-regrowth quantum wires.

heterointerface has been proven for the first time to be sufficienily (a) clean to make quantum wires.

Another method takes advantage of the selective epitaxial growth of $\mathrm{GaAs}$ on a pre-patterned substrate, leading to the facet formation. Quantum wires can be fabricated on the surface of such facets.

Yet another method uses the gentle etching of partially-masked multiple GaAs/InGaP wells, the subsequent overgrowth of GaAs and InGaP on the revealed edges of wells by chloride atomic layer-epitaxy. The resultant T-shaped wire structure (a crossing of.. two, wells) is expected to confine both electrons and holes at the crossing point, since the cross region is energetically more favorable.

Fabricated quantum. wire structures are now being characterized,' especially by magnetotransport and optical spectroscopy: 'using far infrared light, which has started to reveal novel properties of confined electron systems.

Novel quantum structure containing organic conjugated $\pi$-electron materials, such as alkyl-oligothiophenes and oligoacenes, are expected to show interesting properties, owing to their quantum box-like nature. Well-ordered thin films of these materials have been prepared in a UHV chamber. Their optical and transport properties are being studied, including a relatively high hole mobility in a field effect transistor (FET) of sexithiophene systems.

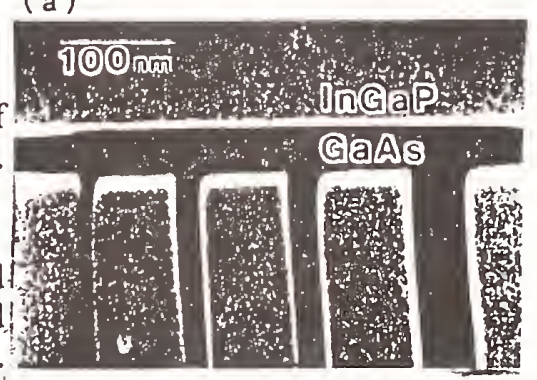

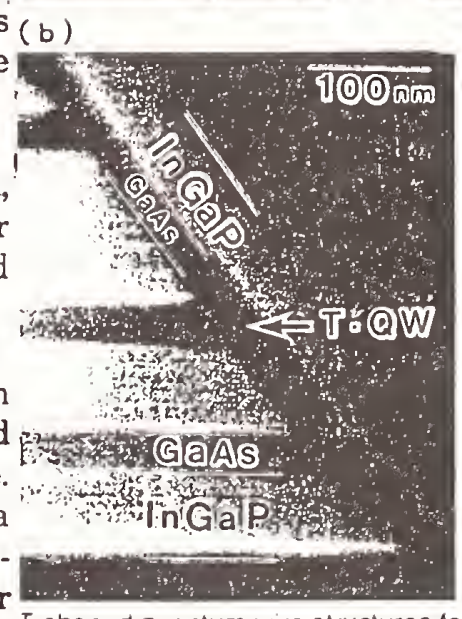

T-shaped quantum wire structures formed oy atomic layer epitaxy on (a) cleaved and (b) V-groove elched edges of GaAs/InGaP superlattice. 


\section{Quantum Functional Devices Project (AIST,MITI)}

FY1991-2000 \$40 Million/ 10 years

The purpose of the project is to establish basic technology for developing electronic devices by controlling quantum effects with ultra-high speed and multi-functions essential to industry in the next generation. 

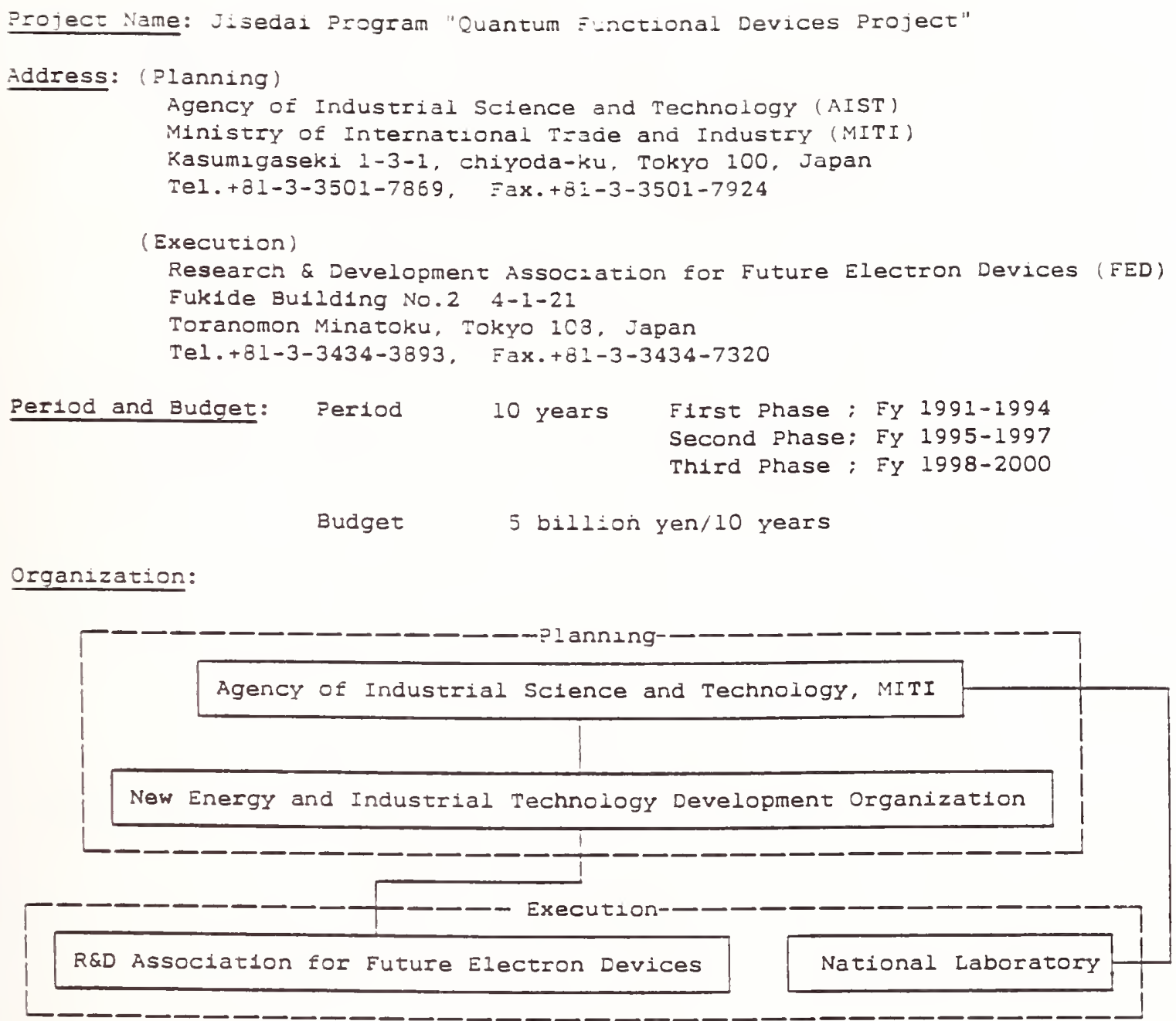

Research Overview:

The purpose of this project is to establish basic technology for developing electronic devices by controlling quantum effects with ultra-high speed and multi-functions essentlal to industry in the next generation.

\section{Research Main Subjects:}

A) RED on basic technologies for establishing quantum functions and R\&D on basic technologies for fabricating and evaluating quantum microstructures.

B) R\&D on device application technologies for quantum functions, R\&D on technologies for fabricating element devices based on quantum functions and R\&D on technologies for fabricating integrated systems.

1) Tunneling control functional device R\&D

2) Quantized-Band-coupiing mult1-functional device R\&D

3) Resonant electron-transfer functional device R\&D

4) Quantized energy level memory device R\&D

5) Coupled quantum dots device R\&D

6) Quantum-wave structure functional- device R\&D 


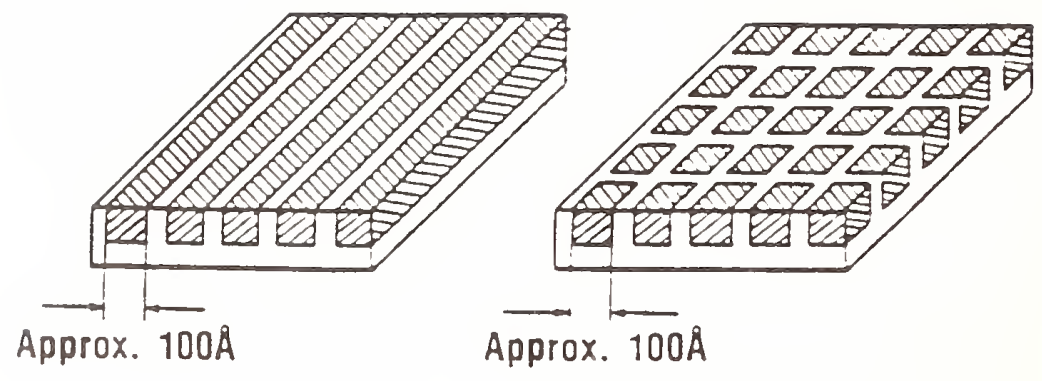

$\begin{array}{ll}\text { (A) Quantum wire } & \text { (B) Quantum box }\end{array}$

- When electrons are confined in a quantum wire or quantum box whose sectional dimension (about 100A) is similar to the electron wavelength, the quantum effects become conspicuous.

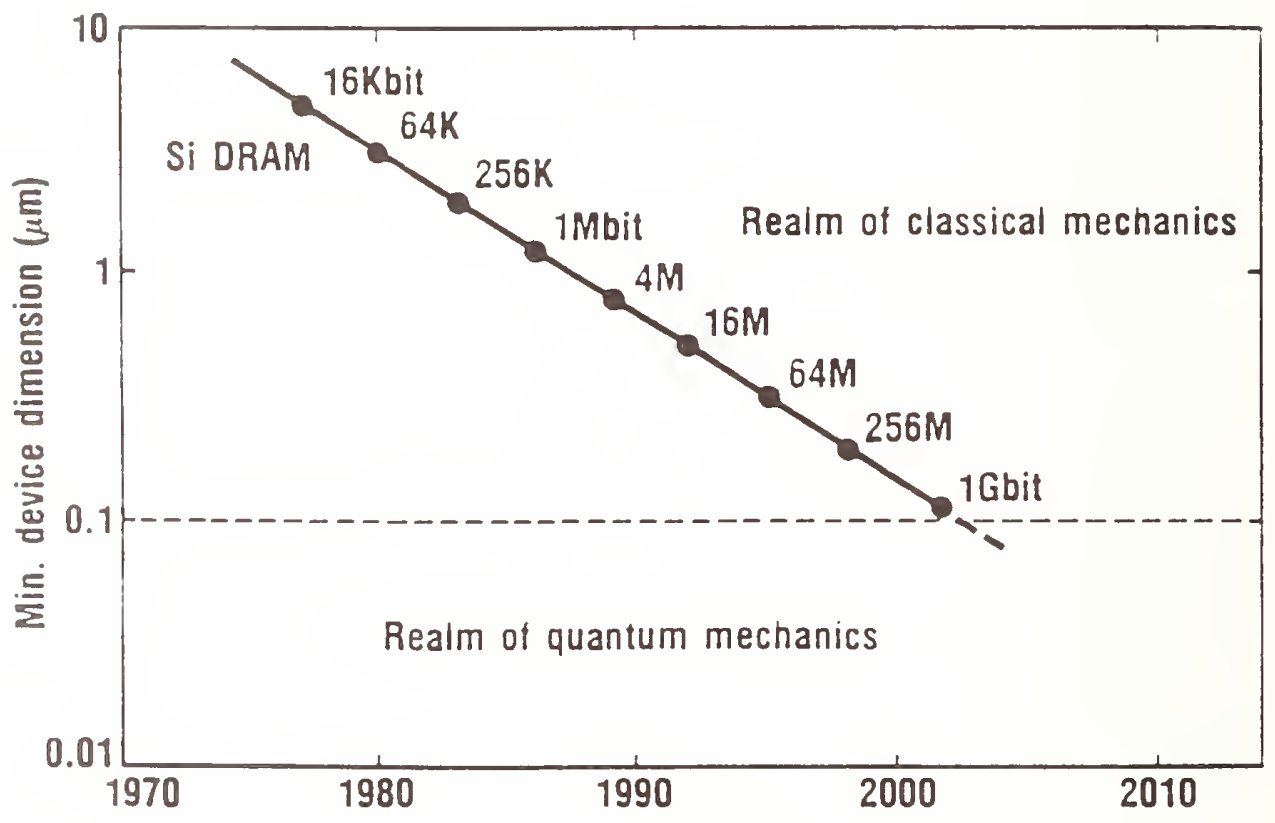

Fig. 1 Basic conceptual diageam of a three-dimensional quantum microstructure and Reducing sizes of devices in DRAM 
Quantized electron energy in zero-dimensional (quantum-dot) structure - Increased information capacity (Applicable to storage devices)

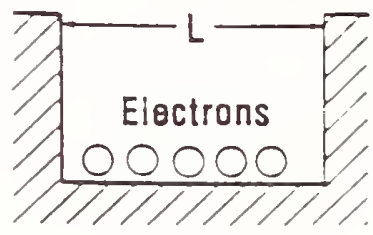

$$
\mathrm{En}-\mathrm{E}_{\mathrm{O}}
$$

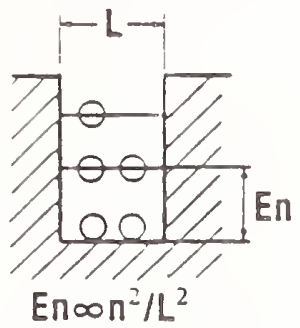

If " $L$ " is large, then all electrons are at the same energy level, but if " $L$ " is small enough, then the electrons separate into different energy levels as illustrated above.

Predominance of the wave motion of electrons, Increased coherence $\rightarrow$ Multiple functions, ultra-high speed, lower power consumption (Applicable to switching devices)

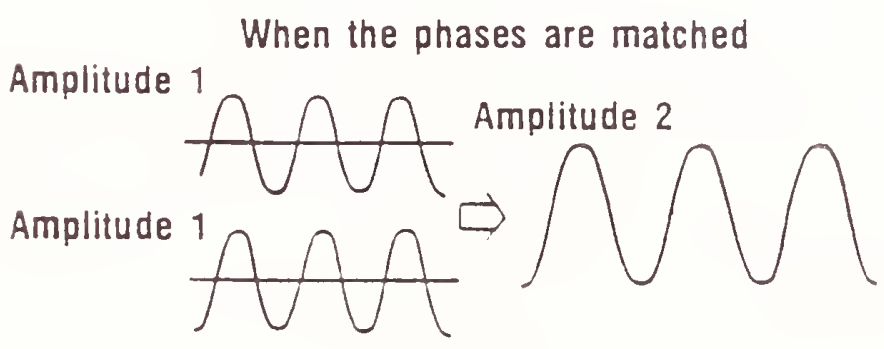

When the phases are shifted 180 degrees

Amplitude 1

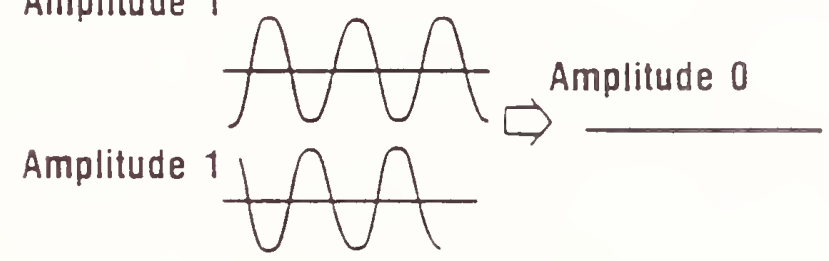

Electrons have two different characteristics; particle and wave motion. The characteristics of the wave motion appear in the ultrafine structure of a device. 
Backaround:

Stepping 1nto the mesoscopic realm in fabrication size the operational limit of conventional devices based on classical solid state electronics 1s going to be encountered due to the appearance of quantum phenomena.

Quantum functional devices which enaple us to overcome this limit and to utilize positively quantum effects appearing in ultrafine structures (less than 0.1 um) are urgently required to pursue.

In addition, the Quantum Functienal Devices Project owes its possible success to the two former Jisedai projects entitled "Superlattice Devices" and "Three Dimensional Integrated C1rcults" utilizing their fruitful results.

The Quantum Functional Devices Profect started in the 1991 fiscal.

Research Issues in details:

New Energy and Industrial Technology Development Organization (NEDO) has entrusted the promotion of this project with FED. FED has subcontracted with the six private companies (NEC. Motorola Inc.. Matsushita Electric Industrlal Co.. Ltd. Fuj1tsu Ltd., Sony Corp., and H1tach1, Ltd.) as research members. They proposed their own sub themes individually as shown in Table 1.

rable 1. Sub-thene devices and their features

\begin{tabular}{|c|c|}
\hline Device & Features \\
\hline $\begin{array}{l}\text { Tunneling-control } \\
\text { functional device }\end{array}$ & $\begin{array}{l}\text { - three-terminal tunnel device named surface tunnel } \\
\text { transistor (STT) } \\
\text { - interband tunnel current between a } 2 \text { dimensional } \\
\text { electron gas ( } 2 \text { DEG) and a p-region } 1 \text { s controlled } \\
\text { by a gate voltage }\end{array}$ \\
\hline $\begin{array}{l}\text { Quantized-band-coupling } \\
\text { multi-functional device }\end{array}$ & $\begin{array}{l}\text { - quantum multi-function transistor (OMT) } \\
\text { channels coupled by resonant tunneling effects } \\
\text { occurring between their quantum wells } \\
\text { the conductivity of the resonant quantum well is } \\
\text { modulated }\end{array}$ \\
\hline $\begin{array}{l}\text { Resonant electron- } \\
\text { transfer functional } \\
\text { device }\end{array}$ & $\begin{array}{l}\text { - device unit consists of a silicon quantum wire and } \\
\text { a silicon dot } \\
\text { - they are coupled each other through tunneling } \\
\text { barrier }\end{array}$ \\
\hline $\begin{array}{l}\text { Quantized energy } \\
\text { level memory device }\end{array}$ & $\begin{array}{l}\text { - quantized electron energy levels in quantum boxes } \\
\text { are utilized for memory states } \\
\text { - quantum boxes are formed at a intersection of two } \\
\text { orthogonal interconnections } \\
\text { - ultra-high density of a } \sim 10 \mathrm{Gbit} / \mathrm{cm}^{2} \text { is realized }\end{array}$ \\
\hline $\begin{array}{l}\text { Coupled quantum dots } \\
\text { device }\end{array}$ & $\begin{array}{l}\text { - quantum dots arranged in a array are utillzed for } \\
\text { coupled quantum dots system (CQDS) } \\
\text { - patterns of electron distribution in the cods } \\
\text { - strength of coupling between dots depends on the } \\
\text { distances between them }\end{array}$ \\
\hline $\begin{array}{l}\text { Quantum-wave structure } \\
\text { functional device }\end{array}$ & $\begin{array}{l}\text { - quantum wire waveguides are formed in parallel on } \\
\text { a substrate } \\
\text { phase modulation of quantum wave in quantum wire } \\
\text { is utilized }\end{array}$ \\
\hline
\end{tabular}


Enternational Cooderaticn:

1) Motorola Inc. (USA) has been partucipating in the project since Fyl991 as a sub-contracted member.

2) FED surveys forelgn activities of quantum functicnal devices research.

In 1992, Prof. ?.M.Petroff (University of California. Santa Barbara) and Prof.Dr. K. V. Klitzing (Max-Planck Institute) will =eport $\leq$ II USA and Europe respectively.

Research Schedule:

Schedule of Jisedal program "Quantum Functional Devices Project" is shown in Fig. 3 .

\begin{tabular}{|c|c|c|c|c|c|c|c|c|c|}
\hline 1991 & 1992 & 1993 & 1994 & 1995 & 1996 & 1997 & 1998 & 1999 & 2000 \\
\hline \multicolumn{4}{|c|}{ Phase I } & \multicolumn{3}{|c|}{ Phase $\square$} & \multicolumn{3}{|c|}{ Phase III } \\
\hline \multicolumn{10}{|c|}{ Fabrication and evaluation of quantua structures } \\
\hline \multicolumn{2}{|c|}{$B$ as ic te } & hnolo & y $1 \circ r$ & \multicolumn{3}{|c|}{ controling quantus } & \multicolumn{3}{|c|}{ function ity } \\
\hline \multicolumn{4}{|c|}{$\begin{array}{l}\text { Basic technology for } \\
\text { device fabrication }\end{array}$} & $\begin{array}{llll}E & \vee & a & 1 \\
p & r & 0 & t \\
e & 1 & e & \end{array}$ & $\begin{array}{l}\text { at ion } \\
t \text { y } p e \\
n t s\end{array}$ & $\begin{array}{l}\text { of } \\
\text { le vice }\end{array}$ & \multicolumn{3}{|c|}{$\begin{array}{l}\text { Evaluation of } \\
\text { adyanced deyice } \\
\text { eleaents }\end{array}$} \\
\hline \multicolumn{4}{|c|}{$\begin{array}{l}\text { Production of unit } \\
\text { device functions }\end{array}$} & $\begin{array}{l}\text { Prod } \\
\text { f } u \cap c \\
b \perp \circ c\end{array}$ & 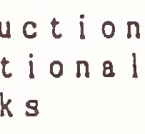 & of & \multicolumn{3}{|c|}{$\begin{array}{l}\text { Production of } \\
\text { integrated } \\
\text { systevs }\end{array}$} \\
\hline
\end{tabular}

Fig. 3. Schedule of Itsedat program "Quantum Functional Devices Profect" 
Research results in FY 1991-1992:

1) 2 dimensional analysis in Surface Tunnel Tzansistor

2) Surface Tunsel Tansistor: Gate - Controlled lateral Internal Interband Tunneling Device

3) Quantum Functional Device (with S1 material)

4) A New II/V-Gbit-SRAM Cell Using A Double-Emitter Resonant-Tunneling Hot Electron Transistor Structure

5) 2-electron energy level in a square quantum dot with limited barrier

6) Direct Measurement of Surface Recombination Life-times GaAs Quantum wires by Time Resolved

7) Electromagnetic field profile of excitonic polariton in quantum wire waveguide

Project Name:

Jisedal Program "Quantum Functional Devices Project" 


\section{Ultimate Manipulation of Atoms and Molecules (AIST MITI)}

FY1992-2001 \$21 Million/ 10 years

The purpose of this project is to develop techniques for probing and manipulating atoms and molecules on solid surface or in three-dimensional space with extreme precision, and their support techniques, as common fundamental technology for such fields as new materials, electronics and biotechnology. 
Atom - molecule Space Plan

- Project : Uitimate Manipulation of Atoms and Molecules -

\author{
K. Tanaka \\ Electrotechnical Laboratory \\ 1-1-4 Umezono, Tsukuba-shi, Ibaraki 305, Japan
}

The Ministry of International Trade and industry has decided to seek budgetary support for a new National $R \& D$ Project entitled "Ultimate Manipulation of Atoms and Molecules" with the aim of contributing to the international community through $R \& D$ in the field of basic science and technology.

The new project is to be carried out at a new AIST institute named "Interdisciplinary Research Institute for Industrial Science (IRIS)" which will be established on the 1 st of January, 1993, in Tsukuba, Japan.

\title{
Introduction
}

On account of recent development in probing and control technology with regard to microscopic objects, larger flexibility has come to be available in developing relevant technologies in such areas as new materials, biotechnology and electronics. New materials bring about new technology and vice versa.

A sort of resonance effect arising in this way has led to such recent developments, and as a result, the technologies in those areas are changing from submicron level to angstrom level in controllable dimensions.

In view of the trend of technological revolution, there is a strong desire for the observation and control technology of microscopic region to be further developed. But there is a serious limitation to the development in a extrapolation of existing technologies.

Therefore, with the objective of realizing a breakthrough over the limitation that is needed to ensure further advance of technological revolution, the project has been worked out that aims to develop, as a generic technology in various fields, new technologies and their support technologies that can allow single atom or molecule either on solid surface or in 3D space to be observed and manipulated with extreme precision.

It has been also decided, in order to attract the best scientists, that the project should run in a new AIST institute with a peer-review granting mechanism and competition by research quality. The new AIST institute is tentatively named as "Interdisciplinary Research Institute for Industrial Science (IRIS)" which will be founded on the 1st of January, 1993, in Tsukuba. An outline of this project is described below (see a cartoon in the figure), although details will be finalized towards the end of 1952 . 


\section{Description of R\&D}

(1)Technology for observing atomic and molecular structures of materials.

* Static atomic- and molecular-scale structure probing technology

To develop fundamental tools for probing and identifying (species and electronic states of) atoms and molecules either on solid surfaces, in vacuum or in solutions. The new technology aims to be applicable to a broad spectrum of materials and structures, while the existing technology is mainly applicable to electrically conductive materials.

*Dynamic atomic- and molecular-scale structure probing technology

To develop fundamental tools for high-speed, time-resolved in-situ observation of surface processes at atomic and molecular levels during growth, reaction and etching of the surface.

*DNA strucrure probing technology

To develop techniques that permit direct observation of DNAs at atomic levels, as a useful tool to unveil the puzzle involved in arrays of particular bases.

(2)Technology for controlling and forming structures at atomic and molecular levels.

*Technology for manipulating atoms and molecules on solid surfaces

To develop techniques that permit atomic layer's at prescribed regions on solid surfaces to pile up or to be peeled off, and particular atoms to be removed, transported or embedded on the surface.

*Technology for manipulating atoms and molecules in 3D space

To develop techniques that permit single ion, atom and molecule to be supplied in a controllable manner, held quiescent, moved, and set into collision and reaction in $3 \mathrm{D}$ space, and that furthermore allow softlanding of those atoms and molecules onto the surface of particular materials.

\section{(3)Basic support technology}

*Theoretical support

To develop simulation techniques for theoretically predicting possible surface processes through theoretical studies to elucidate the phenomena of surface and interface reactions and of atomic and molecular reactions, that are of fundamental importance for probing and controlling atoms and moleculles. 
*Ultra-high vacuum technology

To develop fundamental techniques for achieving a ultra-high vacuum that is essentially necessary for probing and manipulating atoms and molecules on solid surfaces or in 3D space, as well as to develop precision ultrahigh vacuum gauges.

*Femto-second high-power laser technology

To develop a tunable femto-second high-power laser for probing, manipulation and chemical modification of molecules.

\section{Scale of R\&D}

Funding is expected to amount up to around 25 billion Ye.. for 10 years starting 1992, depending on further considerations.

\section{Organization for R\&D}

To be conducted at a newly planned research institute in Tsukuba, Japan, tentatively named "Interdisciplinary Research Institute for Industrial Science (IRIS)", while encouraging researchers from national research institutes, private sectors, and universities to participate in collaborative work involved in the project at the institute. IRIS is to be established on the 1st of January, 1993, as a new instirute attached to the Agency of Industrial Science and Technology (AIST), MITI.

\section{The 1992 plan of $R \& D$}

To conduct feasibility study on basic technologies for probing surface structures at atomic and molecular levels, technologies for controlling and forming structures, and support technologies. 


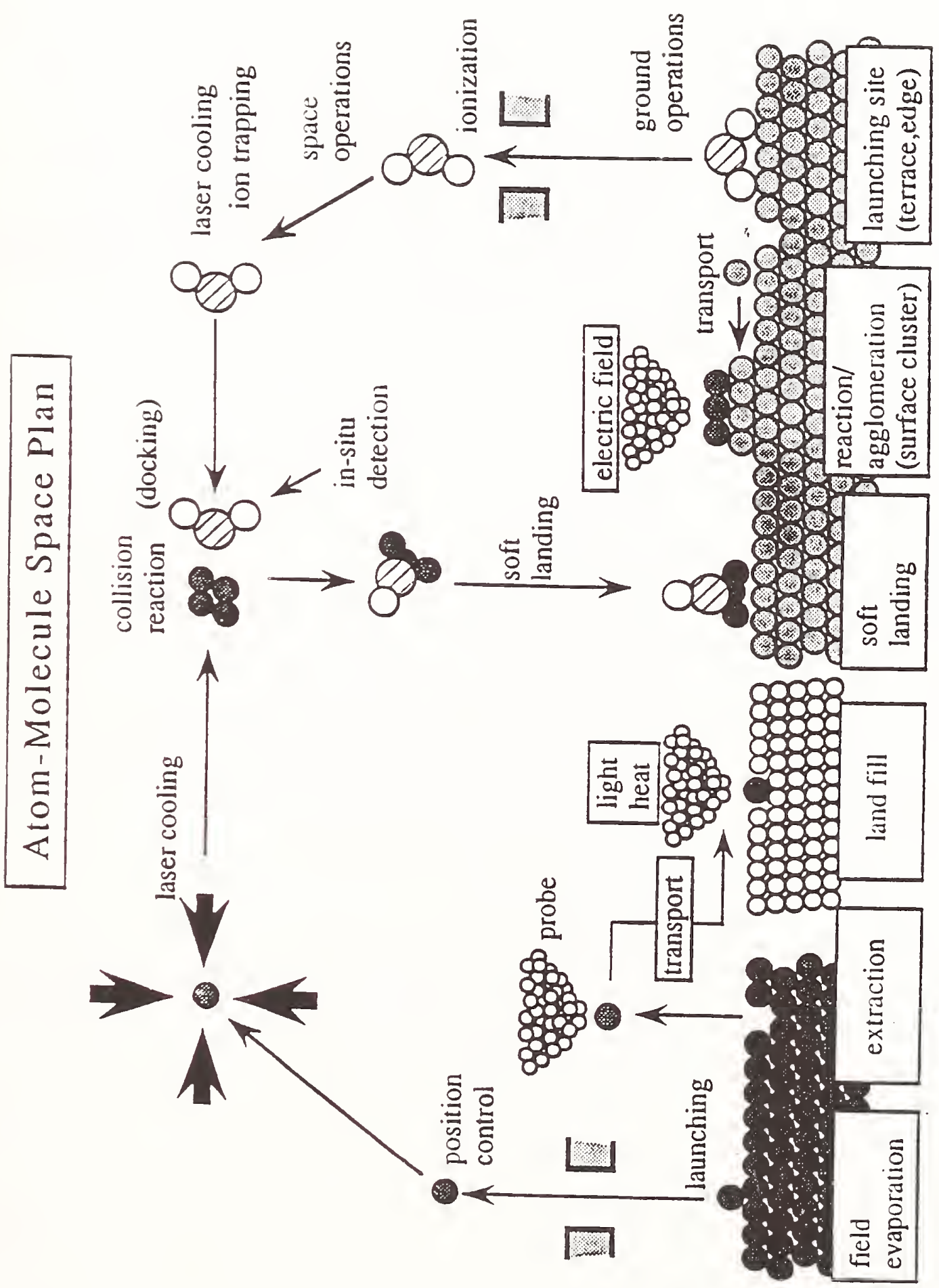




\section{Indivisual Research Activities}

$<$ National Laboratory and Universities>

Mechanical Engineering Lab., AIST, MITI(3)

Sophia University(1)

Tohoku University(1)

University of Tokyo

Faculty of Engineering(3)

IIS(2)

$\operatorname{RCAST}(3)$

$<$ Companies>

Central Research Lab. Mitsubishi Electric Co.(1)

Fuji Electric Co. R\&D Ltd.(1)

Kawasaki Heavy Industries(1)

Matsushita Research Institute Tokyo, Inc.(1)

Mechanical Engineering Research La.,Hitachi(2)

MEITEC Co. R\&D(1)

Olympus Opt, Co.LTD.(2)

Toshiba Co.(3)

Manufacturing Engineering Reserch Center

Energy and Mechanical Eng.ineering Labs. R\&D Center Yokogawa Electric Co.(1) 
Scientist: K.Okano, T.'Waida \& T.Sutoh

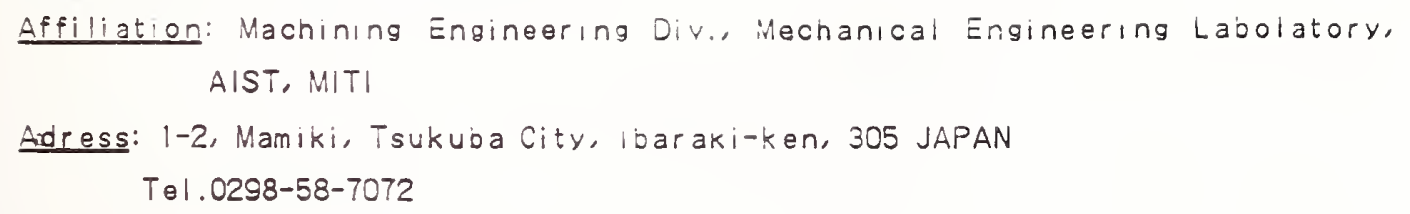

\section{Research Overview:}

Micro-grinding by which 3-dimensional micro-parts such as micro turbine-roter \& helical gear can be machined has been investigating. The micro-grinding is to be comornea with eiectro-cnemical process to improve its micromachining ability.

\section{Research Topics:}

1) Characteristics of micro grinding

a) Smallest part to be machinea

b) Machining Accuracy

2) R\&D of forming technique of micro grinding tool

a) Forming of grinding whes for micro form grinding

b) Application of electro-chemical dressing to micro grinding wheol

3) R\&D of Electro-Chemical Micro-Grinding(E.M.G.)
a) Characteristics of E.M.G.
b) Effect of comoination of Grinaing ana Electro-cnemical machining

\section{Research results in fiscal year of 1992:}

) Characteristics of micro grinding

Smallest dimensions of micro part obtainable in grinding was experimentally investigated. A rib with minimum $8 \mu \mathrm{m}$ thickness and maximum $200 \mu \mathrm{m}$ hight can be machined on cemented carbide. In cylindrical grinding, minimum diameter of $40 \mu \mathrm{m}$ with maximum aspect ratio of 50 can be obtained.

The relation oetween wear of grinding wheel and work materlal properties such as hardness, iracture toughness, tensile strengtn was examined. The wheol wear is influencea considerably by hardness of the material.

\section{References:}


"Micro-grinding"

Grinding:
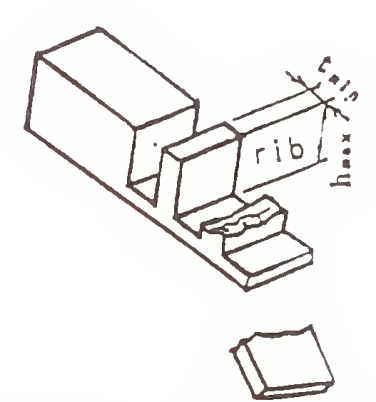

¿.Okano, T. Whaida \& T.Suton

Hechanical Engineering Labolatory, AIST, iNITI

Merit $O$ good machining accuracy and good surface roughness Demerit Deformation or rupture of micro-parts by grinding force

Grinding force reduction by assistance of electro-. chemical process and/or electro-chemical dressing

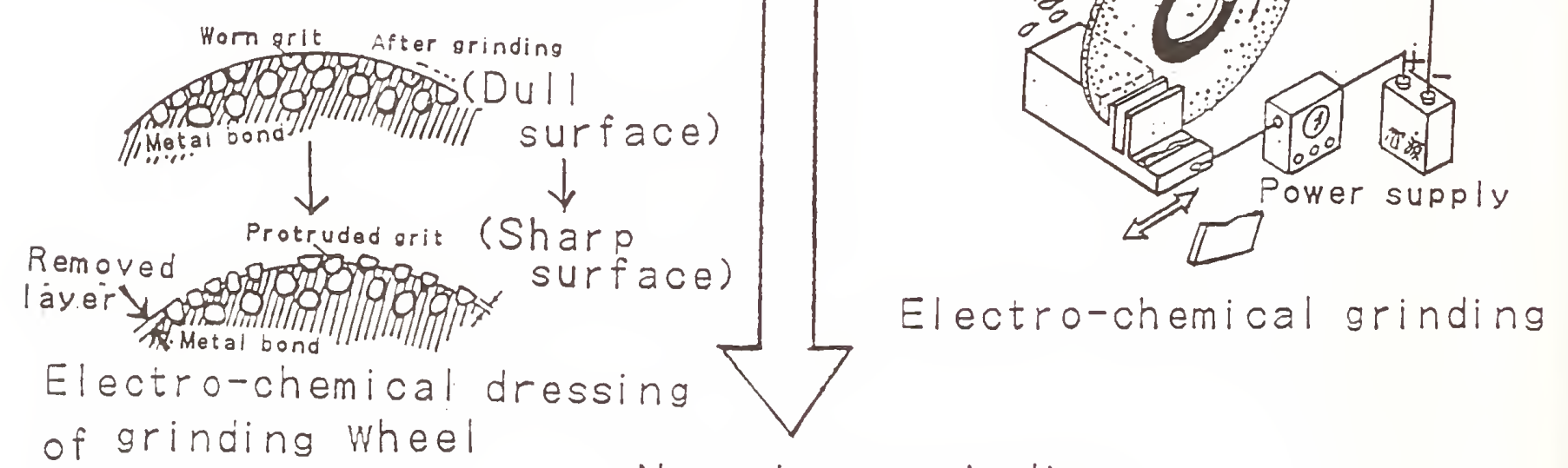

New micro-grinding

3-dimensional micro-parts

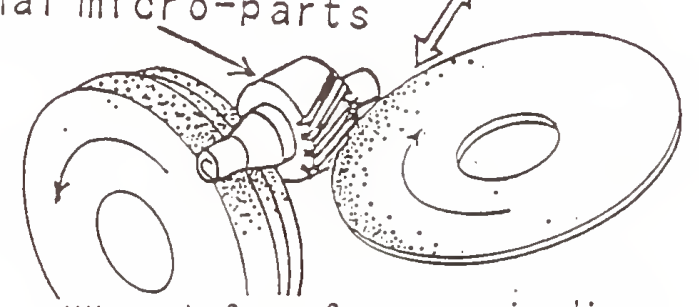

Target:

Wheel for form grinding

Development of high-precision machining for 3-dimensional micro-parts 
Primal Scientist : Ryutaro MAEDA

Affiliation: Mechanical Engineering Laboratory /AIST/MITI

Address: 1-2 Namiki Tsukuba Japan 305

Number of staffs:2

\section{Research Overview}

Interface activation method, pressure joining under ultra high vacuum condition is studied, by which the joining can be done at low temperature and low deformation of the joint. The method was mainly applied to the joining ceramics to metals and is going to be applied to silicon to metal joining for micromachine fabrication. The author aims to accomplish the joining for the sample of practical size and the effect of surface conditions such as composition or surface morphology is investigated. Electro-chemical polishing, CVD process, Sputtering deposition are also studied for surface preparation.

\section{Research Topics}

1) Ceramics to metals joining by interface activation method

The joining is performed by the method in Ultra high vacuum condition for $\mathrm{Al} 2 \mathrm{O} 3, \mathrm{ZrO} 2$, and $\mathrm{Si} 3 \mathrm{~N} 4$ to aluminum alloy

2) Silicon to metal joining by surface activation method for micromachine fabrication

The joining Si to metals is investigated with special emphasis is laid on pressure loading. The pressure load is applied by electrostatic or electromagnetic force in order to attain uniform pressure distribution in the wafer.

3) Surface preparation for joining

Electrochemical polishing, EEM like polishing are studied to obtain flat and defect free surface, and sputtering and chemical vapor deposition process are investigated for surface modification technique for joining.

\section{Research results in fiscal year of 1993}

1) Joining strength was strongly affected by surface preparation. Clean, flat and defect free surface is suitable for the joining.

2) Utilization of sputter etching and deposition and relative rotational sliding between joining surfaces realized edge to edge joining of $\mathrm{Al}_{2} \mathrm{O}_{3}, \mathrm{ZrO}_{2}$ and $\mathrm{Si}_{3} \mathrm{~N}_{4}$ to aluminum alloy.

3) Single crystal film of Si was proved to be formed on Silicon or metal by surface activation method.

\section{References}

(1) R. MAEDA, H. YAMAMOTO : Application of friction in vacuum to solid state bonding.", Journal of Japanese Society of Tribologist, vol. 34, 1989, No.12, p860.

(2)R. MAEDA, H. YAMAMOTO :"Low temperature bonding using friction in a vacuum", MRS Int'l.. Mtg. on Adv. Mats. vol8,p286,1989 Material Research Society

(3) H.Takagi et al.:"High resolution electron microscopy of Al/Si and Al/Si3N4 interfaces prepared by room temperature bonding method", J. Jap. Inst., Metals, vol. 55, No,8(1991)p907 


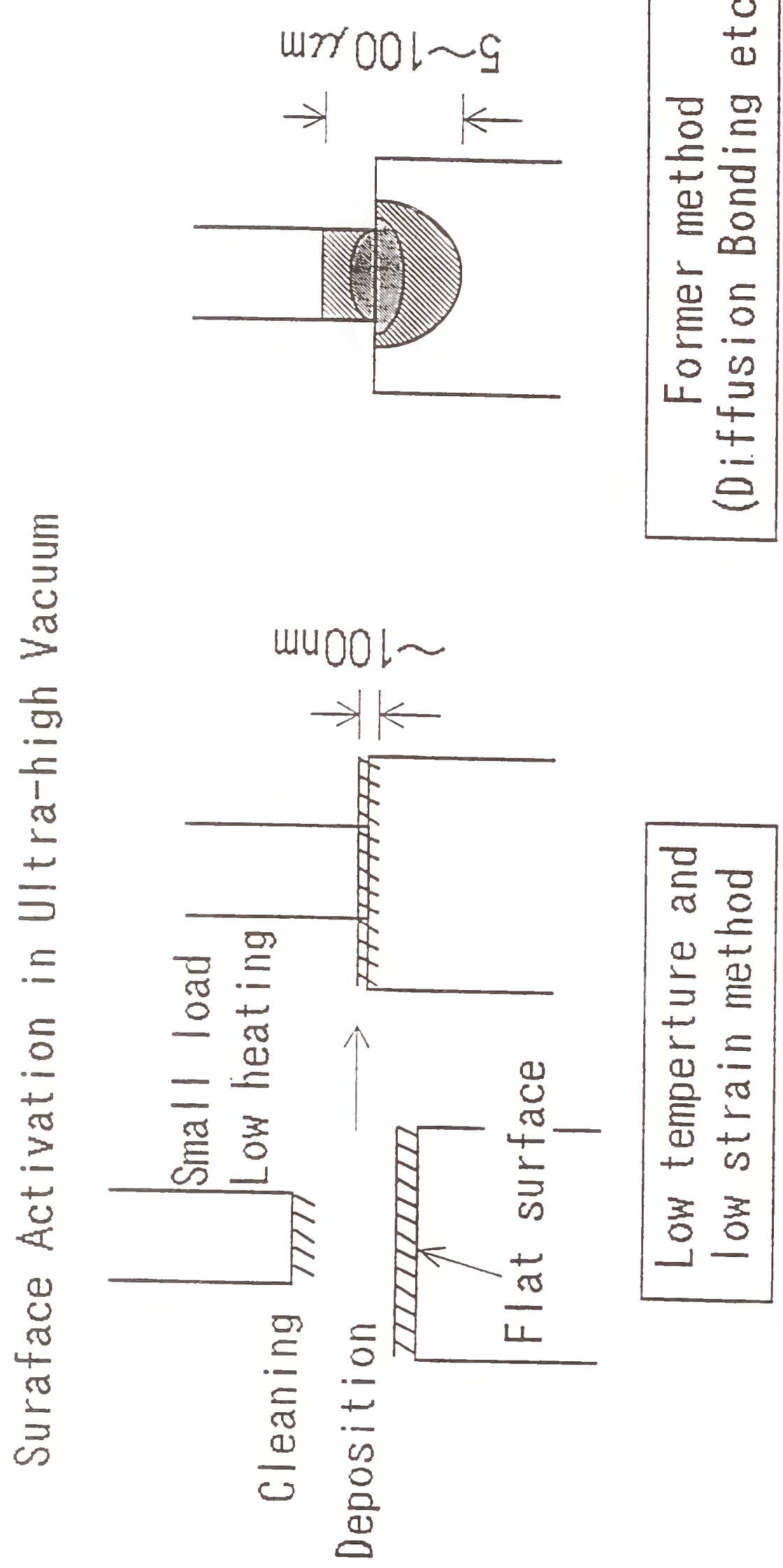


Primai Scientist: Shizuka NAKANO

Affiliarion: Machinery Department, Advanced Technology Division

Mechanical Engineering laboratory, AIST, MITI

Address: Namiki 1-2, Tsukuba, Ibaraki, Japan 305

Tel. +81-298-58-7163, Fax. +81-298-58-7007

Number ob staff: 2

Research Overview:

"Functional Fabrication" is a new concept of fabrication technique for micro machine elements. Owing to the thin thickness of modified layer and the capability of making small spot of modified area. the high energy ion implantation method becomes one of the effective material modification technique: for micro-machine elements. In addition, the combination of the modified materials brings about a new functional effect as a whole.

\section{Research Topics:}

Concept: (1) It is better that the function of micro elements is made from material control (design) than form control (design). Because, the material fabrication is more easily than precise forming.

(2) The high energy ion implantation technique is better process to control a material of micro elements. The region it controlled is $0.1 \mu \mathrm{m}$ order and the and implanted ion are freely selectable.

(3) For examples, the elastic property of ion implanted materials are decreased over the $20 \%$. The fracture toughness of silicone are increased by ion implantation. The electric reactance are decreased by gold ion implantation.

Research results in, fiscal year of 1992 :

1) Evaluation technique for elastic properties: We have developed the micro three point bending tester. The distance between supporting edges is $400 \mu \mathrm{m}$. This system can load from 0.098 to $490 \mathrm{mN}$ and measure displacement of loading edge with $10 \mathrm{~nm}$ resolution. Young's modulus of ion implanted stainless wire was measured to be lower than that un-implanted one.

\section{Referance:}

1: S.NAKANO, K.YAMANAKA, H.OGISO, T.KODA, "Functional Fabrication for Micro-Machine Elements Using High Energy Ion Implantation Technique" Proc. of 3rd Int. sympo. of Micro Machine and Human science (Oct-1992) Nagoya 2: S. NAKANO, K.YAMANAKA, H.OGAWA, T.KODA, "Three point bending test for Micro Machine Components", Proc. of 70th Conf. Vol.B (Sep-1992) Nagano (in japaniese) 


\section{"Functional Fubrication"}

for micro machine elements using $\mathrm{MeV}$ ion implantation

Shizuka NAKANO (Mechanical Engineering Laboratory, AIST, MITI)

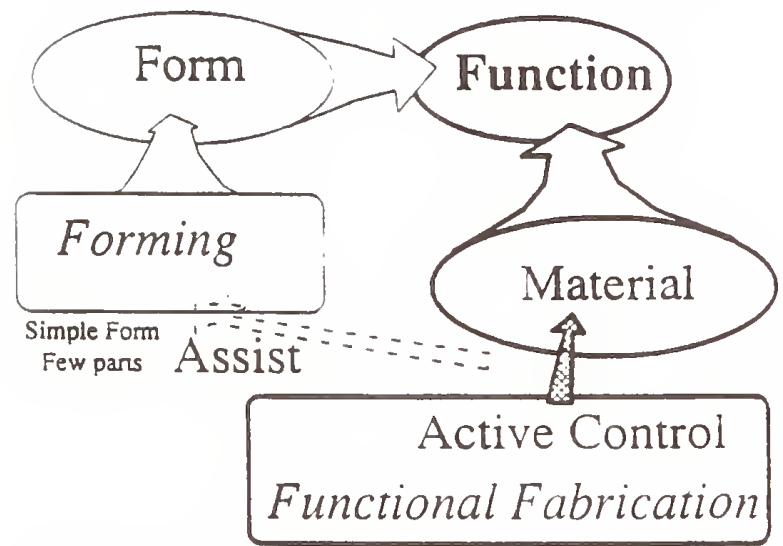

Fig 1 Functional Fabrication control the material of elements activlly using high energy ion implantation.
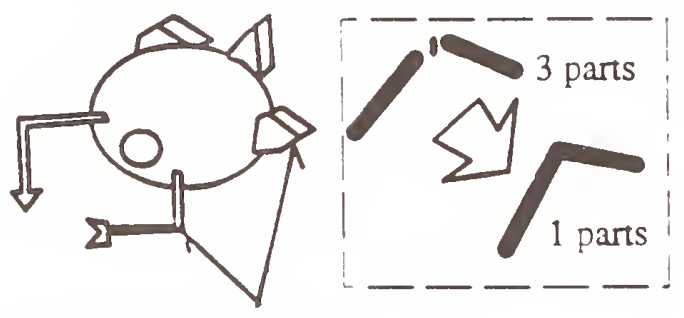

Elastic Flexible Joints

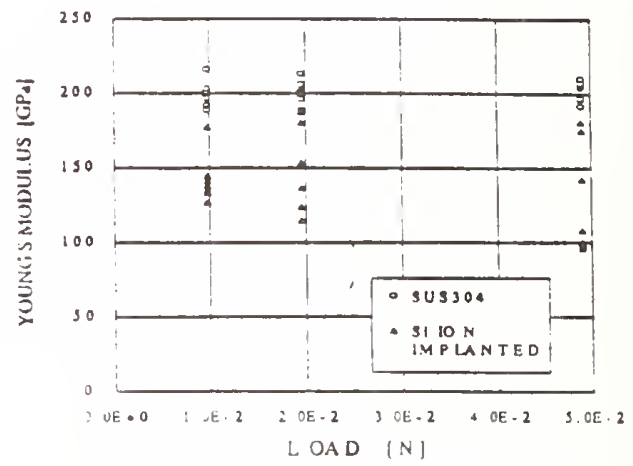

Fig.2 Young's modulus of stainless wire. Si $2.5 \times 1017 / \mathrm{cm} 2$ implanted wires were lower than that of un-implanted.

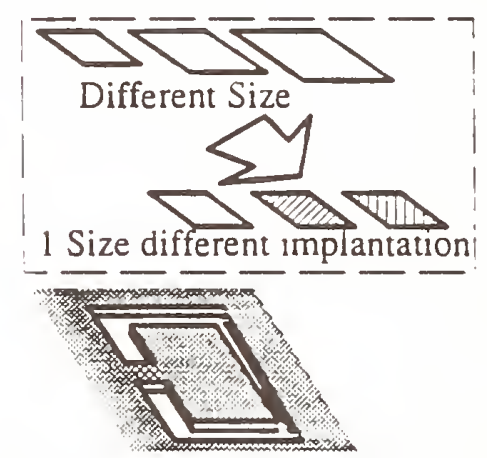

Tuning : Elastic Actuator or Sensor

Fig3 Exaples; Changing elastic properties:

1) Elastic Flexible Joints decrease the number of elements and assemble process.

2) Tuning the sensor or actuator corrects it's forming error and decrease the forming pattern.
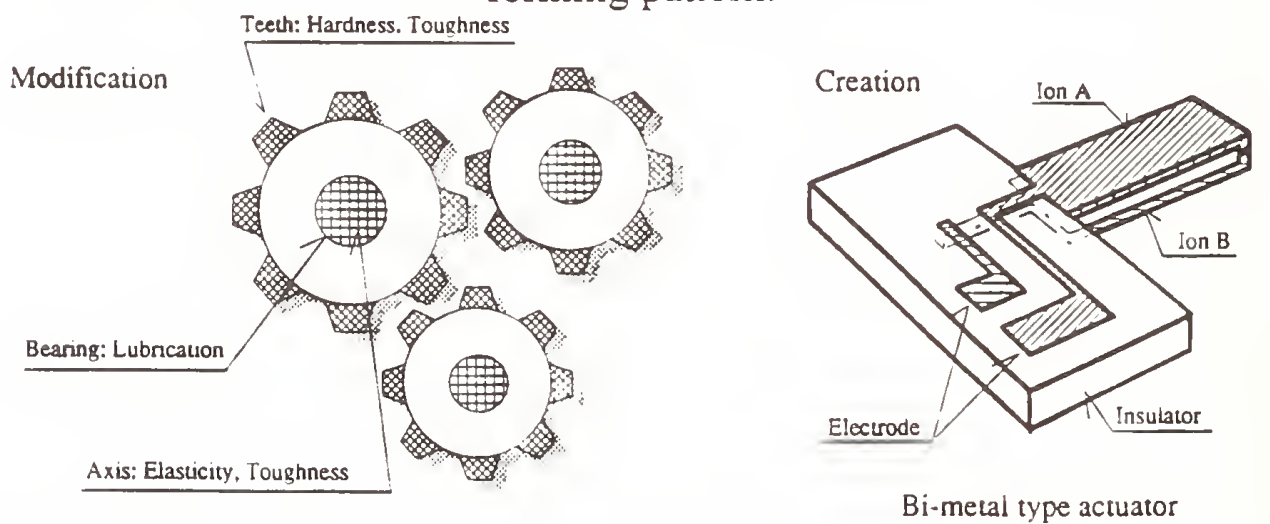

Fig4 Functional Fabrication has 2 Roles: Material modification and creation. 
Primai Scientist: Katsufusa SHONO

Afriliation: Sophia University. Facuity of Science and Technology

Adress: Ḱioichco-i. Cliyoda-ku. Tokyo, Japan 102

Tel.03-3238-3412. Fax.03-3238-4156

Number of staffs: 2 (11 students)

\section{Research Overview:}

Main target of our research is CMOS integrated circuits. Our tools are Bitmap CAD, EB direct lithography, and other process equipments. By the use of clelineation lechnology and materials. microfabrication of polysilicon sliders and rotors is possible. Olsservations of micro step motion and combination with CMOS control circuits and solar cell power supply are our way of research on micro-machining on an Si waier.

Research Topics:

1) Micro Turn Table: By the use of self-align process technology, a rotor with a shaft and a cap was fabricated as an assembled form. The diameter was $100 \mu \mathrm{m}$. The rotation speed can be controlled by the frequency of AC supply. 2) Micro Slider: The polysilicon piate $(100 \mu \mathrm{m} \times 50 \mu \mathrm{m})$ with bushing $(\mathrm{h}=$ $3 \mu \mathrm{m})$ moves along the polysilicon belts. The step motion mechanisms are analyzed and the movement was controlled by the frequency and voltage of AC supply.

Research results in fiscal year of 1993:

A new step motion of polysilicon siiders and rotors was found. They will be used in electronic consumer prociucts and computer periphery.

\section{References:}

1) Terunobu Akiyama and Katsulusa Shono: An Electrostatic Polysilicon Actuator for Micro-motors, Proceeding of Japan-Korea Joint Seminar, Taegu, Korea, pp164-173 (August 1992).

2) Cong-Kha Plam and Katsufusa Shono: CMOS Cell Compiler for a BitMapping CAD System. IEICE Trans., Ei4 (1991) pp2603-2611.

3) Katsulusa Shono and Ryo-ll Kang: Operation Cell Blocks for Combination CMOS Digital Analog LSI. IEEE Tokyo Chapter Denshi Tokyo, 30 (1991) pp16-20. 
Micro slider and rotor fabricated on an Si wafer Katsufusa Shono (Sophia University)

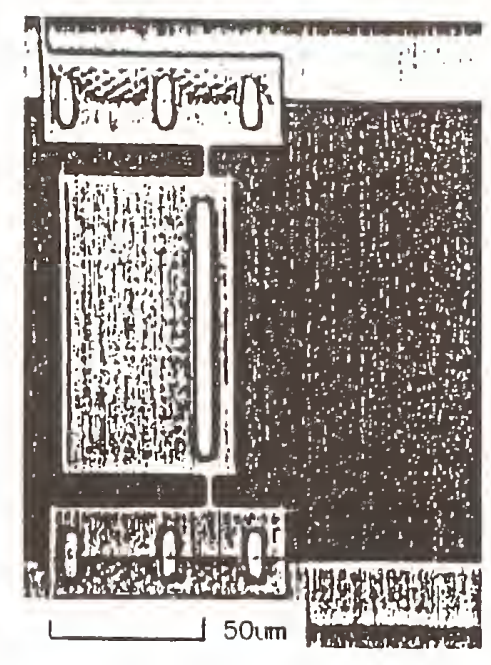

Fig. I Microphotograph of a polysilicon slider on rails.

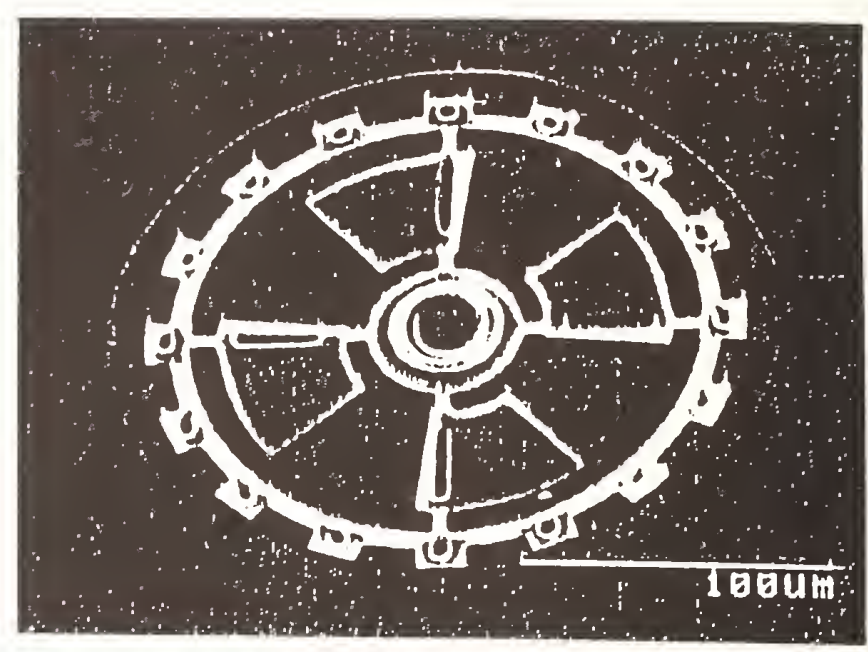

Fig. 2 SEM photograph of a polysilicon rotor.

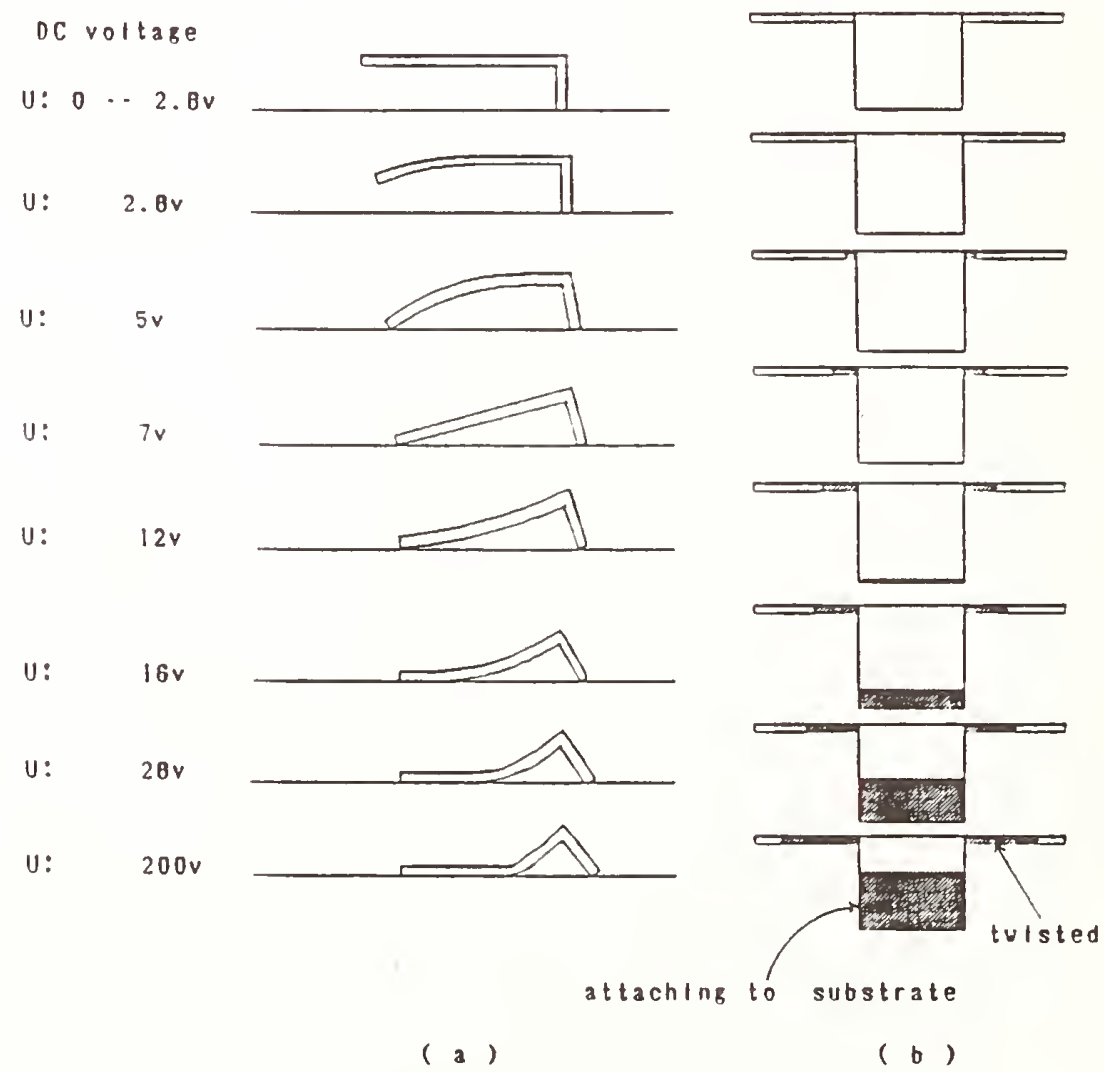

Fig.3 Molion of a microslider. (a) Cross-sectional view. (b) Top view. 
Primal Scientist: Masayoshi Esashi

Affiliation:

Department of Mechatronics and Precision

Engineering

Tohoku University

Address:

Aza Aoba, Aramaki, Aoba-ku, Sendai, Japan 980

Tel.+22-222-1800 ext.4207, Fax.+22-215-4845

Number of staffs: $3(17$ students $)$

Research Overview:

Sophisticated micro actuators and micro sensors by micromachining: Micro actuators, micro sensors, and integrated sensor and actuator systems fabricated by micromachining have been studied. Examples of research projects are as follows: development of electrostatic micro actuators, integrated sensors, micro flow control systems and micro resonant sensors. Micropackaging techniques for micro sensors and three-dimensional micro fabrication techniques are also studied.

Research Topics:

1) Electrostatic micro actuators: A micro actuator consists of many distributed driving units is studied to realize large force and large displacement. Development of a linear micro actuator which has many stepping electrodes is another topic of this project.

2) Accelerometers: Various types of accelerometers are designed and fabricated to achieve high sensitivity and stability. The packaging problems are also studied.

3) Micro flow control systems: Integration of micro flow control devices and micro sensors enables very small flow control systems. Precise gas flow control systems and integrated chemical analysis systems are the topics of this project.

4) Micro resonant sensors: In order to realize high sensitivity and good stability, resonant type vacuum sensors and infrared sensors are studied.

5) Three-dimensional micro fabrication techniques: Selective patterning and deposition by means of excimer laser beam are studied. YAG laser assisted etching techniques are also developed to realizing sophisticated silicon micro structures.

Research results in f scal year of 1993 :

1) Electrostatic actuator: Fundamental studies of distributed electrostatic actuator were done. The motion of the actuator was analyzed by finite element model and investigated by the macro model.

2) Integrated accelerometer: An integrated silicon capacitive accelerometer with novel balancing was developed. It has glasssilcon-glass structure realizing a micropackaging. The CMOs capacitance to frequency convertor is integrated and the phaselocked-loop circuit is used for the force balancing system.

3) Micro flow control device: High output pressure micropump was studied and a novel check valve was developed.

4) Packaged resonant sensor: A packaged resonant sensor with high Q-factor was fabricated. The torsional type mono-crystalline silicon resonator was fabricated in glass-silicon-galss structure. 
5) High-speed directional ary etching: Low temperature reactive ion etching using $\mathrm{SF}_{6}$ was studied to realize three-dimensional silicon structure. A maximum etch rate of 2.35 umimin with small undercut ratio of 0.03 was acnieved at $-120 \mathrm{C}$.

\section{References:}

1) S.Kawamura, K.Minami, M.Esashi,"Fundamental Research of Distributed Electrostatic Micro ictuator", Tech. Dig. of llth Sensor Symposium, pp27-30, (1992).

2) Y.Matsumoto, M.Esashi,"Integrated Capacitive Accelerometer with Novel Electrostatic Force Balancing", Tech. Dig. of llth Sensor Symposium, pp47-50 (1992).

3) S.Shoji, B.van der Schoot, N.F.de Rooij, M.Esashi, "A study of high pressure micropump", Sensors and Actuators, A32, pp335-339, $(1992)$.

4) K.Yoshimi, K.Minam1, Y.Wakabayashi, M.Esashi,"Packaging of Resonant Sensors", Tech. Dig. of ilth Sensor Symposium, pp35-38 (1992).

5) M.Takinami, K.Minami, M.Esashi,"High-speed Directional Lowtemperature Dry Etching for Bulk Silicon Micromachining", Tech. Dig. of lith Sensor Symposium, ppi5-18 (1992). 
"Sophisticated micro sensors and micro actuators

by micromachining"

Masayoshi Esashi(Tohoku University)
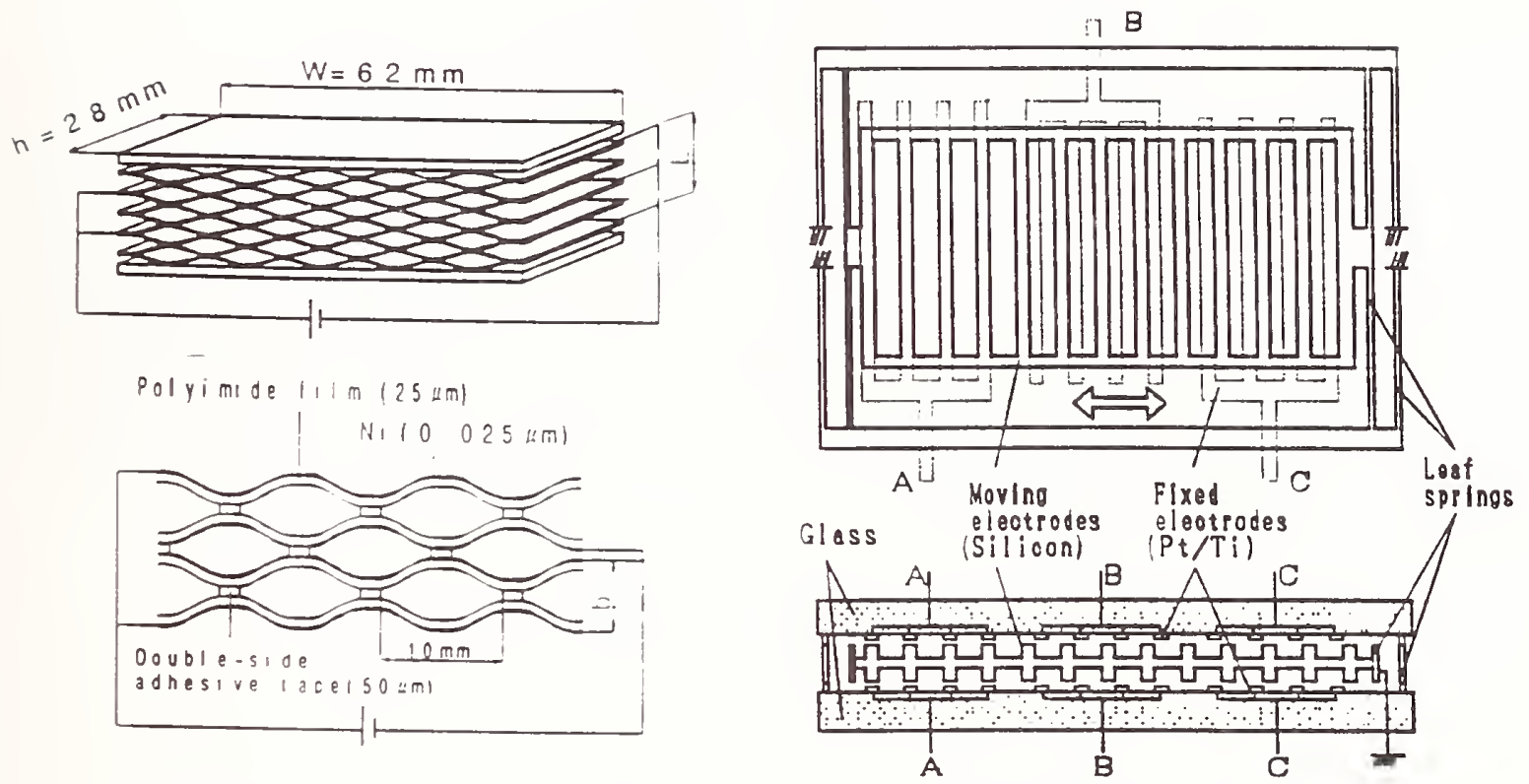

(a)Distributed Electrostatic Type (b)Stepping Electrostatic Type Fig. I Electrostatic micro actuators
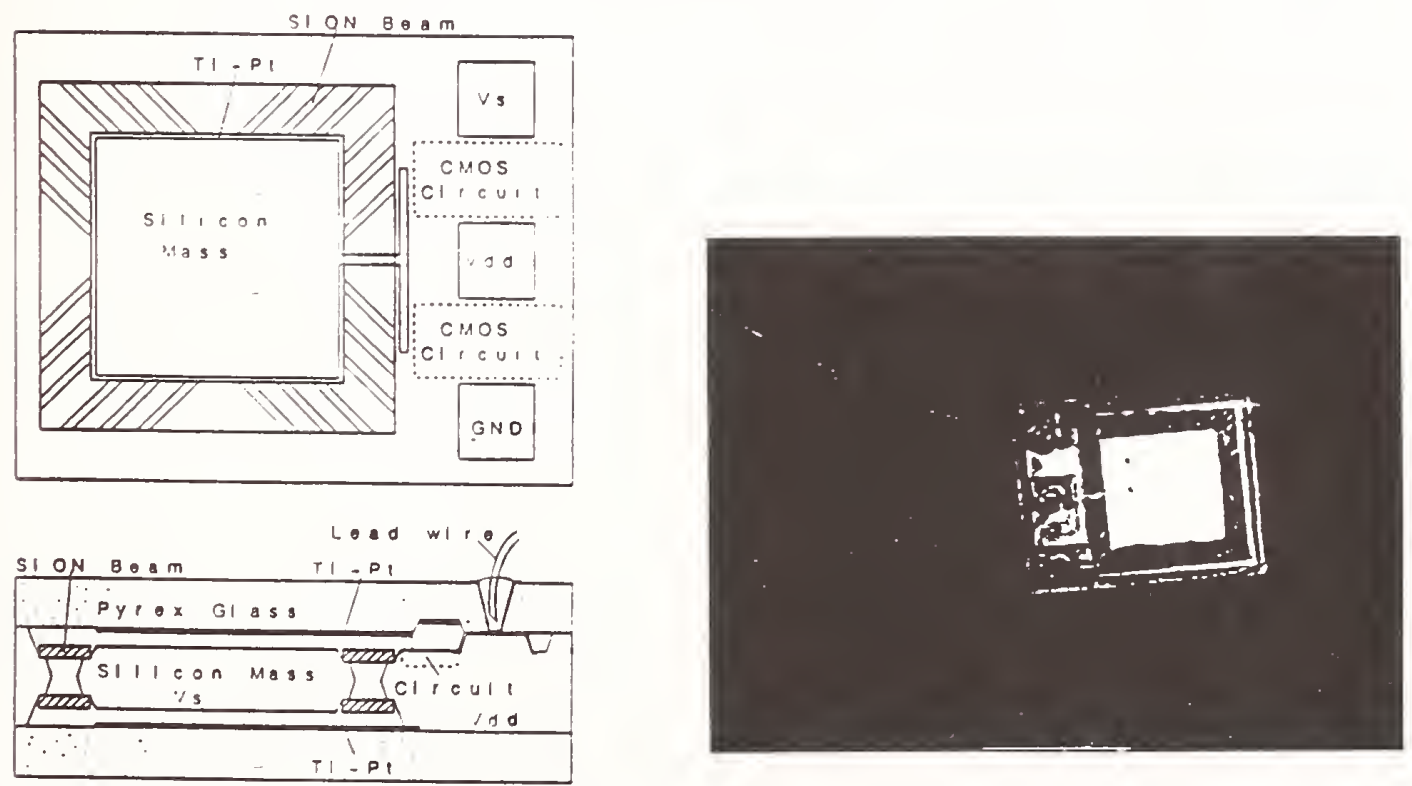
(a) Structure of the sensor (b) Photomicrograph of the sensor
Fig.2 Integrated Accelerometer 
Primal Scientist: Yotaro HaTAMURA, Gesayuki vakaO

Affiliation: The University of Tokyo, Faculty of Engineering

Engineering synthesis

Address: 7-3-1 Hongo, Zunkyo-ku. Tokyo, 113 Japan

TEL +3-3812-2111 ex. 6361 FAX +3-3818-0835

Number of staffs: 4 employees, 13 students. and 5 researchers

(For this project: 2 employees. 5 students, and 1 researcher)

Research Overview:

Nano Manufacturing Horld is being developed.

Some physicists are trying to go up nanometers scale from angstrom scale by handling atoms through Scanning Tunneling Microscope (STM). He machanical engineers are newly challenging to come down there from macro scale. It supports the human to work in nanometer world as' if they were there by using dyanmic. real-time, and 3-dimensional observation/handling instruments. Combination of the two directions maxes the human step into an unknorn and fruitful world. namely Viano Manufacturing horld (Figure 1).

Research Topics:

We have been engaged in developing Nano Manufacturing World for 6 years. Through the development we realized that it needs the following 4 elements.

1) Micro Tools: He are trying various actions with Micro Tools (Figure 2). Blowing off. scraping off. and attracting are useful in nanometer world besides nipping and digging which are widely tried.

2) Nano Manipulator: He have already realized a real-time.

3-dimensional, and ultra-precise nano manipulator in Vano Robot ll (Figure 3). It can be operated within 5 nm preciseness through transmission mechanism that is newly designed.

3) Reality Transmission System: He have already realized this system in Nano Robot 11 . In order to support the operator, stereoview, small sound, and micro force that happen in nanometer world through Scanning Electron Microscope (SEM) are transmitted to the operator.

4) Softwear for Dominant Factors Conversion: He realized through Viano Robot 11 operation that dominant factors in nanometer world are totally different from those in human-size world. in order to prevent a fatal damage caused by mis-operation and to realize easy operation, a hidden support that automatically converts the dominant factors is ind i spensable.

Reseach Results in 1992 :

The new results in this year are as follows:

1) Micro Tools: Tools for nipping, blowing off and attracting have been developed. Those for dipping and scraping off cannot be realized because their rigidities are too small against the operating force.

2) Nano Manipulator: A new rotation mechanism for the various tools has been developed by using ultra-sonic motor.

3) Reality Transmission System: An ultra-micro force sensor is being developed through semiconductor manufacturing process. Even 1 nano Newton 
can be detected with semiconductor s:rain gauges on parallel thin plates of 0.7 micron thickness.

Reference:

1) Y. Hatamura and H. Morishita: Direct Couping System Between Nanometer Horld and Human Horld. Proc. of HEMS 1990. IEEE, pp203-208 (1990)

2) Y. Hatamura: Micro Hanipulation and Reality Transmission. Journal of JSME, 6-1992, pp25-29 (1992), in Japanese

3) Y. Hatamura, M. Nakao et al: A Measurement of SIiding Resistance Forces for Various Heads and Disks by High-Rigid Force Sensor. IEEE Trans. of Magn. Vol. 24, No. S, pp2638-2640 (1988)

4) Y. Hatamura: A Ring Shape 6-Axis Force Sensor and Its Apprications. Int. Conf. on Advanced Mechatronics, pp647-652. (1989)

5) Y. Hatamura, M. Mitsuishi et al: A Fundamental Structure for Intelligent Manufacturing. Proc. of 6 th Annual Conf. ASPE. pp188-191 (1991) 


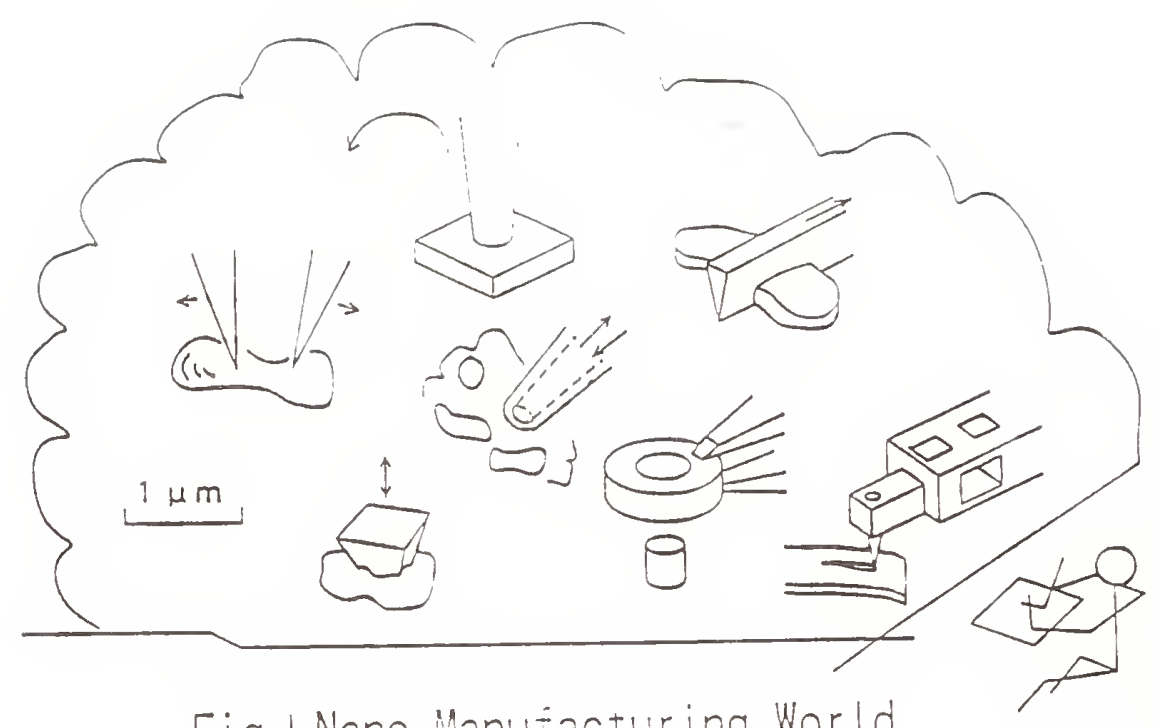

Fig. I Nano Manufacturing World

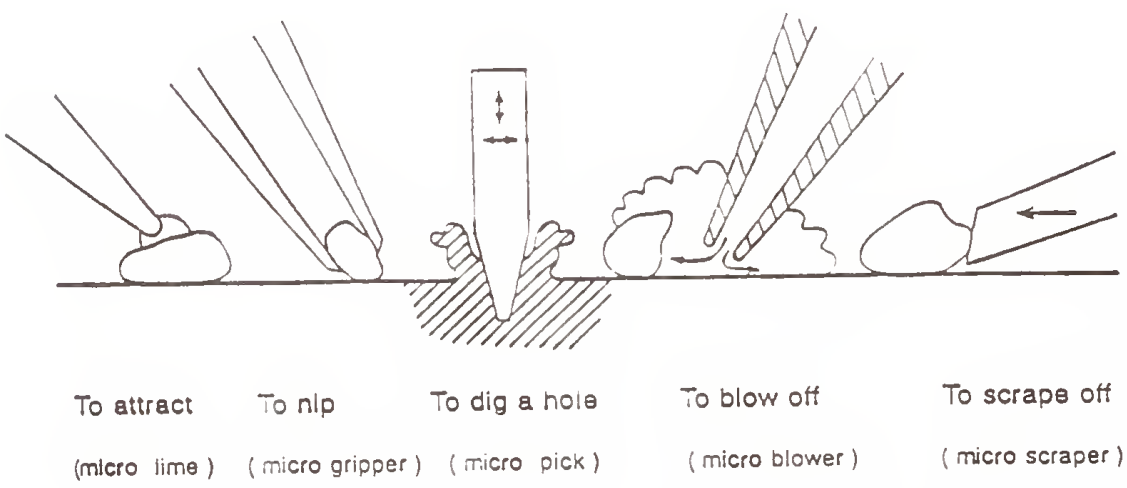

Fig. ZVarious Tools Needed in Micro Manipulation

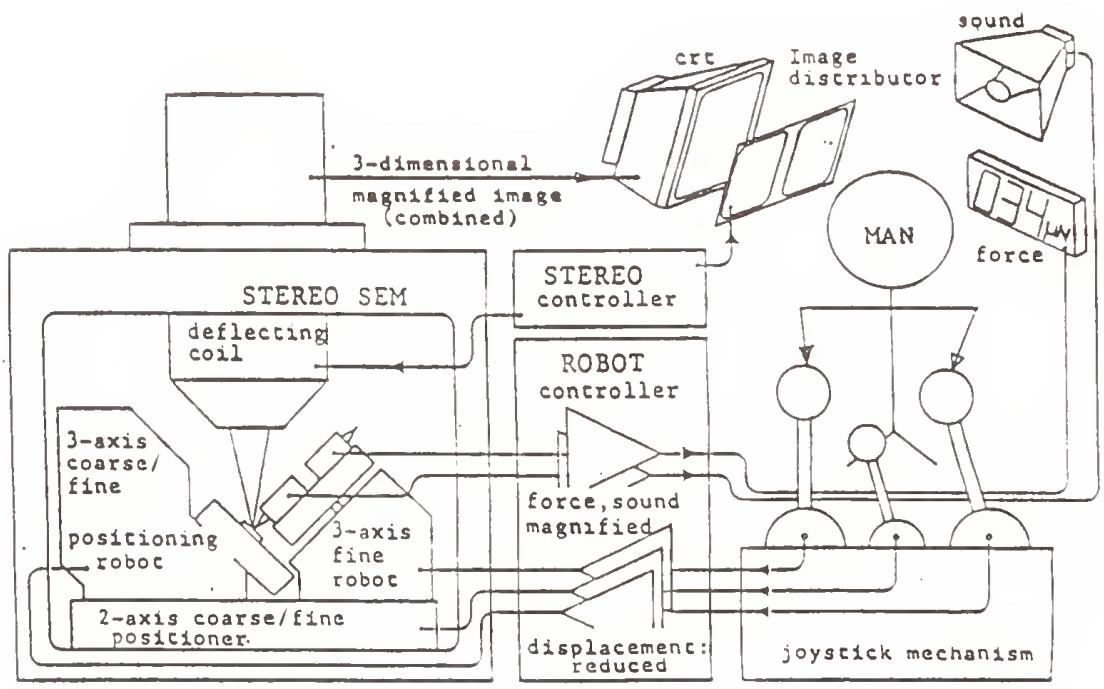

Figure 3 System Diagram of Nanorobot System II 
"Micromachine Design \& Rapid Manufacturing"

Naomasa NAKAJIMA (Mechanical Engineering for Production. The University of Tokyo)

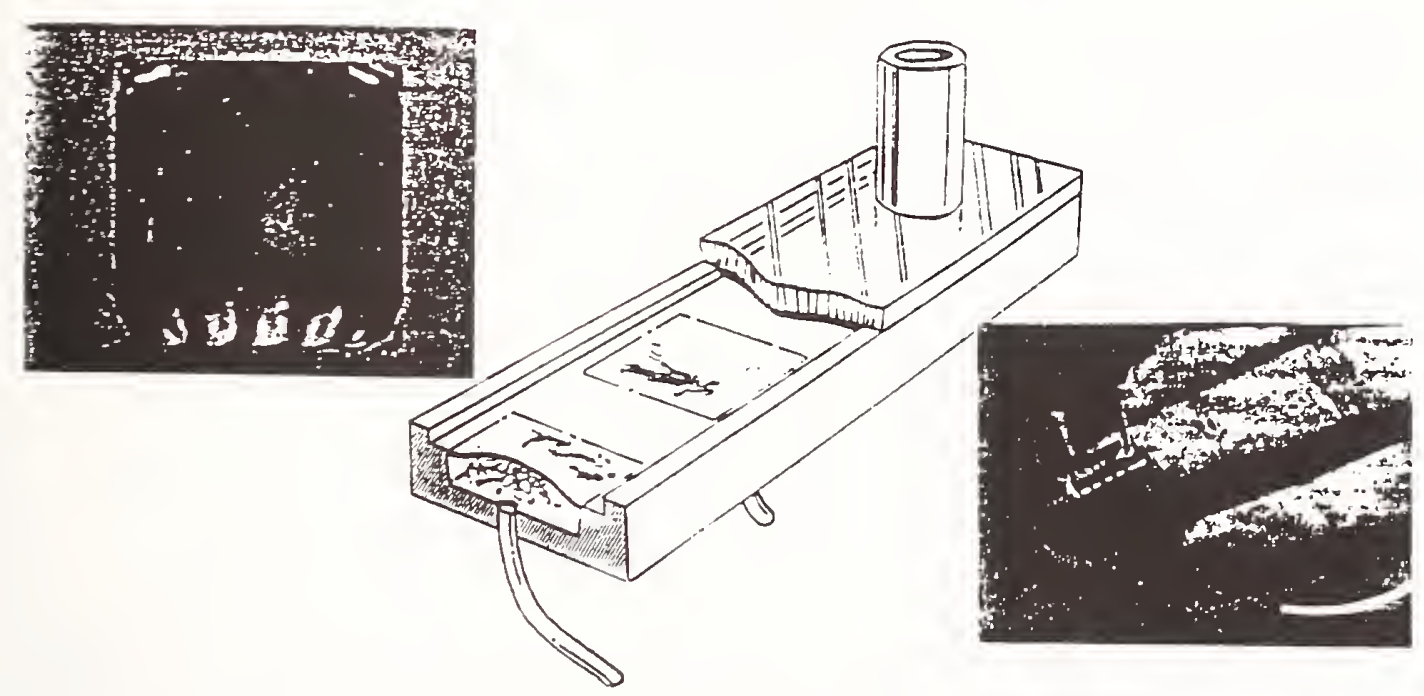

Pump with five micro-actuators driven by vaporization of fluid, heated by light source through optical fiber

Light Driven Micro-Pump
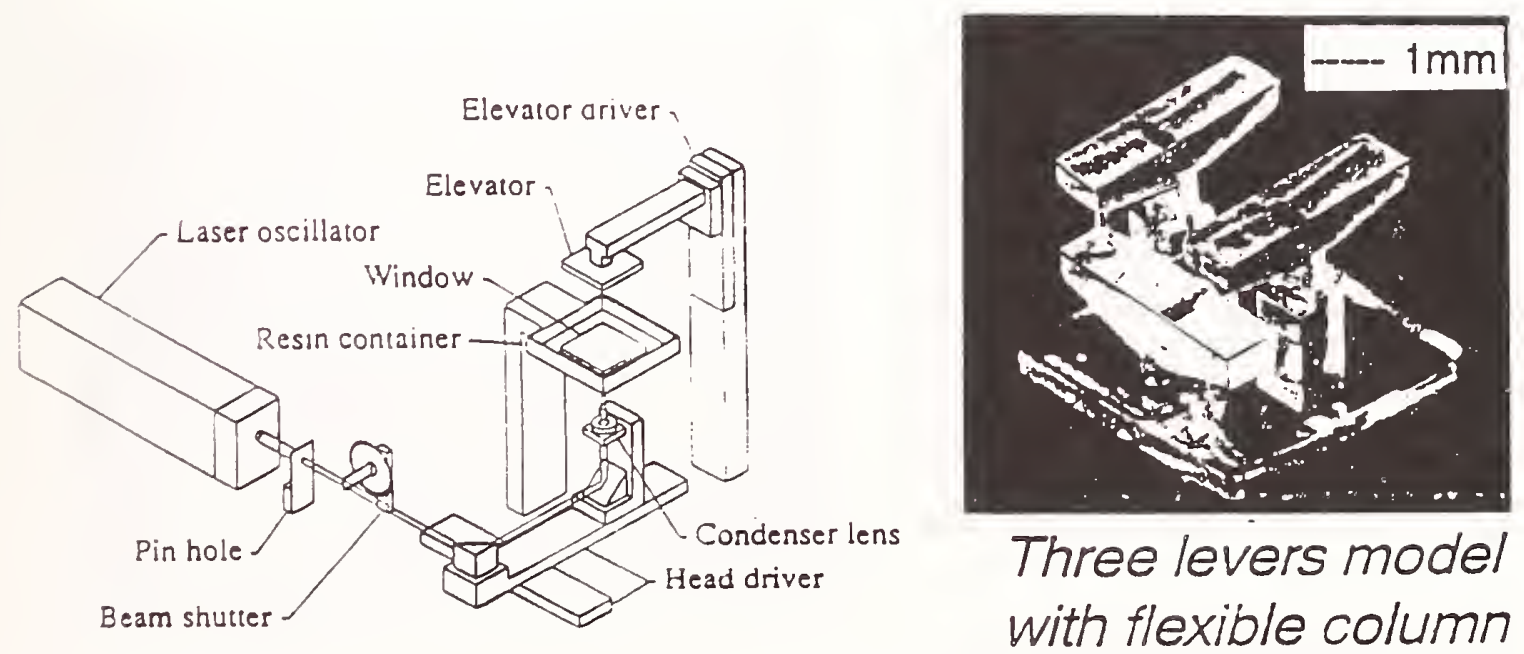

Three levers model with flexible column 
Primal Scientists: Hirofumi Miura, Isao Shimoyama

Affiliation: Department of Mechano-Informatics

The University of Tokyo

Address: $\quad 7-3-1$, Hongo, Bunkyo-ku, Tokyo 113, Japan

phone (country code 81)-3-3812-2111 x6318

fax (country code 81 ) $-3-3818-0835$

Number of Staffs: $\quad 2(23$ students)

Research Overview:

We are interested in an approach to micromachines, which makes the most of our background of robotics Our final goal is to build microrobots whose behavior and structures are similar to real insects.

Research Topics:

1) Insect Based Microrobot with an External Skeleton and Elastic Joints ${ }^{[2][3]}$

2) Analysis of insect motion ${ }^{[1]}$

Research results in fiscal year of 1992:

1) A flying microrobot is nearly finished.

\section{References:}

1] Isao Shimovama, Hirofumi Miura, Chiaki Kimura. Manabu Kikuta. "Analyzing the Dynamics of Ants and Application to Microrobots, "ASME Symposium on Micromechanical Sensors Actuators and Systems, DSC-Vol.32, pp.279 - 285, 1991.

2] Kenji Suzuki, Isao Shimoyama, Hirofumi Miura. Yuichi Ezura, "Creation of an Insect-based Microrobot with an External Skeleton and Elastic Joints." Proceedings of IEEE Workshop on Micro Electro Mechanical Systems, pp.190-195, 1992.

3] Isao Shimoyama, Hirofumi Miura, Kenji Suzuki, Yuichi Ezura, "3D Structure of an Insect-based Microrobot with an External Skeleton, "IEEE Robotics \& Automation, pp.693698, 1992. 


\title{
3D Structure of an Insect-based Microrobot with an External Skeleton
}

\author{
Hirofumi Miura \& Isao Shimoyama \\ Department of Mechano-Informatics \\ The University of Tokyo
}

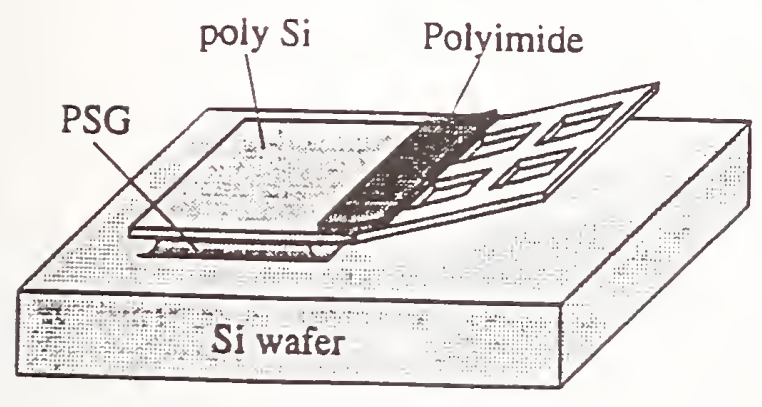

Fig.1. 3D structure with elastic joint.

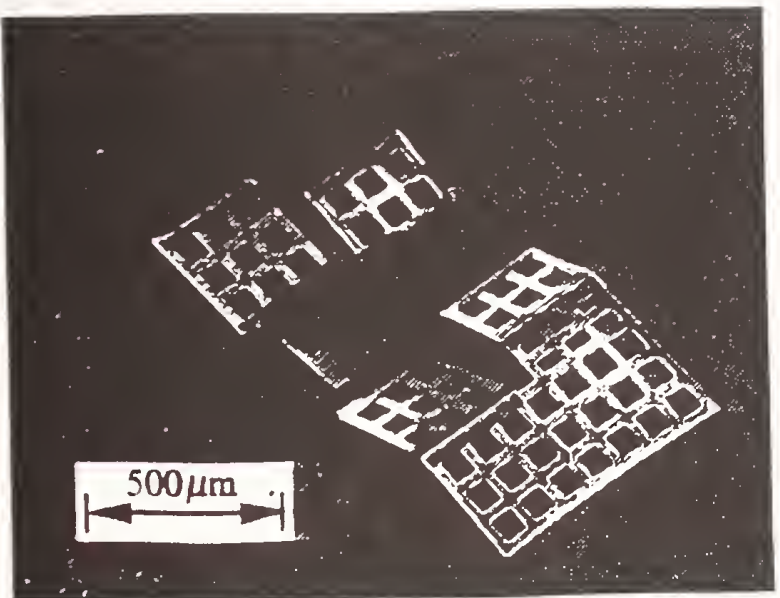

Fig.3. Microsized model of wings.

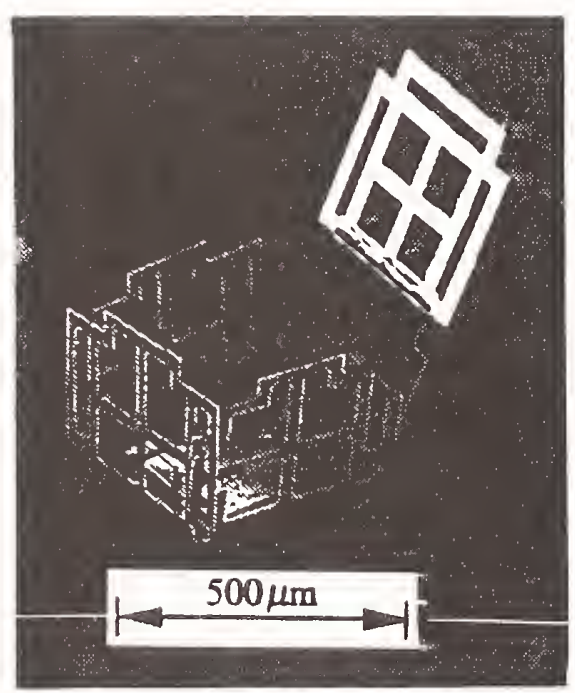

Fig. 2 Microcube.

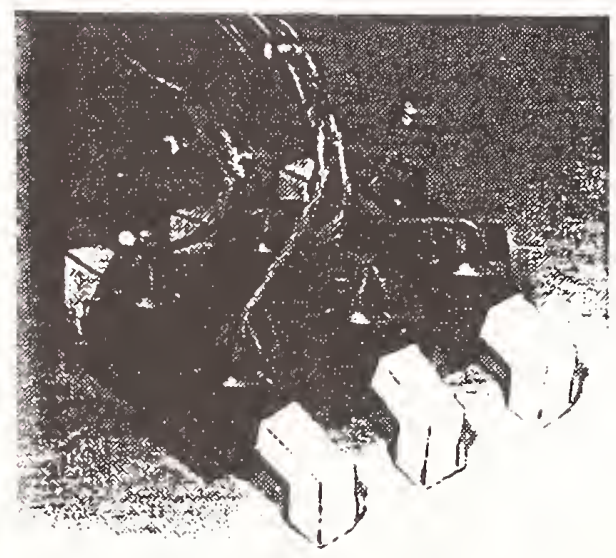

Fig.4. Large scale artificial ant consisting of the leg joint mechanism. 


\title{
MICROACTUATORS FOR THE CILIARY MOTION SYSTEM
}

\author{
Manabu Ataka. Hiroyuki Fujita (IIS. The Univesity of Tokyo)
}

The photograph shows a microactuator array for the ciliary motion system[1]. The system mimics the motion of cilia in living organisms. Many cilia vibrate in synchronization to convey objects or fluids. A cilium has two-degree-of-freedom (rotation and bending). Since the micromachined actuator has only simple motion. two actuator element are combined to achieve the two-degree-of-freedom motion. We have fabricated a thermally driven contilever micro actuator[2].

The SEM photograph of cantilever actuators is shown. The basic driving principle is similar to that reported by Riethmüller. et al.[3]. The differences are the material (polyimides) and the simple fabrication process. Two lavers of polyimides with different thermal expansion coefficients sandwitches a metal heater. Aluminum was used as a sacrificial material. Since the polyimide used in the upper laver has the larger thermal expansion coefficient than the lower layer the residual tensile stress in that laver curls the cantilever up. (Note that the tensile stress builds up when the polyimide is cured at elevated temperature and cooled down.) When the current flows in the heater and the temperature rises the cantilever bends down. The dimensions of the cantilever are: $500 \mu \mathrm{m}$ in length, $100 \mu \mathrm{m}$ in width, $6 \mu \mathrm{m}$ in thickness. The displacement was $66 \mu \mathrm{m}$ in the horizontal direction and $123 \mu \mathrm{m}$ in the vertical direction with $30 \mathrm{~mW}$ in the heater. The frequency response without any particular cooling wasmeasured using sinusoidal wave. The cut-off frequency $(-3 \mathrm{~dB})$ is $10 \mathrm{~Hz}$. We fabricated microactuators in an array. We operated the actuators in coordination to carry an object on the array, although all the control signals were supplied from outside. The object is a silicon chip of $1 \times 1 \times 0.5 \mathrm{~mm}^{3}$. The chip was conveyed for the distance of $0.5 \mathrm{~mm}$ while 30 cycles of the coordinated motion were repeated.

\section{REFERENCES}

[1] N. Takeshima, H Fujita. 'Design and Control of Systems with Microactuator Array', Proc. IEEE Workshop in Advanced Motion Control. Yokohama. Japan. March 1990, pp.219-232.

[2] N. Takeshima. H Fujita. 'Polyimide Bimorph Actuators for a Ciliary Motion System' ASME Winter Annual Meeting, Atlanta. Georgla. Dec 1-6 (1991) DSC-Vol.32 pp.203-209.

[3] W. Riethmüller. W. Benecke. 'Thermally Excited Silicon Microactuators', IEEE Trans on Electron Devices. ED-35. pp.758-763 (1988). 


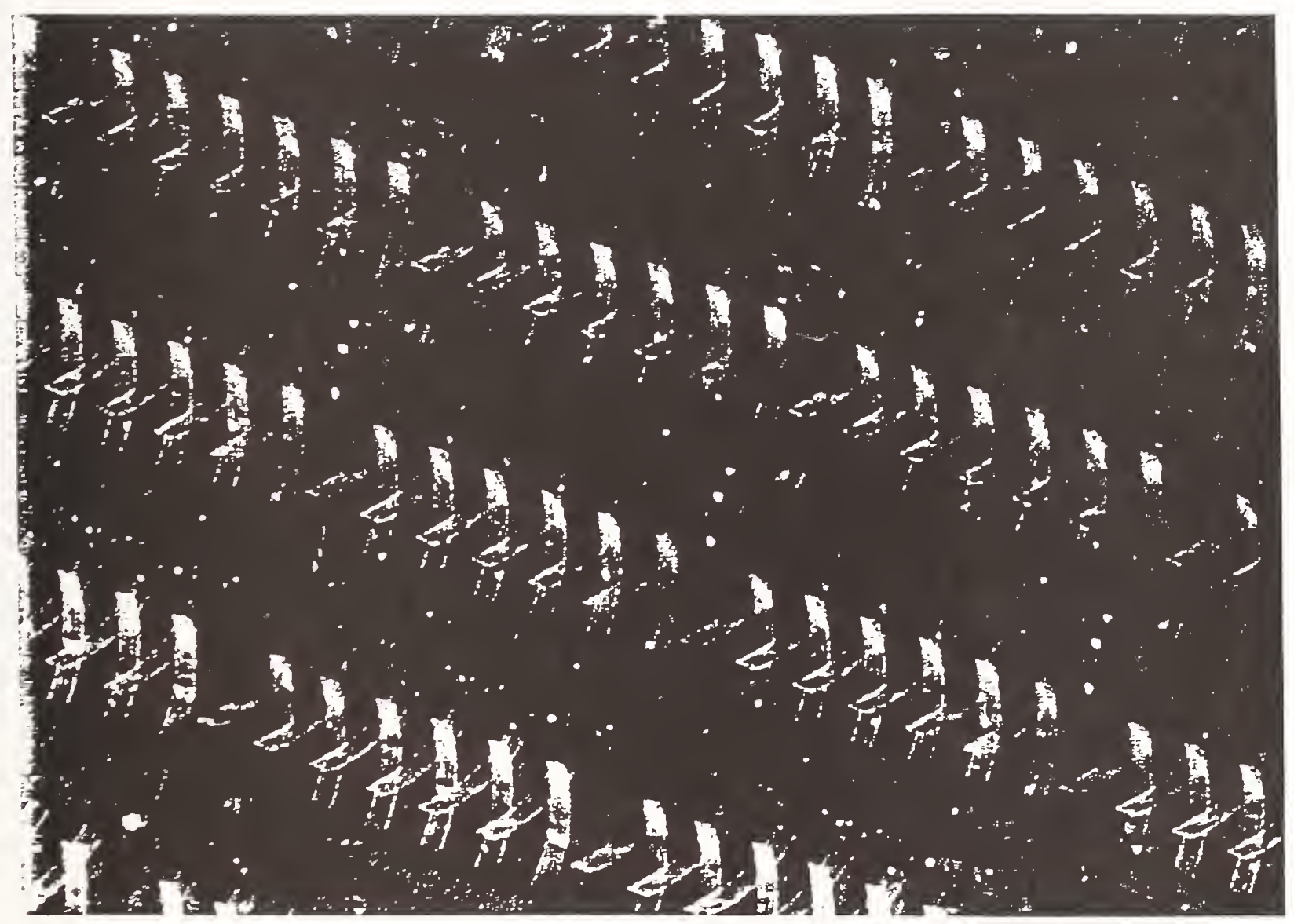

Array of Thermo Bimorph Actuators for Ciliary Motion Sýstem. Each actuator is composed of two layers of polyimides with different thermal expansion coctficients and a micro metallic heater sandwiched between them. (Fujita Lab.. IIS. The University of Tokyo) 
Primal Scientist: Takahisa MASUZAWA

Afflliation: I.I.S. (Institute of Industrial Science) University of Tokyo

Address: $\quad 7-22-1$ Roppongi, Minato-ku. Tokyo 106, Japan Tel.+81-3-3402-6231, Fax .+81-3-3478-0216

Number of staffs: 2 ( 3 students)

Research Overview:

The activity in this laboratory is concentrated on the development of technologies relating the production of micro parts. Manufacturing methods for basic components such as microholes, microspindles, micronozzles are the main targets of the research works.

Research Topics:

1) Micromachining: Machining of microspindles or micropins as the application of WEDG (wire electrodischarge grinding), machining of mocroholes by EDM, punching and drilling. machining of microgrooves by miling and machining of micro nozzles by combination of WEDG, ECM and electroplating, etc.

2) Measuring technology for micro parts: Measurement of inner dimensions of microholes by a newly developed method 'vibroscanning'.

3) Micro assembly: On-machine assembly system for microparts by using WEDG. EDM and ulstrasonic assembly.

Research results in fiscal year of 1992:

1) Inner dimension of $\mathrm{a} \phi 200 \mu \mathrm{m}, 700 \mu \mathrm{m}$ deep hole was successfully measured by vibroscanning method.

2) Machining and assembly of a micropart for Liquid Metal Ion-beam emitter was achleved.

References:

1) C.-L. Kuo, T.Masuzawa, II.Fujino. "IIIgh-Precision

Micronozzle Fabrication". Proc. of IEEE'MEMS '92 (Feb-1992)

2) T.Masuzawa, C.-L.Kuo, M.Fujino, "Drilling of Deep Microholes by EDM using Additional Capacity", Bull.. JSPE, 24,4 (Dec-1990)

3) T.Masuzawa, M.Yamamoto, M.Fujino, "A Micropunching System using Wire-EDG". Proc. of ISEM-9 (Apr-1989)

4) T.Masuzawa, M.Fujino, K.Kobayashi, T.Suzuk1, "W1re Electro-Discharge grinding for Micro-Machining". Annals of the CIRP, 34, 1 (Aug-1985)

5) T.Masuzawa, I.Tsuchiya, "Low-Energy High-Current Ion

Source for Ion-Milling Equipment". Annals of the CIRP, 33, 1 (Aug-1984) 


\section{Microfabrication Technologies \\ Takahisa MUSUZAWA (I.I.S., University of Tokyo)}

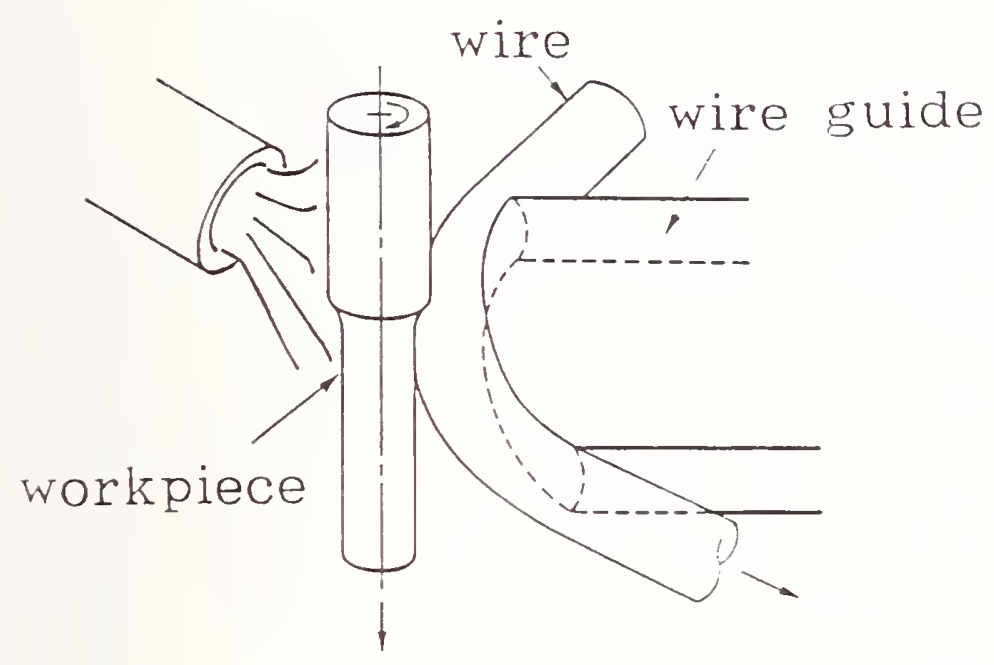

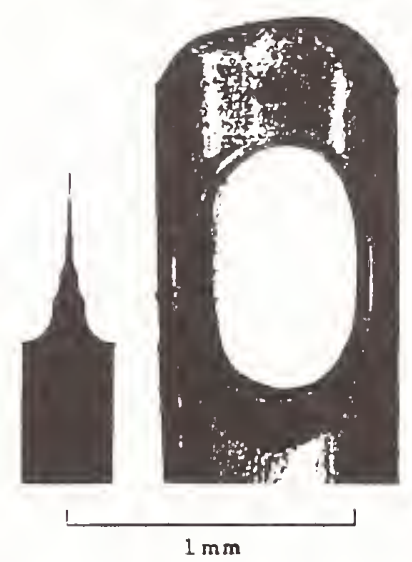

A $\phi 5 \mu$ m tungsten micropin (compared with a sewing needle head).

Fig.1. Wire electrodischarge grinding method for producing micropins, microspindles and microtools.
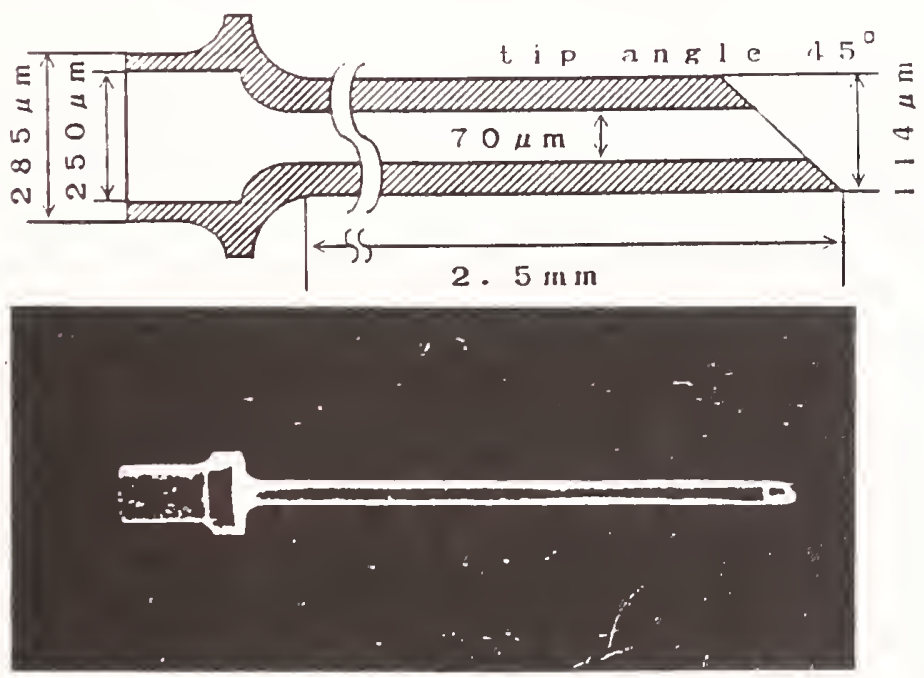

fig.2. A micro injection needle produced by a combined process with WEDG, ECM (electrochemical machining) and electroplating. 


$\begin{array}{ll}\text { Primal Scientist: } & \text { Isao KARUBE } \\ \text { Affiliation: } & \text { RCAST(Research Center for Advanced Science and Technology) } \\ & \text { University of Tokyo } \\ \text { Address: } & 4-6-1, \text { Komaba, Meguro-ku, Tokyo, Japan } 153 \\ & \text { Tel. +3-3481-4470, Fax. }+3-3481-4581\end{array}$

\section{Besearch Overview:}

Miniaturization of biosensing system using micromachining techniques is now under investigating. Enzymatic flow injection system is mainly studied.

Electrochemical detector, photochemical detector, and enzyme reactor have been fabricated, and also integrated each other. Further research will focus on micropump, which makes it possible to fabricate handy-type flow injection system for clinical, industrial process and environmental monitoring.

Besearch Topics and Research results in fiscal year of 1991:

1) Glucose sensing system with electrochemical detector:

Silicone capillary of $0.1 \mathrm{~mm}$ width and $1 \mathrm{~m}$ long was fabricated, and glucose oxidase was covalently immobilized on inner surface of the capillary. And thin film gold electrodes were integrated to detect hydrogen peroxide which is product of enzyme reaction.

2) Glucose sensing system with photochemical detector:

Glucose oxidase immobilized glass beads were packed into the chamber of device which has the other chamber to mix product of enzyme reaction and reagents to get chimiluminescence detected by photodiode connected on the device

\section{References:}

1) Y.Murakami, et al. "Flow type biosensing system using micromachining techniques", proc. of annual meeting of Japan Chem. Soc. I pp.370, (Oct.-1992) 2) T.Takeuchi, et al. "Enzyme FIA system using micromachining techniques", Kagaku, Vol.47, No.6, pp.434 (Jun.-1992)

3) M.Suda, et al. "Micromachined Biosensors", proc. of Biosensors, pp.400 (May1992) 

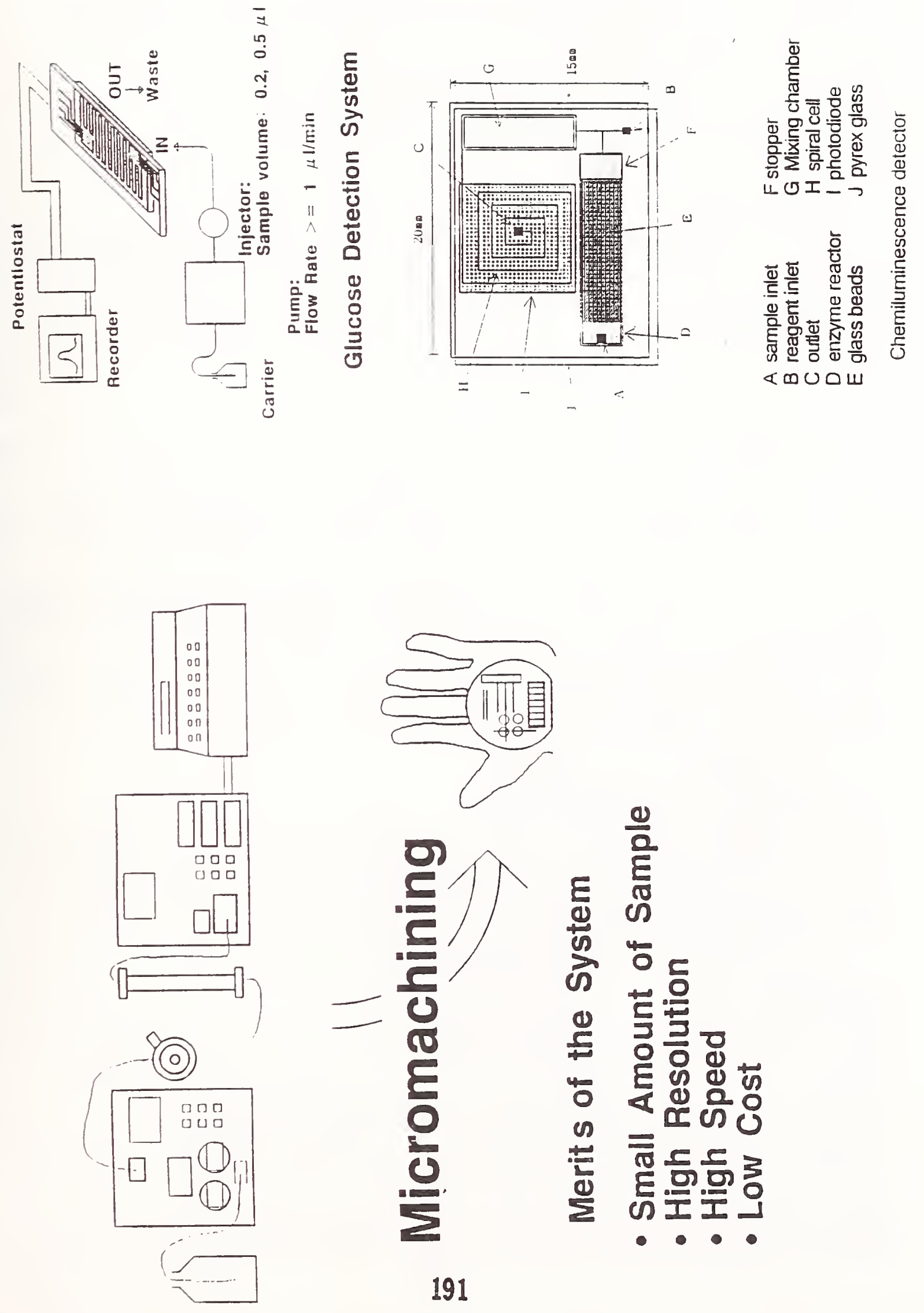
Primai Scientist: Tomomasa SATO

Affiliation: RCAST(Research Center for Advanced Science and Technology) University of Tokyo

Adress: $\quad 4-6-1$, Komaba, Meguro-ku, Tokyo, Japan 153

Tel.+3-3481-4479, Fax.+3-3481-4584

Number of staffs: 2 ( 7 students)

Research Overview:

Intelligent robot to handle very small objects has been investigating. The following are the examples of tasks: assembly of micro machines, repair of VLSI's, micro surgery, physical measurement of very small biological organs such as years and cells, physical handling of genes. We have be en conducting the research systematically from mechanism and control to intelligence for task execution and friendly human robot interraction.

Research Topics:

1) Micro and nano object handling robor. A manipulator mechanism and its control, vision and force sensor fusion, model based realtime task oriented intelligence are studied to realize an autonomous hand-eye system consists of optical microscopy or SEM (scanning electron microscopy) and micro handling manipula tor with sensitive force sensor.

2) Micro and nano tereoperation: The research topics includes such robot support function for human operator as damage prevention, perception enhancemant, knowledge augmentation, shared skillful task execution and learning of the task.

3) Multirobot for human support. An automatic behavior understanding of a)robot action, b)human operator and c)surrounding robot behavior is the base of the coperation between multirotbots as well as human operator and robots.

Reseasrch results in fýscal year of 1993 :

1) Micro object handling robot A "vision/motion/operation co-focused manipulator system" suitable for micro handling task was realized. In this system a work space locates inside the manipulator because the handling object is far smaller than the manipulator, while a work space exisits around the manipulator and the task is performed by extending its manipulator in conventional industrial robot.

References:

1]T.SATO,"Tcleopcraton Technology in MITT Advanced Robot Technology Project", IEEE Int. Conf. on Robotics and Automation (May-1992)

2]Sakanc、Sato、" Automatic Planning of Light Source and Camera Placement for an Active Photometric Stereo System" 、IEEE Robotics and Automation (May-1991) 3]S.Sakane, T.SATO, M.KAKIKURA."Sctup Planning of Act ive Sensing for Autonomous Robots", J. of Robotics and Mechatronics, Vol.3,No.3.pp196-200(1991) 4]S.HIRAI, T.SATO, T.MATSUI,"Intelligent and Cooperative Control of Telerobot Tasks", IEEE Control Systems, Vol.12, No.1,pp51-56 (Feb-1992)

5]Sato、Hiari、Matusi : " A Telerobot System MEISTER: An Integration of Task Knowledge Base and Cooperative Maneuvaring System" 11th Int. Conf. on Structural Mechanics in Reactor Technoiogy (Aug-1991) 


\section{"Intelligent Robot to Handle Very Small Object"}

Tomomasa SATO (RCAST, University of Tokyo)

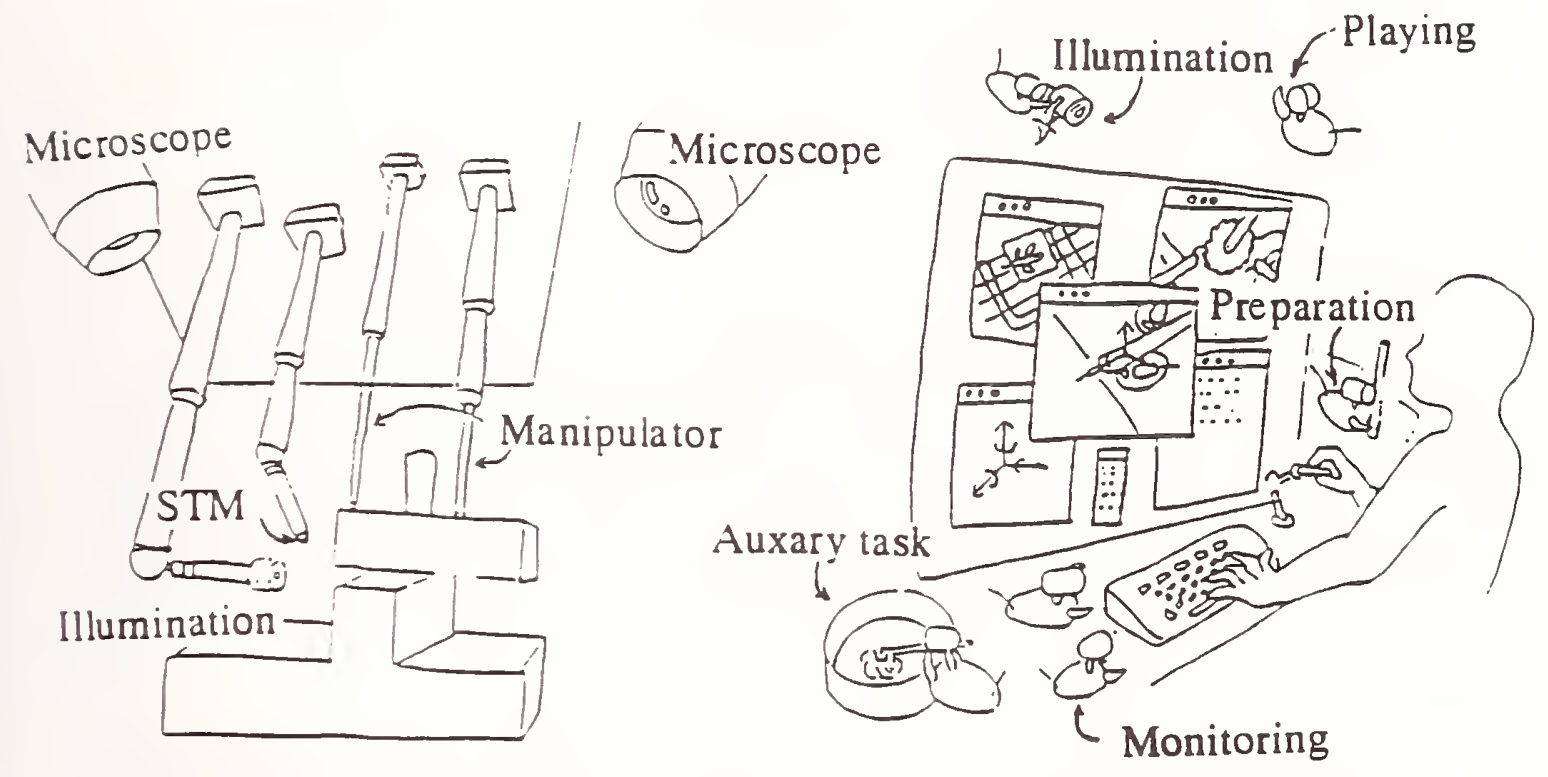

Fig.1 Image of intelligent robot system to handle very small object

The system consists of the following tree components;

1) micro object handling manipulator system,

2) intelligent teleoperation system,

3) multirobot system to support human operator.
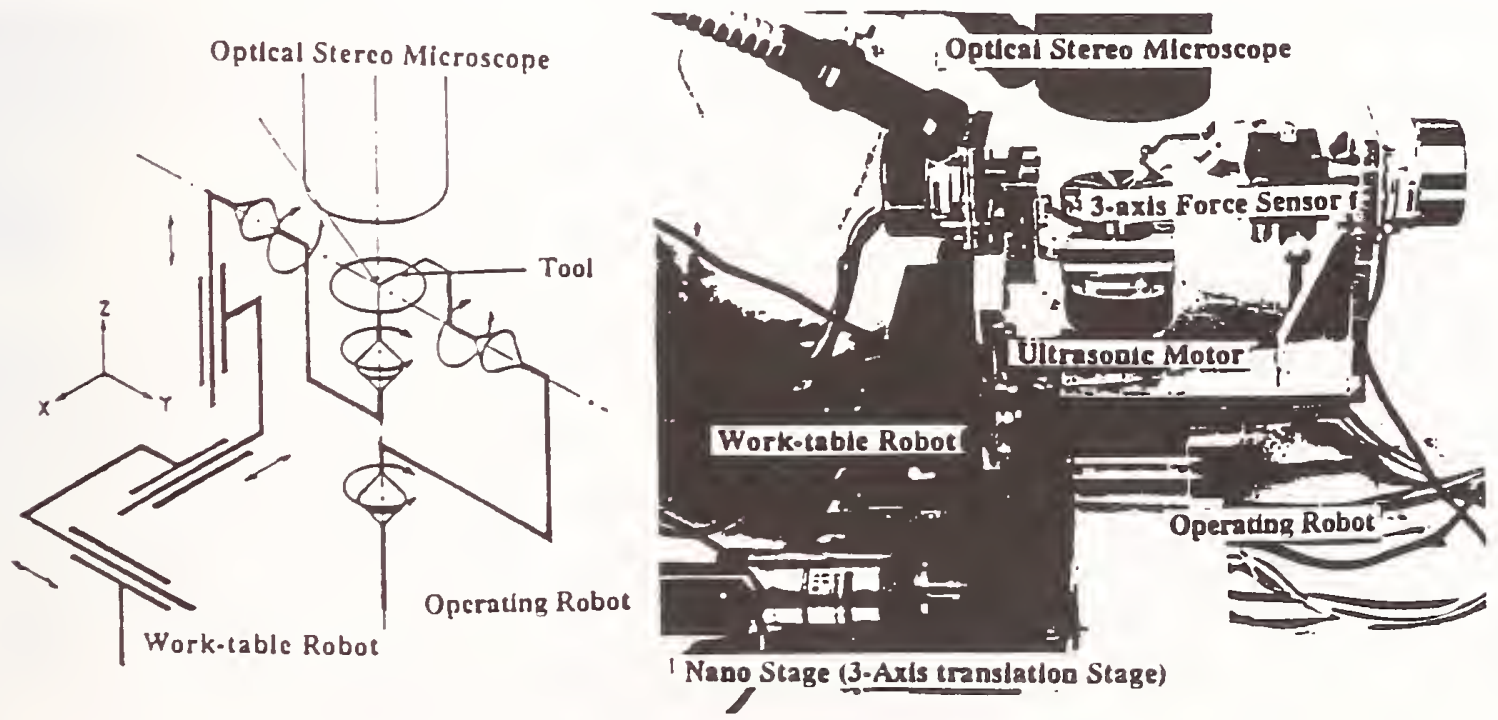

Fig.2 Realized micro object handling manipulator system

The main feature of this manipulator system is that the work space is located inside the manipulator while the work space is spread around the manipulator in case of conventional industrial robot. This new configulation makes the robot suitable for very small object handling. 
Primal Scientist: Tadatomo SUGA

Affiliation: RCAST(Research Center for Advanced Science and Technology) The University of Tokyo

Address: $\quad 4-6-1$, Komaba. Meguro-ku, Tokyo, Japan 153

Tel./Fax. 03-3481-4488

Number of staffs:3(10 students)

Research Overviews:

We are developing noble techniques for assembling micro-components such as sensors, actuators, processors and structural components in micron-scale, and for constructing integrated micro-robot systems. The basic technologies for the micro-assembly include the development of the micro-machining process for silicon, direct bonding of silicon and piezo-electric ceramics, micro-bonding of LSI circuits. and micro-manipulation of the in scanning electron microscope, as well as fundamental understanding of the mechanism of adhesion and bonding.

Reasearch Topics:

1)Development of the surface activated bonding ( $\mathrm{SAB}$ ) method for room temperature joining; a) development of the SAB process, b) investigation and optimization of the process parameters in the $S A B$ method.

2) Characterization of the microstructure of $S A B$ joined interfaces by high resolusion electron microscopy.

3)Development of a bonding apparatus for manipulation and assembly of micro-components in UHV; a)development of the micro-manipulation and precise allignment system.

4)Development of a micro-force sensor and it application to the atomic force microscopy(AFM).

5)Analysis of adhesion and bonding process by means of the molecular-dynamic simulation and finite element method.

Research results in fiscal year of 1992 :

1) We have succeeded in microbonding of LSI and microelectronic components such as LSI flip chip by SAB method at room temperature.

2) We have developed the new $S A B$ process using the radical beam source or the fast atom beam source in $\operatorname{UHV}\left(<10^{-8} \mathrm{~Pa}\right)$.

3) The force sensor using piezoelectric cantilever for the noncontact AFM has been developed.

\section{References:}

1)Yutaka TAKAHASHI, Eiichi HOSOMI and Tadatomo SUGA, "Low-Resistivity Contact of YBa2Cu3O7-x/Al Joint Bonded at Room Temperature". Jpn J. Appl. Physics. 30.12A(1991) L2028-

3]Hideki TAKAGI, Yutaka TAKAHASHI. Tadatomo SUGA and Yoshio BANDO, "High Resolution Electron Microscopy of $\mathrm{Al} / \mathrm{Si}$ and $\mathrm{Al} / \mathrm{Si} 3 \mathrm{~N} 4$ Interfaces Prepared by Room Temperature Bonding Method(Japanese)", J. Japan Inst. Metals, 55(1991) 907-908

4]Yutaka TAKAHASHI, Hideki TAKAGI, Tadatomo SUGA, Borris GIBBESCH, Gerhard ELSSNER and Yoshio BANDO, "Enviromental EFFects on Structural, Mechanical and Electrical Properties of Al/AJ Interfaces Joined at Room Temperature(Japanese)", J. Japan Inst. Metals. 55(1991) 1002-1010 
"Micro-assembly and Interconnection"

Tadatomo SUGA (RCAST. The University of Tokyo)
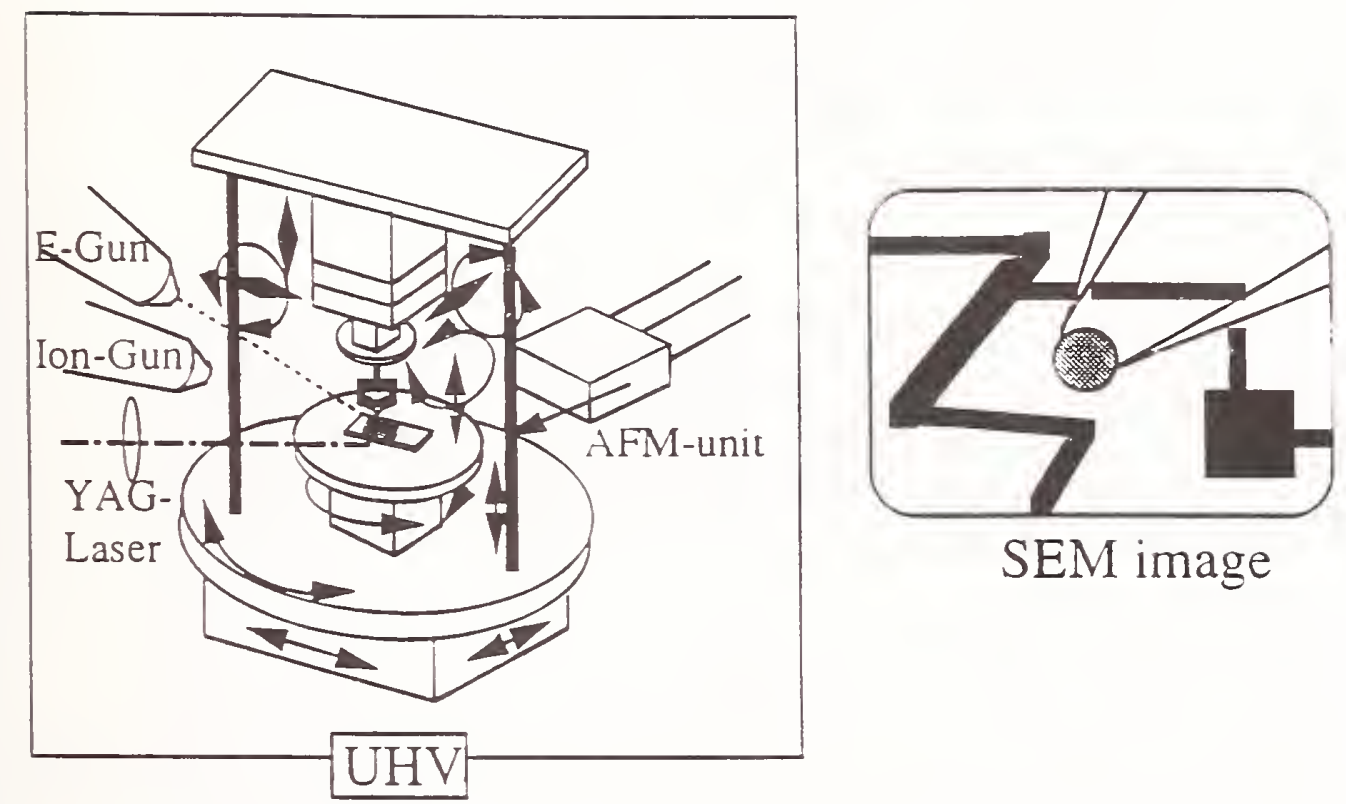

Fig.1 Schematic illustration of micro-assembly system in UHV. The system possesses the following functions: (1) surface activated bonding at room temperature, (2) manipulation and assembly of micro-components in SEM, (3) characterization of the surface topography by atomic force microscope.

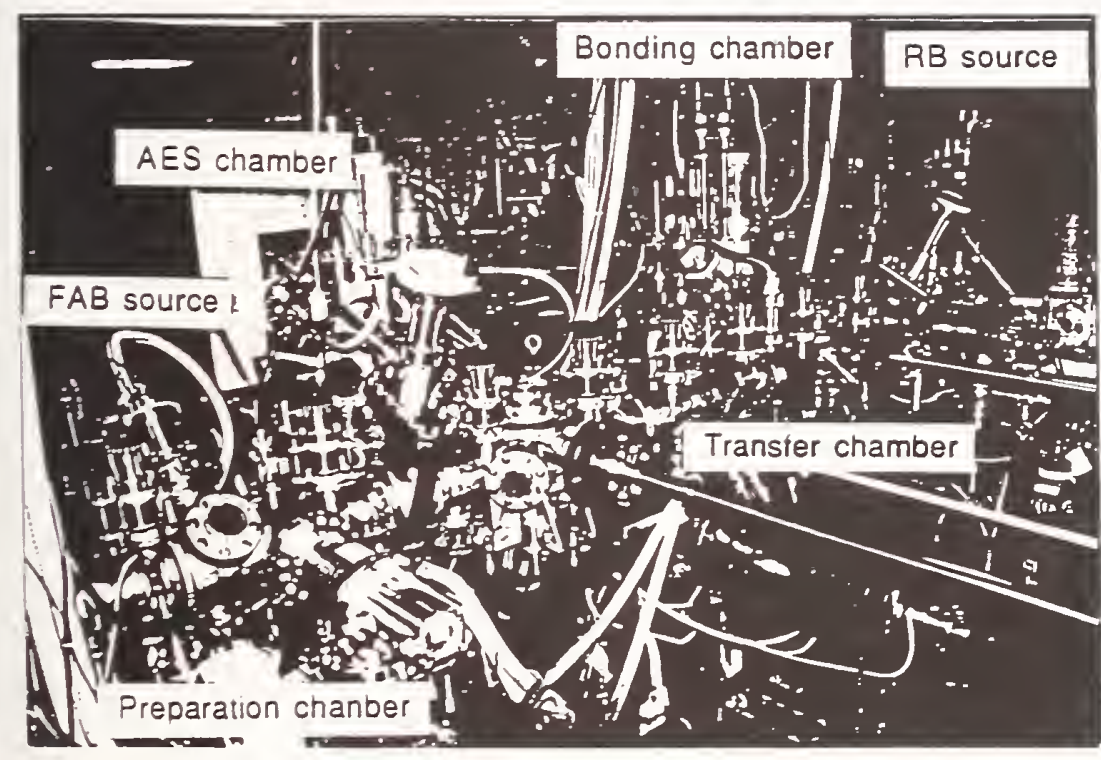

Fig.2 Apparatus for the surface activated bonding (SAB)method. The apparatus consists of UHV bonding chamber, transfer chamber and two preparation chambers with the radical beam source or the fast atom beam source.

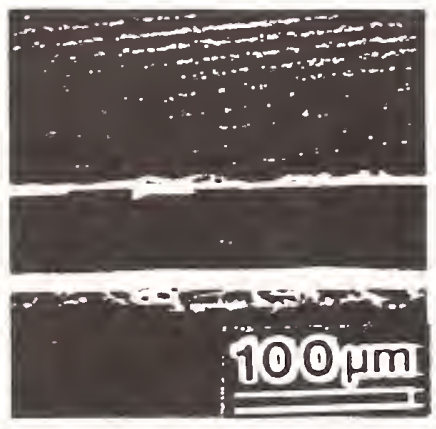

Fig. 3 SEM micrograph of LSI flip chip bonded by SAB method at room temperature. 
Primary Scientist: Hideharu TANAKA

Affiliation:

Advanced Mechanical System Dept.

Central Research Laboratory,Mitsubishi Electric Corp.

Address: 1-1,Tsukaguchi-Honmachi. 8-chome.Amagasaki.Hyogo,661

Japan. Tel.+6-497-7165,Fax.+6-497-7291

Number of staffs: $\quad 15$

Research Overview:

$R \& D$ of $3 D$ micro magnetic structures and its appliances has been conducting. Targets of R\&D are establishment of $3 D$ material processing, rising power density(output power/volume), size reduction to microscopic, and application to micro-magnetic devices.

Research Topics :

1) Energy product(coercivity, residual flux density) upgrading of thin-film permanent magnet: Main technical subjects are formation of uniform composition ,homogenization of crystal structure, anisotropic crystal orientation along the direction of magnetic flux .

2) Wire-wound microscopic structure: A structure consists of thin-film core stack and $3 \mathrm{D}$ coil. Material processing is investigated to realize a stereoscopic and complicated structure such like this.

3)Micro-electric power generating device: This consists of turbine, speed-up gears and $\mathrm{AC}$ electric generator to converse water flow energy to electric power energy. This R\&D was planned to participate in National Large-Scale Project" Micromachine Technology".

Research Results in fiscal year of 1992

1) Fundamental approach to establish the uniform formations of composition and film thickness was experimentally carried out in the study of thin-film permanent magnet.

2) Several approaches to the material processing for $3 D$ wiring were examined.

3) To extract technical subjects on rising power density, a electric generator of 7 $\mathrm{mm}$ in diameter and $9.5 \mathrm{~mm}$ in length and also speed-up planetary gears of 4.6 $\mathrm{mm}$ in diameter and $3 \mathrm{~mm}$ in length were manufactured on a trial basis. Output power of approximately $2 \mathrm{~W}$ was obtained at the rotor speed of 0.15 million rpm. 


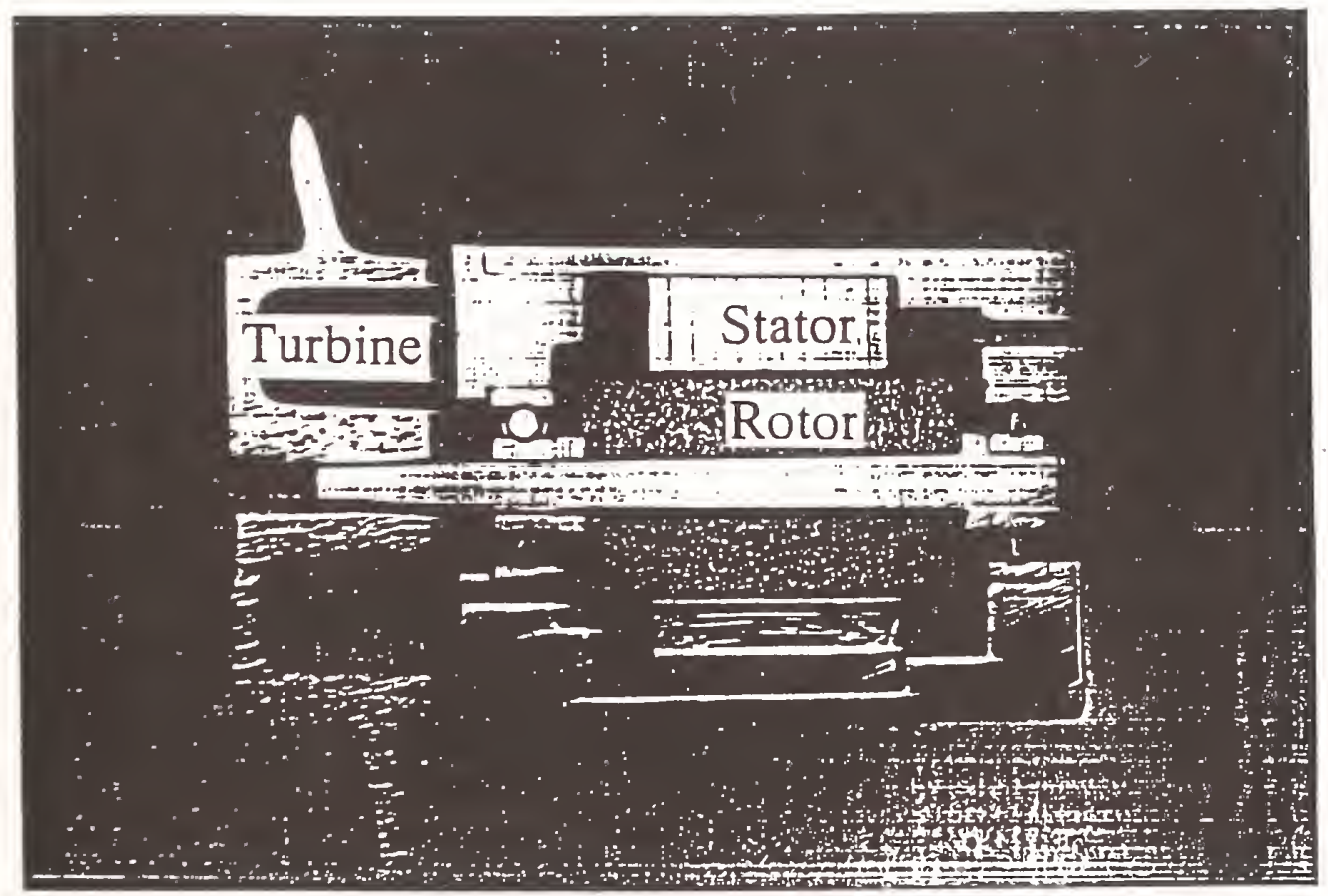

Fig. 1 Electric Generator Driven by Air Turbine

The structure is as following;

1)Stacked cores(silicon steel) of a stator were processed

by focused Ion Beam.

2)Winding (30 $\mu \mathrm{m}$ wire in diameter) was performed

by hand work using a microscope.

3)Rotor was made of rare-earth plastic permanent magnet. 
Primal Scientist: Shinobu SaGISAWA

Affiliation: Fuji Electric Corporate Research and Development. Ltd.

Ayress: 2-2-1, Vagasaka, Yokosuka city, Kanagawa, Japan 240-01

Tel. +468-57-6734, Fax. +468-56-2751

Number of staffs: 10

Research Overview:

Silicon based sensors such as tactile sensor, pressure sensor and acceleration sensor have been investigating.

Tactile image recognition system using the data from 3 axis tactile sensor array have been also investigating. " 3 " axis means a pressure and 2 shear forces

Micro actuators based on the principle of magnetic and electrostatic force have been investigating.

Research Topics:

1)Tactile sensor and image recognition system: 3 types of tactile sensors, which are 3 axis-3mm, 3 axis-imm and 1 axis-2mm, had been developed. Low-cost and size-extensible sensor array for comnercial needs has been developping.

Tactile image recognition system, which can recongnize the force pattern, moment, force centroid, sliding and hardness of grasped object, had been investigating.

2)Micro Actuator: Sizing down the magnetic actuator and enlarging the force and displacement of electrostatic actuator have been promoting.

Research results in fiscal year of 1991:

1)Tactile sensor and image recognition system: Size-extensible tactile sensor array was realized. The array has $16(4 \times 4)$ sensing elements and a scanner IC. The arrays can be connected each other easily by soldering the pads and thus can meet various size demands. Tactile image recognition system, which has above menti-oned faculties, was realized.

2)Micro Actuator: A $4 \mathrm{~mm}$ dia. stepping motor(actuator), which has good speedcotrolability, was develoed. A $2 \mathrm{~mm}$ dia. actuator have been fabricated. A proto type mm-sized electrostatic actuator for the proof of new principle has been tested.

Refereces:

1]S.Sgisawg et al. "Three Direction Sensing Tactile Sensor" Proc. IEEE, Intern. Workshop on Intell igent Robot and Systems, pp. 47-51 (Nov. 1988).

2]S. Sgisawa et al., "Accurate Tactile Sensor Array for Robot Fingertip" Proc.

Intern. Symposium on Industrial Robots, pp. 243-248 (Oct. 1990).

3]M. Ooka et al.: "Tactile Expert System Using a Parallel Finger Hand with ThreeAxis Tactile Sensors" Trans. JSME, Vol.C-57, No.544, pp.3855-3862, (Dec. 1991) (Japanese).

4]K. Ueyanagi et al., "Extensible Tactile Sensor Array and its Application" Proc. Symposium on Robotics and Mechatoronics '92, Vol.A, pp.781-784, (June 1992) (Japanese).

5]H. Nakazawa et al., "Parmanent Magnet Type Stepping Motor which have Magnetic Cercuits Adapted Small Diameter" Proc. Symposium on Robotics and Mechatoronics '92. Vol.A, pp.1003-1004, (June 1992) (J'spanese). 
"Tactile Sensor Array and Micro Actuator"

Shinobu SiGisalA (Fuji Electric C.R.\&D. Ltd.)

Table 1 Specifications of 3 Types of Tactile Sensors

\begin{tabular}{|c|c|c|c|}
\hline & $303 M$ & $3 D \perp M$ & $102 M$ \\
\hline xeans of rorce oetection i & f Pletoresistive Ellect & Ifletoresistlve Elfeet & Pletoresistive Ellect \\
\hline $\begin{array}{c}\text { Deteecuble Comoonents } \\
\text { of force }\end{array}$ & J cosponencs & 3 Cosponerts & 1 conponent \\
\hline 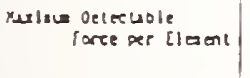 & $\begin{array}{l}r x: \pm O N \\
r r: \pm O N \\
r r: 20 N\end{array}$ & $\begin{array}{l}r x: \pm 0.7 \mathrm{~N} \\
r: \pm 0.1 \mathrm{~N} \\
r 2: \quad 2 \mathrm{~N}\end{array}$ & $n: 10 \mathrm{~N}$ \\
\hline senstitivig & 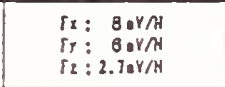 & $\begin{array}{l}\Gamma: 107 a Y / H \\
f r: 107 a V / 11 \\
r_{2}: 1002 V / H\end{array}$ & $12: 60$ V/ \\
\hline slze of an Elatent & 3at square & I se Lons of bese & I we Square \\
\hline theber of Elesents & $9 \times 15$ & $1 \times 4.1 \times 12$ & 11.8 .7 \\
\hline Nerarsaent of Elatents & atelx & ratrix. & Ourved surface \\
\hline Heber of Electrle viresi & $\theta$ & 7 & 7 \\
\hline
\end{tabular}
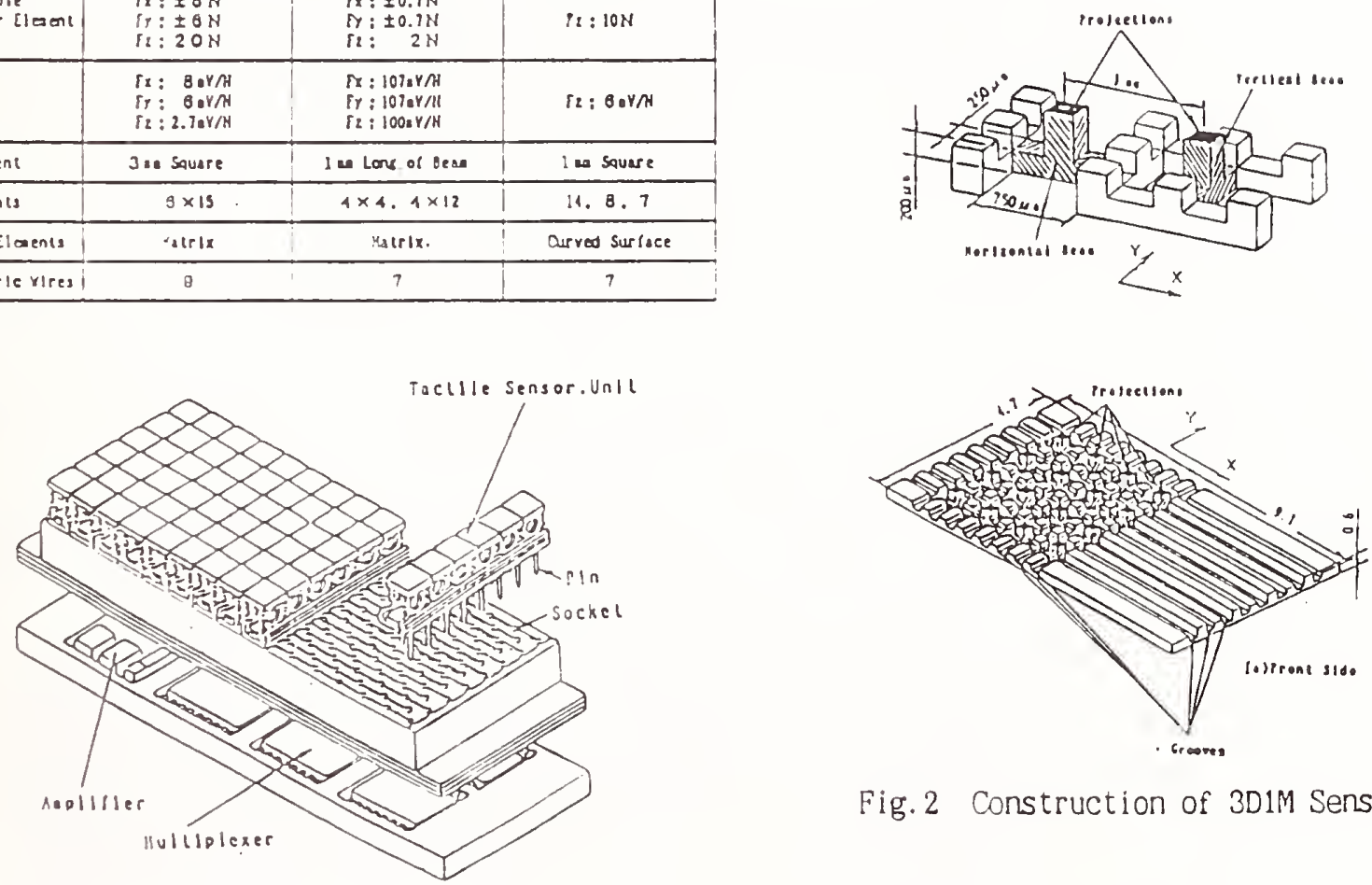

Fig. 2 Construction of 3D1M Sensor

Fig. 1 Construction of 3D3M Sensor

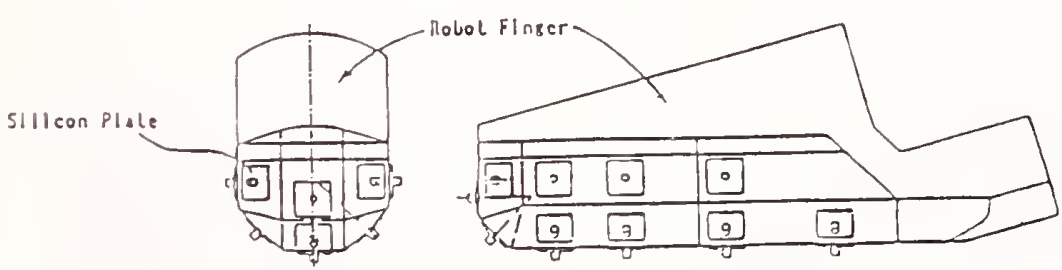

Fig. 3 Construction of 1D2M Sensor

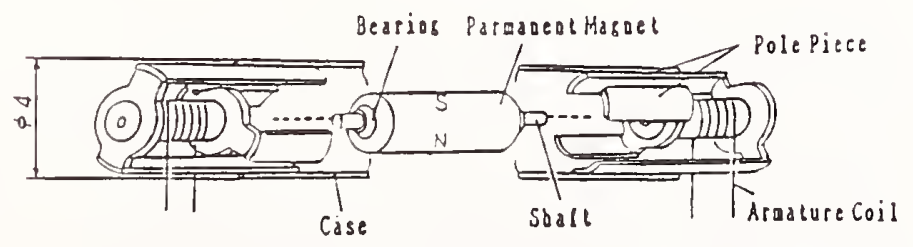

Fig. 4 Construction of Magnetic Micro Actuator 
Primal Scientist: Yoshimitsu KUROSAKI

Affiliation: KAWASAKI liEAVY INDUSTRIES.LTD.(KHI)

System Technology Development Center

Address: $\quad$ 1-l.Kawasaki-cho.Akashi.673 Japan

Tel. $+81(\mathrm{~J}$ apan $)-78-921-1643, \mathrm{Fax} .+81-78-921-1610$

Number of staffs: 8

Research Overview:

A ultra-precision servo control system has being investigated. The following are the examples ol tasks;a nanometer allgnment system the future linear collider,fine motion stage for precision machining and laser mirror alignment. We have constructed a test facility to study the position control system with multiple degrees of freedom .

Research Topics:

1)Ultra-precision alignment for the future linear collider : It is commonly recognized that a nanometer alignment system for will be required for the final focusing magnets of the future e+e- collider. A alignment contorl system for a massive load is to cancel the effect of thermal deformation due to the local temperature difference ground motion and the vibration due to the cooling water pulsation .

2)fine motion mechanism and motion stage using parallel spring: We study

(a)position control method and (b)control system configuration for the six-degrees of freedom fine motion mechanism. We are also building a new fine motion stage using parallel spring for precision machining.

3) Nanotechology in metrology: The iodine-stabilized HeNe laser is currently the best practical realization of the unit of length. We study anew measurement of the transverse displacement using a laser beam and a pair of position sensors. We will be to study length scales that have a large dynamic range up to a meter. but will allow tenth nanometer measurements with high bandwidth.

Research results in fiscal year of 1993:

1)Position control table for FFTB final lenses: A position control table supports three final lenses of a final focus test beam line (FFTB). The table position is controlled with the accuracy of $50 \mathrm{~nm}(\mathrm{rms})$ in vertical and horizontal directions in order to keep the beam position stable as 60 $\mathrm{nm}$ (rms) for the iron table and three magnets that are twenty-five tons in weight.

\section{References:}

1) N.Ishihara et al., "A Position Feedback Control System for the Test Facility of JLC"in Proceedings of the international Conference on Accelerator and Large Experiment Physics Control Systems, KEK.

Nov.11-15, 1991

2)T.Kubota et al., "A Test Facility for the Position Control System of JLC"in Proceedings of the 2nd International Workshop on Accelerator Alignment. DESY, JUL.10-13, 1990

3)K.Mlyashita et al.,"Transverse Displacement Measurement using Sprî Laser Beam"in proceedings of XVTH International Conference on High Energy Accelerators. Hamburg, JUN. 20-24, 1992 


\section{"Ultra-Precision Servo Control System" \\ ioshimitsu niROSAKI(Kawasaki Heavy industries. Ltd.)}

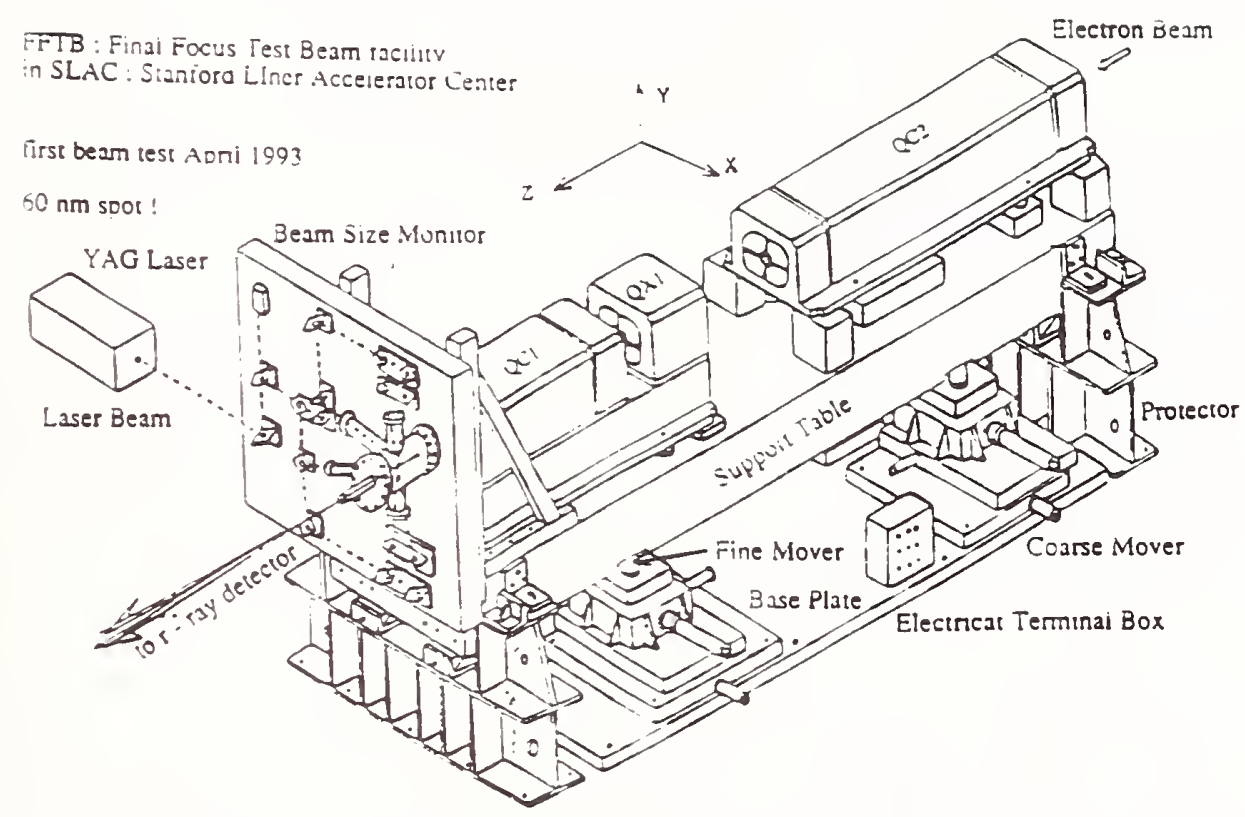

Flg.1 Illustration of the position control table and the final lenses

The system consists of the following components:

1) the rable is supported by four movable legs consisting of screw jacks as coarse movers and piezoelectric actuators as flne movers.

2) control system consists of actuators. laser interferometer and hlgh-speed controller using VilE modules.

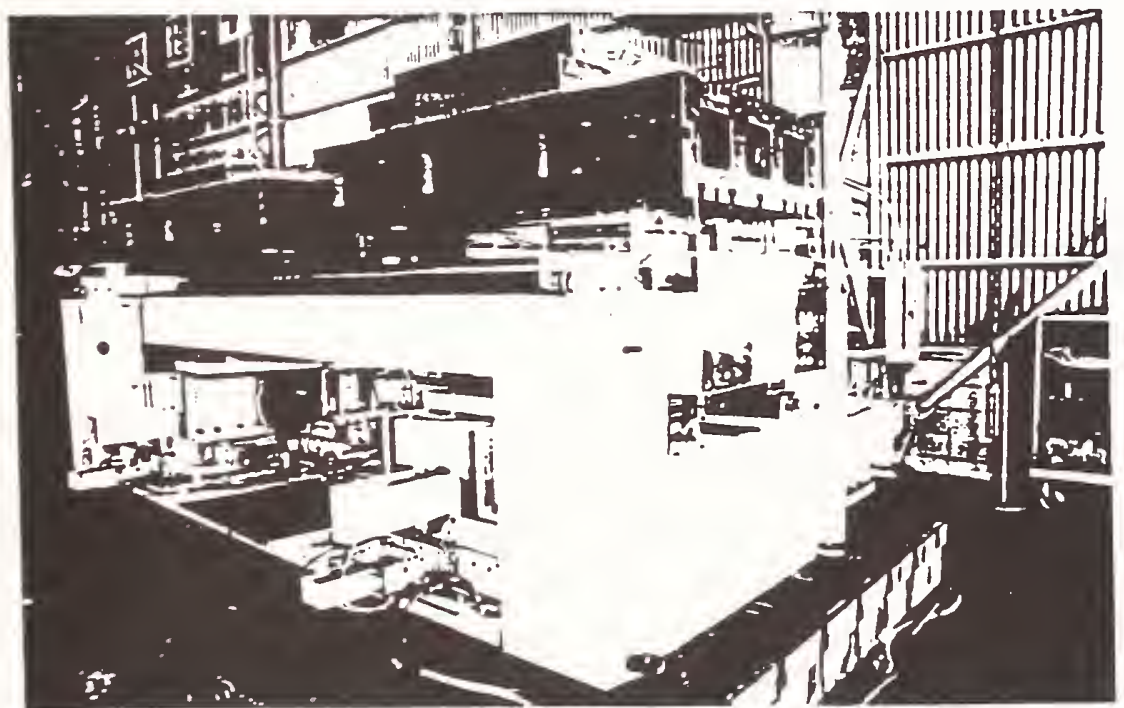

Fig.2 Position control table loaded with dummy weights Maln parameters of the control tables

$\begin{array}{lll}\text { Table Load capacity } & 8 \mathrm{t} \\ & \text { Slze } & 1000(\mathrm{~W}) \\ & \text { Empty weight } & 16 \mathrm{t} \\ \text { Natural frequency } & 90 \mathrm{~Hz} \\ \text { Mover } & 10 \mathrm{~mm} \\ & \text { Tlme response } & >10 \mathrm{~nm} / \mathrm{s} \\ \text { Tolerance } & 50 \mathrm{~nm} \text { (Y-axis) } \\ & 500 \mathrm{~nm} \text { (X-axis) }\end{array}$


Primal Scientist: Tsutomu YANO

Affiliation: Opto-electro Mechanics Research Laboratory

Matsushita Research Institute Tokyo, Inc.

Address: $\quad 3-10-1$ Higashimita. Tama-ku, Kawasaki 214, Japan

Number of staffs: 8

Research Overview:

We have been developing the micro electro-discharge machines for the micro machining. The capability of machining a micro hole and a micro shaft as small as $5 \mu \mathrm{m}$ in diameter have been achieved. We are now studving the technologies of the micro EDM for the production of the micro mechanical parts which will be required in the fields of the micro electro mechanical systems.

\section{Research Topics:}

1) Three dimensional micro machining

Three dimensional micro machining as well as a simple micro boring has been achieved by minimizing the discharging energy to $10^{-7} \mathrm{~J}$ level and by realizing a precise mechanism providing submicron accuracy. ")

2) Silicon EDM

Boring a micro through-hole and forming a three dimensional micro structure in a silicon wafer which is very difficult by the silicon process has been done by the micro EDM technologies. ${ }^{3)}$

3) Micro air-turbine

A prototype micro air turbine, which can be inserted into a catheter of $2.2 \mathrm{~mm}$ in external diameter, has been built by micro EDM and rotated at the speed of approx.1000rpm. ${ }^{3)}$

Research results in 1992 :

1) Mold for the micro-gear

Technologies to reduce the wear of electrode for forming a high precision complex shape has been developing, and a micro mold for the injection plastic micro-gear which has 9 involute curved teeth in $0.3 \mathrm{~mm}$ pitch circle diameter has been machined. ${ }^{4)}$

\section{References:}

1) T.Sato, T.Mizutani, K.Kawata ; "Electro-Discharge Machine for Micro hole Boring", National Technical Report, Vol.81 No.5 p105-113,Oct. 1985

2) T.Masaki, K.Kawata, T.Mizutani, K.Yonemoti, A.Shibuya, T.Masuzawa : "Micro ElectroDischarge Machining", Proceedings of International Symposium for Electro-Machining,p26-29.1989

3) T.Masaki, K.Kawata, T.Masuzawa; "Micro Electro-Discharge machining and its applications",Proceeding IEEE Micro Electro Mechanical Systems, Napa Valley, CA, Feb. 1990, p21-26

4) K.Nakamura, K.Amemiya, K.Sato, T.Masaki, R. Toyoda ; "The research for the micro-sinking with micro EDM", Proceeding Precision Engineering Oct. 1992. p679-680 (in Japanese) 


\section{Micro EDMed Examples}

Photo 1. Pyramid on $2 \mathrm{~mm}$ dia. ball

Pyramid dimension :

$150 \mu \mathrm{m}$ base square. $\mathrm{H} 50 \mu \mathrm{m}$

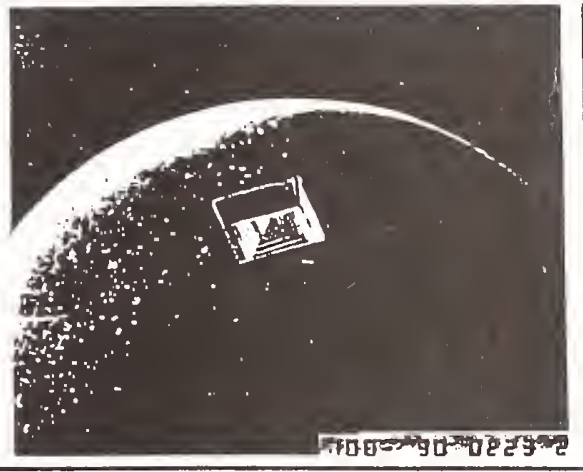

Photo 2. Vertical beam in Silicon

Beam dimension :

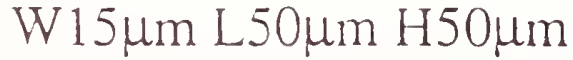

Silicon: P-type, $<1.1,1>$

$10 \sim 100 \Omega \mathrm{cm}$

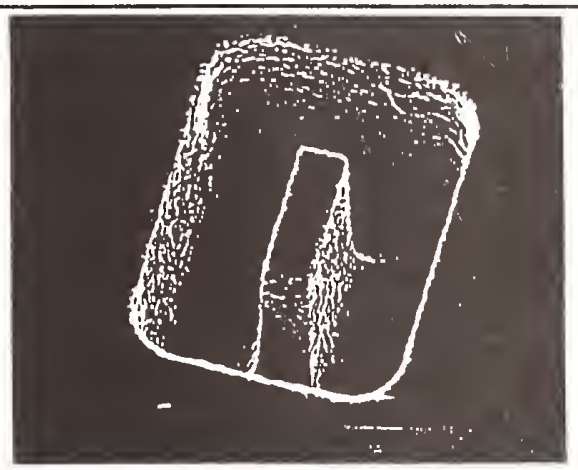

Photo 3. Micro Air tubine/rotor

Rotor outer diameter:0.95mm

Shaft diameter: $0.3 \mathrm{~mm}$

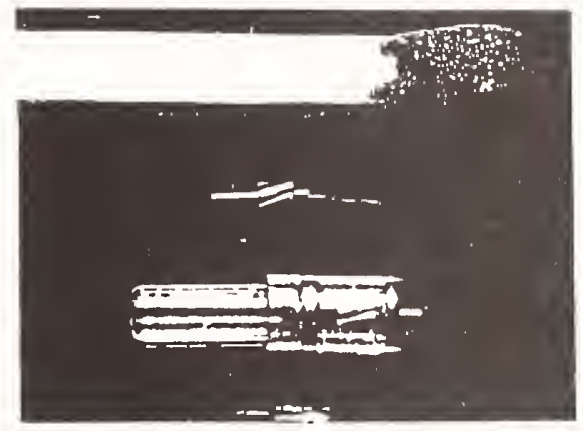

Photo 4. Micro-gear mold

$0.3 \mathrm{~mm}$ p.c.d.

Stainless steel 304

$0.1 \mathrm{~mm}$ thickness

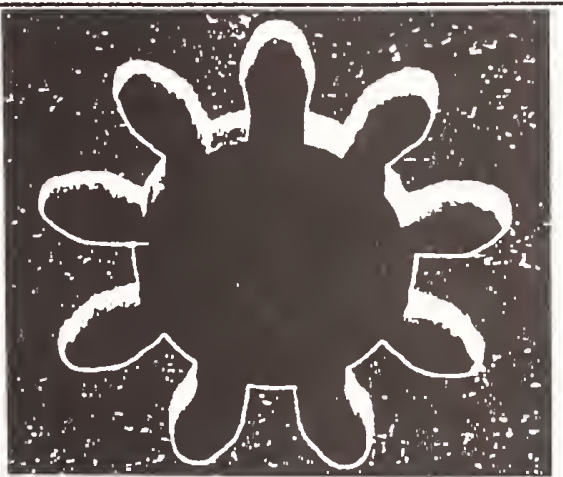


Primal Scientist: Akiomi KOHNO

Affiliation: Mechanical Engineering Research Lab.,Hitachi,Ltd.

Address: 502 Kandatsu, Tsuchiura, ibaraki 300, Japan

Phone: +81.298 .32 .4111$, Fax: +81.32 .8251$

Research Overview:

Micro-joining has emerged as a major element of the micro-assembly and micro-mechanics technologies receiving significant interest today.

Attention has been paid to low temperature bonding by means of Argon atom bombardment, because the process is expected to apply to heat sensitive materials and delicate micro-devices and mechanics. The method is based on the fact that when two clean surfaces are brought into contact, strong adhesive bond forces can develop at the interface between the solids. This project aims to develope techniques to overcome the process assembly problems including a general reduction in process tolerances, surface contamination and distortion of components due to heating and pressure during bonding.

\section{Research Topics:}

1) Surface activation technology

The standard joining (mainly solid phase bonding or soldering) require clean surfaces to be able to achieve high integrity adhesion. With micro-components decreasing in size, contamination problems are more critical. Sputter-cleaned technique by Argon atom bombardment has been developed as the surface activation method for low temperature joining.

2) Surface analytical technique for defining surface condition and to quantify its effect on bondability.

The UHV bonding apparatus has been developed, in which surfaces of specimens to be bonded can be analyzed in-situ by AES and SIMS.

3) Flip chip bonding process with fluxless

Argon beam cleaning and heating is shown to be well suited for reflowing solder pads for subsequent joining of circuit chips to substrates. The process can eliminate the need for chemical flux in obtaining high quality solder joints.

4) Silicon bonding

Interest is now being directed towards silicon to silicon, metals and glass bonding for which processes have not yet been demonstrated. A number of techniques offer potential for this materials, and trials will be carried out using electrostatic bonding, diffusion bonding, eutectic bonding and adhesives. Work will be directed towards developing low temperature bonding procedures. 
Reference:

1) M.HORINO,A.KOHNO,"Low temperature bonding with an interlayer of in-Sn alloy" , Preprints of the national meeting of Japan Institute of Metals, p.265 (1987)

2) M.HORINO,A.KOHNO,K.TAGUCHI,"Effect of bonding circumstances in low temperature bonding ",Preprints of the national meeting of Japan institute of Metals, p399 (1991)

3) M.HORINO,A.KOHNO,K.SAHARA," Activation process for surface of solder bumps on LSI chip" Preprints of the national meeting of Japan Welding Society, p396 (1991) 
Primal Scientist: Kazuo SATO

Affiliation: Mechanical Engineering Research Laboratory, Hitachi, Ltd.

Address: 502 Kandatsu, Tsuchiura, Ibaraki 300, Japan

Fhone: +81.298.32.4111 Fax: +81.32 .8251$

Research overview:

Silicon micromachining technology and its applications are investigated. Activities on anisotropic chemical etching technology is outstanding.

Orientation dependence of the etch rate has been first measured to the complete orientations[1]. Based on this results, etch profile simulation system has been developed[1]. Novel micromechanical devices has been developed using bulk micromachining technologies including anisotropic[2][3] and isotropic[4] etching processes. Recently, a new type of electrostatic actuator to be applied to gas valve system has been invented[5].

\section{Research topics:}

1) Anisotropic etching simulation system[1]:

This system is developed to predict etch profiles of single crystal silicon using an etchant of $\mathrm{KOH}$ water solution. The system contains a data base of the etch rate related to the crystallographic orientations. Arbitrary masked area, initial wafer shape, and etching temperature can be considered in the analysis.

2) Silicon capacitive acceleration sensor[2]:

A complicated 3-D structure of the sensor gage has been fabricated by applying multiple steps of anisotropic etching processes, instead of conventional process carried out by a single step. Developed gage structure has minimized cross-sensitivity of the sensor.

3) One-to-one biological cell fusion apparatus[3]:

Micromechanical silicon devices has been successfully applied to biological cell operations. The apparatus has 1584 fusion chambers made on a silicon wafer. A cell pair from different species becomes a hybrid in the chamber.

4) Silicon lens for Scanning Acoustic Microscope [4]:

Single crystal silicon lens has been newly developed to be used in a frequency range of $\mathrm{GHz}$. Controlled isotropic etching system has enabled to fabricate a small concave surface whose radius is less than 50 microns.

5) Electrostatic actuator[5]

Novel electrostatic actuator having a moving film element which is elastically bent in an S-shape has been proposed. The actuator is designed to be applied to rarefied gas valve system. Contrary to the conventional micro valve actuator, it allows a large conductance of rarefied gas flow.

References: [1] Koide, A. et al.: Proc. of MEMS'91, 1991, 216-220. [2] Koide, A. et al.: Tech. Digest of the 11 th Sensor Symposium, 1992, 23-26. [3] Sato, K. et al.:Sensors and Actuators, A21-A23, 1990, 948-953. [4] Hashimoto, H. et al.:Tech. Digest of Transducers'91, 1991, 853-856. [5] Sato, K. and Shikida, M.: Proc of MEMS'92, 1992, 1-5. 
Silicon micromechanical devices developed by Hitachi, Itd.

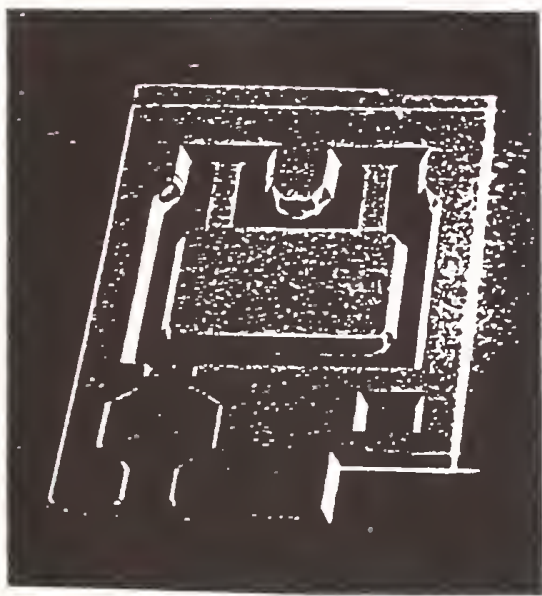

$\longmapsto 1 \mathrm{~mm}$

Fig.1 Silicon acceleration sensor chip.

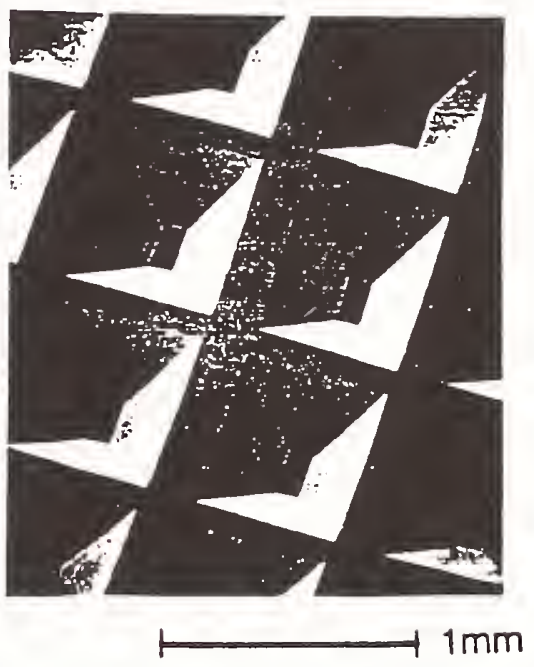

Fig.2 Microchamber array on a silicon wafer applied to biological cell fusion operation.

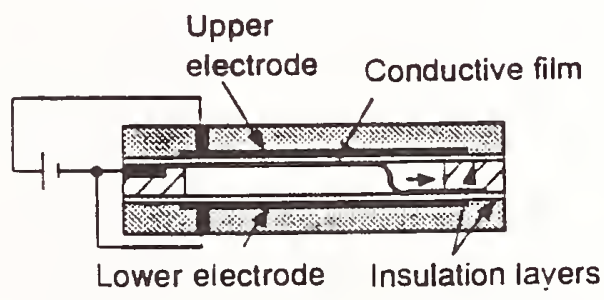

(a) Voltage applied between upper electrode and conductive film

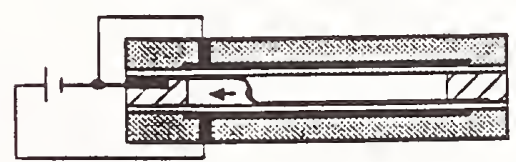

(b) Voltage applied between lower electrode and conductive film

Fig.4 Principle of the S-shaped electrostatic film actuator.
Fig.3 Silicon lens for scanning acoustic microscopy. Lens body (top) and an enlarged view of the tip(bottom). 
Primal:Teruyuki MATSUI

Affiliation:MEITEC Corp.R\&D

Adress:2-20-1 Kohsei-dori, Nishl-ku, Nagoya 451

Number of staffs:4(Hiroshi SHIONO, Hitomi YAMADA, Tomoyasu TAGUSAGAWA, Hiroshi

FURUSHIMA)

\section{Research Overriews}

Developments of high accurate $x$-ray mask to be necessary to fabricate the submicron patern on either planar or non-planar surfaces, such as the cylindrical and irregular structure have been performed. X-ray mask consists of 3-um thick Si menbrane as an $\mathrm{x}$-ray transmitting material and submicron patterned metakkic film on SI menbrane as an $x$-ray absorbing material. For the high accurate $x$-ray mask, it bas been aimed to form an $x$-ray absorbing metallic film with the stress free by controlling the fllm composites and their formation conditions. The micropattern formation technology on non-planar surface has heen developed by using plasma polymerization technique which can photochemically react in dry-developable process under UV irradiation. At present, the application of this technology to microacruator formatlon is under investigation.

\section{Resegrce Topics}

(1)Hlgh accurate $x$-ray mask

It is almed to form the mettalic film with the stress free on 3-um thlck Si membrane by investigating the metallic material, formation process and their formation conditions.

(2)Fabrication technology on non-pianar surface

Fabrication technology of precise micropattern on cylindrical or irregular structure have been investigated by the deveiopment of the plasma polymerized film technique whlch can photochemically react under UV irradiatlon.

(3)Fabrication of flexible microactuator

Developments of flexibly movable microactuator to be applicable to handle the micromechanical parts and that of assemblized technology to drive the microactuater with the resolution of micro-order are under investigation.

\section{Research results in fiscal year of 1993}

(1)Fabrication of flexible microactuator

Cantilever type flexible microactuator based on the sandwitched structure of polyimide/metallc film heater/polyimide was fabricated by thin film process. As the driving mechanlsm, the hending motion induced by the difference of thermsl expansion coefficients between polyimides during charging process of the metallic fllm with electricity was used. It was observed that the each cantilever could be driven by applying $1 \mathrm{~V}$ with the frequency range from 1 to $10 \mathrm{~Hz}$.

\section{References}

(1)H.Fukushima, et.al.,"X-ray absorbing and mechanical properties of Au-C film for $x$-ray lithography", SPIE(7-8 March 1990)

(2)H.Yamada,et.al.,patent application, No.200894

(3)T.Tagusagawa,et.al.,"Fabrication of the flexible cantllever type microgripper by thin film process ",'94 MEMS abstract(in preparation) 


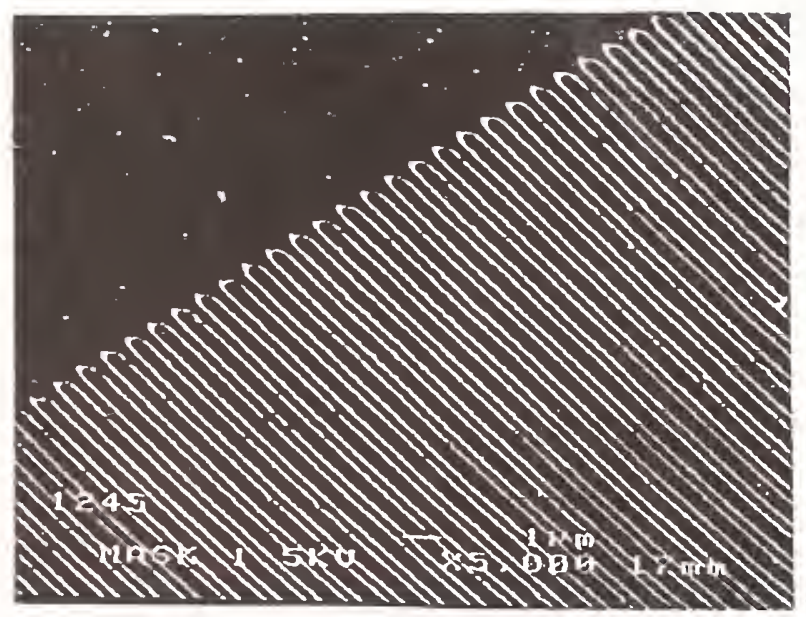

Fig.! Submicron pattern of x-say absorbing metallic film

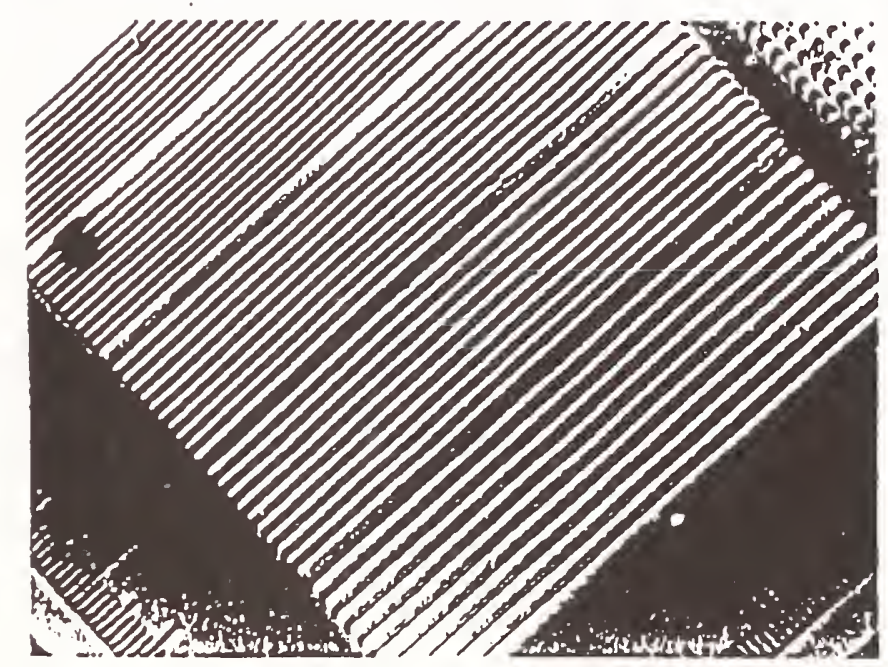

Fig.2 Micropattern formed by non-planar dry-developable fabrlcation process

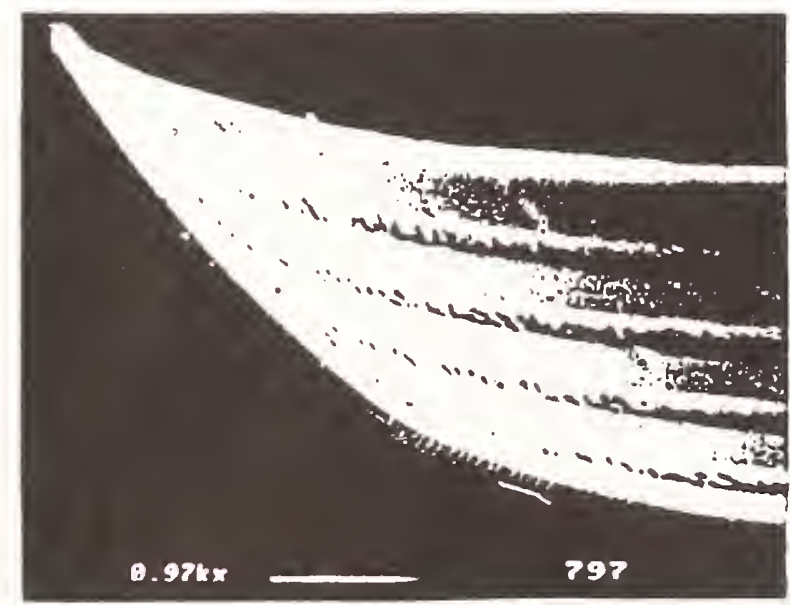

Fig. 3 The tip of cantilever type microactuator fabricated by thin film process 209 


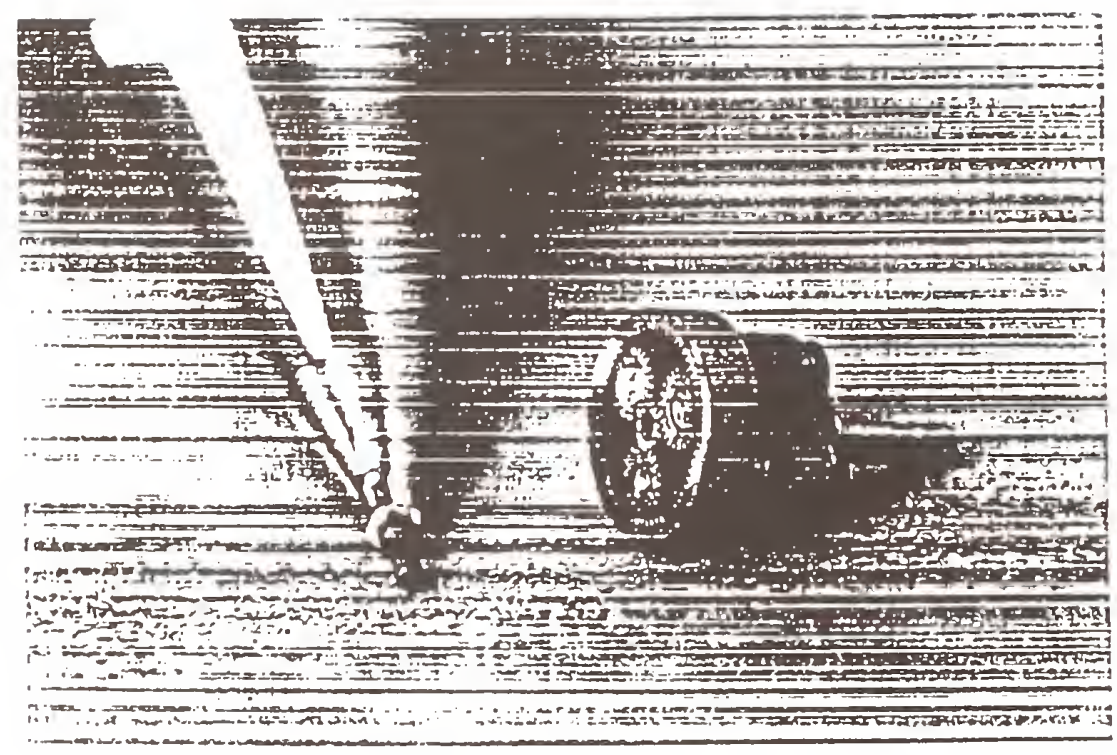

Fig. 2 Speed-Up Planetary Gears

The specification is as following;

1) Diameter of sun gear : $0.96 \mathrm{~mm}$

2) Diameter of planetary gear $: 1.62 \mathrm{~mm}$

3) Gear ratio : 31

4) Maximum output speed : 0.25 million rpm

5) Processing of gears : Electrical discharge machining 
Primai Scientist: Tomoki FUNAKUBO

Affiliation: Production Engineering Dept. of OLYMPUS OPTICAL CO.,LTD.

Address: 2951,Ishikawa-cho,Hachioji-shi,Tokyo,Japan 192

Tel.0426-42-2111 Fax.0426-42-2109

Number of staffs: 7

Research Overview:

Study of Ultrasonic Motors and Piezoelectric Actuators.

We have been studying ultrasonic motors and actuators which are driven by piezoelectric effect. Based upon our study, we have been developing X-Y Stages to which the above motors and actuators were applied.

Research Topics:

(1) Two-dimensional drive ultrasonic motor

(2) Linear drive ultrasonic motor

(3)Rotary drive ultrasonic motor

(4)Multilayered piezoelectric actuator

(5)X-Y Stage using two-dimensional drive ultrasonic motor ${ }^{1}$ )

(6)X-Y Stage using muitilayered piezoelectric actuator ${ }^{2}$ )

Research Result in fiscal year of 1992:

High-resolution X-Y Stage using two-dimensional drive ultrasonic motor :

We have developed an ultrasonic motor which is capable of driving a slider tw'(). dimensionally. And we have made a X.Y Stage which is directly driven by the ultrasonic motor. The dimensions of the X.Y Stage is $40 \times 40 \times 53(\mathrm{~mm})$. The stroke of $X-Y$ Stage is $8 \times 8(\mathrm{~mm})$. The following results of $X-Y$ Stage characteristics were known: Resolution of displacement is $5(\mathrm{~nm})$; Response timc in 1 (msec); Maximum speed is $50(\mathrm{~mm} / \mathrm{sec})$.

\section{References:}

1)T.Funakubo, T.Tsubata, T.Fujimura,"High-resolution X-Y Stage using twodimensional drive ultrasonic motor" the 1992 Spring Meeting of the Japan Societ! for Precision Engineering (1992) 341

2)H.Adachi,T.Funakubo,"Detecting Instrument for detailed surface form" , ELECTRONIC CERAMICS 22 No.10 (1991) 41 


\section{"High-resolution X-Y Stage}

using two-dimensionai drive ultrasonic motor" Tomoki FUNAKUBO(OLYMPUS OPTICAL CO.,LTD.)

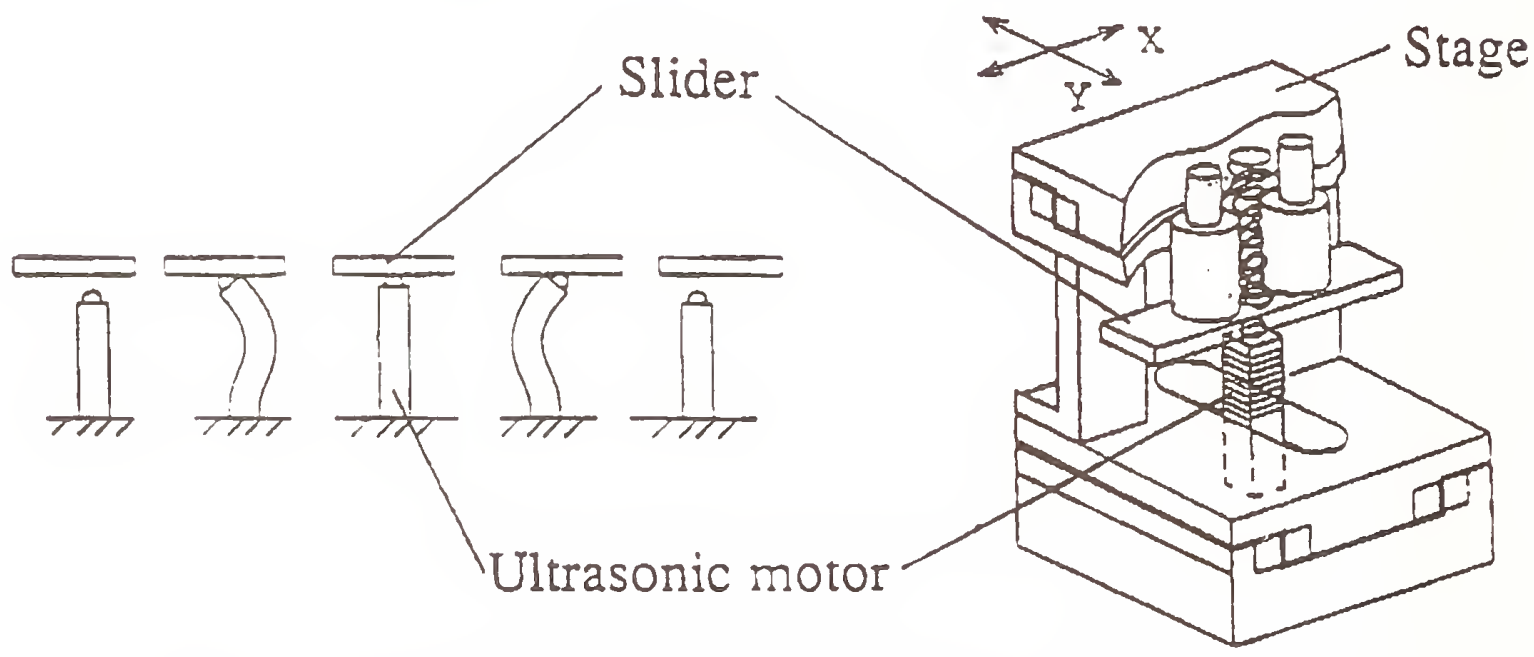

Fig. 1 Principle of drive and Outline of X-Y Stage

A slider is driven to any direction on $X-Y$ plane by rotating ultasonic elliptic vibration plane of ultrasonic motor. The stage connected to the slider can be driven to any direction on $X-Y$ plane.

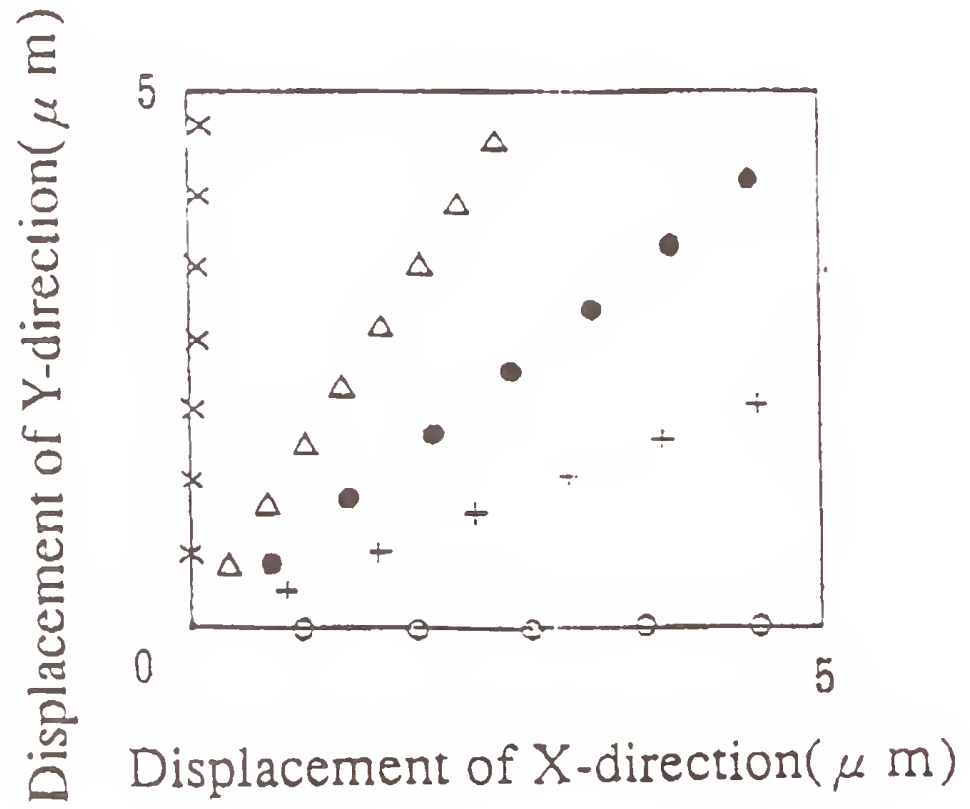

Fig.2 Traces of displacement when X-Y Stage is driven two-dimensionally. 
Primal Scientist: Akitoshi Toda

Affiliation: R\&D dept. OLYMPUS Opt.Co.LTD.

Address: $\quad 2-3$ Kuboyamacho Hachioji Tokyo, Japan 192

Vumber of staffs: 6

Tel:+426-91-7111, Fax:+426-91-5709

Research Overview:

Microfabrication technology applicable for Scanning Probe

Microscopy (SPM) have been investigated. Microfabricated silicon nitride cantilevers have been studied as a main theme in early days of our study. Combining with a study of sensors and actuators, we aim at new types of SPMS and device which are able to use easily in several different environments. We take "practical use" in seriously so that our microfabricated cantilevers have already been applied in our SPM equipments. which have been developed by another group in our laboratry.

\section{Research Topics:}

1)Fabrication of the cantilevers with sharp tips:

Sharp tip is essensial in SPM to reveal the sample surface in atomic size resoltion. Tip sharpening methods which make batch fabrication possible, have been studied.

2)Study of interaction between the tip and sample surface:

Surface modification tip is designed for the study. Understanding and Controlling the tip surface is one of our interests.

3)Sensors and actuators:

Sensor and/or actuator included device may change the style of the SPM drastically and widely open up novel applications.

Research results in fyscal year of 1992:

1) Sharpened pyramidal tip; tip radius $15 \mathrm{~nm}$, tip vertex angle 50 degree. are successfully obtained by applying Low Temperature Oxidation process in furnace into Micro casting method

2)Specially inclined tips are fabricated. The inclined tips obtain the ideal position towards the sample surface to normal, in usual tilted holding of cantilever tip in SPM equipment

\section{Reference:}

1] A.TODA et.al: The Extended Abstructs (The 52th Autumn Meeting 1991); The Japan Society of Applied Physics

2] K.MATSUYAMA et.al: The Extended Abstructs (The 53th Autumn Meeting 1992); The Japan Society of Applied Physics 
"Microfabricated cantilever with sharpened tip for SPM" Akitoshi Toda (R\&D dept.. OLYMPUS)

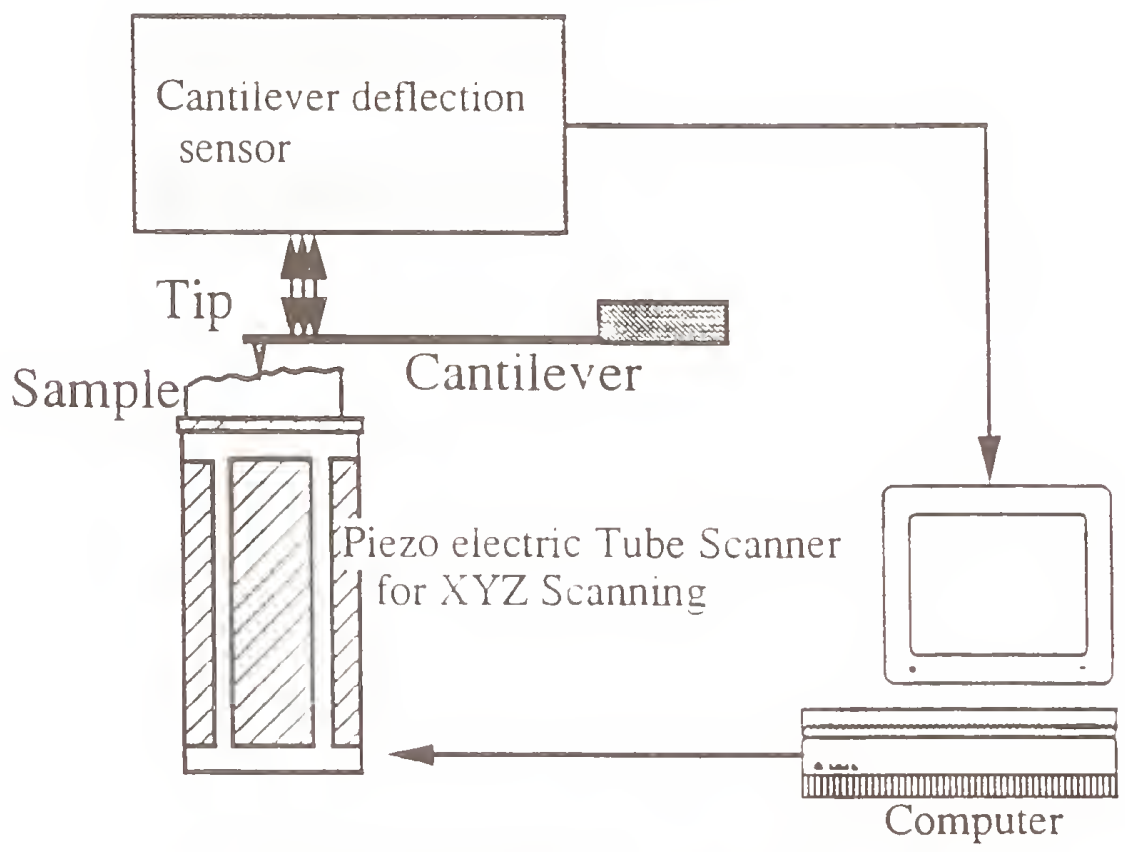

Fig.1 Schematic diagram of SPM

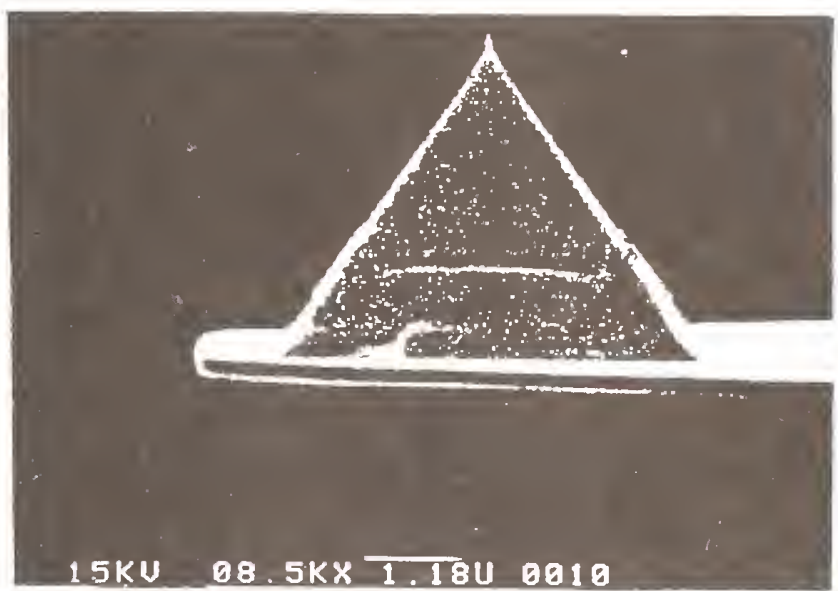

Fig.2 Sharpened pyramidal tip on the end of the cantilever

Cantilever is made by Micro casting method.

Sharpened part of the cantilever tip is presented on from the top about $1 u \mathrm{~m}$ down.

$$
\begin{aligned}
& \text { tip radius } \leqq 20 \mathrm{~nm} \\
& \text { vertex angle } \leqq 50 \text { degree }
\end{aligned}
$$

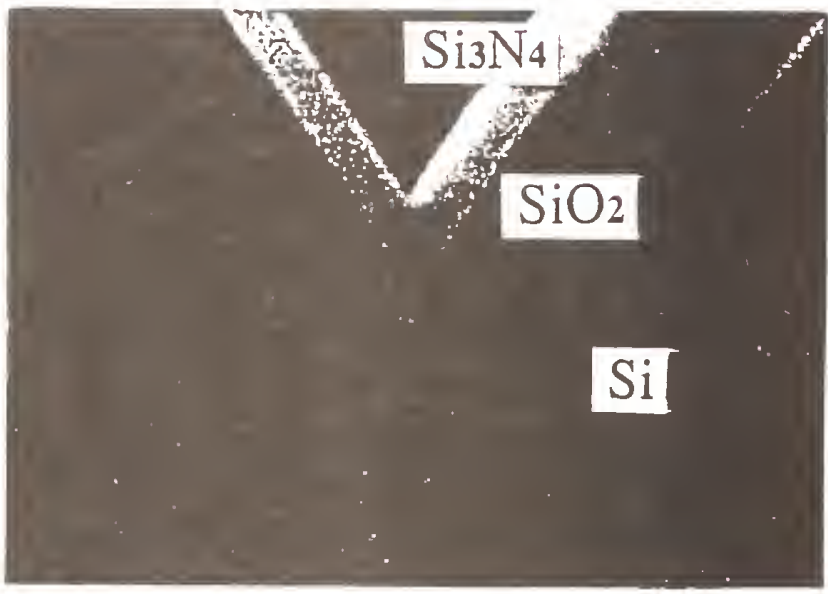

Fig.3 Deformed pyramidal etch pit as a micro cast of silicon

Etch pit on the silicon wafer is deformed by Low Temperature Oxidation in furnace. Silicon nitride is deposited on it. Sharpened silicon nitride tip is obtained after whole etching of silicon and oxide layer. 
Primal Scientist: Kohei HORI

Affliliation: Energy and Mechanical Research Labs,

Address:

R\&D Center, Toshiba Corporation

4-1, Ukishima-cho, Kawasaki-ku, Kawasaki-shi, 210 , Japan

Number of Staffs: 2

Tel. $+44-288-8087$, Fax. $+44-288-8214$

Research Overview:

A micro planetary reduction gearing has been developed for micromechanisms. In spite of a simple configuration with only six gears, the gearing has a higher gear ratio than 40:1. These microgears were machined by a wire electric discharge machining (WEDM) which is able to cut hardened steel with a high aspect rat1o, and they were assembled. The gearing was driven by a DC motor and functioned to drive certain load successfully. We plan to make a smaller one.

Research Topics:

l)Gearing: A $4.25 \mathrm{~mm}$ in diameter gearing with Mechanical Paradox was developed. (see Fig.1)

2) Gear design: The gearing has external and internal involute profile shifted spur gear of 0.08 module. Each gear has a fine tooth profile which was designed correctly to avoid all kinds of interference for each meshing.

3) Mlcrogear machning: Using fine wire electrode of $0.025 \mathrm{~mm}$ in diameter, all the external and internal gears were machined by the WEDM. The smallest gear has a tooth tip circle diameter of $1 \mathrm{~mm}$. (see Fig. 2)

$4)$ Microgear inspection and assembly:

Research results in fiscal year of 1992 :

1)M1cro machining: The miniaturization of the gearing depends on that of the six gears. We have been trying to make smaller one, and have achieved a involute gear of 0.04 module which has a half size of the former one. (see F1g.3)

\section{Reference:}

llK.HORI, A.SATO, "Development of micro planetary reduction gear", Proc. of '90 Autumn Meeting, JSPE, pp.67(Oct-1990)(in Japanese)

2 IK.HORI, A.SATO, "Micro planetary reduction gear", Proc. of 2 nd Int' 1 Symposium on Micro Machine Science, pp.53(1991)

3IR.HORI, "Development of micro planetary reduction gearing (Wire Electric Discharge Machining of Micro Gears)", Proc. of 92 Symposium on Robotics and Mechanical-electronics system, JSME (1992) (in Japanese) 


\section{"Micro Planetary Reduction Gearing"(1)}

Kohei HORI (R\&D Center, Toshiba Corporation)

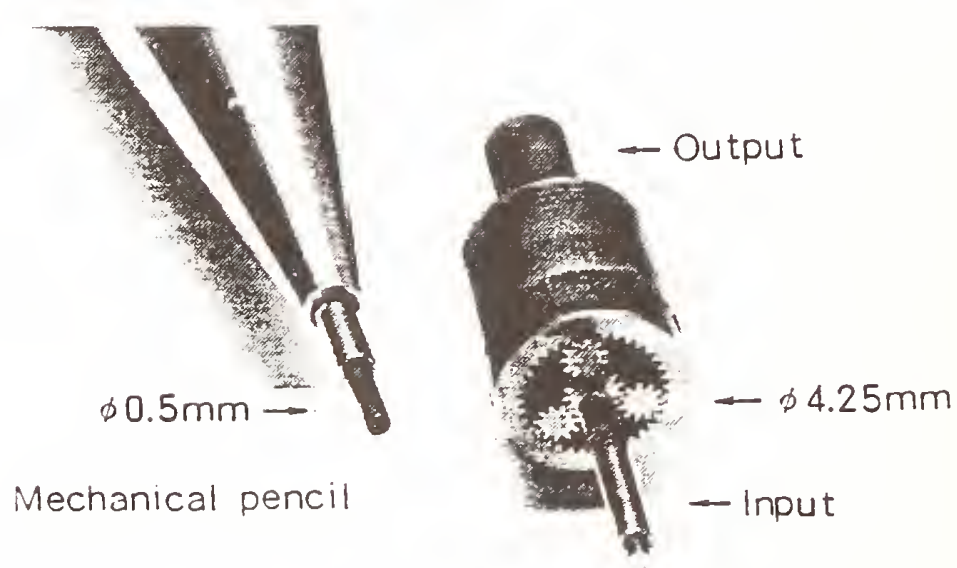

Eig. 1 Micro Planetary Reduction Gearing

(without gear case) The gearing has a high gear ratio of 44.2:1. This is suitable to connect to a motor and load because both the input and output are coaxial.

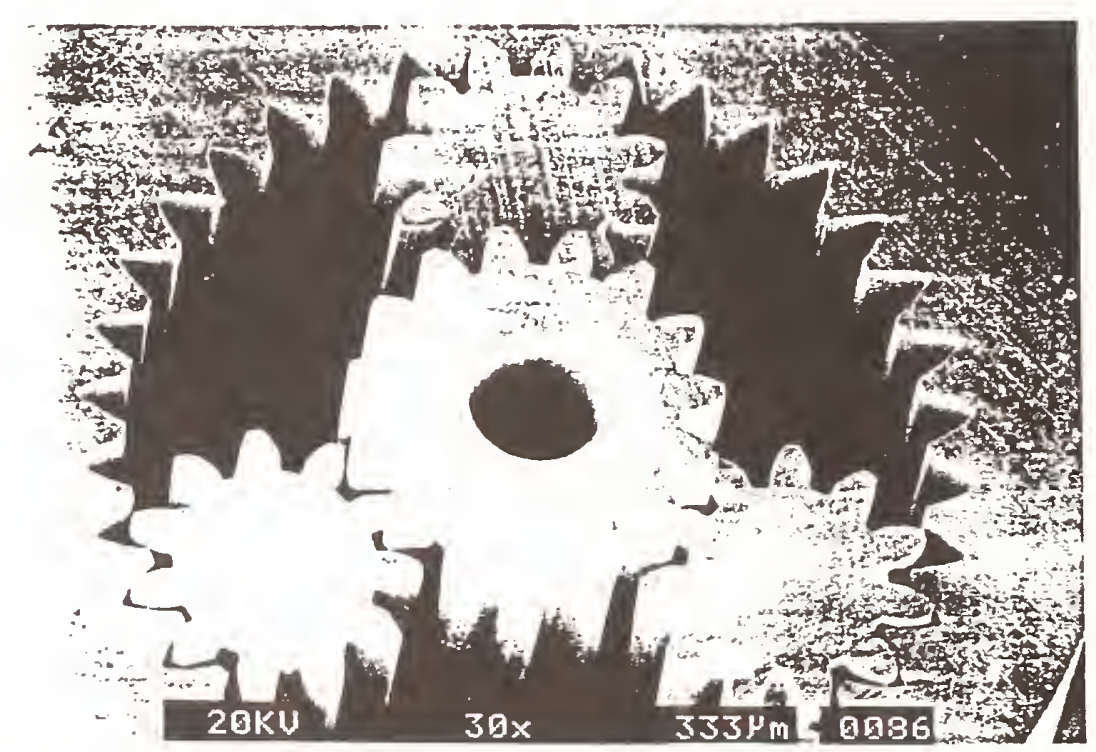

Fig.2 Detail of Micro Planetary Gearing

These micro external and internal gears of 0.08 module were machined by WEDM. This is also suitable for miniaturization because of a simple configuration without a carrier and bearing to support planet gears. 


\section{"Micro Planetary Reduction Gearing"(2)}

Kohei HORI (R\&D Center, Toshiba Corporation)

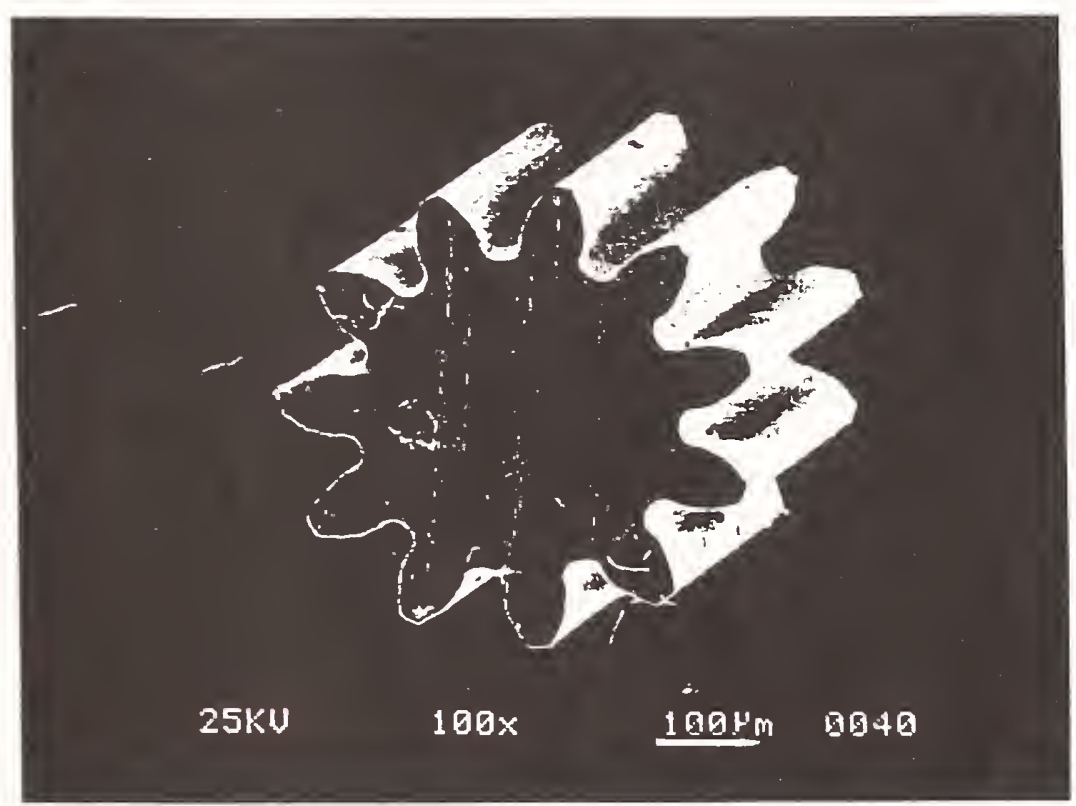

Fig. 3 Result of trial gear cutting by WEDM We plan to make smaller gearing, and tried to cut a gear of 0.04 module, $0.5 \mathrm{~mm}$ in diameter and $1 \mathrm{~mm}$ long. 
Primal Scientist: Manabu Okamura

Affiliation: Small Motor Developement Center

Manufacturing Engineering Research Center

Toshiba Corporation

Adress: $\quad 4-21$ Yoshihara-cho,Nishi-ku,Nagoya 451,Japan

Tel.+81-52-532-6389, Fax.+81-52-524-0920

Number of staffs:

Research Overview:

Electromagnetic small motors used in various fields have been developing.

Research Topics:

1) Research of Motor speed control system

2) Manufacturing of Miniaturized motor

Research results in fiscal vear of 1992:

1) Electromagnetically actuated ultra small DC motor Axial gap type motor $0.8 \mathrm{~mm}$ in external diameter

\section{References:}

1] H.Izawa, et al.,“ Slow Speed Brushless DC Motor Control System With Linear Voltage Drive", SPC-92-35, presented in the IEEJ, Okayama, Japan

2] T.Itoh, M.Okamura,“ Development Of Ultra Small DC Motor”, 3rd International Symposium on Micromachine and Human Science, pp.27-33, 1992 
"Ultra Small DC Motor"

-Electromagnetic motor-

Manabu Okamura ( SMC, Toshiba Corporation)
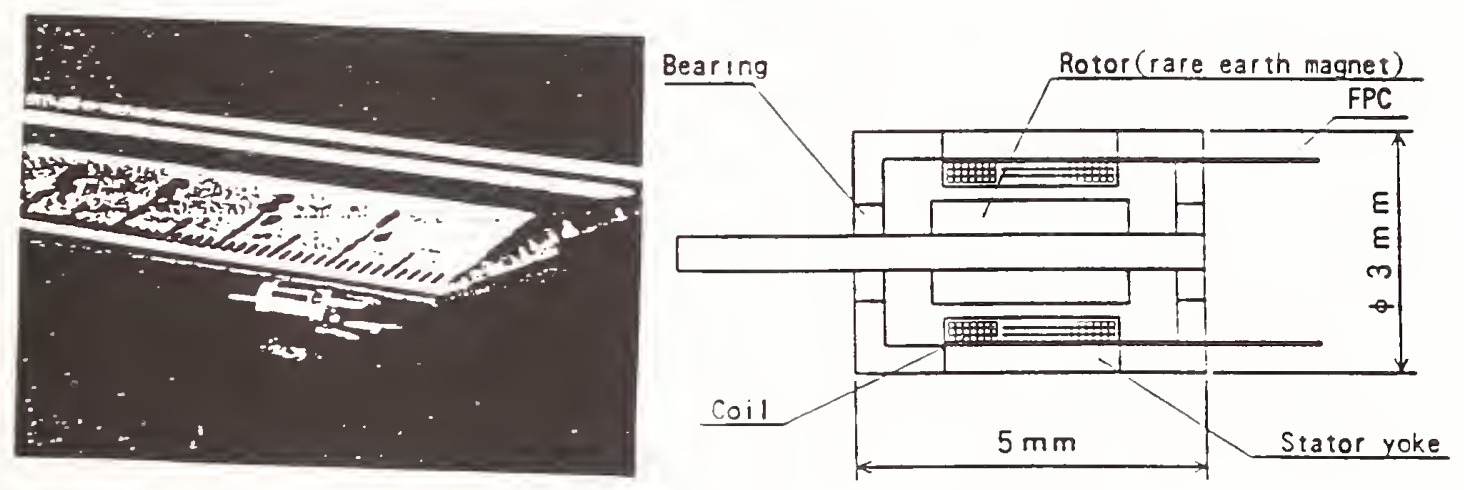

Fig.1 Cylindrical motor( $3 \mathrm{~mm} \times 5 \mathrm{~mm}$ )
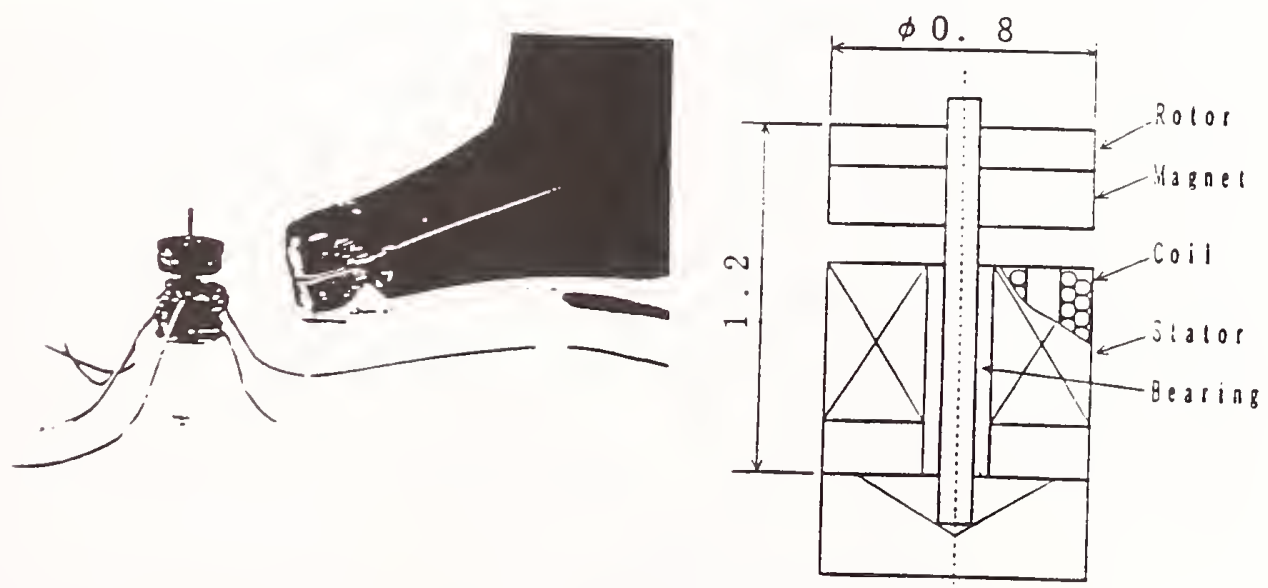

Fig.2 Axial gap motor ( $0.8 \mathrm{~mm} \times 1.2 \mathrm{~mm})$ 


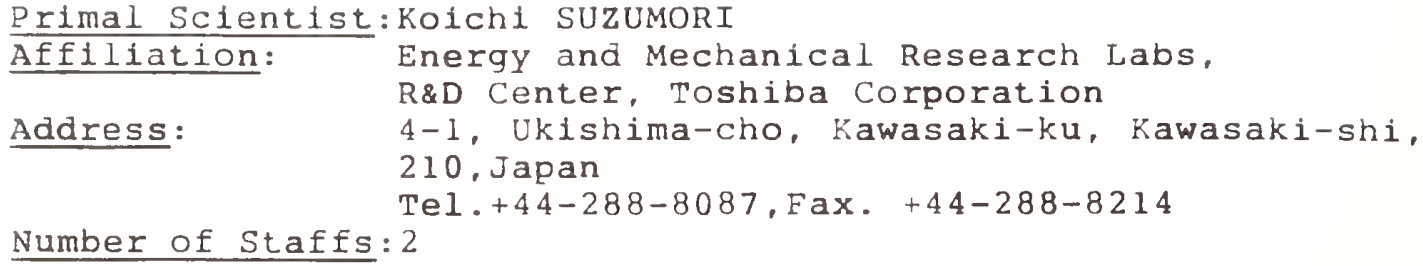

Research Overview:

A new type of pneumatic actuator, named Flexible Microactuator or FMA, for miniature robots[1] has been developed. FMA has so simple structure that it is easily miniaturized. FMAs have been applied to several miniature robot mechanisms such as fingers, arms, and legs. The robots consisting of FMAs are suitable for inspection tasks in a narrow space and gentle handling of fragile work.

Research Topics:

1)Miniature robot arm[2]: A $4 \mathrm{~mm}-\mathrm{diameter}$ arm with a mini-gripper was developed. It has seven degrees of freedom including the gripper. (see Fig.2)

2) Robot hand[2]: Multi-fingered robot hand with simple mechanism was developed. It can handle fragile and complicate shaped works with ease.

3) Miniature walking robot[3]: The actuator, FMA, can easily achieve leg motions. A prototype shown in Fig.3 is $15 \mathrm{~mm}$ long and weighs 1 gram.

4) Pipeline inspection robot [4]: The actuator is also applied to inspection robots in a small pipeline. A prototype was made of serially connected two FMAs and its snake-like movements drive the robot in $1 \mathrm{~mm}$ internal diameter pipelines.

Research results in fiscal year of 1992 :

1) Pipeline inspection robot [4].

\section{Reference:}

IJK.SUZUMORI, et al., "Flexible Microactuator for Miniature Robots". IEEE Workshop on Micro Elector Mechanical Systems, pp. 204-209 (Jan.-1991)

2lK.SUZUMORI, et al.. "Applying a Flexible Microactuator to Robotic Mechanisms", IEEE Control Systems, Vol.12, No.1, pp.21-27 (Feb.-1991)

3lk.SUZUMORI, et al.. "Mintature Walking Robot Using Flexible Microactuators", 2nd Int. Symp. on Micro Machine and Human Sciences, pp.29-36(oct.-1991)

4]K.SUZUMORI, et al.," Applying Flexible Microactuators to Pipeline Inspection Robots", IMACS/SICE Int. Symp. on Robotics, Mechanics, and Manufacturing Systems, pp.631-636(Sep.-1992) 


\section{"Flexible Microactuator (FMA)" (1)}

Koichi SUzUMORI (R\&D Center, Toshiba Corporation)

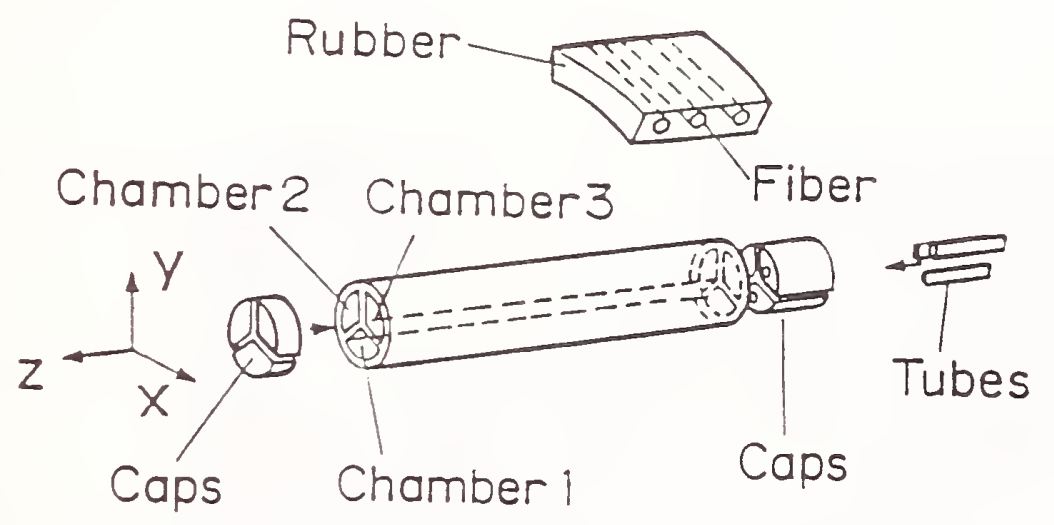

Fig. I Structure of Flexible Microactuator (FMA) The actuator is made of fiber-reinforced rubber and is driven pneumatically or hydraulically. Independent pressure control in each chamber causes FMA to move smoothly and easily in all directions.

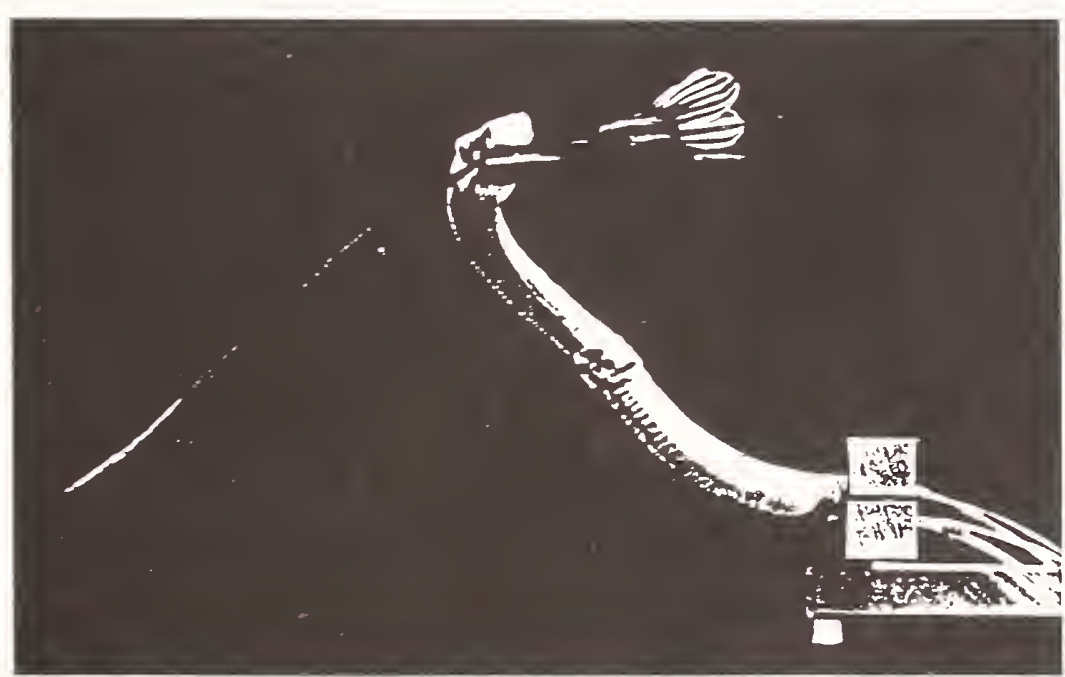

Fig. 2 Miniature robot arm, $4 \mathrm{~mm}$ in diameter By connecting the actuators serially, we get an arm with many degrees of freedom and snake-like movements. This prototype consisits of two FMAs and a mini-gripper. It can accomplish delicate tasks. 
"Flexible Microactuator (FMA)" (2) Koichi SUZUMORI (R\&D Center, Toshiba Corporation)

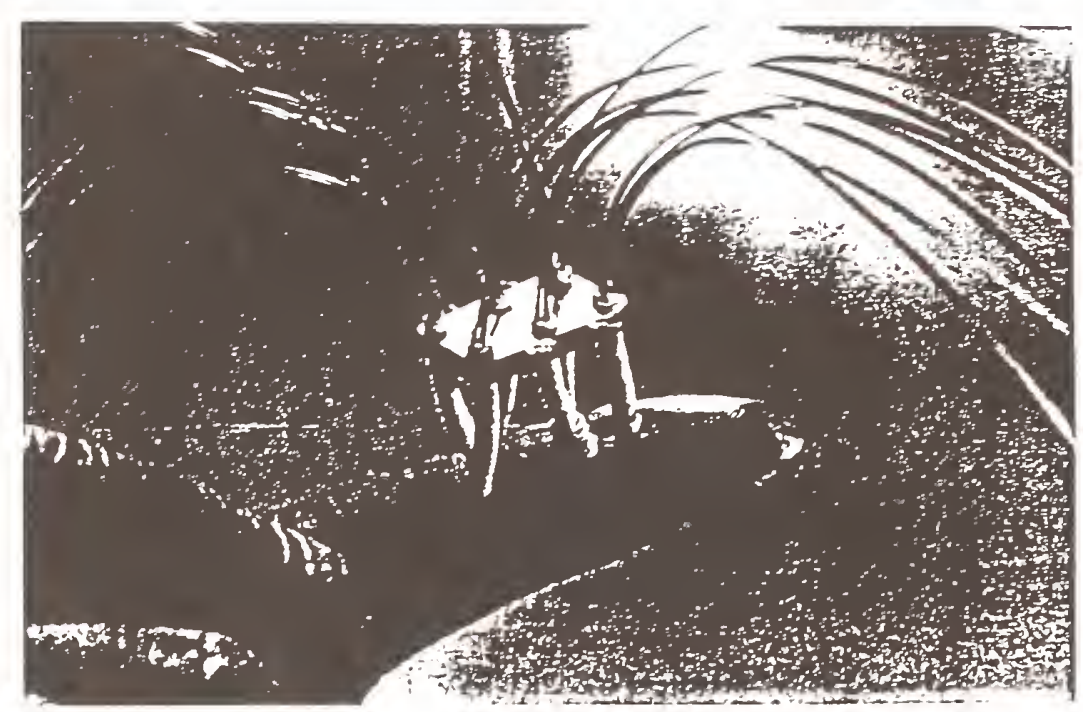

Fig. 3 Miniature walking robot

It is $15 \mathrm{~mm}$ long and weighs only one gram. Each leg is just $2 \mathrm{~mm}$ in diameter.

It can walk omni-directionally. 


$$
\text { アンケートの回答 }
$$

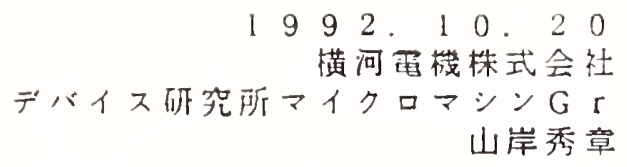

1. Affiliation

横河龟械株式会社

技術開発部門デバイス咞究所

マイクロマシンGr

2. Adress

₹180 東京都武蔵野节中町2-9-32

TEL : $04222-52-5551$

F A X : $04222-52-4892$

3. Research Overview

シリコンを中心としたマイクロマンニング技術によるセンサ、アクチェエータの咞究開発

4. Research Tooics

1) 通産省の大型ブロシェクト「マイクロマシン技術」に参画し、超小型の光分析システ ムの要素技術開発に䟾り組んている。

2) 水晶のマイクロマシニングによるセンサ、アクチュエータの開発。

3) シリコンタイアフラム上に形成した歪センサによる圧カセンサの開発。

\section{References}

1) T. Ueda, F. kohsaka, D. Yamazaki, T. Iino: Quartz Crystal Micromechanica Devices.

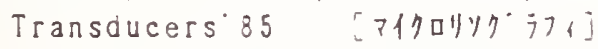

2 ) K. Ikeda, H. Kumayama. T. Kobayasini. T. Htanabe. T. Nishikawa. T. Yoshida: Three Dimensional Micromachining of Silicon Resonant Strain Gage.

7 th Sensor Symposium, 1988 . [3 次元扣工]

3 ) K. Ikeda. K. Kumayama. T. Kobayasini. T. Wtanabe. T. Nishikawa. T. Yoshida. K. Harada: Silicon Pressure Sensor Integrates Resonant Strain Gauge on Diaphragm. Sensor and Actuators.A21-A23.1990 [3 次元加工]

4) S. Miyazaki.T.Kawai, M. Araragi : 'A Piezo-Electric Pump Driven by a Flexurai Progressive Have ${ }^{-}$. CH2957-9/91.1991 IEEE [傎斜機能材料]

5) K. Ishi i. Y. Tamaragi. I. Inamura.Y. Suzuki, M. Araragi. "High-Temperature Pressure Sensor Using ZMR-SOI Structure ". Technical Digest of The 11 th Sensor Symposium.pp. 131-134,1992. 


\title{
Worldwide Microfabrication Research and Development
}

\author{
Robert O. Warrington \\ Director \\ Institute for Micromanufacturing \\ Louisiana Tech University \\ Ruston, Louisiana 71272 \\ (318) 257.2357 \\ FAX -2562 \\ e-mail row@engr.latech.edu
}

\section{INTRODUCTION}

Often defined as an "emerging" technology, the microelectromechanical systems (MEMS) technologies have their roots in research activities back to the early 60s, as the first micro pressure sensors were fabricated using the anisotropic etching method [1]. Since then, the fabrication techniques developed in microelectronics have begun to directiy impact the progress in micromechanics. During these years, pioneer research work in electrostatically-driven microstructures has been performed [2] which a decade later found its further development in surface micromachining for sensor formation [5].

During the 1970s, numerous industrial companies were involved in the efforts to commercialize the existing microfabrication technologies for a new generation of products featuring light weight, small volume and high efficiency. Among those pioneers, Texas Instruments succeeded in marketing micro printing elements in computer accessories and terminal products [3]. At the end of the 70 s, the controlled anisotropic undercut etching technique was further developed which resulted in microcantilever beams and similar micromechanical structures.

The continuing exploitation of VLSI processing methods in the 1980s has opened considerable opportunities for the further invention of unique silicon-based micromechanical devices as well as the creation of new markets [4]. In response to the growing need for application specific integrated circuit chips (ASICs), custom design and fabrication facilities have been implemented. The concept of the "IC Foundry" quickly found its expression as the "Silicon Micromechanics Foundry" in the development and production of micromechanical structures [6]. Also during this time, based on a combination of deep-etch lithography and subsequent high-precision replication, a new micromachining technique, known as the "LIGA" process, was introduced in Germany for producing three dimensional microstructures [7]. Innovative improvement and modification to this process have subsequently been made by researchers at the University of Wisconsin [17]. Besides conventional electromagnetic actuators, various types of electrostatic motors and actuators featuring simple structure. micro size and high force/volume ratio were developed worldwide [8] - [11]. Also, different materials were investigated for possible applications in the micro robot domain, such as the shape memory alloy (SMA) [12].

Parallel to the endeavors of pushing ahead the micromanufacturing technique down to the order 
of submicron and nanometer scales, there have been numerous activities reported which focus on applying different micromachining technologies to fabricate end products which are mainly mini with microcomponents, such as the microcompact heat exchangers produced with diamond bit cutting [13]. To meet the increasing need for metrology and products inspection in the submicron and nano scale, atomic-force microscopes are under further development [14]. Also, micro EDM, molding, plating and many other new techniques are emerging to augment the microsensor and actuator fabrication [16]. It is evident that micromanufacturing technologies will lead to commercialization of revolutionary devices which will dramatically change our lives in the 21 st century.

The rest of this paper will describe recent worldwide activities in MEMS, including the Louisiana initiatives in MEMS through the newly formed Institute for Micromanufacturing at Louisiana Tech University and their collaboration with the Center for Advanced Microstructures and Devices (CAMD) at Louisiana State University.

\section{MEMS ACTIVITIES IN THE UNITED STATES}

The Institute for Micromanufacturing (IfM) and the Center for Advanced Microstructures and Devices (CAMD)

The Center for Advanced Microstructures and Devices (CAMD) at Louisiana State University was established in 1987 by a grant from the Department of Energy. The facility currently consists of an electron storage ring with a linac injector, two beam-lines which are under construction, and ancillary equipment. The Institute for Micromanufacturing (IfM) at Louisiana Tech University was established in 1991 by grants from the Department of Energy. This institute consists of a research building for multiple process micromachining, cleanrooms, process equipment, and state-of-the-art metrology and testing equipment. Additional equipment and line item funding for personnel, operating and supplies, for both facilities has been provided by the state of Louisiana. CAMD synchrotron is very close to being operational with the first beamlines due to be installed shortly. The institute building is currently under architectural design and construction should start by late 1992 or early 1993. Staffing for both facilities is underway. A more complete description of CAMD and IfM are given below.

The Institute for Micromanufacturing is composed of three components. The focal point for the Institute for Micromanufacturing will be the component for research and development located on the Louisiana Tech University campus in Ruston. A second component will be associated with the Center for Advanced Microstructures and Devices (CAMD) at Louisiana State University in Baton Rouge. This component will perform research associated with the X-ray lithography micromachining capability at CAMD. The third and final component of the Institute is Technology Transfer. This component will be located in Shreveport/Bossier in order to take advantage of the unique opportunities and resources offered in this region. There will be a strong interaction among the three components of the proposed Institute and each of the components will interact, to varying degrees, with universities, industries and research centers within the state and region. 
A major strength of the institute will be the complete integration of multiple process microtechnologies which will span the spectrum from nano to macro. Macro, mini, micro and nano are all a part of MEMS or micromanufacturing. An important component of the institute will be the development of minidevices with microcomponents requiring nanomeasurements with connections to the macroworld. These minidevices could very well become the economic drivers of the technology well into the next century.

The research and development component will consist of a new 43,000 sq. ft. building which will accommodate institute faculty, graduate students, visiting scientists and engineers. Almost 20,000 sq. ft. of laboratory space will include space for metrology and testing (2,700 sq. ft.), lithography (initially over $3,000 \mathrm{sq}$. ft. of class 1000/100 cleanroom space will be available, expandable to 5,500 sq. ft.), and alternative micromachining technologies such as energy beams and EDM. The entire floor of the laboratory area will be isolated from the structure and, in addition, many areas within the laboratory space will be isolated from the main floor pad. The laboratory bay will be kept at $68 \pm 1{ }^{\circ} \mathrm{F}$ and $45 \pm 5 \%$ relative humidity. Four areas of concentration will be developed within the facility at Louisiana Tech University. They are:

* The design and fabrication of microdevices. such as micro-motors, actuators, sensors, pumps, valves, and connectors.

* The design and fabrication of microstructures, such as micro-heat exchangers, filters, distillation columns and supports for micro-devices and systems.

* Research related directly to the manufacturing processes, including fabrication, metrology assembly and testing of the microproducts mentioned above.

* Microsystem research involving the integration of these microdevices/structures and interfacing of these systems with the macroworld.

Several technologies will be developed and used for the fabrication of these micro devices and structures. First, the existing capabilities in diamond bit machining at Louisiana Tech University will be enhanced. Micro electrical discharge machining capabilities are being acquired along with micro drilling and power beam micromachining (excimer laser and focused ion beam) will be developed. Second, conventional photo lithography and chemical etch will be developed and used for the fabrication of low aspect ratio devices and structures. Third, as X-ray lithography technology becomes available at CAMD, Louisiana Tech and LSU researchers will utilize a dedicated beam line to fabricate high aspect ratio devices and structures. Finally, research and development will be performed on small machines techniques that can build and assemble these microproducts.

The $\mathrm{x}$-ray lithography component for high aspect ratio structures and devices consists of a dedicated beam line (off of the electron storage ring at CAMD and associated equipment specifically for the fabrication of high aspect ratio structures and devices. Researchers from Louisiana Tech and Louisiana State University will work at CAMD on research directly related to the fabrication of microdevices and structures using selective etch techniques and the X-ray depth lithography available at CAMD. Direct communication with the component of the Institute 
in Ruston. will facilitate the design and fabrication of the structures and devices at the CAMD facility. This type of machining is currently available at only KfK in Karlsrhue, Germany and the University of Wisconsin.

Of course, one of the key components of the institute will be the synchrotron light source. This electron storage ring has been optimized for soft X-ray lithography [15]. The CAMD storage ring has an energy of $1.2 \mathrm{GeV}$ with $400 \mathrm{Ma}$ circulating current. The ring can operate at $1.4 \mathrm{GeV}$ with a decrease in circulating current to $200 \mathrm{Ma}$. The mean radius of the ring is $8.78 \mathrm{~m}$ with a circumference of $55.2 \mathrm{~m}$. The ring has been designed with four straight sections, one of which is used for the $200 \mathrm{MeV}$ low energy injection for the linac. The other three sections will be used for insertion devices such as undulators and wigglers.

The beamline for the micromachining application is currently being designed. Preliminary specifications for the line are that the line must transmit photons of $2-8.5 \mathrm{KeV}$ and the high energy transmission must be less than $15 \%$ at $10 \mathrm{KeV}$. The photons must be incident vertically over a field of view of $50 \mathrm{~mm}$ horizontally with a uniformity of $\pm 3 \%$ and with a beam spot of less than $3 \mathrm{~mm}$ height. The beamline must be capable of exposing 100 micron thick $50 \mathrm{~mm} \mathrm{x}$ $25 \mathrm{~mm}$ PMMA resists to a minimum of $4 \mathrm{kj} / \mathrm{cc}$ and a maximum of $20 \mathrm{kj} / \mathrm{cc}$ in less than 120 seconds with the CAMD storage ring being operated at nominal conditions. The beamline will have a calorimeter and beam position sensor which has a resolution of better than $.05 \mathrm{~mm}$ for the vertical direction. The beryllium window must be of variable thickness and the transverse window size must be $10 \mathrm{~mm} \times 50 \mathrm{~mm}$. The beamine must be compatible for operation with a superconducting wiggler insertion device.

In addition to micromachining the following uses are anticipated for the facility:

* X-ray lithography for sub - .05 micron featured integrated circuits (the ring was optimized for this application).

* Electronic structure, surface science. etc.

* Geometrical structure, crystallography, etc.

* Imaging, microscopy, tomography, etc.

* Medical technology.

* Education of engineers, scientists and technicians.

Technology transfer is intended to help existing manufacturers obtain and use new and existing technologies to modernize their manufacturing processes and improve their productivity. Existence of such a facility should be helpful in attracting new industry as well. Staff members would conduct training at the facility or off-site. as needed, as well as using computer and video linkages to efficiently serve industry. In addition, they would seek to develop markets for existing products, look for new products to be developed. 
Two facilities will be available for this activity. Space and limited conferencing facilities will be available at the research and development building on the Louisiana Tech University campus. A larger facility is being planned for Shreveport, Louisiana. This proposed facility of 30.000 sq. ft. will be used for conferencing, technology transfer and for close interaction with the Louisiana State University-Shreveport Biomedical Research Center.

The Institute for Micromanufacturing is currently involved in the integration of different technologies with direct applications. Severai examples of this will be detailed. These applications include micro heat exchangers and heat and mass transport at the micro level, smart bearings with self-diagnostic capabilities, advanced ultra-precision air bearings, surface-driven electrostatic micro positioners and shape memory alloy propulsion for micro robots. The following examples are presented to show the breadth of MEMS and its relation to precision engineering.

\section{Micro Heat Exchangers}

There are applications of micromanufacturing where the final device is in the "mini" region but has elements in the micro domain. Such a device is a micro heat exchanger. A micro heat exchanger is hereby defined as a device with a heat transfer surface density (heat transfer surface area divided by active heat transfer volume) above 5000. Typical compact heat exchangers have a surface density of only 1000 to 3000 . With such a high surface density, micro heat exchangers have a very high volumetric heat transfer coefficient.

The micro heat exchangers currently under development are based on high conductivity copper and precision diamond machining. For the plate-type cross flow heat exchanger, thin foils of oxygen free (SAE alloy CA122) or electronic grade (SAE alloy CA110) are used to form the plates. These foils are typically 125 micrometers thick. In the surface of these foils, micro flow channels are machined with specially contoured diamond tools. This machining is performed on an air bearing spindle to reduce vibration and improve channel surface finish. The size of the channels can be variable but are typically 85 micrometers deep and 100 micrometers wide at the bottom [4]. A machined foil is shown in Figure 1 and a single folw channel is shown in Figure 2. After machining, the foils are stacked such that each layer has its channels running perpendicular to the adjacent layers, thus forming the cross flow device. The stack is then vacuum diffusion bonded and the faces are diamond machined flat. The device is then ready for use.

The current design is very conservative so that the fabrication and operating variables may be more easily identified. Current testing is with a device composed of a total of 80 layers. Thus each fluid side has 1440 flow passages and the total active volume is 1.64 square centimeters. The surface density for this particular device is 6876 square meters/cubic meter. Filtered water at $20^{\circ} \mathrm{C}$ and $70^{\circ} \mathrm{C}$ were used as the working fluids. The mass flow rate was typically 0.02 to 0.04 kilograms/second. These operating parameters gave a 2 to 5 atmosphere pressure drop through the core and a volumetric heat transfer coefficient of 45 megawatts/cubic meter- $\mathrm{K}$ (log-mean temperature difference). A design model predicts that a device with a volumetric coefficient over 300 mega-watts/cubic meter- $\mathrm{K}$ is easily attainable [5].

\section{Smart Bearings with Self-diagnostic Capabilities}


Bearings are the fundamental mechanical components widely used in manufacturing and other industrial branches. Though small in volume, they are highly complex in construction, featuring different parts like rolling-elements, raceways and cages. Depending on the type of applications, bearings are mostly sealed up after machine assembly and often used under extreme conditions such as in cryogenic regions or high temperature, corrosive media or ultra high speeds. In case of overloading or overheating, bearing failure will occur and manufacturing precision will suffer greatly or a critical component may fail endangering human life.

An effective way of preventing such critical situations and thus helping to maintain the manufacturing precision and improve the machine operation security is the on-line, real time supervision of bearing operating environment [6]. The environment mainly consists of the bearing load and operating temperature. This can be achieved by equipping the bearings with self-checking and error reporting functions through integration of sensors and microelectronics into the bearing environment. This concept is shown in Figure 3.

The sensors embedded in the "smart bearings" generate real time electronic signals which correspond to the force and temperature variations in the bearing components. The operating signals will be continuously monitored by microelectronic circuitry located in the bearing housing. The operating signals will be compared with pre-determined "threshold" values which represent a critical loading or temperature condition. Should a critical condition exist, a signal indicating potential damage will be sent from an embedded high frequency data transmitter to the machine control system which then can make corresponding adjustments. In using only an overload signal, the control system is not burdened with a continual stream of data. However, to generate critical "signatures", the real-time data can be monitored and stored for subsequent evaluation which will also be beneficial to improving the existing machine control algorithm. A novel feature of the smart bearing is that for data transmission, no direct cable connection will be needed. This wireless method is especially suitable for applications where the accessibility of the measurand is not easily available. Similarly, the power supply for the embedded transducer will be provided through non-contact voltage induction.

In contrast to traditional methods of manufacturing precision controls which focus on post-error adjustment and compensation, instrumented smart bearings will allow on-line error source location and pre-failure adjustment. This method can be very well applied to the high-tech areas like aerospace and the military or automotive industry, where high precision, reliability and accuracy of manufacturing and operation are required.

\section{Herring Bone Air Bearings for Ultra-Precision Spindles}

Air bearings of all types (including linear guides, $x-y$ tables, and spindles) have been widely employed in the ultra-precision engineering field to ensure the extremely high precision requirements of machinery such as in diamond-tool machining. The design optimization of the journal air bearing for precision and high performance applications is currently in progress. Among various self-acting air bearings, the herring bone type shown in Figure 4 has been considered as one of the best bearings for high speed spindles due to its high efficiency and high stability. For the best possible bearing design, the relationship between the design specifications and the bearing characteristics, such as load capacity and stability, must be known. However, 
the design information available in the literature only give a limited number of design specification sets. This information is, in most cases, insufficient for design optimization. Therefore, the design of herring bone bearings, especially when high speed and stability are required. still depends mainly on testing and the experience of the designer. Because of this, the design of herring bone air bearings is still very challenging.

The Reynolds equation, which governs the performance of the air bearing, has been numerically solved by specially developed finite element method programs. Once the solution, that is the pressure distribution over the bearing surface, is obtained, the bearing performance may be simulated in the computer.

The groove pump-in angle $\beta$ affects the bearing load capacity $\mathrm{W}$, as well as the stability indirectly through the bearing attitude angle $\Theta$, (which is a divergent angle between the eccentricity and the direction of load), as shown in Figure 5. The eccentricity ratio in the figure is defined as a ratio of eccentricity to average bearing clearance $\left(\varepsilon=e / h_{0}\right)$, while $\Lambda$ is a nondimensional parameter used to express the rotational speed and $\mathrm{n}$ is the number of grooves. Through such figures, the influence of the design specifications on the performance of the herring bone bearing over the most common ranges have been discussed. Consequently, the design optimization of the bearing has been made possible [7].

\section{Surface-driven Micro Electrostatic Positioner}

In the past several years, there has become a growing need for micro-sized motors and actuators for applications in micromanufacturing and other microelectromechanical systems domain (MEMS). Among other topics, the design and fabrication of micro electrostatic motors have found widespread interests. Compared to conventional electromagnetic motors commonly used in the large-scale motion world, electrostatic equivalents promise numerous advantages like simple structure, small size, high force-to-volume ratio and fine motion/step control.

Among different types of electrostatic motors (side-driven, surface-driven and cylindrical harmonic or wobble), the surface-driven version effectively utilizes the whole stator/slider overlapping area so that its force density is the highest. The basic motion principle is that a sequence controlled multiphase excitation voltage pattern (positive, negative and ground) is applied on the electrodes which are either evenly or unevenly pitched on the stator board. This voltage pattern will induce electrical charges in the slider film which is laid on the top of the stator surface. The interaction between the induced electrical charges in the slider film and the applied charges on the stator electrodes results in three types of forces: an upward levitational force which reduces the contact friction between the slider and the stator, a repulsive force between electrical charges of the same polarity and an attractive force between opposite charges. The combined effects of these forces is that each time the voltage pattern is applied, the slider will move a certain length (step), which corresponds to the electrode pitch width, in a certain direction and at a certain speed, depending on the configuration of the excitation voltage pattern. The slider motion will continue when the voltage pattern cycle applied on the electrodes is shifted and repeated. To enable easy modifications and flexible changes of the excitation voltage pattern for any desired slider motion behavior. the electronic circuits are software controlled by a computer. The excitation voltage generation part of the circuits was built with power bipolar 
and MOSFET transistors. For control unit protection and isolation, opto-couplers were used. In Figure 6, the principle of an electrostatic motor is schematically shown.

The arrangement of the stator electrodes (linear or radial) determines, whether the slider will perform a linear or a rotary motion. The resolution of the motion steps is mainly dependent on the dimensions and manufacturing precision of the electrodes. By appropriate connection of the slider to further mechanism, it can be well expected that high precision positioners, micro conveyors, micro feeders or micro drive systems can be realized which will find wide applications in conventional and micro manufacturing, medical, biochemical, aerospace or other relevant fields.

\section{Biomechanical Micro Swimming Robots Using Smart Materials}

The objective of this research is to design and fabricate microrobots with a simple method of propulsion using smart materials instead of electric motors. Such devices can be fabricated at a very small scale and will have a high strength to weight ratio for special applications.

In this study, two types of micro robots will be designed and fabricated with smart materials based on biomechanical similarity principles. The first type, as shown in Figure $7 \mathrm{a}$, is a jellyfish-like robot with an umbrella made of shape memory alloy (SMA) which has the capability of remembering and reproducing its original shape when exposed to a change in temperature. The second type, as shown in Figure $7 \mathrm{~b}$, is a tadpole-like device with muscles made of either SMA or piezoelectric materials, which can change dimensions upon electrical stimulation.

The muscles within the umbrella of the jellyfish will be activated by heat generated from an electric current flowing in the SMA, while cooling will come from the liquid through which the robot is swimming. As the umbrella is heated, it will contract and will result in forward movement of the device. As the umbrella cools, it will return to its original position. With proper design, this impulse will provide a forward propulsion. The muscles on the sides of the tadpole will differentially expand and contract causing the tail to move in a sidewise direction. This reversing process will cause the tail to provide a forward propulsion similar to a fish. The main advantage of this robot is that it is easy to fabricate at small dimensions due to its simplicity of design, it should have high reliability due to the simple movement, and it has high efficiency because no mechanical mechanisms are used.

Designs using SMA materials, and the control systems required for the robots, are often complex and difficult to perform because of the lack of appropriate models. In addition, the hysteresis of the material causes added complexity to the design and fabrication and the hysteresis is not properly understood. A dynamic model of the SMA material has been developed to aid the design and control of the robots. The shape memory effect is the result of a crystalline transformation between two phases of the material and so the model is based upon that phenomenon. From this, the physical properties and behavior of the SMA may be computed for a specific configuration and set of parameters. The SMA is divided into the martensitic and austenitic phases, and the behavior of each is computed for variations in the stress and temperature fields. 
To confirm the applicability of the model, a comparison between the model and experimentation was made. In the experiment, TiNi50 wire of $0.1 \mathrm{~mm}$ diameter and $20 \mathrm{~mm}$ length was loaded with a $360 \mathrm{~g}$ mass, and then heated. The heating power was supplied as a square pulse and the wire was allowed to cool by natural convection and radiation into the room at $18^{\circ} \mathrm{C}$. Using heat transfer theory for the heating and cooling process, the simulation was developed for the two phase material. Excellent agreement was found between the simulation and experimental results.

\section{Focused ion beam micromachining}

Energy beam micromachining represents a true bridge between lithographic micromachining technologies and the more traditional precision engineering technologies. Shown in Figure [8] is an example of ion beam micromachining. The needle structure is made of tungsten and is 13 microns long and has .7 micron wide vertical members. This technique could be used to micromachine resist to use as a mold for the "back end" of the LIGA process.

\section{Other MEMS Research in the United States}

The description of the research activities in MEMS at other locations in the United States will be much briefer and, because of space and time limitations, not all activities will be mentioned below. It has been estimated that the US research expenditures for MEMS is 10-15 million \$/yr.

The Berkeley Sensor and Actuator Center (BSAC) at the University of California, Berkeley, is undoubtedly one of the world leaders in MEMS research. They developed the concept of the sacrificial layer and have made many pioneering developments in surface micromachining of silicon. Significant advances in bulk micromachining have been made by the Center for Integrated Sensors and Circuits at the University of Michigan, Ann Arbor. Other focus areas for MEMS in the United States include the University of Wisconsin (LIGA), MIT (robotics. motors,etc.), the National Nanofabrication Facility, MCNC, the Center for Engineering Design (also bridges MEMS and precision engineering), and other university research groups. Several national laboratories have ongoing programs such as Lawrence Livermoore, JPL, and Los Alamos. Industrial players include Lucas Nova Sensors, IC Sensors, Analog Devices, GM Research, Texas Instruments, Delco Electronics, Honeywell and others.

\section{MEMS Activities in Germany}

Germany is certainly a leader in Microsystems Technology (MST)- both in research and in educational programs. The talk will outline the level of effort of several of the research groups and will outline the extensive technology transfer efforts and educational programs. Estimates of research expenditures for MST in Germany range from 70 to 100 million $\$ / y r$.

\section{MEMS Activities in The Netherlands, Switzerland and Russia}

The Netherlands has identified MEMS as a key technology for their future. The focal point for their research is Delft University. Estimates of research expenditures in MEMS run as 
high as 100 million $\$ / y r$. Switzerland has several areas of research in MEMS and includes their watch maker skills in this technology. Research expenditures range from 5 to 10 million $\$ / y r$. Russian research expenditures in this area would be impossible to estimate at this time.

A United States-Russia forum on manufacturing, factories of the future, and productivity enhancement was held in St. Petersburg, Russia from 18 to 21 May, 1992. The first author presented a paper on micromanufacturing [18] and interacted with researchers interested in MEMS. In addition to this interaction, several universities and companies were visited in the St. Petersburg area. A follow-on trip to Moscow resulted in a visit and presentation to the recently formed Russian Academy of Sciences (includes engineering and everything else). Several general observations from this visit listed are: 1) the status of MEMS in the United States is not well known in Russia (the reverse is also true); 2) the status of MEMS research in Russia does not seem to be well known by researchers in Russia, particularly what is being done in defense related industries - this is just now becoming available and it appears that everything is opening up; 3) the Russian researchers are eager to collaborate and have initiated some collaborations, particularly with Europe; 4) until the economy stabilizes, their resources (for travel, operating, etc.) appear to be very limited; 5) their higher educational system and structure is currently undergoing major review and it appears that the revisions which will be implemented will incorporate both the US and European (particularly German) systems; and 6) the Russian Academy of Sciences is extremely sensitive and worried about the movement of scientists and bright students from Russia to other parts of the world.

There appears to be considerable activities in MEMS throughout Russia, however, several scientists felt that this was a smail field of activity. MEMS interest appeared to be mostly focused on sensors, optics, acoustics, and materials. None of the researchers that were contacted knew of research in micro gears, motors, or systems, however most were interested in extending their work into these areas. Several robotics researchers attended the workshop and indicated that they were interested in microrobots, although none knew of any current research activities in this area. Listed below are a few current MEMS activities from one large microelectronics firm and one university research center.

* Avangard (microelectronics company outside of St. Petersburg)

- $\quad$ Ion sensor (ion-sensitive field effect transistor), chip size $5 \times 1 \mathrm{~mm}$.

- Multiple gas sensor on chip (up to three) with local calorimetric control and heater temperature control.

- $\quad$ Acoustoelectronic devices with reflector arrays.

- Approximately 35,000 sq. ft. of class 1000 (?) cleanroom space.

* Scientific-Educational Center of Microtechnology and Testing (St. Petersburg Electrical Engineering Institute)

- Bio crystals of phospholipid analogues for sensors and molecular electronics micro actuators.

- Starting to investigate micromechanical device fabrication. 
These facilities were in relatively good shape. Processing equipment used 2-3 inch wafer technology and most of the equipment was of Russian origin. The laboratories were well maintained. however, the cleanrooms were not of high quality. It appears that the many Russian microelectronic industries are not competitive for VLSI but could be very competitive in MEMS.

\section{MEMS activities in Japan and Taiwan}

Japan is clearly the leader in research expenditures in MEMS. Estimates run as high as 200 million \$/yr. The Minsitry for International Trade and Industry has taken a lead role in the development of MEMS technology and have designated micromachines, particularly microrobots, as their focus. The level of effort in Taiwan appears to be very small, however they have a tremendous amount of capital, good microfabication capabilities, and some interest in developing a program.

\section{Summary}

The key to future technological applications will be the ability to rapidly and effectively integrate, as necessary, the macro-, mini-, micro-, and nano-world. Basic science is driving the scale down to, and beyond, the nano-domain. These investigations are necessary to understand material properties and behavior at the fundamental level. These studies are also necessary to understand the fundamental interactions between materials and outside influences such as electrical and magnetic fields, gravity, light, and electromechanical driving forces. Although the science leamed at this level will greatly aid in the design and control of micro and nano devices, these devices must still adapt to the macro world.

The Institute for Micromanufacturing is dedicated to the integration of these various domains. Total integration will not be possible at the process level because of the large difference in the dimensional orders of magnitude within the domain. Therefore it is necessary to design and fabricate assist-devices so that either humans or their kinematic extensions can grasp, manipulate, position. adjust, and assemble nano-components or attach/integrate nano-components into a macro- or mini-device. In addition, it will be necessary to develop the speed, sensitivity, reliability, and inspection aspects of micromanufacturing so that these curiosities may move from the laboratory to a production environment. 
References

[1] O.N. Tufte, P.W. Chapman and D. Long, "Silicon Diffused-Element Piezoresistive Diaphragms", J. Appl. Physics, vol. 33, pp. 3322-3329, 1962.

[2] H.C. Nathanson, W.E. Newell, R.A. Wickstrom and J.R. Davis, "The Resonant-Gate Transistor", IEEE Trans. ED, vol. 14, 117-133, 1967.

[3] Texas Instruments Thermal Character Print Head, EPN3620, Bulletin DL-S7712505, 1977.

[4] H. Guckel and D.W. Bums, "A Technology for Integrated Transducers", Transducers '85. IEEE Int'l Conf. on Solid-State Sensors and Actuators, 90-92, Philadelphia, PA, 1985.

[5] R.T. Howe and R.S. Muller, "Resonant-Microbridge Vapor Sensor", IEEE Trans. Electron Devices, vol. 33, pp. 499-506, 1986.

[6] K. Petersen, "The Silicon Micromechanics Foundry", IEEE, 87TH0204-8, 1987.

[7] W. Ehrfeld, P. Bley, F. Götz, P. Hagman. A. Maner, J. Mohr, H.O. Moser, D. Münchmeyer, W. Schelb, D. Schmidt and E.W. Becker, "Fabrication of Microstructures Using the LIGA Precess", IEEE, 87TH0204-8, 1987.

[8] S.D. Senturia, "Microfabricated Strucrures for the Measurement of Mechanical Properties and Adhesion of Thin Films", in Proc. 4th Int. Conf. Solid-State and Sensors and Actuators (Transducers '87), pp. 11-16, Tokyo, 1987.

[9] W.S. Trimmer and K.J. Gabriel, "Design Consideration for a Practical Electrostatic Micromotor", Sensors and Actuators, vol. 11, pp. 189-206, 1987.

[10] H. Fujita and A. Omodaka. "The Fabrication of an Electrostatic Linear Actuator by Silicon Micromachining", IEEE Trans. Electron Devices, vol. 35, pp. 731- 734, 198

[11] S.C. Jacobsen, R.H. Price, J.E. Wood, T.H. Rytting and M. Rafaelof, "The Wobble Motor: An Electrostatic Planetry-Armature Microactuator", in Proc. IEEE Micro Electro Mechanical Systems, Salt Lake City, Utah, 1989.

[12] K. Kuribayashi, "Milimeter Size Joint Actuator Using Shape Memory Alloy", 1989 IEEE Micro Electro Mechanical Systems Workshop, pp. 139-144, Salt Lake City, Utah, 1989.

[13] C.R. Friedrich and R.O. Warrington, "Machining of Metal Foils for Use in Microcompact Heat Exchangers", in Proc. Micro System Technologies 90, pp. 509-514, Berlin, Germany, 1990.

[14] L.C. Kong, B.G. Orr and K.D. Wise, "A Micromachined Silicon Scan Tip for an Atomic Force Microscope", Digest IEEE Solid-State Sensor Workshop, Hilton Head, S.C. pp. 2831, 1990. 
[15] R.L. Stockbauer, et al, "Center for Advanced Microstructures and Devices at Louisiana State University", Physica Scripta, vol. 41, pp. 788-792, 1990.

[16] J. Simon, G. Engelmann, O. Ehrmann and H. Reichl, "Plating of Microstrutures for Sensors", in Proc. Micro System Technologies 91, pp. 315-321, Berlin, Germany, 1991.

[17] H. Guckel, K. Skrobis, T. Christenson, J. Klein, S. Han, B. Choi and E. Lovell, "Fabrication of Assembled Micromechanical Components via Deep X-Ray Lithography", in Proc. IEEE Micro Electro Mechanical Systems, pp. 74-79, Nara, Japan, 1991.

[18] R.O. Warrington, C.R. Friedrich, R.X. Gao and G. Lin, "Micromanufacturing, An Emerging Technology", presented at the 1992 US-Russia Forum on Manufacturing, Factories of the Future and Productivity Enhancement, St. Petersburg, Russia, 1992.

[19] E.W. Becker, H. Betz, W. Ehrfeld, W. Glashauser, A. Heuberger, H.J. Michael, D. Münchmeyer, S. Pongratz and R.v. Siemens, "Production of Separation Nozzle Systems for Uranium Enrichment by a Combination of X-Ray Lithography and Galvano-plastics, Naturwissenschaften, 69, 520-523, 1982.

[20] C.R. Friedrich and S.W. Kang, "Performance of High Flux Heat Exchangers Fabricated by Diamond Machining", submitted to Precision Engineering, 1992.

[21] R.X. Gao, M. Bhandiwad and R.O. Warrington, "Smart Grinding Balls and Smart Bearings for On-line Process Supervision", to be presented at 7th ASPE Annual Meeting in Orlando, Fl, October 1992.

[22] G. Lin and T. Satomi, "Characteristics and Optimization of the Spiral Grooved Thrust Air Bearings", Trans. JSME, Ser. C, No. 541, vol. 57, pp. 2971-2977, (in Japanese), 1991.

Useful References

1. "Integrated Circuit Fabrication Technology," David J. Elliott, McGraw-Hill, Second Edition, 1989

2. "Semiconductor Lithography - Principles, Practices and Materials," Wayne M. Moreau, Plenum, 1987

3. "VLSI Technology," S. M. Sze, McGraw-Hill, 1983

4. "The Physics of Microfabrication," Brodie and Muray, Plenum, 1987

5. "ESD Program Management," Danglemayer, Van Nostrand Reinhold, 1990

6. "Cleanroom Practices," Kozicki, Hoenig and Robinson, Van Nostrand Reinhold, 1991

7. "Handbook on Synchrotron Radiation," Koch, Volumes 1a, 1b and 2, Elsevier, 1983

8. "Electronic Materials," Warnes, Van Nostrand Reinhold, 1990

9. "Proligh/2 User's Manual," Finle Technologies, 1992

10. "Excimer Laser Lithography," Jain, SPIE Press, 1990

11. "Introduction to Microelectronic Fabrication," Volume 5, Richard C. Jaeger, AddisonWesley 


\section{Useful Journals/Proceedings}

1. Journal of Microelectromechanical Systems. IEEE/ASME

2. Sensors and Actuators, Elsevier Sequoia

3. Journal of Micromechanics and Microengineering, Institute of Physics

4. Nanotechnology, Institute of Physics

5. Precision Engineering, Butterworth-Heinemann

6. Transducers - Biannual Conference Proceedings

7. MEMS - Annual Conference Proceedings

8. Symposium on Microlithography - Annual Conference Proceedings

9. Solid State Sensors and Actuators - Biannual Conference Proceedings

10. Micro Systems Technologies - Annual Conference Proceedings

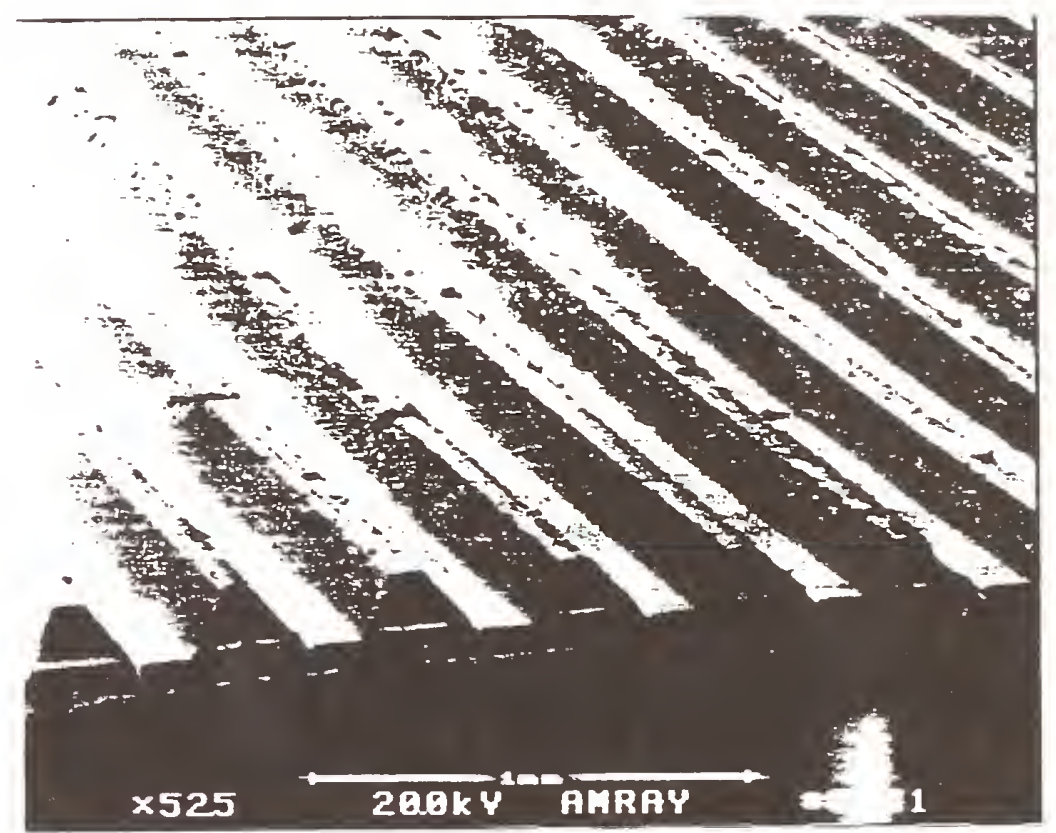

Figure 1. Micrograph of machined flow channels 


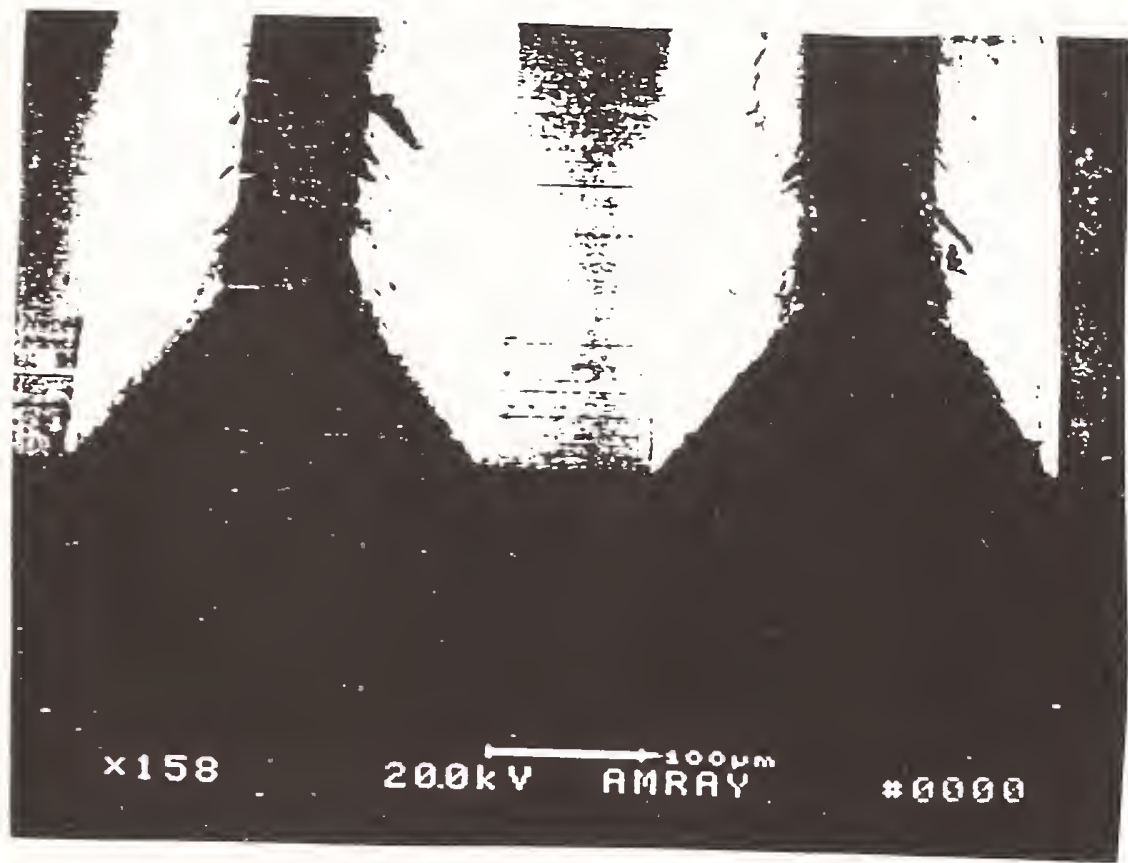

Figure 2. Micrograph of single flow channel (rms roughness $39 \mathrm{~nm}$ )

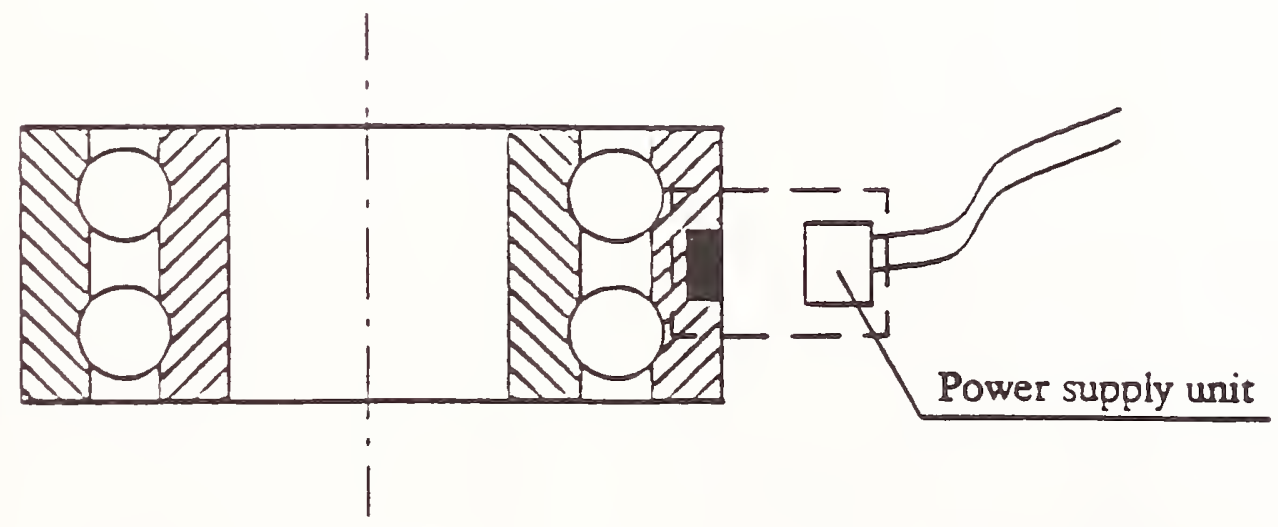

Figure 3. Sensor located in smart bearing 


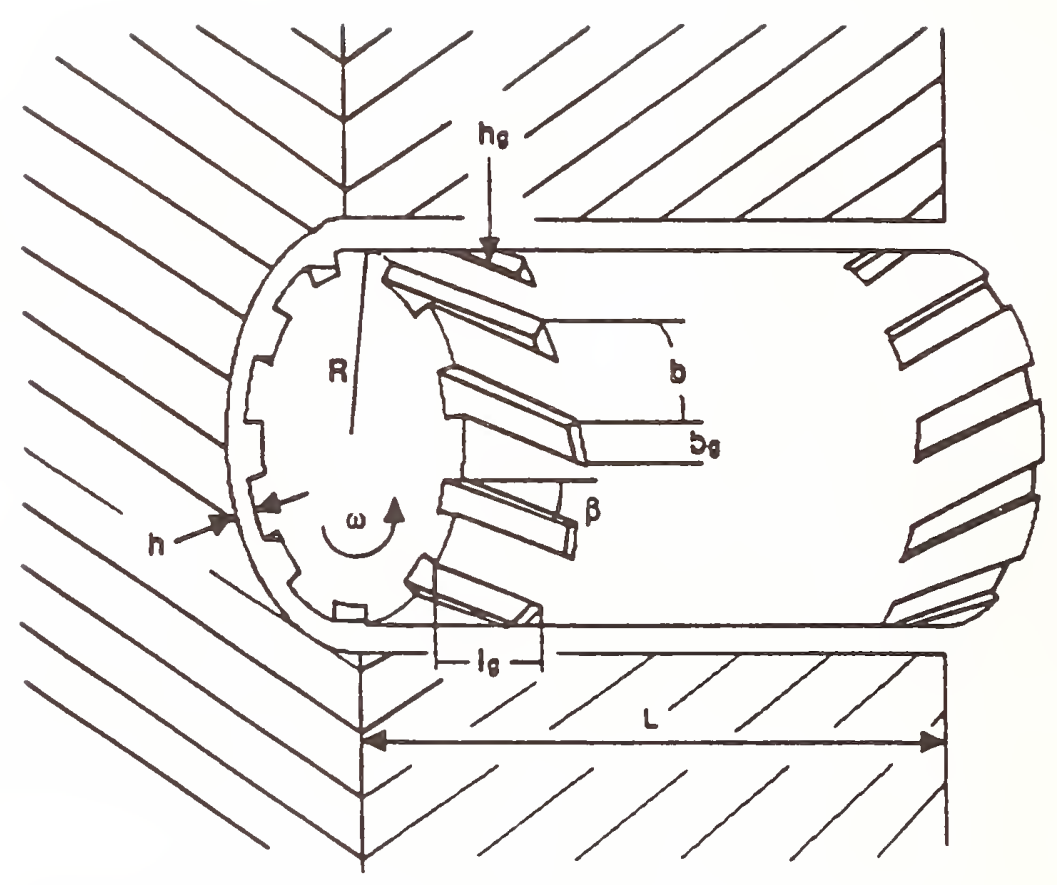

Figure 4. Configuration of a herring bone air bearing
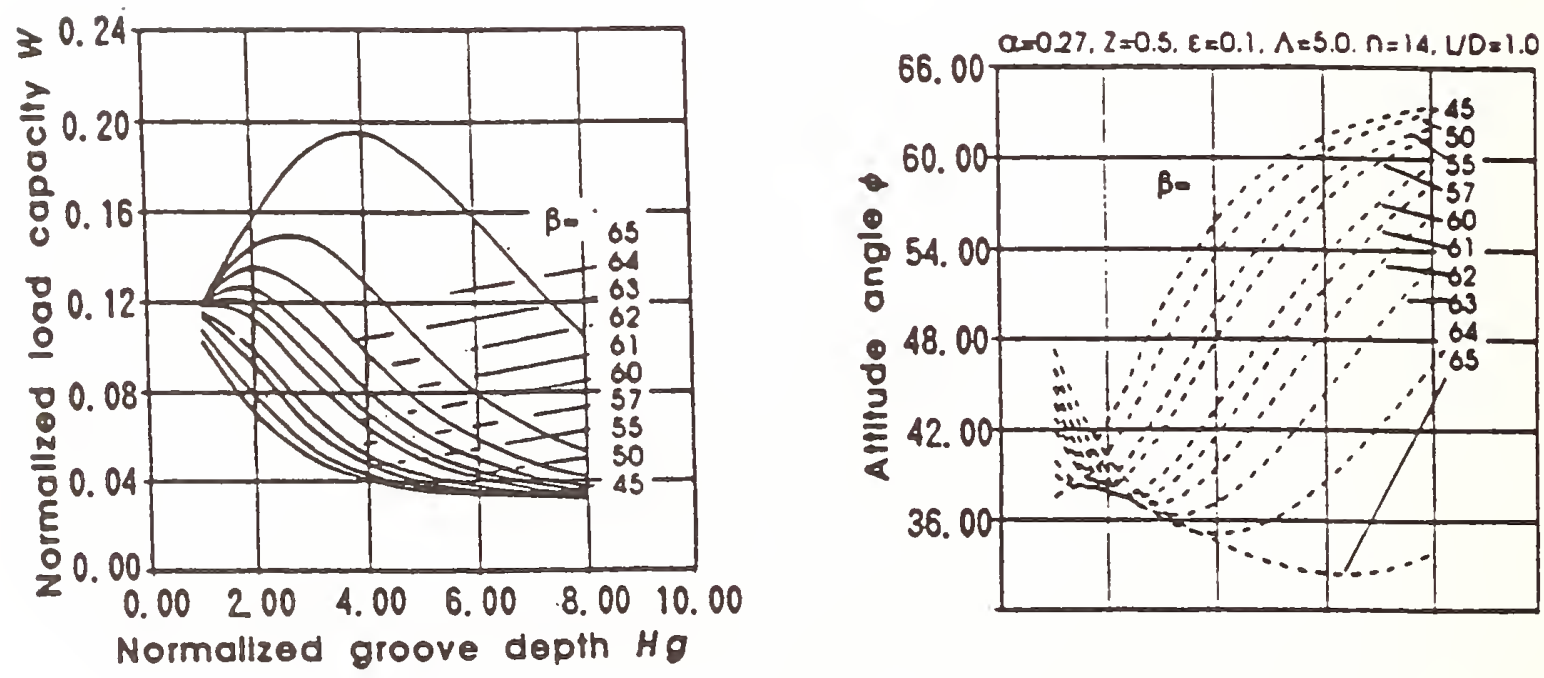

Figure 5. Influence of the groove pump-in angle 


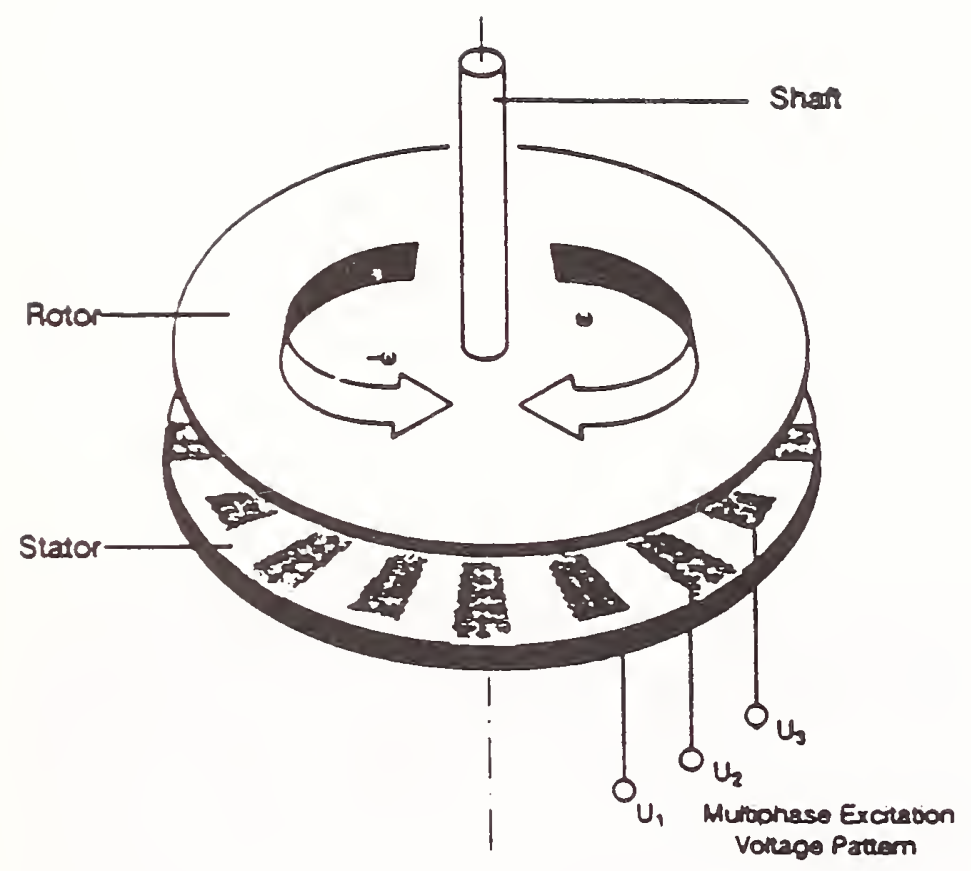

Figure 6. Layout of electrostatic motor

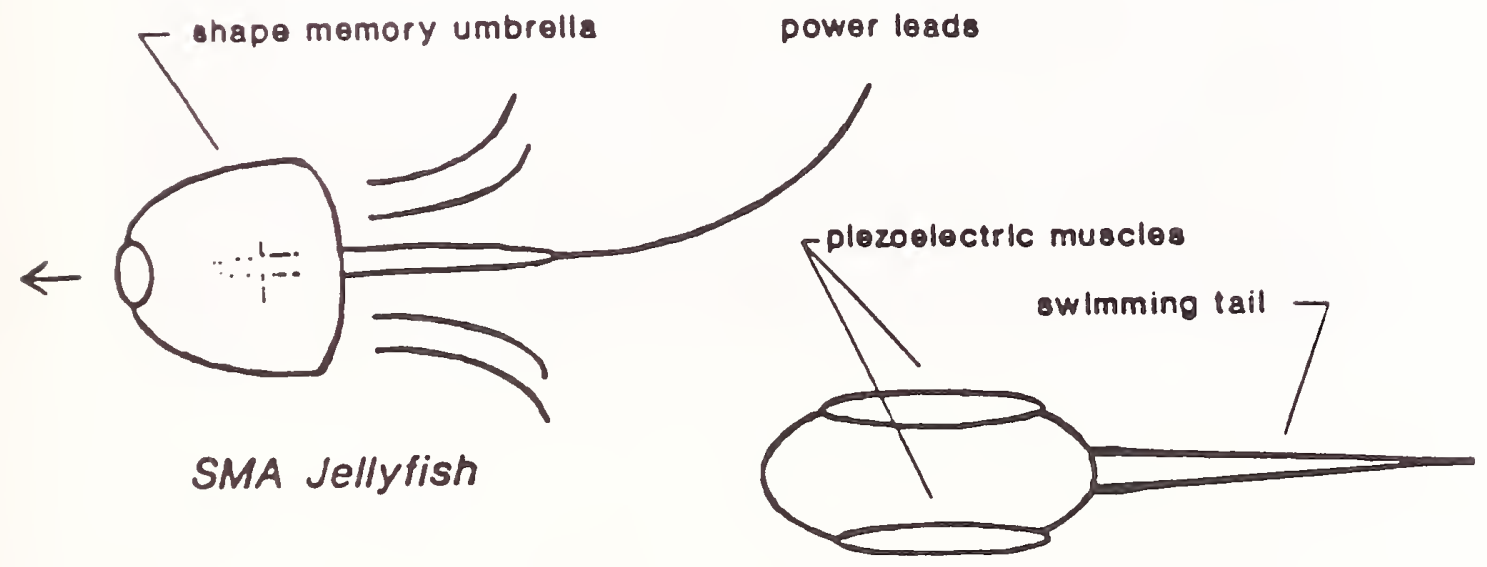

SMA Tadpole

7a. Jelly-fish like robot

7b. Tadpole-like robot

Figure 7. Shape memory alloy robots 


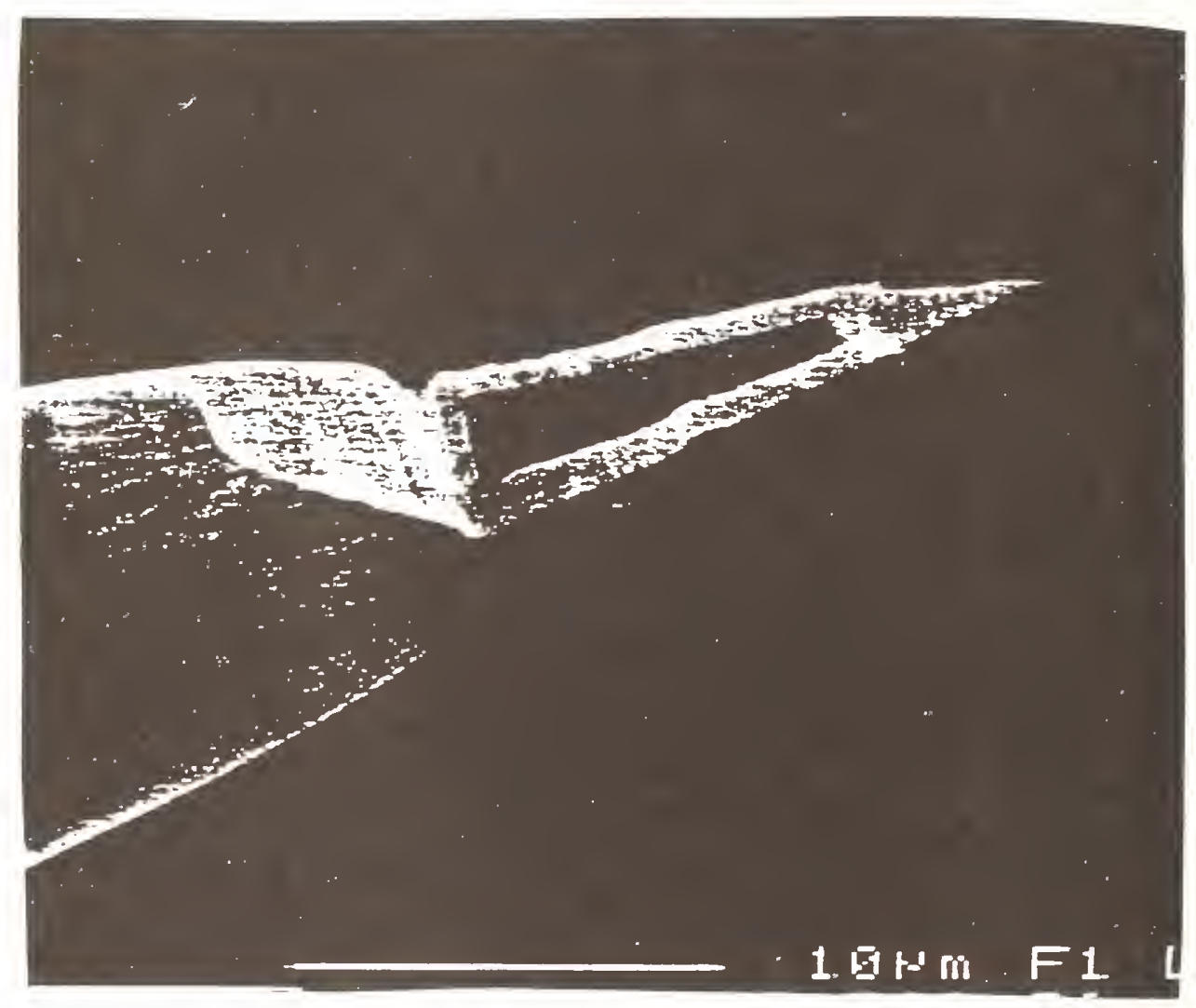

Figure 8. Example of Focused Ion Beam Micromachining 



\section{NIST $T_{\text {Technical Publications }}$}

\section{Periodical}

Journal of Research of the National Institute of Standards and Technology-Reports NIST research and development in those disciplines of the physical and engineering sciences in which the Institute is active. These include physics, chemistry, engineering, mathematics, and computer sciences. Papers cover a broad range of subjects, with major emphasis on measurement methodology and the basic technology underlying standardization. Also included from time to time are survey articles on topics closely rulated to the Institute's technical and scientific programs. Issued six times a year.

\section{Nonperiodicals}

Monographs-Major contributions to the technical literature on various subjects related to the Institute's scientific and technical activities.

Handbooks - Recommended codes of engineering and industrial practice (including safety codes) developed in cooperation with interested industries, professional organizations, and regulatory bodies.

Special Publications - Include proceedings of conferences sponsored by NIST, NIST annual reports, and other special publications appropriate to this grouping such as wall charts, pocket cards, and bibliographies.

Applied Mathematics Series-Mathematical tables, manuals, and studies of special interest to physicists, engineers, chemists, biologists, mathematicians, computer programmers, and others engaged in scientific and technical work.

National Standard Reference Data Series - Provides quantitative data on the physical and chemical properties of materials, compiled from the world's literature and critically evaluated. Developed under a worldwide program coordinated by NIST under the authority of the National Standard Data Act (Public Law 90-396). NOTE: The Journal of Physical and Chemical Reference Data (JPCRD) is published bimonthly for NIST by the American Chemical Society (ACS) and the American Institute of Physics (AIP). Subscriptions, reprints, and supplements are available from ACS, 1155 Sixteenth St., NW, Washington, DC 20056.

Building Science Series-Disseminates technical information developed at the Institute on building materials, components, systems, and whole structures. The series presents research results, test methods, and performance criteria related to the structural and environmental functions and the durability and safety characteristics of building elements and systems.

Technical Notes-Studies or reports which are complete in themselves but restrictive in their treatment of a subject. Analogous to monographs but not so comprehensive in scope or definitive in treatment of the subject area. Often serve as a vehicle for final reports of work performed at NIST under the sponsorship of other government agencies.

Voluntary Product Standards-Developed under procedures published by the Department of Commerce in Part 10, Title 15, of the Code of Federal Regulations. The standards establish nationally recognized requirements for products, and provide all concerned interests with a basis for common understanding of the characteristics of the products. NIST administers this program in support of the efforts of private-sector standardizing organizations.

Consumer Information Series - Practical information, based on NIST research and experience, covering areas of interest to the consumer. Easily understandable language and illustrations provide useful background knowledge for shopping in today's technological marketplace. Order the above NIST publications from: Superintendent of Documents, Government Printing Office, Washington, DC 20402.

Order the following NIST publications-FIPS and NISTIRs-from the National Technical Information Service, Springfield, VA 22161.

Federal Information Processing Standards Publications (FIPS PUB) - Publications in this series collectively constitute the Federal Information Processing Standards Register. The Register serves as the official source of information in the Federal Government regarding standards issued by NIST pursuant to the Federal Property and Administrative Services Act of 1949 as amended, Public Law 89-306 (79 Stat. 1127), and as implemented by Executive Order 11717 (38 FR 12315, dated May 11, 1973) and Part 6 of Title 15 CFR (Code of Federal Regulations).

NIST Interagency Reports (NISTIR) - A special series of interim or final reports on work performed by NIST for outside sponsors (both government and non-government). In general, initial distribution is handled by the sponsor; public distribution is by the National Technical Information Service, Springfield, VA 22161, in paper copy or microfiche form. 


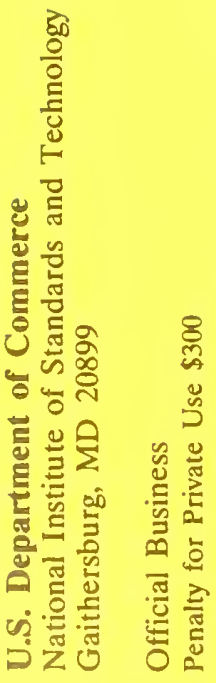

